\title{
Essays on Inequality and Mobility of Korean Households' Income and Consumption
}

\author{
A Dissertation \\ presented to \\ the Faculty of the Graduate School \\ at the University of Missouri-Columbia
}

In Partial Fulfillment

of the Requirements for the Degree

Doctor of Philosophy

by

Sanguk Kwon

Dr. Shawn Ni, Dissertation Supervisor

MAY 2021 
The undersigned, appointed by the Dean of the Graduate School, have examined the dissertation entitled:

\section{Essays on Inequality and Mobility of Korean \\ Households' Income and Consumption}

presented by Sanguk Kwon, a candidate for the degree of Doctor of Philosophy and hereby certify that, in their opinion, it is worthy of acceptance.

\section{Professor Shawn Ni}

Professor David M. Kaplan

Professor Aaron Hedlund

Professor Rui Yao 


\section{ACKNOWLEDGMENTS}

I would like to appreciate my advisor, Dr. Shawn Ni. He was always interested in this dissertation from the selection of the research topic to the completion of the thesis. Also, when I am in trouble from theoretical and empirical obstacles, he always provided solutions and advice to me. I think it is great luck to see him as a supervisor.

I would like to thank to my dissertation committee members: Dr. Kaplan, Dr. Hedlund, and Dr. Yao. Even if they are very busy for their own works, they spent lots of time on me. Especially, at dissertation proposal and defense, their advice and comments on my dissertation are meaningful and makes my research to be more rigorous and logical.

I thank to my class-mates; Mr. Joonhong Ahn and Mr. Heon Lee. They lived together in the economics department from admission to graduation. Even if we have different major field, our academic discussions helped my research to understand and persuade general audience. Also, sharing their thoughts with them through private discussions helped me a lot in overcoming my loneliness in American life and in releasing stress.

Finally, I am grateful to Dr. Sanha Noh, Dr. Ingul Baek, Dr. Taehawm Kim, Mr. William Park, and Mr. Dongho Kang. They are interested in my research and give questions and comments to develop my research. 
TABLE OF CONTENTS

ACKNOWLEDGMENTS ................ ii

LIST OF TABLES $\ldots \ldots \ldots \ldots \ldots \ldots$ vii

LIST OF FIGURES $\ldots \ldots \ldots \ldots \ldots \ldots \ldots \ldots \ldots$ ix

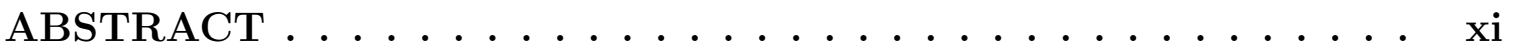

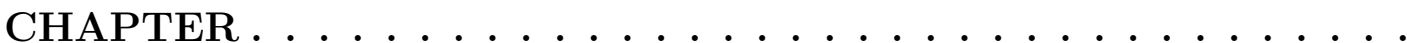

1 Introduction ......................... 1

2 Inequality and Mobility of Household Earnings over the Life Cycle and Business Cycles ................ 5

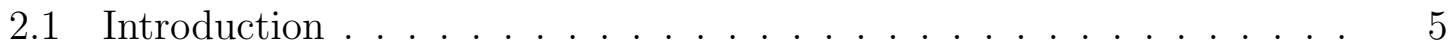

2.2 Empirical Patterns in the KLIPS Data . . . . . . . . . . 9

$2.2 .1 \quad$ KLIPS Data . . . . . . . . . . . . . . . . . . 9

2.2 .2 Detrended Income . . . . . . . . . . . . . . . . . . . . . 12

2.2.3 Measuring Income Inequality and Mobility . . . . . . . . . 13

2.2.4 Implications of the RIP and HIP Models . . . . . . . . . . 14

2.2.5 Stylized Facts and the RIP and HIP Models . . . . . . . . 15

2.2.6 Models of Income Process with a Macro Factor _ . . . . . . 19

2.3 Estimation of Income Models . . . . . . . . . . . . . . . . . . . 21

2.3.1 Model Identification and Estimation _. . . . . . . . . . 22

2.4 Estimates of Competing Income Models _ . . . . . . . . . . 26

2.4 .1 Income inequality . . . . . . . . . . . . . . 26

2.4.2 Other moments of the covariance matrix . . . . . . . 30

2.4 .3 Mobility . . . . . . . . . . . . . . . . . 31 
2.4.4 Model comparison . . . . . . . . . . . . . . . . . . . 33

2.4.5 Decomposing inequality in household earnings . . . . . . . 34

2.5 Concluding Remarks . . . . . . . . . . . . . . . . . . . . 39

3 Household Inequality and Mobility over the Lifecyle: Evidence from Korean Household Panel Data on Income and Consumption 40

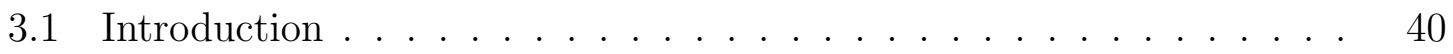

3.2 KLIPS Data and Stylized Facts _ . . . . . . . . . . . 43

3.2.1 KLIPS data on income, consumption, and net wealth . . . . 43

3.2.2 Stylized facts on inequality and mobility for Korean income and consumption . . . . . . . . . . . . . . . 46

3.2.3 Factoring in measurement errors in consumption expenditure . 52

3.3 Empirical Observations and Models of Income and Consumption . . . 56

3.3.1 Income Models of RIP and HIP . . . . . . . . . . . 56

3.4 Consumption Models . . . . . . . . . . . . . . . . . . . . . 59

3.4.1 Empirical models of consumption growth _ . . . . . . 59

3.4.2 A theory of optimal consumption with heterogeneous conditional mean in consumption growth . . . . . . . . . . . 60

3.5 Estimation of Income and Consumption Model . . . . . . . . . . . 61

3.5.1 Estimating a model income and consumption growth . . . . 61

3.6 Estimating Income and Consumption Models Based on Covariance Matrices . . . . . . . . . . . . . . . . . 63

3.6.1 Three Models of Income and Consumption . . . . . . . . . . 64

3.7 Estimates and Fit of Competing Income Models . . . . . . . . . 65

3.8 Concluding Remarks $\ldots \ldots \ldots \ldots \ldots$

4 Estimating Consumption Inequality in the Presence of Non-classical Measurement Errors . . . . . . . . . . . . . . 72

4.1 Introduction . . . . . . . . . . . . . . . . 72 
4.2 Data and inequality trends . . . . . . . . . . . . 75

$4.2 .1 \quad$ Data . . . . . . . . . . . . . . . . . 75

4.2 .2 Inequality trends $\ldots \ldots \ldots \ldots \ldots \ldots$. . . . . . . . 77

4.3 Estimating Consumption Inequality through "Double Differencing" . 79

4.3.1 Double differencing correction method . . . . . . . . . 79

4.3.2 Proxy for permanent income based on PIH . . . . . . . . 86

4.4 Estimation Result . . . . . . . . . . . . . . . . . . . . . . . . . . 89

4.4 .1 Aguiar and Bils Estimates . . . . . . . . . . . . 89

4.4.2 Using PIH as instrument in the first step . . . . . . . . . 97

4.5 Conclusion . . . . . . . . . . . . . . . . . . . . . . . . 101

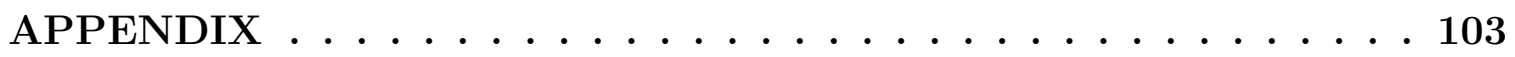

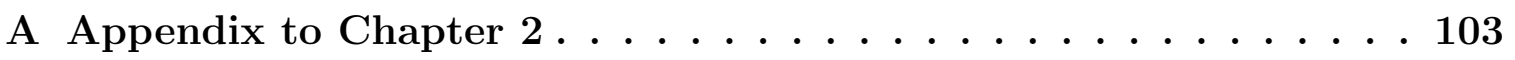

A.1 Sample Selection . . . . . . . . . . . . . . . . . 103

A.1.1 Test for bias in sample attrition . . . . . . . . . . . 103

A.2 Moment Conditions of $\frac{1}{\mathbf{N}} \mathbf{Y}^{\prime} \mathbf{Y} \ldots \ldots \ldots \ldots \ldots$

A.2.1 Estimation . . . . . . . . . . . . . . . . . . . 109

A.2.2 RIP Model . . . . . . . . . . . . . . . . . . . . . . . 109

A.2.3 Alternative Identification of RIP based on BPP . . . . . . 111

A.2.4 HIP Model . . . . . . . . . . . . . . . . . . . . . 113

A.2.5 Baker/Solon Model . . . . . . . . . . . . . . . . . . . . . 114

A.2.6 G-RIP Model . . . . . . . . . . . . . . . . . . . . . . 115

A.2.7 SHIP Model . . . . . . . . . . . . . . . . . . . . . . . . . 117

A.3 The Compositions of Earnings Inequality by Education . . . . . . . 122

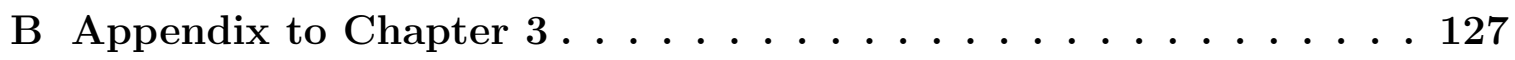

B.1 Euler Equation of Optimal Consumption . . . . . . . . . . 127 


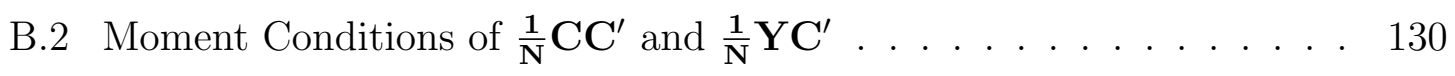

B.2.1 HIP-Consumption Model . . . . . . . . . . . . . . . . 130

B.2.2 RIP-Consumption Model . . . . . . . . . . . . . . . . 132

B.2.3 The BPP Estimation of RIP-Consumption Model . . . . . . . 138

B.2.4 GRIP-HCM Consumption Model . . . . . . . . . . . . . . . . 139

Bibliography ...................... 142

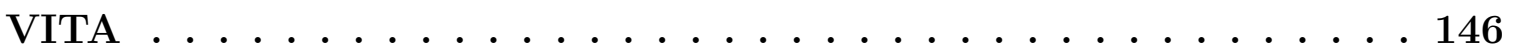




\section{LIST OF TABLES}

Table $\quad$ Page

2.1 Average demographic characteristics $\ldots \ldots \ldots \ldots \ldots \ldots$

2.2 Average labor, transfer, and disposable income by education level . . 12

2.3 Residual statistics . . . . . . . . . . . . . . . . . . . 13

2.4 Estimation results of HIP, RIP, and G-RIP . . . . . . . . . 27

2.5 Estimation results of Baker-Solon and SHIP $\ldots \ldots \ldots \ldots$

2.6 Model comparison . . . . . . . . . . . . . . . . . . . . . . . . . . . . . 33

2.7 The within- and between-group variance of log of earnings by education of household head . . . . . . . . . . . . . . . . . . . 35

2.8 The compositions of earning inequality $\ldots \ldots \ldots \ldots \ldots$

3.1 Descriptive statistics of disposable income, non-durable expenditures, and net wealth $\ldots \ldots \ldots \ldots \ldots \ldots \ldots \ldots$

3.2 Descriptive statistics of $\mathrm{ABB}(2017) \ldots \ldots \ldots \ldots \ldots$

3.3 Residual statistics for income and consumption . . . . . . . 48

$3.4 \operatorname{cov}\left(y_{i t}-y_{i 3}, y_{i 1}\right)$ and $\operatorname{cov}\left(c_{i t}-c_{i 3}, c_{i 1}\right) \ldots \ldots \ldots \ldots \ldots \ldots$

3.5 A summary of likely patterns of cross-household moments over lifecycle 59

3.6 Estimation results of RIP- and HIP-Consumption Models . . . . . . . 66

3.7 Estimation results of GRIP-HCM Consumption Model . . . . . . . 67

3.8 Model comparison . . . . . . . . . . . . . . . . . . . . . 70 
4.1 Housing tax in South Korea . . . . . . . . . . . . . . 78

4.2 Descriptive statistics $\ldots \ldots \ldots \ldots \ldots \ldots$

4.3 Estimation of the $1^{\text {st }}$ step $\ldots \ldots \ldots \ldots \ldots$

4.4 Correlation of elasticities estimated in each sub-period . . . . . . 91

4.5 Consumption inequality for the unbalanced panel . . . . . . . . 96

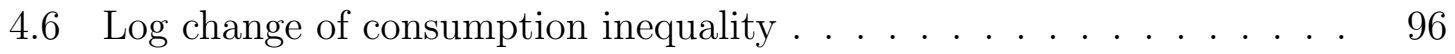

4.7 Total expenditure elasticity for the balanced panel . . . . . . . . 98

4.8 Trends in consumption inequality for the balanced panel . . . . . . 99

A.1 Response and nonresponse rates for original 5,000 households in KLIPS 104

A.2 Drop-out sample . . . . . . . . . . . . . . . . . . 105

A.3 1997 characteristics by attrition: Age 25-64 . . . . . . . . . 106

A.4 Ever-Out attrition probits for household labor income . . . . . . . 107

A.5 $1997 \log$ household labor income for BGLW test. . . . . . . . . 108

A.6 The compositions of earning inequality for the RIP . . . . . . . . 122

A.7 The compositions of earning inequality for the HIP . . . . . . . 123

A.8 The compositions of earning inequality for the Baker/Solon . . . . . . 124

A.9 The compositions of earning inequality for the G-RIP . . . . . . 125

A.10 The compositions of earning inequality for the SHIP . . . . . . . 126 


\section{LIST OF FIGURES}

Figure

Page

$2.1 \operatorname{var}(y)$ and GDP growth rate . . . . . . . . . . . . 15

$2.2 \operatorname{var}(\Delta y)$ and $\operatorname{var}\left(y_{t}-y_{1}\right) \ldots \ldots \ldots \ldots$

$2.3 \operatorname{corr}\left(y_{t}-y_{3}, y_{1}\right) \ldots \ldots \ldots \ldots \ldots \ldots$

2.4 Mobility $\left(1-\hat{\rho}_{t}^{2}\right) \ldots \ldots \ldots \ldots$. . . . . . . . . . . . . 17

$2.5 \operatorname{var}\left(y_{t}\right)$ and $\operatorname{var}\left(y_{t}-y_{1}\right)$ by cohorts . . . . . . . . . . . . 18

2.6 Fitted income inequality . . . . . . . . . . . . . . . . . 29

2.7 Fitted inequality for cumulative income growth . . . . . . . . . 30

2.8 Fitted $\operatorname{cov}\left(y_{t}-y_{3}, y_{1}\right) \ldots \ldots \ldots \ldots \ldots \ldots$

2.9 Fitted mobility . . . . . . . . . . . . . . . . . . . 32

2.10 Inequality of residuals of income by education . . . . . . . . . 36

3.1 Income and consumption inequality . . . . . . . . . . . . . . . 42

3.2 Income and consumption growth inequality . . . . . . . . . . . 49

3.3 Income and consumption inequality in cumulative growth rate . . . . 50

3.4 Income and consumption inequality by cohort for the balanced panel during $2000-2015 \ldots \ldots$. . . . . . . . . . . . . . . . . . 50

3.5 Income and consumption inequality by cohort for the balanced panel during 1997-2015 . . . . . . . . . . . . . . . . . 51

3.6 Income and consumption mobility . . . . . . . . . . . . . . . 52 
$3.7 \operatorname{corr}\left(c_{t}-c_{2}, c_{1}\right) \ldots \ldots \ldots \ldots \ldots \ldots \ldots \ldots \ldots \ldots \ldots$

3.8 Model fit of income and consumption inequality for the HIP-Consumption, RIP-Consumption, and GRIP-HCM Consumption Models . . . . . . 68

3.9 Model fit of income and consumption mobility for the HIP-Consumption, RIP-Consumption, and GRIP-HCM Consumption Models . . . . . . 69

3.10 Model fit of $\operatorname{cov}\left(y_{i t}, c_{i t}\right)$ for the HIP-Consumption, RIP-Consumption, and GRIP-HCM Consumption Models . . . . . . . . . . . . 69

3.11 Model fit of $\operatorname{cov}\left(c_{i t}-c_{i 2}, c_{i 1}\right)$ for the HIP-Consumption, RIP-Consumption, and GRIP-HCM Consumption Models . . . . . . . . . . 70

4.1 Income inequality and consumption inequality for the unbalanced panel 81

4.2 Income inequality and consumption inequality for the balanced panel 82

4.3 Stability of expenditure elasticities over time . . . . . . . . . . 92

4.4 The share of total expenditure . . . . . . . . . . . . . . . . 93

4.5 Trend in consumption inequality . . . . . . . . . . . . 95

4.6 Consumption inequality adjusted for measurement errors $\ldots \ldots$. . . 97

4.7 Consumption inequality for the balanced panel . . . . . . . . . . . . 100 


\section{ABSTRACT}

This dissertation analyzes income and consumption inequality empirically and theoretically using Korean Labor and Income Panel Study (KLIPS). This dissertation consists of three chapters. First two chapters are about detrended income and consumption excluding the effects of household's characteristics. Third chapter is about observed income and consumption.

In the chapters 1 and 2, we track income and consumption of same cohort of Korean households over the lifecycle and find empirical evidences are not explained by existing income and consumption models with iid assumption of income shocks. For example, future cumulative gains in consumption (income) are negatively correlated with initial consumption (income). Second, consumption inequality does not grow over the lifecycle. At the chapter 1, we develop new income process model. Our suggesting generalized restricted income profiles (G-RIP) and stochastic heterogeneous income profile (SHIP) consider iid income shocks as well as household-specific factors of macroeconomy. We find that the estimated model fits the dynamics of inequalities and mobility of income better than the conventional RIP or HIP models. At the chapter 2 , we develop new consumption process model. New consumption model has consumption shocks as well as household-specific uncertainty. Therefore, consumption risk is correlated with past consumption, which can explain the observed consumption moments. Our suggesting heterogeneous conditional mean (HCM) model fits the dynamics of inequalities and mobility of income and consumption better than the conventional model that assume iid income shocks.

At the chapter 3, we deal with non-classical measurement errors in consumption using a double-differencing correction method. Aguiar and Bils (2015) develop a double differencing correction method to estimate the relative consumption inequality adjusted for measurement errors. In the first step they estimate Engel curve which 
measurement errors are correlated with error terms of and use current income as an instrument for total expenditure. This chapter provides an alternative instrument based on the permanent income hypothesis (PIH) for total expenditure. A long panel data is required to capture a household's permanent income and using a Korean household panel allows to test a hypothesis that permanent income could be more appropriate instrument than current income. We find the expected lifecycle income is better instrument than current income for current consumption. 


\section{Chapter 1}

\section{Introduction}

Household income and consumption inequalities have been studied extensively in recent literature. The proposed thesis intends to contribute to this growing literature through empirical analysis of Korean Labor and Income Panel Study (KLIPS). While economic theories shed light from the distributional aspects of inequality and mobility on the income, consumption, and wealth variables, there is scant research in examining the empirical regularities of a single panel data set from both aspects on all variables; and examining whether commonly employed economic models fit both aspects of all variables. In contrast to the most commonly studied data sets of the U.S. households, such as PSID or CEX, the KLIPS data contain a long panel of household data on both income, consumption expenditure, and net wealth. This presents an opportunity to explore the empirical relationships between inequality and mobility in Korean household income, consumption, and net wealth; and to retest income and consumption models prevailing in the recent literature on household inequalities.

Inequality and mobility concern different aspects of distributions of household variables. Inequality concerns cross-sectional dispersion. Some common measures of inequality include cross-sectional variance and ratios of different quantiles. Mobility concerns the change in the relative standings of households. 
Quantitative analysis of the dynamics of inequality depends on the model of income dynamics. In the vast literature on household income and consumption inequalities, two commonly used benchmark models for household income dynamics are RIP (Restricted Income Profiles) and HIP (Heterogeneous Income Process).

The RIP model identifies income shocks that consist of a permanent and a transitory components: the permanent component is a random walk and both permanent and transitory shocks are assumed to be (a) independent over time for each household and (b) identically and independently distributed (iid) cross households in each period (see e.g., Meghir and Pistaferri (2004); Blundell et al. (2008) (BPP); Blundell and Etheridge (2010); Jappelli and Pistaferri (2010); Moffitt and Gottschalk (2011)). The HIP model assumes earnings fluctuate with household-specific linear trends that have constant intercepts and slopes (e.g., Mincer (1974); Becker (1975); Carroll and Summers (1991); Baker (1997); Haider (2001); Guvenen (2009), etc).

We find empirical evidence of violations of the key assumptions of both RIP and HIP models in the Korean household KLIPS data. We find that cumulative household income (consumption) changes over a range of distant future and is negatively correlated with the initial income (consumption). This suggests that the permanent income shocks in distant future are affected by the initial income. We also find that in recessions income inequality rises but consumption inequality falls. This suggests the state of macroeconomy affect household income and consumption beyond a reduction in cross-household average.

In the RIP model, evolution of inequality among a given panel of households depends on realization of risks. In the HIP model, inequality can be attributed to risks as well as time-invariate heterogeneity in lifetime income profile. The empirical evidence suggests that models that fit the income and consumption inequalities in KLIPS may require introducing state-dependent heterogeneity in household risks. We propose such models in the first and second essay and report preliminary analysis 
of the models.

In the first essay, we explore household labor earnings from 1997 to 2015 in KLIPS. We find empirical evidence against the iid shocks. We model the income process with the focus of the dependence and heterogeneity of income shocks to the macroeconomy. The new model which is called as Generalized Restricted Income Profile (G-RIP model) considers the macro effect on the permanent component and the G-RIP model fits the KLIPS data better than the model with the conventional models.

In the second essay, we examine the joint dynamics of household income and consumption inequalities using KLIPS data of 2000-2015, with the focus of consumption inequality over the lifecycle. Data that track consumption of a given cohort over the lifecycle are rare and with limitation (e.g., a long panel of PSID contains only food consumption, and a panel of PSID that contains more comprehensive expenditures is short and bi-annual.) The empirical evidence discovered in the KLIPS data is of particular interest. We first document empirical patterns rarely mentioned in the literature. For examples, for the long panel consumption inequality decreases over time and consumption growth is correlated with consumption level in distant past. These observations are inconsistent with income models such as RIP and HIP under the assumption of iid income shocks. They also pose challenges to benchmark models of optimal consumption with iid shocks. For a rational household, optimal consumption only changes with unexpected shocks. In particular, the consumption growth should not be correlated with the past consumption. If the optimal consumption is approximately a random walk then consumption inequality, measured by the the cross sectional variance, should increase in each period by the amount of variance of consumption growth. We propose an explanation to the apparent contradiction to the conventional consumption theory. We assume that across households, the conditional mean of consumption growth (which reflects the precautionary motive for saving) is heterogeneous correlated with the level of consumption. We find a consumption model 
with G-RIP income and heterogeneous conditional mean of consumption growth fits the income and consumption data better than the conventional models.

The third essay also focuses on the joint dynamics of income and consumption. We focus on treatment of measurement errors in consumption expenditure and while comparing the trends in income and consumption inequalities. In a similar setting Aguiar and Bils (2015) develop a double-different correction method to adjust three types of measurement errors (i.e., good-time specific, income-time specific, and goodhousehold-time specific measurement errors). To adjust measurement errors, they estimate Engel curve by using current income as an instrument for current total expenditure. This chapter also suggests alternative instruments corresponding to permanent income and does the rework of Aguiar-Bill's double-different correction method. We find the PIH instrument has a slightly higher first stage $R^{2}$ than the Aguiar and Bils instrument in Engel curve and after adjusting for measurement errors, the trend in consumption inequality tracks that of income inequality more closely. 


\section{Chapter 2}

\section{Inequality and Mobility of Household Earnings over the Life Cycle and Business Cycles}

\section{$2.1 \quad$ Introduction}

The trend in household inequality has been heavily studied in empirical and theoretical economic literature. Quantitative analysis of the household income dynamics hinges on the assumptions to identify two income components (permanent component and transitory component). Distinguishing permanent and transitory components is necessary to understand the source of income inequality, which is useful to make economic policy. If the permanent component is a main driver of inequality, effective inequality-reduction public policies should focus on career trajectories through improvement in education and health. In contrast, if the transitory component is a main driver of inequality, inequality-reduction public policies should focus on social insurance and access to credit when there are short-term income shortfalls.

There are two main approaches to model the permanent component in the income unexplained by household demographics and macro shocks. One widely employed 
model for the permanent component is random walk, which Guvenen (2009) calls a Restricted Income Profiles (RIP) process. For model identification, the shocks to the permanent component and the innovations to the transitory component are assumed to be (a) - independent over time for each household and (b) - identically and independently distributed cross households in each period (see e.g., Meghir and Pistaferri (2004); Blundell et al. (2008); Blundell and Etheridge (2010); Jappelli and Pistaferri (2010); Moffitt and Gottschalk (2011)). Meghir and Pistaferri (2004) allow the distributions of income shocks to be time varying while maintaining the assumptions (a) and (b).

Another approach models life-cycle earnings by a function of experience profiles, with household-specific but time-invariant random parameters on the intercept and the slope. A vast literature accounts for the heterogeneity in the average of lifecycle income profiles (e.g., Mincer (1974); Becker (1975); Carroll and Summers (1991); Baker (1997); Haider (2001); Guvenen (2009), etc). Guvenen (2009) labels this a Heterogeneous Income Process (HIP) model in contrast to the RIP model, and shows that the HIP for unexplained earnings fits Panel Study of Income Dynamics (PSID) data well.

Both the RIP and HIP models exclude an aggregate factor under an implicit assumption that aggregate shocks affect the cross sectional mean of income but not the variance of idiosyncratic shocks across households. In other words, they exclude the scenario that some households are always more affected by aggregate shocks than other households. They also rule out the possibility that income shocks are related to past income. Empirical evidence suggests that these restrictions are counterfactual.

Several recent empirical studies on U.S. household income data suggest that household income shocks are not iid and maybe dependent on past income. Arellano et al. (2017) estimate a nonparametric model of PSID household earnings and find the presence of nonlinear persistence and conditional asymmetries in earnings. Guvenen et al. 
(2015) analyze a large sample of life-cycle earnings of U.S. workers and find heterogeneity: in each period where most individuals experience small earnings shocks and few experience large shocks. They find that low-income workers experience earnings shocks that are large but not persistent, whereas high-income individuals experience shocks that are persistent but are smaller. Also, positive (negative) shocks to highearnings workers are transitory (persistent), and the opposite is true for low-earnings workers.

A number of stylized facts in the Korean Labor and Income Panel Study (KLIPS) data contradict predictions of RIP and HIP models. To improve upon these conventional models, this study explores parametric income models in which income shocks depend on latent household-specific and macro factors.

The long longitudinal data allow us to evaluate income models based on statistics beyond a simple measure of inequality (e.g., variance of cumulative income and the relationship between initial income and income growth). One of these statistics is income mobility, which represents the change in the relative standings of households. Inequality and mobility concern different aspects of distributions of household variables. Inequality may be studied by cross-sectional or panel data. Mobility can only be studied in a panel data setting. Higher mobility is desirable but it does not necessarily associated with reduced inequality. From an economic policy perspective, inequality (dispersion) of income matters, so is mobility.

In this paper, we address the following empirical questions:

(1) What is the trend of cross sectional distributions of household earnings? Some aspects of the distributions alluded earlier include inequality, measured by cross sectional variance; correlation between initial income and future income growth; and income mobility.

(2) Do commonly employed models fit the trend of cross sectional distributions of household earnings? If not, what model does? And how does the best model explain 
the drivers of income inequality?

Most of existing Korean studies analyze the trend of Korean household income inequality. They draw mixed conclusions on the trend in the past two decades. A number of studies (Kim and Kim (2015); Hong (2015)) find that the share of top income households has steadily increased since mid-1990s, indicating a widening inequality. On the other hand, Choi et al. (2018) find that the Gini coefficient of household income fluctuates after the 1998 Asian Financial Crisis and trends downwards after the 2008 Global Financial Crisis. These studies suggest that the measurement of income inequality is influenced by the metric and data. While a specific metric for inequality provides a simple description, it does not by itself shed much light on the drivers of inequality.

We explore inequality in household earnings by following a cohort of households in KLIPS over 19 years, from 1997 to 2015. By tracking a fixed cohort over the life cycle, we are able to examine how earnings of each household evolve over time and relative to earnings of other households. The sample period includes large macroeconomic shocks of the Asian Financial crisis of 1998 and the Global Financial Crisis of 2008 and the subsequent recoveries. The presence of a large macroeconomic shock permits exploration of parametric income models in which income shocks depend on latent household variables and macro factors. We model the income process with the focus on the dependence and heterogeneity of income shocks to the macroeconomy.

We focus on household labor income inequality for households with a head under working age during 1997-2015. Empirical evidence suggests that the lifetime income profile may shift over time but not proportionally. We estimate alternative generalizations of the RIP and HIP that differ from the Baker and Solon (2003) model, by allowing income profile shifting over time but not proportionally. In particular, we examine a generalized RIP (G-RIP) model with a heterogeneous permanent effect of macro factor, and a generalization of the HIP model with "stochastic experience 
premium" (stochastic heterogeneous income profile, or SHIP model). We estimate competing models by the method of moments. For model comparison, we use the selection criteria proposed by Andrews and Lu (2001) that balance the fit and the size of the models.

We make the following contributions to the literature:

(1) We report empirical pattern of lifecycle income dynamics in KLIPS. We find that cumulative household income changes over a range of distant future are negatively correlated with the initial income. This suggests that the permanent income shocks in distant future are correlated with the current income.

(2) We estimate competing models of income process with the focus on the dependence and heterogeneity of income shocks. We consider a battery of parametric models that include and nest the RIP and HIP models. We find that the G-RIP and SHIP models are better than the RIP and HIP models for the KLIPS data based on the model selection criterion of Andrews and Lu (2001). We then decompose the components of income inequality in each model.

In Section 2.2 we discuss the KLIPS data set and report observed trends in household earning inequality and mobility. In Section 2.3 we outline our approach to estimate and select competing models. In Section 2.4 we report the estimate and misfit of the exiting income models, compare that with estimated alternative income models and analyze the drivers of income inequality. Section 2.5 concludes.

\subsection{Empirical Patterns in the KLIPS Data}

\subsubsection{KLIPS Data}

The Korean Labor and Income Panel Study (KLIPS) is comparable to the PSID in the U.S. KLIPS is a publicly available annual survey for social and demographic as 
well as economic data of individuals and households. The first wave of KLIPS started from 5,000 urban households in 1998 and 1,415 new households were added in 2008 to compensate for sample attrition.

KLIPS uses a two-stage stratified clustering method for sample and data collection. Enumeration districts (EDs) are selected and then households are selected in the EDs. Every household in the population is assigned into only one ED. KLIPS collects data via annual face-to-face surveys. Every member aged 15 or older of each household participates in annual surveys on household and individual information such as economic activities, employment status, income, expenditures, education, housing status, financial and real estate property wealth, debt, and so on. Sample attrition occurs. Table A.5 of Appendix A rejects bias in sample attrition.

A key variable is household earnings. The KLIPS surveys earnings of the previous year. We use the nineteen waves from 1998 (on 1997 income data) through 2016 (on 2015 income data) to analyze inequality and mobility and only focus on married households with observations in all 19 years. Our study focuses on household's labor income for households with a head going through the lifecycle of working age. We follow several common practices in sample selection (e.g., Blundell et al. (2008)). First, divorced, separated, and one-person households are dropped. Second, households with missing report on labor income are dropped. Third, split offs of the original household are excluded. Finally, households with a heads under 25 years or over 65 years old in any year between 1997 and 2015 are dropped. Details of analysis on sample selection are provided in Appendix A.1.

Some studies remove households experiencing large or small income changes in accord with the assumption of cross-household homogeneity in the income shocks. We do not remove income outliers because our analysis is not reply on the assumption of iid income shocks. But the empirical pattern reported later is qualitatively the same for the sample with or without outliers. The final sample after filtering work consists 
of the balanced panel data with 545 households (with 10,355 observations). We use 2015 as the base year to compute for real earnings.

Table 2.1 and 2.2 report household demographic variables and a decomposition of disposable income by education level, respectively. Family size declines since 2004 and a number of workers steadily increase over time, which implies that as parents are getting old, their descendants tend to have a job and make new household moving out of their parents' house. Approximately fifty percent of sample households live in metropolitan cities of more than one million people. Thirty percent of households have a head with college or higher educated.

Table 2.1: Average demographic characteristics

\begin{tabular}{c||cccc} 
Year & Family size & Children & Workers & Share of bigcity ${ }^{a}$ \\
\hline \hline 1997 & 3.983 & 1.725 & 1.420 & 0.554 \\
1998 & 4.050 & 1.750 & 1.510 & 0.552 \\
1999 & 4.064 & 1.714 & 1.505 & 0.547 \\
2000 & 4.092 & 1.681 & 1.543 & 0.545 \\
2001 & 4.110 & 1.628 & 1.628 & 0.541 \\
2002 & 4.127 & 1.538 & 1.655 & 0.547 \\
2003 & 4.123 & 1.455 & 1.672 & 0.539 \\
2004 & 4.114 & 1.352 & 1.716 & 0.538 \\
2005 & 4.097 & 1.255 & 1.758 & 0.538 \\
2006 & 4.057 & 1.163 & 1.835 & 0.534 \\
2007 & 4.006 & 1.039 & 1.853 & 0.528 \\
2008 & 3.961 & 0.943 & 1.837 & 0.525 \\
2009 & 3.901 & 0.837 & 1.868 & 0.527 \\
2010 & 3.864 & 0.736 & 1.877 & 0.525 \\
2011 & 3.798 & 0.639 & 1.910 & 0.527 \\
2012 & 3.728 & 0.543 & 1.883 & 0.521 \\
2013 & 3.695 & 0.428 & 1.850 & 0.523 \\
2014 & 3.622 & 0.343 & 1.927 & 0.517 \\
2015 & 3.538 & 0.250 & 1.875 & 0.517 \\
\hline
\end{tabular}

Note: The table is based on the balanced panel of 545 households. ${ }^{a)}$ represents the proportion of a household that live in metropolitan cities of more than 1 million people. 
Table 2.2: Average labor, transfer, and disposable income by education level

\begin{tabular}{l||crc|ccc|ccc}
\multicolumn{1}{l|}{} & \multicolumn{4}{|c|}{ All } & \multicolumn{3}{c|}{ College or higher educated } & \multicolumn{3}{|c}{ High school or under educated } \\
Year & L.I ${ }^{a)}$ & T.I I $^{b}$ & D.I & L.I & T.I & D.I & L.I & T.I & D.I \\
\hline \hline 1997 & 3,471 & 1 & 3,584 & 4,335 & 0 & 4,477 & 3,105 & 1 & 3,207 \\
1998 & 3,145 & 45 & 3,551 & 4,026 & 43 & 4,609 & 2,773 & 46 & 3,104 \\
1999 & 3,441 & 23 & 4,008 & 4,314 & 42 & 4,827 & 3,072 & 15 & 3,661 \\
2000 & 3,742 & 27 & 4,105 & 4,719 & 42 & 5,593 & 3,329 & 21 & 3,476 \\
2001 & 4,291 & 66 & 4,764 & 5,503 & 140 & 6,498 & 3,779 & 34 & 4,031 \\
2002 & 4,515 & 52 & 5,089 & 5,727 & 82 & 7,074 & 4,002 & 39 & 4,249 \\
2003 & 4,933 & 61 & 5,262 & 6,410 & 105 & 7,010 & 4,309 & 42 & 4,523 \\
2004 & 4,990 & 103 & 5,414 & 6,268 & 183 & 6,862 & 4,450 & 69 & 4,802 \\
2005 & 5,268 & 117 & 5,928 & 6,546 & 171 & 7,917 & 4,728 & 94 & 5,086 \\
2006 & 5,475 & 164 & 6,188 & 6,853 & 258 & 8,074 & 4,892 & 124 & 5,390 \\
2007 & 5,820 & 110 & 6,303 & 7,279 & 176 & 7,993 & 5,203 & 83 & 5,588 \\
2008 & 5,675 & 85 & 6,210 & 7,211 & 96 & 7,923 & 5,026 & 80 & 5,486 \\
2009 & 5,765 & 109 & 6,553 & 7,399 & 197 & 9,149 & 5,074 & 73 & 5,455 \\
2010 & 5,819 & 131 & 6,332 & 7,313 & 156 & 8,132 & 5,187 & 120 & 5,571 \\
2011 & 5,892 & 152 & 6,409 & 7,347 & 205 & 8,052 & 5,277 & 129 & 5,714 \\
2012 & 5,994 & 154 & 6,430 & 7,672 & 119 & 8,217 & 5,284 & 168 & 5,675 \\
2013 & 6,102 & 191 & 6,769 & 7,485 & 196 & 8,330 & 5,516 & 188 & 6,109 \\
2014 & 6,202 & 220 & 6,796 & 7,755 & 203 & 8,685 & 5,546 & 228 & 5,997 \\
2015 & 6,170 & 304 & 6,969 & 7,619 & 425 & 9,158 & 5,558 & 253 & 6,044 \\
\hline
\end{tabular}

Note: The table is based on the balanced panel of 545 households. ${ }^{a)},{ }^{b)}$, and ${ }^{c)}$ represent real labor income, real transfer income, and real disposable income, respectively and unit is ten thousand Korean Won in 2015.

\subsubsection{Detrended Income}

The income process for each household $i$ is (for $t=t_{i}, \cdots, T, i=1, . ., N$ )

$$
Y_{i t}=\mathbf{Z}_{\mathbf{i t}}^{\prime} \gamma_{\mathbf{y}}+y_{i t}
$$

where real $(\log )$ labor income, $Y$, can be decomposed predictable and stochastic components. For the former, $\mathbf{Z}^{\prime}$ is a $1 \times m$ row vector of income characteristics observable (e.g., a head's education and birth year, residential district, family size, number of workers, number of children, and year dummy) and known by households at time t. $\gamma_{\mathbf{y}}$ is an $m$-dimensional unknown parameter vector. Boldface letters represent vectors or matrices. Defining $y_{i t}=Y_{i t}-\mathbf{Z}_{\mathbf{i t}}^{\prime} \gamma_{\mathbf{y}}$ as the log of real labor income net of 
predictable individual components. Because of the presence of year dummy in the equation (2.1), $y_{i t}$ has mean zero in each year $t$. The variance, skewness and kurtosis are reported in Table 2.3.

Table 2.3: Statistics of Income Residuals

\begin{tabular}{r||rrr} 
Year & Variance & Skewness & Kurtosis \\
\hline \hline 1997 & 0.241 & 0.012 & 6.066 \\
1998 & 0.243 & -0.774 & 4.875 \\
1999 & 0.201 & -0.261 & 4.509 \\
2000 & 0.199 & -0.589 & 7.062 \\
2001 & 0.193 & -0.866 & 6.397 \\
2002 & 0.193 & -0.388 & 4.192 \\
2003 & 0.210 & -0.225 & 4.972 \\
2004 & 0.213 & -0.334 & 5.651 \\
2005 & 0.195 & -0.148 & 6.344 \\
2006 & 0.197 & -0.756 & 7.562 \\
2007 & 0.182 & 0.049 & 3.782 \\
2008 & 0.227 & -0.949 & 8.827 \\
2009 & 0.194 & 0.134 & 4.369 \\
2010 & 0.234 & -1.093 & 9.391 \\
2011 & 0.220 & -0.980 & 9.847 \\
2012 & 0.199 & -0.099 & 3.648 \\
2013 & 0.244 & -0.675 & 7.104 \\
2014 & 0.252 & -0.535 & 5.620 \\
2015 & 0.287 & -1.540 & 14.467 \\
\hline
\end{tabular}

\subsubsection{Measuring Income Inequality and Mobility}

An increase in variance affects both income inequality and income mobility. Inequality is a static statistic and mobility is a dynamic one. We use cross-sectional variance $\operatorname{var}\left(y_{i t}\right)$ to measure income inequality and the correlation of the deviation from the mean over time to measure income mobility.

Denote $z_{i t}=\frac{y_{i t}}{\sqrt{\operatorname{var}\left(y_{t}\right)}}$. By construction $z_{i t}$ has a sample mean of 0 and sample variance of 1 . Is the deviation from mean persistent $(t=1, . ., T)$ ? We run the regression $z_{i t}=\rho_{t} z_{i t-1}+\mu_{i t}$. The OLS estimate $\hat{\rho}_{t}=\frac{\sum_{i=1}^{n} z_{i t-1} z_{i t}}{\sum_{i=1}^{n}\left(z_{i t-1}\right)^{2}}=\operatorname{corr}\left(y_{i t-1}, y_{i t}\right)$. We 
use $1-\hat{\rho}_{t}^{2}$ to measure mobility. ${ }^{1}$

\subsubsection{Implications of the RIP and HIP Models}

Let $y_{i t}$ be unexplained earnings of household $i$ in period $t$. The RIP model assumes

$$
\mathbf{R I P}: y_{i t}=P_{i t}+v_{i t}
$$

where permanent component $P_{i t}$ is a random walk (i.e., $P_{i t}=P_{i t-1}+\zeta_{i t}$, where $\zeta_{i t}$ are the permanent shocks) and independent of the transitory shocks $v_{i t}$ across households and over time. In the literature on the dynamics of household income inequality, the variance of persistent income shocks in each period is identical for all households (but may be time-varying); so is the variance of transitory income shocks.

Suppose the head of the household has experience $t_{i}$ in the initial period of the sample. We calculate the initial work experience of household head $i$ by $t_{i}=$ initial age $_{i t}-26$. Then with the life-cycle earning HIP model

$$
\text { HIP : } y_{i t}=\delta_{i}+\left(t+t_{i}\right) \beta_{i}+v_{i t}
$$

where the slope $\beta_{i}$ is the experience premium. The income shocks $v_{i t}$ is assumed to be serially correlated but stationary.

The income models have different implications on household risk, inequality, and mobility. The RIP model ties together household risk, inequality, and mobility. The RIP model assumes income shocks are iid across households, which means that a

\footnotetext{
${ }^{1}$ More generally, the density of $z_{i t}$ is $f_{t}($.$) and the CDF is F_{t}($.$) . The ranking of household i$ is $F_{t}\left(z_{i t}\right) \in(0,1)$. The statistic $M_{t}=1-\operatorname{corr}\left(F_{t}\left(z_{i t}\right), F_{t-1}\left(z_{i t-1}\right)\right)$ measures mobility. Alternatively we can use the following discrete measure: Since $z_{i t}$ is memorialized to have mean 0 and variance 1 , we divide the space of $z_{i t}$ into $K$ intervals $\left(-\infty, a_{1}\right),\left(a_{1}, a_{2}\right), \ldots,\left(a_{K},+\infty\right)$. Denote the state $s_{i t}=k$ if $z_{i t}$ is in the $k$-th interval. Then the mobility of ranking of household $i$ is given by a $K \times K$ transition matrix $\mathbf{T}_{\mathbf{t}}$ whose $(k, m)$ element is $\mathbf{T}_{t}(k, m)=\operatorname{prob}\left(s_{i t}=m \mid s_{i t-1}=k\right)$. We find the alternative measures of mobility yield similar results.
} 
larger variance of income shocks in a given period captures both the higher income risk faced by each household and larger income inequality across households, as well as more potential for mobility in the relative rank across households.

The HIP model separates household risk, inequality, and mobility. Tracking the lifecycle of a cohort of households with income generated by the HIP model yields transitory income risk, expanding inequality and diminishing income mobility.

\subsubsection{Stylized Facts and the RIP and HIP Models}

Table 2.3 presents descriptive statistics of income, $y_{i t}$ detrended from the equation (2.1). We make five observations on KLIPS detrended household labor earnings (y). A number of them present challenges to the RIP and HIP model.

\section{Observation 1.}

The labor income inequality, $\operatorname{var}(\mathrm{y})$ is negatively correlated with GDP growth (i.e., counter cyclical), especially during recessions. In the 1998 Asian Financial Crisis and the 2008 Global Financial Crisis the KLIPS households earnings are more dispersed. These also occur the end of the sample, possibly because of heterogeneity in retirement timing. (See Figure 2.1).

Figure 2.1: $\operatorname{var}(y)$ and GDP growth rate

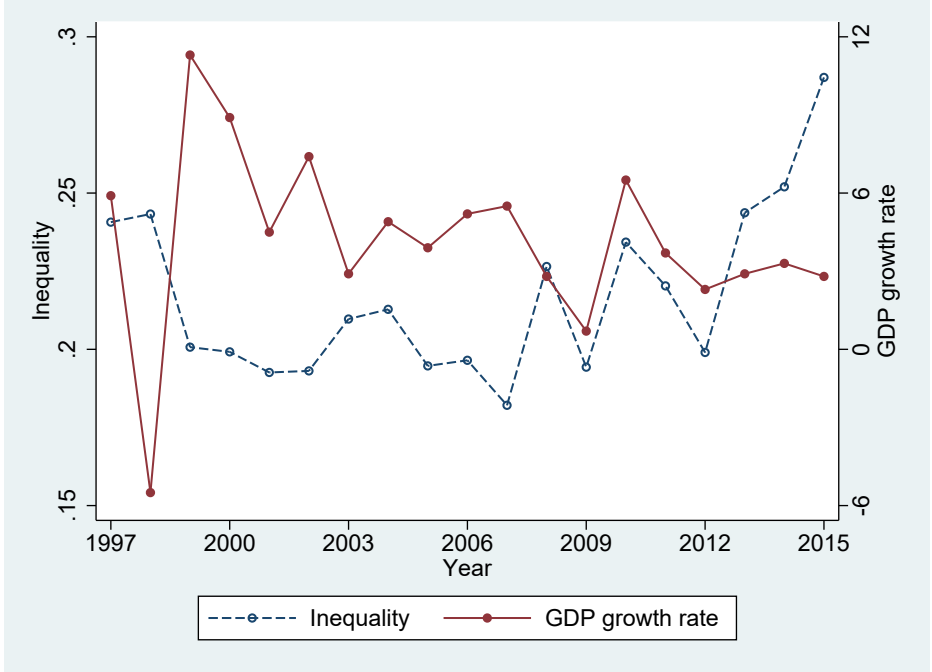


If we only focus on income inequality, the correlation of earnings inequality and GDP growth may be captured by a time-varying variance of income shocks $\zeta_{i t}$ or $v_{i t}$. However, it turns out that iid income shocks do not match some cross-household covariances of income.

\section{Observation 2.}

Inequality of cumulative growth income (i.e., $\left.\operatorname{var}\left(y_{t}-y_{1}\right)\right)$ expands, which implies a permanent force of divergence. In the RIP model it can be used to estimate the variance of permanent component relative to the variance of transitory component. In the HIP model the divergence of $\operatorname{var}\left(y_{t}-y_{1}\right)$ may due to accumulation of a permanent component (intercept) or the presence of a heterogeneous experience premium proportional to experience (slope $\beta_{i}$ ).

Figure 2.2: $\operatorname{var}(\Delta y)$ and $\operatorname{var}\left(y_{t}-y_{1}\right)$

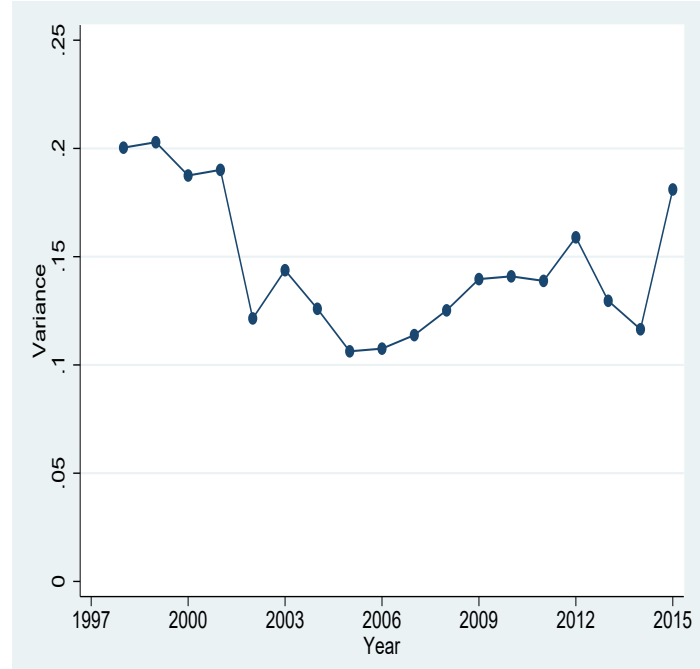

(a) Variance of income growth

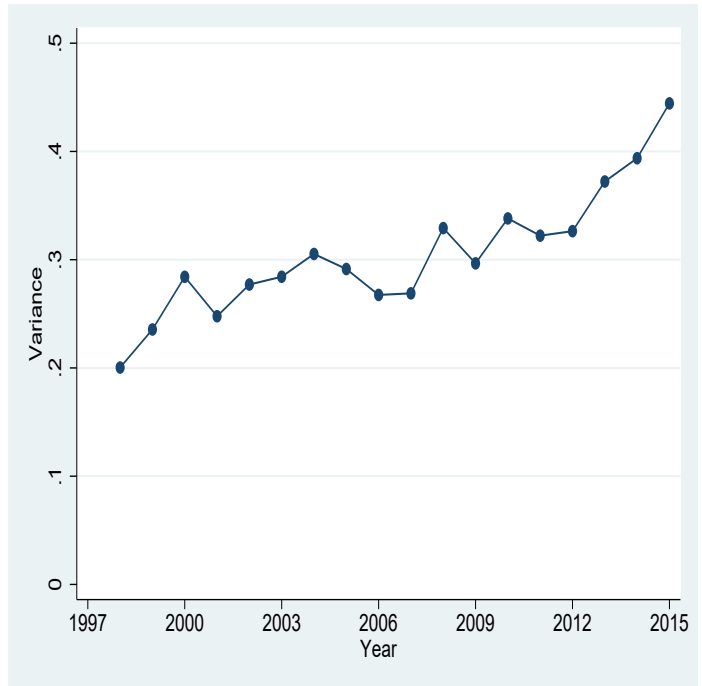

(b) Variance of cumulative growth of income

\section{Observation 3.}

The covariance $\operatorname{Cov}\left(y_{t}-y_{3}, y_{1}\right)<0$, i.e., households with high initial income $y_{1}$ experience more large negative shocks later in the lifecycle. This contradicts to the RIP model. In the HIP model the negative correlation between $y_{t}-y_{3}$ and $y_{1}$ is consistent with a negative correlation between $\beta_{i}$ and $\delta_{i}$. 
Figure 2.3: $\operatorname{corr}\left(y_{t}-y_{3}, y_{1}\right)$

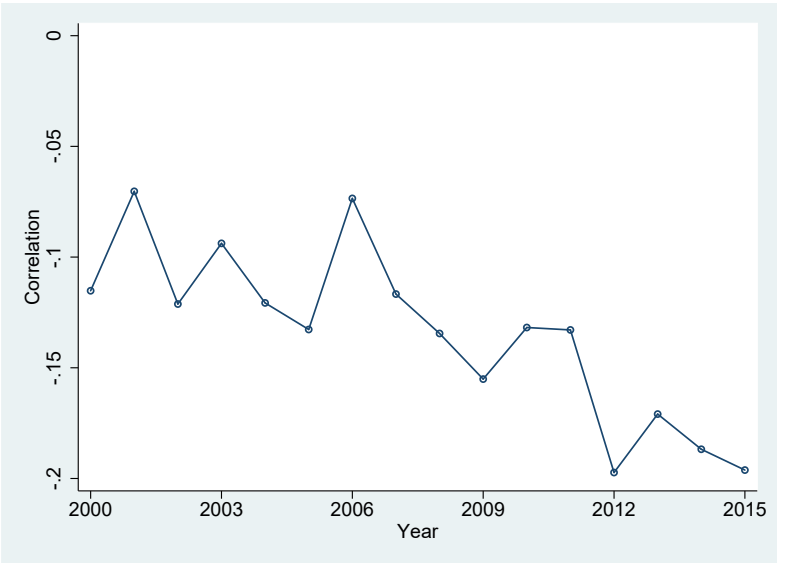

\section{Observation 4 .}

Labor income mobility is higher post-recession, and is relatively persistent. This suggests that in the RIP model permanent component has to be small (relative to transitory shocks), otherwise the income will diverge quickly over time and the mobility shrinks over time. In the HIP model variance of $\beta_{i}$ is close to zero or the variance of transitory income shocks has to grow over time, otherwise income mobility should shrink to 0 .

Figure 2.4: $\operatorname{Mobility}\left(1-\hat{\rho}_{t}^{2}\right)$

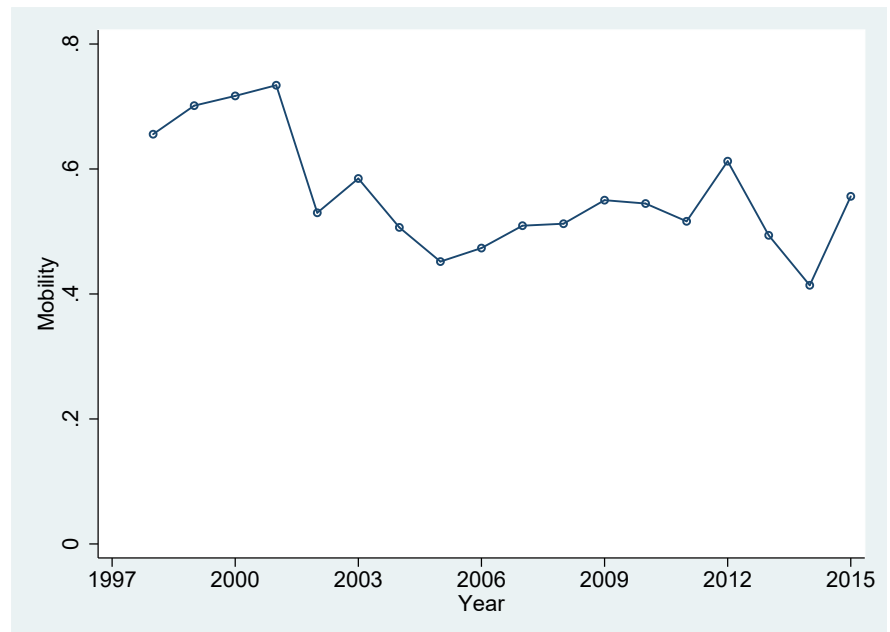

\section{Observation 5 .}

The within-cohort $\operatorname{var}\left(y_{i t}\right)$ is higher for the older cohort. $\operatorname{var}\left(y_{i t}-y_{i 1}\right)$ expands 
for all cohorts, and expands faster for older households. One may argue that Figure 2.5(a) is consistent with the theory that the post 1997 permanent income shocks on different cohort are of the same variance but these shocks are small than that prior to 1997. However, the theory does not explain Figure 2.5(b), which shows the variance of cumulative growth of older cohort grows faster than that of the younger one. If all cohorts are subject to the same variance of idiosyncratic permanent shocks, the variance of cumulative growth should be the same. And if the idiosyncratic permanent shocks are small as Figure 2.5(a), then there should not be expanding variance for the older cohort in 2.5(b).

Figure 2.5: $\operatorname{var}\left(y_{t}\right)$ and $\operatorname{var}\left(y_{t}-y_{1}\right)$ by cohorts

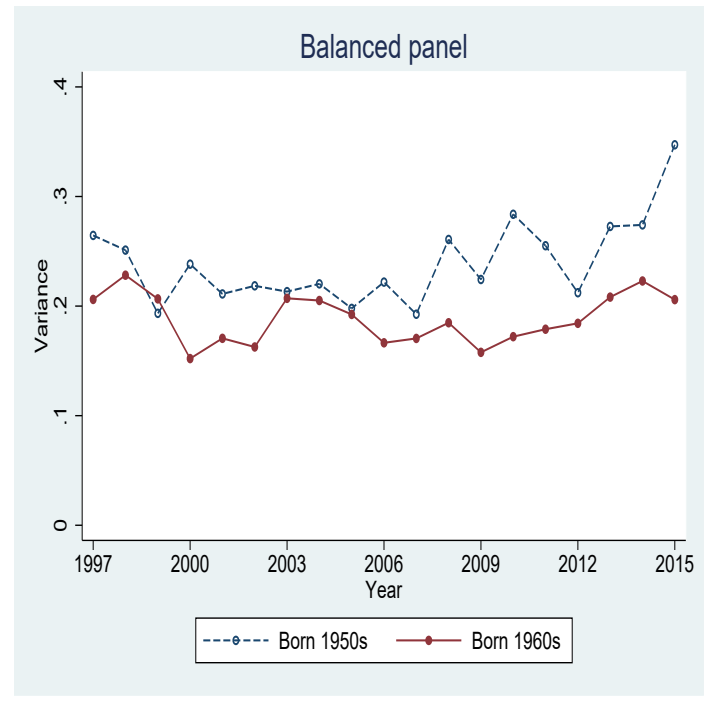

(a) $\operatorname{var}\left(y_{t}\right)$

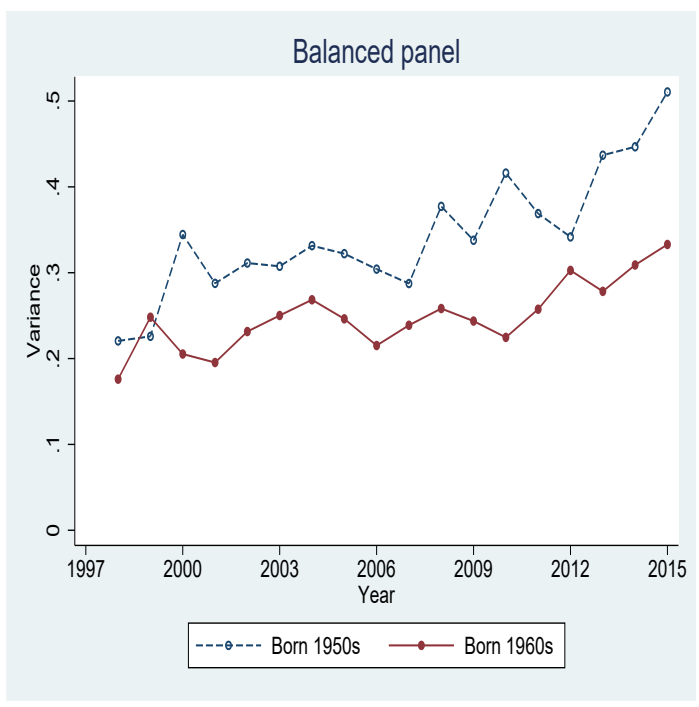

(b) $\operatorname{var}\left(y_{t}-y_{1}\right)$

Figure 2.5(b) is consistent with the HIP model, in which the heterogeneous income profile diverges over the life cycle (diverging experience premium $=$ experience $\times \beta_{i}$ for household $i$ ). However the HIP with a constant $\beta_{i}$ over time cannot explain the flat within-cohort inequality $\operatorname{var}\left(y_{i t}\right)$ over the life cycle. The constant $\beta_{i}$ version of the HIP also predicts that over the life cycle the households become more locked-in in the income ranking. This also contradicts the persistent mobility shown in Figure 2.4. The data on life-cycle income inequality by cohorts suggest the presence of stochastic 
experience premium. The variance of the experience premium is trending lower post 1997.

We now go over the above arguments in algebra in a model that combines the RIP and HIP models. Suppose for household with initial experience $t_{i}$

$$
y_{i t}=\left(t+t_{i}\right) \beta_{i t}+P_{i t}+v_{i t} .
$$

If $\beta_{i t}=0$ then we have the RIP model with $\operatorname{var}\left(y_{i t}\right) \approx \operatorname{var}\left(P_{i 1}\right)+\sum_{j=2}^{t} \operatorname{var}\left(\zeta_{i t}\right)+$ $\operatorname{var}\left(v_{i t}\right)$. If all cohort experience the same $\operatorname{var}\left(\zeta_{i t}\right)$ then the gap in $\operatorname{var}\left(y_{i t}\right)$ across cohort has to be explained by the gap in $\operatorname{var}\left(P_{i 1}\right)$, i.e., older cohorts are more diverse in 1997 because they have accumulated more years of permanent shocks than younger households up to 1997. For var $\left(y_{i t}\right)$ to be flat over the lifecycle there should be very small $\operatorname{var}\left(\zeta_{i t}\right)$ (hence no trend in the accumulation of the $\operatorname{var}\left(\zeta_{i t}\right)$ ). But Figure 2.5(b) suggests the presence of substantial permanent shocks at least for the older cohort. Hence this rejects the hypothesis $\beta_{i t}=0$. Another piece of evidence against the hypothesis $\beta_{i t}=0$ is the Observation 3. If $\beta_{i t}=0$ future shocks should be independent of $y_{1}$ and not negatively correlated with $y_{1}$.

Now consider the hypothesis $\beta_{i t}=\beta_{i}$ and let $P_{i t}=0$. In the case we have the HIP model, with $\operatorname{var}\left(y_{i t}\right) \approx\left(t+t_{i}\right)^{2} \operatorname{var}\left(\beta_{i t}\right)+\operatorname{var}\left(v_{i t}\right)$. Since $\left(t+t_{i}\right)^{2}$ expands over time, for $\operatorname{var}\left(y_{i t}\right)$ to stay flat over 20 years $\operatorname{var}\left(\beta_{i t}\right)$ must be very small and/or $\operatorname{var}\left(v_{i t}\right)$ must shrink fast over time. But if that were the case then we should not observe the growing trend in Figure 2.5(b) for the older cohort. Hence the HIP model does not explain all of the observations neither.

\subsubsection{Models of Income Process with a Macro Factor}

The above discussion shows that neither HIP nor RIP model can account for the apparent connection between macroeconomic state and household lifetime income 
profile. To improve the empirical performance of the income model we now introduce a macro state proxied by $f_{t}$ into the model (2.2). Experience in the initial period of the sample of a head of a household $i$ is $t_{i}$. We assume three sources of variation in detrended labor income for a household $i, y_{i t}$ : a direct household-specific impact of macroeconomy $\delta_{i} f_{t}$, a permanent component, and a transitory component.

A central feature is the correlation between business cycle and inequality. The correlation may stem from three sources: the direct effect, change in the variance of permanent component and change in the variance of transitory component.

We consider the following model that nests the RIP and HIP models and includes a macro factor. Instead of assuming a time-invariant slope for experience premium we assume the slope $\beta_{i t}$ be potentially stochastic.

$$
y_{i t}=\delta_{i} f_{t}+\left(t+t_{i}\right) \beta_{i t}+P_{i t}+v_{i t} .
$$

The household income residual has four components: (i) the effect of aggregate time varying factor on the households (the macro effect), $\delta_{i} f_{t}$. (ii) the effect of household's career trajectory; $\beta_{i t}\left(t+t_{i}\right)$ captures the heterogeneity in the lifecycle trajectory (relative to other households in the sample). The slope $\beta_{i t}$ is a "experience premium" and a key determinant of the lifetime income. There are two types of idiosyncratic risks: (iii) The idiosyncratic permanent component $P_{i t}=P_{i t-1}+\zeta_{i t}, \zeta_{i t}$ has zero mean, variance $\sigma_{\zeta_{t}}^{2}$. Shocks in $\zeta$ in the initial sample period have a variance $\sigma_{\zeta_{1}}^{2}$ (or $\operatorname{var}\left(P_{i 1}\right)$. This assumption is useful in explaining the higher inequality of older cohort in 1997 and (iv) the idiosyncratic transitory component (or measurement errors) $v_{i t} . v_{i t}=\xi_{i t}+\theta_{1} \xi_{i t-1}$ is $\mathrm{MA}(1), \xi_{i t}$ has zero mean, variance $\sigma_{\xi_{t}}^{2}$. 
This model nests some popular existing models. We assume

$$
\begin{aligned}
& E P_{i j}=E v_{i t}=E \delta_{i}=E \beta_{i t}=0, \\
& \operatorname{cov}\left(P_{i j}, v_{i t}\right)=0 \text { for all } j \text { and } t \\
& \operatorname{cov}\left(\delta_{i}, \beta_{i t}\right)=\operatorname{cov}\left(\delta_{i}, \beta_{i 1}\right) ; \\
& \operatorname{cov}\left(\delta_{i}, P_{i t}\right)=\operatorname{cov}\left(\delta_{i}, \alpha_{i}\right) .
\end{aligned}
$$

$\operatorname{var}\left(\alpha_{i}\right), \operatorname{var}\left(\beta_{i 1}\right), \operatorname{cov}\left(\delta_{i}, \alpha_{i}\right)$ and $\operatorname{cov}\left(\delta_{i}, P_{i 1}\right)$ are unknown parameters.

From the assumptions of the idiosyncratic shocks, for $t \geq 2$

$$
\begin{aligned}
\operatorname{var}\left(P_{i t}\right) & =\operatorname{var}\left(P_{i 1}\right)+t_{i} \sigma_{\zeta_{0}}^{2}+\sum_{k=2}^{t} \sigma_{\zeta_{k}}^{2}, \\
\operatorname{cov}\left(v_{i t}, v_{t+j}\right) & =\operatorname{var}\left(v_{i t}\right)=\sigma_{\xi_{t}}^{2}+\theta^{2} \sigma_{\xi_{t-1}}^{2} \text { for } j=0 \\
& =\theta \sigma_{\xi_{t}}^{2} \text { for } j=1, \\
& =0 \text { for } j>1 .
\end{aligned}
$$

\subsection{Estimation of Income Models}

In the literature on the dynamics of household income inequality, the variance of persistent income shocks in each period is identical for all households (but may be time-varying); so is the variance of transitory income shocks. As noted earlier, a fundamental identifying assumption is that persistent income shocks are serially and cross-sectionally uncorrelated. This assumption implies that household persistent income shocks are not directly related to shocks common to the households.

Data start on income of 1997, we track households for 19 years, to 2015. Denote the vector of unexplained income for household $i$ as $\mathbf{y}_{\mathbf{i}}=\left(y_{i 1}, . ., y_{i T}\right), T=19$.

By design the cross-household average of $\mathbf{y}_{\mathbf{i}}$ are zero. The $T \times T$ sample covariance 
matrices of $\mathbf{y}_{\mathbf{i}}$ is

$$
\operatorname{Var}(\mathbf{y})=\sum_{i=1}^{N} \frac{1}{N} \mathbf{y}_{\mathbf{i}}^{\prime} \mathbf{y}_{\mathbf{i}}
$$

In matrix form we denote variables $\mathbf{Y}=\left(\mathbf{y}_{\mathbf{1}}^{\prime}, \cdots, \mathbf{y}_{\mathbf{N}}^{\prime}\right)_{N \times T}^{\prime}$. Then $\frac{1}{N} \mathbf{Y}^{\prime} \mathbf{Y}$ is a $T \times T$ covariance matrix and diagonal element represents cross-sectional variance for each year. The details of moment conditions of $\frac{1}{N} \mathbf{Y}^{\prime} \mathbf{Y}$ are in Appendix A.

\subsubsection{Model Identification and Estimation}

We will discuss how to identify and estimate five models in the framework of (2.3) from sample moments of $\frac{1}{N} \mathbf{Y}^{\prime} \mathbf{Y}$.

The method of the moment-based estimation is outlined in Appendix A2.

The details of the moment conditions of each of the five models are also provided in Appendix A.2.

\section{The RIP model.}

The RIP is a special case with $f_{t}=0$ or $\delta_{i}=0$, and $\beta_{i t}=0$.

In this case $y_{i t}$ is decomposed into a permanent component $P$ and a mean-reverting transitory component $v$

$$
y_{i t}=P_{i t}+v_{i t}
$$

The permanent component is

$$
P_{i t}=P_{i t-1}+\zeta_{i t}
$$

where $\zeta$ is a permanent income shock with variance $\sigma_{i, t, \zeta}^{2}$, and the transitory component is $v_{i t}=\sum_{j=0}^{p} \theta_{j} \xi_{i, t-j}, \xi_{i, t}$ is a transitory income shock, with variance $\sigma_{t, \xi}^{2}$. For this study we let $\theta_{j}=1$ for $j=0, \theta_{j}=\theta$ for $j=1$, and $\theta_{j}=0$ for $j>1$. The permanent component $P_{i t}$ is assumed to be independent of the transitory shocks $v_{i t}$.

We now discuss what parameters in the RIP model can be identified from sample 
moments. The initial variance of the permanent component and permanent shock are indistinguishable, so we denote $\operatorname{var}\left(P_{i 1}\right)=\sigma_{\zeta_{1}}^{2}$. In the Appendix A2 we show one can solve $\theta, \sigma_{\xi_{1}}^{2}, \sigma_{\xi_{0}}^{2}$ from combinations of moments of $y_{i 1}, y_{i 2}, y_{i 3}, y_{i 4}$. Plugging them to $\operatorname{var}\left(y_{i 1}\right)=\operatorname{var}\left(P_{i 1}\right)+\sigma_{\xi_{1}}^{2}+\theta^{2} \sigma_{\xi_{0}}^{2}$ solves $\operatorname{var}\left(P_{i 1}\right)$. For $\mathrm{t}=2, . . \mathrm{T}-1, \sigma_{\xi_{t}}^{2}$ can be identified from $\operatorname{cov}\left(y_{i t}, y_{i t+1}\right)$, and then $\sigma_{\zeta_{t}}^{2}$ from $\operatorname{var}\left(y_{i t}\right)$. At the end of the sample period, with $\operatorname{var}\left(P_{1}\right)$ and $\sigma_{\xi_{T-1}}^{2}$ identified, $\operatorname{var}\left(y_{i T}\right)=\sum_{k=1}^{T} \sigma_{\zeta_{k}}^{2}+\sigma_{\xi_{T}}^{2}+\theta^{2} \sigma_{\xi_{T-1}}^{2}$. We can only identify $\sigma_{\zeta_{T}}^{2}+\sigma_{\xi_{T}}^{2}$ but not $\sigma_{\zeta_{T}}^{2}$ and $\sigma_{\xi_{T}}^{2}$ separately because in the last period we cannot distinguish permanent from transitory shocks. In sum, there are $2 T$ identifiable unknown parameters $\boldsymbol{\theta}=\left\{\theta, \operatorname{var}\left(P_{1}\right), \sigma_{\zeta_{t}}^{2}, \sigma_{\xi_{t}}^{2}\right\}$.

Our estimation of the RIP model is based on the moments of income . A more common approach to estimation of the RIP model is based on moments of income growth, $\Delta y$. Identification based on the covariance of growth rates recovers fewer parameters than from the covariance of levels. The Appendix A presents details of identification following BPP (2008). The scheme identifies $2 T-7$ parameters of the RIP model: $\sigma_{\zeta_{t}}^{2}, \sigma_{\xi_{t}}^{2}$ for $t=3, . ., T-2$ and $\theta$.

The additional parameters based on the moments of covariance of income are useful for analyzing statistics related to covariance of income.

\section{The HIP Model.}

With $f_{t}=1, P_{i t}=0$, and $\beta_{i t}=\beta_{i}$ in the equation (2.3) we have

$$
y_{i t}=\delta_{i}+\left(t+t_{i}\right) \beta_{i}+v_{i t}
$$

where the slope $\beta_{i}$ is the time-invariant experience premium and $\mathbb{E}\left(\beta_{i}\right)=0$. We assume $\xi_{i 0}=0$.

The HIP model implies $\Delta y_{i t}=\beta_{i}+\Delta v_{i t}$. Hence $\operatorname{var}\left(\beta_{i}\right)$ can be solved from $\operatorname{cov}\left(\Delta y_{i t}, \Delta y_{i t+3}\right) ;$ and subsequently $\operatorname{cov}\left(\delta_{i}, \beta_{i}\right)$ can be solved from $\operatorname{cov}\left(\Delta y_{i t}, y_{t+3}\right)$ and $\operatorname{var}\left(\beta_{i}\right) ; \sigma_{\xi_{t}}^{2}$ from $\operatorname{var}\left(\Delta y_{i t}\right)$ and $\operatorname{var}\left(\beta_{i}\right) ;$ and $\operatorname{var}\left(\delta_{i}\right)$ from $\operatorname{var}\left(y_{i t}\right), \operatorname{var}\left(\beta_{i}\right), \operatorname{cov}\left(\delta, \beta_{i}\right)$ 
, and $\sigma_{\xi t}^{2}$.

There are $3+T$ unknown parameters $\boldsymbol{\theta}=\left\{\sigma_{\delta}^{2}, \sigma_{\beta}^{2}, \operatorname{cov}\left(\beta_{i}, \delta_{i}\right), \theta, \sigma_{\xi_{t}}^{2}\right\}$.

\section{The Baker/Solon Model.}

Baker and Solon (2003) combine the RIP model with the HIP, and introduce a macro factor, $p_{t}$ :

$$
y_{i t}=p_{t}\left(\delta_{i}+\left(t+t_{i}\right) \beta_{i}+P_{i t}\right)+v_{i t}
$$

where $P_{i t}=P_{i t-1}+\zeta_{i t}, v_{i t}=\xi_{i t}+\theta_{1} \xi_{i t-1}$. In the Baker/Solon model variance of $\zeta_{i t}$ assumes time-constant and $\operatorname{var}\left(P_{i 0}\right)$ is zero. So, $\operatorname{var}\left(P_{i t}\right)$ is $t \sigma_{\zeta}^{2}$ and the macro factor amplifies permanent and lifetime income profile proportionally. There are $2+2 T$ unknown parameters $\boldsymbol{\theta}=\left\{\theta, \sigma_{\delta}^{2}, \sigma_{\beta}^{2}, \operatorname{cov}\left(\beta_{i}, \delta_{i}\right), \sigma_{\zeta}^{2}, \sigma_{\xi_{t}}^{2}, p_{t}\right\}$.

We now introduce two new models that generalize the RIP and HIP models.

\section{A Generalized RIP (G-RIP) Model.}

The conventional identification assumptions of the RIP yields counterfactual predictions. We consider a generalized version of the RIP: We introduce a macro effect $m_{i t}$ to the permanent component: $m_{i t}=f_{t} P_{i t-1}$. If $f_{t}$ is negative (positive) in a recession then high income households who have $P_{i t-1}>0$ suffer (gain) relative to low income households.

We assume $\operatorname{cov}\left(P_{i t}, \zeta_{i t+j}\right)=0$ for $j>0$ and $\operatorname{cov}\left(P_{i t}, \xi_{i j}\right)=0, \operatorname{cov}\left(\xi_{i t}, \zeta_{i t+j}\right)=0$ for all $t$ and $j$ and $\operatorname{cov}\left(\zeta_{i t}, \zeta_{i t+j}\right)=\operatorname{cov}\left(\xi_{i t}, \xi_{i t+j}\right)=0$ for all $t \neq j$. In the initial period we set $f_{1}=0$.

To illustrate properties of the GRIP model we first let the transitory component be iid, so $v_{i t}=\xi_{i t}$. The permanent component is now

$$
P_{i t}=\left(1+f_{t}\right) P_{i t-1}+\zeta_{i t},
$$


with $f_{t}>-1$. The model can be identified through the following moment conditions:

$$
\begin{aligned}
& \operatorname{cov}\left(y_{i t}, y_{i t+j}\right) \\
& =\operatorname{cov}\left(P_{i}, P_{i t+j}\right)+\operatorname{cov}\left(P_{i t}, v_{i t+j}\right)+\operatorname{cov}\left(P_{i t+j}, v_{i t}\right)+\operatorname{cov}\left(v_{i t+j}, v_{i t}\right) \\
& =\operatorname{var}\left(P_{i t}\right) \prod_{k=1}^{j}\left(1+f_{t+k}\right)
\end{aligned}
$$

The ratio in (2.11) yields

$$
\operatorname{cov}\left(y_{i t}, y_{i t+j}\right) / \operatorname{cov}\left(y_{i t}, y_{i t+j-1}\right)=1+f_{t+j}
$$

From (2.10)

$$
\operatorname{var}\left(P_{i t}\right)=\operatorname{var}\left(P_{i 1}\right)\left(\prod_{j=1}^{t}\left(1+f_{j}\right)\right)^{2}+\sum_{j=1}^{t-1}\left(\prod_{k=1+j}^{t}\left(1+f_{k}\right)\right)^{2} \sigma_{\zeta_{j}}^{2}+\sigma_{\zeta_{t}}^{2}
$$

We also have from the identifying restrictions

$$
\operatorname{var}\left(y_{i t}\right)=\operatorname{var}\left(P_{i t}\right)+\operatorname{var}\left(v_{i t}\right)
$$

The above conditions solve for $f_{t}, \operatorname{var}\left(v_{i t}\right)$, and $\sigma_{\zeta_{t}}, \operatorname{var}\left(P_{i 1}\right)$.

Lastly we consider a generalization of the HIP model.

\section{Stochastic Heterogeneous Income Profile: (SHIP Model).}

In the equation (2.3) $\beta_{i t}$ has time varying persistence with $\mathbb{E}\left(\beta_{i t}\right)=0$ :

$$
\beta_{i t}=\rho_{t} \beta_{i t-1}+\omega_{i t}
$$

where $\rho_{t}$ is a persistent parameter and $\omega_{i t}$ is innovations to the experience premium and correlated with a permanent shock $\zeta_{i t}$. There are $1+4 T$ unknown parameters $\boldsymbol{\theta}=\left\{\theta, \sigma_{\delta}^{2}, \operatorname{var}\left(P_{1}\right), \operatorname{var}\left(\beta_{i 1}\right), \operatorname{cov}\left(\delta_{i}, P_{i 1}\right), \operatorname{cov}\left(\delta_{i}, \beta_{i 1}\right), \operatorname{cov}\left(P_{i 1}, \beta_{i 1}\right), \sigma_{\omega}^{2}, h_{t}, \rho_{t}, \sigma_{\zeta_{t}}^{2}, \sigma_{\xi_{t}}^{2}\right\}$ 


\subsection{Estimates of Competing Income Models}

We use the method of moment estimator to estimate unknown parameters in the 5 competing income models. Tables 2.4 and 2.5 present estimation results of the competing income models including the three existing models (i.e., the RIP, HIP, and Baker/Solon models). As we discuss the RIP and HIP models based on the stylized facts in the section 2.2.5, the estimates for the both models are reasonable. First, permanent income shocks are small relative to transitory income shocks in the RIP model and variance of household-specific experience premium in the HIP model is small, which makes $\operatorname{var}(y)$ flat until 2007 and labor income mobility relatively persistent. Second, in the HIP model the household-specific intercept $\left(\delta_{i}\right)$ is negatively correlated with the household-specific experience premium $\left(\beta_{i}\right)$, which results in a negative correlation between income growth and initial income, $\operatorname{corr}\left(y_{t}-y_{3}, y_{1}\right)$.

\subsubsection{Income inequality}

We now examine whether the income process models explain the second moments of income level. Diagonal elements of the covariance matrix, $\frac{1}{N} \mathbf{Y}^{\prime} \mathbf{Y}$ represent crosssectional variance and Figure 2.6 displays the fitted inequality based on the estimates of Tables 2.4 and 2.5. Comparing Figure 2.6(a) and 2.6(b), the G-RIP and SHIP models considering heterogeneous macro effects better fit than the existing models for inequality. The Baker/Solon model considers the macro factor proportional to permanent component and is not enough to explain lifetime income profile compared to the G-RIP and SHIP models considering heterogeneous macro effects.

Under the assumptions of the RIP and HIP models, inequality tends to increase over time among the same cohort. We find income inequality depends on the state of the economy. Inequality tends to rise during a recession and to fall during a recovery. It is difficult to match this pattern by varying the variance of permanent shocks in the 
Table 2.4: Estimation results of HIP, RIP, and G-RIP

\begin{tabular}{|c|c|c|c|c|c|c|}
\hline \multirow[b]{2}{*}{ Year } & \multirow{2}{*}{$\begin{array}{l}\mathrm{HIP} \\
\sigma_{\xi_{t}}^{2}\end{array}$} & \multicolumn{2}{|c|}{ RIP } & \multicolumn{3}{|c|}{ G-RIP } \\
\hline & & $\sigma_{\zeta_{t}}^{2}$ & $\sigma_{\xi_{t}}^{2}$ & $f_{t}$ & $\sigma_{\zeta_{t}}^{2}$ & $\sigma_{\xi_{t}}^{2}$ \\
\hline \multirow[t]{2}{*}{1997} & 0.0599 & & 0.1332 & & & 0.0000 \\
\hline & $(0.0123)$ & & $(0.0150)$ & & & $(0.9032)$ \\
\hline \multirow[t]{2}{*}{1998} & 0.0992 & 0.0000 & 0.1503 & -0.4095 & 0.0734 & 0.0858 \\
\hline & $(0.0171)$ & $(0.0076)$ & $(0.0159)$ & $(1.7853)$ & $(0.3163)$ & (0.1184) \\
\hline \multirow[t]{2}{*}{1999} & 0.0657 & 0.0000 & 0.1010 & -0.2863 & 0.0254 & 0.0951 \\
\hline & $(0.0138)$ & $(0.0069)$ & $(0.0130)$ & $(0.5215)$ & $(0.0616)$ & $(0.0172)$ \\
\hline \multirow[t]{2}{*}{2000} & 0.0883 & 0.0014 & 0.0955 & -0.1402 & 0.0178 & 0.0992 \\
\hline & $(0.0184)$ & $(0.0070)$ & $(0.0130)$ & $(0.1098)$ & $(0.0080)$ & (0.0171) \\
\hline \multirow[t]{2}{*}{2001} & 0.0864 & 0.0104 & 0.0986 & 0.0424 & 0.0139 & 0.0753 \\
\hline & $(0.0188)$ & $(0.0064)$ & $(0.0149)$ & $(0.0860)$ & $(0.0087)$ & $(0.0136)$ \\
\hline \multirow[t]{2}{*}{2002} & 0.0889 & 0.0000 & 0.0962 & -0.0331 & 0.0058 & 0.0765 \\
\hline & $(0.0114)$ & $(0.0058)$ & $(0.0091)$ & $(0.0588)$ & $(0.0066)$ & (0.0097) \\
\hline \multirow[t]{2}{*}{2003} & 0.1128 & 0.0095 & 0.1066 & 0.0160 & 0.0196 & 0.0714 \\
\hline & $(0.0144)$ & $(0.0061)$ & $(0.0114)$ & $(0.0669)$ & $(0.0080)$ & $(0.0095)$ \\
\hline \multirow[t]{2}{*}{2004} & 0.1134 & 0.0045 & 0.1025 & -0.0924 & 0.0222 & 0.0767 \\
\hline & $(0.0177)$ & $(0.0059)$ & $(0.0135)$ & $(0.0572)$ & $(0.0070)$ & $(0.0112)$ \\
\hline \multirow[t]{2}{*}{2005} & 0.0969 & 0.0000 & 0.0870 & -0.0547 & 0.0000 & 0.0680 \\
\hline & $(0.0154)$ & $(0.0054)$ & $(0.0123)$ & $(0.0543)$ & $(0.0074)$ & $(0.0127)$ \\
\hline \multirow[t]{2}{*}{2006} & 0.0923 & 0.0000 & 0.0837 & 0.0156 & 0.0080 & 0.0612 \\
\hline & $(0.0154)$ & $(0.0052)$ & $(0.0142)$ & $(0.0480)$ & $(0.0057)$ & (0.0187) \\
\hline \multirow[t]{2}{*}{2007} & 0.0789 & 0.0056 & 0.0696 & -0.0620 & 0.0208 & 0.0434 \\
\hline & $(0.0099)$ & $(0.0056)$ & $(0.0079)$ & $(0.0521)$ & $(0.0060)$ & $(0.0068)$ \\
\hline \multirow[t]{2}{*}{2008} & 0.1096 & 0.0055 & 0.0965 & -0.0862 & 0.0226 & 0.0869 \\
\hline & $(0.0230)$ & $(0.0065)$ & $(0.0178)$ & $(0.0492)$ & $(0.0085)$ & (0.0199) \\
\hline \multirow[t]{2}{*}{2009} & 0.0759 & 0.0137 & 0.0556 & -0.0462 & 0.0242 & 0.0427 \\
\hline & $(0.0113)$ & $(0.0068)$ & $(0.0080)$ & $(0.0596)$ & $(0.0067)$ & $(0.0080)$ \\
\hline \multirow[t]{2}{*}{2010} & 0.1145 & 0.0081 & 0.0921 & -0.0602 & 0.0225 & 0.0798 \\
\hline & $(0.0289)$ & $(0.0071)$ & $(0.0235)$ & $(0.0548)$ & $(0.0094)$ & $(0.0250)$ \\
\hline \multirow[t]{2}{*}{2011} & 0.0527 & 0.0000 & 0.0384 & -0.0715 & 0.0095 & 0.0687 \\
\hline & $(0.0181)$ & $(0.0080)$ & $(0.0131)$ & $(0.0535)$ & $(0.0090)$ & (0.0218) \\
\hline \multirow[t]{2}{*}{2012} & 0.0610 & 0.0112 & 0.0489 & -0.0590 & 0.0250 & 0.0462 \\
\hline & $(0.0116)$ & $(0.0091)$ & $(0.0112)$ & $(0.0649)$ & $(0.0079)$ & (0.0139) \\
\hline \multirow[t]{2}{*}{2013} & 0.1001 & 0.0230 & 0.0668 & 0.0051 & 0.0344 & 0.0556 \\
\hline & $(0.0257)$ & $(0.0092)$ & $(0.0189)$ & $(0.0566)$ & $(0.0109)$ & $(0.0162)$ \\
\hline 2014 & 0.0770 & 0.0000 & 0.0759 & -0.0290 & 0.0103 & 0.0639 \\
\hline & $(0.0186)$ & $(0.0091)$ & $(0.0193)$ & $(0.0426)$ & $(0.0114)$ & $(0.0222)$ \\
\hline$\theta$ & 0.3851 & & & & 0.1094 & \\
\hline & $(0.0273)$ & $(0.0$ & & & $(0.0300)$ & \\
\hline$\sigma_{\xi_{0}}^{2}$ & & $\begin{array}{r}0.1 \\
0.0\end{array}$ & & & & \\
\hline$\sigma_{P_{1}}^{2}$ & & $0.0^{\prime}$ & 15 & & 0.2407 & \\
\hline & & $(0.0$ & & & $(0.9136)$ & \\
\hline$\sigma_{\delta}$ & 0.5774 & & & & & \\
\hline & $(0.0302)$ & & & & & \\
\hline$\sigma_{\beta}$ & 0.0253 & & & & & \\
\hline & $(0.0012)$ & & & & & \\
\hline $\operatorname{corr}(\delta, \beta$ & -0.8835 & & & & & \\
\hline & $(0.0146)$ & & & & & \\
\hline
\end{tabular}

Note: Standard errors are in the parenthesis. 
Table 2.5: Estimation results of Baker-Solon and SHIP

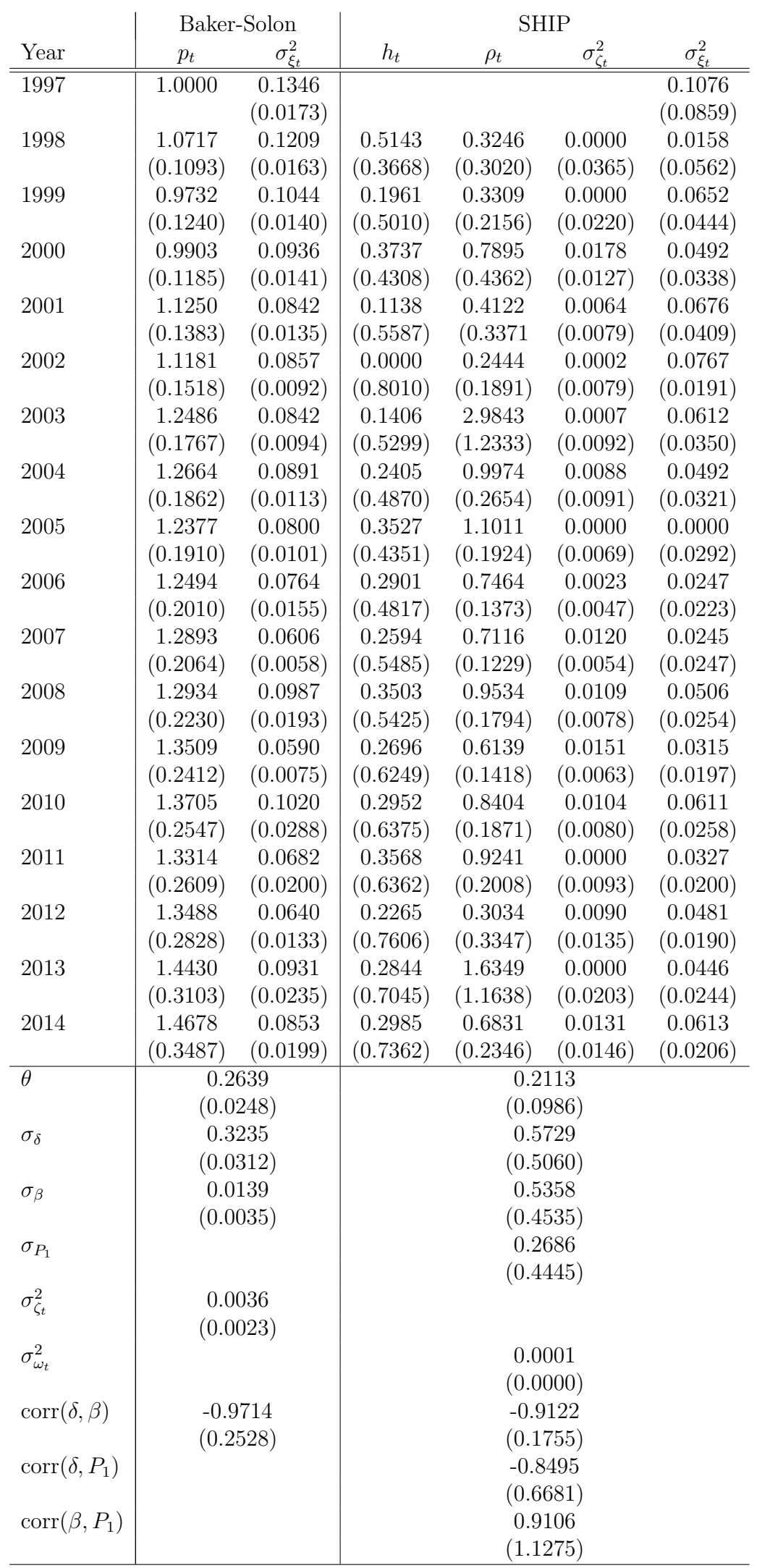

Note: Standard errors are in the parenthesis. 
Figure 2.6: Fitted income inequality

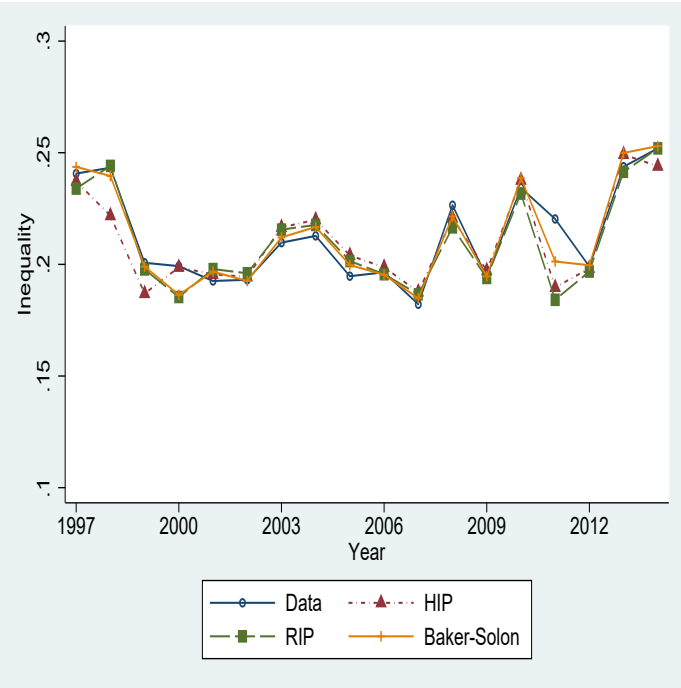

(a) Existing models

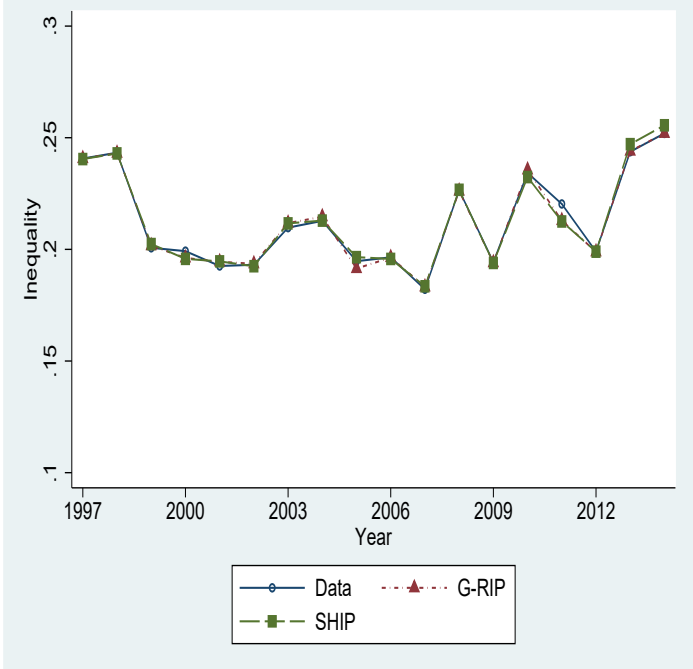

(b) New income models

RIP model. The variance of permanent shocks should drop to explain the decrease in inequality during a recovery. With deterministic component driven by time-constant experience profile in the HIP model, variance of experience premium is rising over time, making it hard to explain the decrease in inequality during a recovery.

In the G-RIP and SHIP models with heterogeneous effect of macro shocks, a recession (recovery) is not necessarily associated with increase (decrease) in variance of permanent shocks. For example, in the G-RIP model, if a macro effect parameter, $f_{t}>0$ in a recession, low income households who have $P_{i t-1}<0$ suffer more relative to high income households, leading to an increase in income inequality. In the SHIP model, if a macro effect parameter, $h_{t}$ is higher in a recession, a direct householdspecific impact of the macroeconomy is stronger, which can also lead to an increase in income inequality. The estimates of the SHIP model suggest that a direct householdspecific impact of macroeconomy dominates idiosyncratic permanent shock (i.e., variance of permanent shock is small) during the Asian Financial crisis of 1998. However, during the Global Financial Crisis of 2008, idiosyncratic permanent/transitory shocks dominate a direct household-specific impact of macroeconomy (i.e., variance of per- 
manent(transitory) shocks is relatively high). Based on the estimation results of the G-RIP model, both permanent and transitory shocks are relatively high during the Asian Financial Crisis of 1998 as well as the Global Financial Crisis of 2008, which means idiosyncratic shocks dominate the direct household-specific impact of macroeconomy. We will examine which component derives change in inequality in the section 2.4.5.

\subsubsection{Other moments of the covariance matrix}

We analyze off-diagonal elements as well as diagonal elements by using a long panel data of KLIPS. From Figure 2.7, all models can explain the divergence of variance of cumulative income growth (i.e., $\operatorname{var}\left(y_{t}-y_{1}\right)$ ). In the RIP model, inequality of cumulative income growth are proportional to cumulative variance of permanent shocks. In the HIP model, inequality of cumulative income growth are proportional to $t^{2}$. The G-RIP and SHIP models better fit than the existing models for inequality for cumulative income growth.

Figure 2.7: Fitted inequality for cumulative income growth

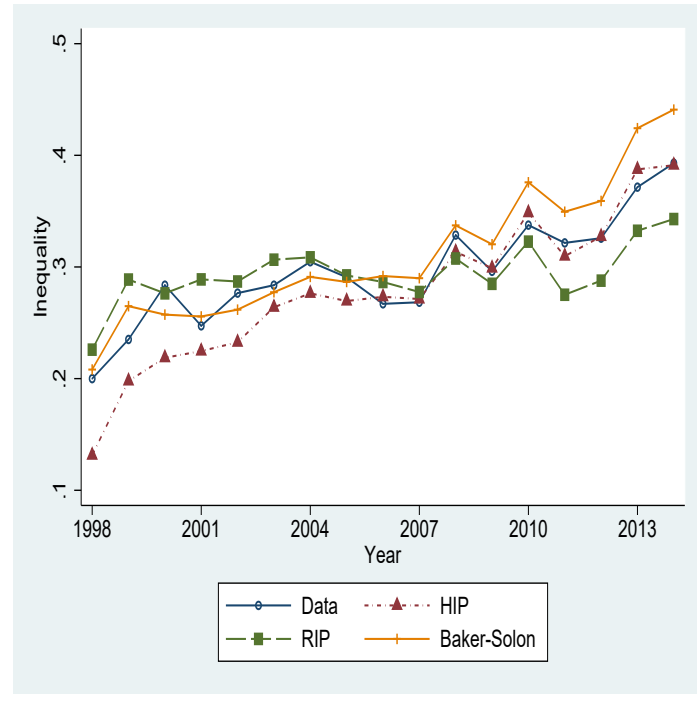

(a) Existing models

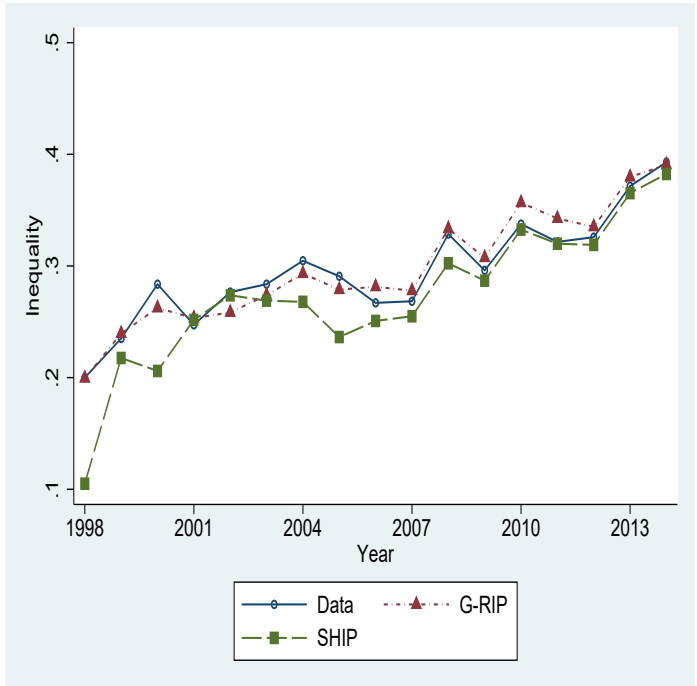

(b) New income models 
The G-RIP and SHIP models better fit than the existing models as well for $\operatorname{cov}\left(y_{t}-y_{3}, y_{1}\right)$ (See Figure 2.8). The RIP model predicts the correlation $\operatorname{cov}\left(y_{t}-y_{3}, y_{1}\right)$ is 0 . Under the assumption of the RIP model, as transitory component assumes an MA(1) process, income at time $t$ is not correlated with income ahead two years. Under the HIP model, although the correlation between household-specific experience premium and household-specific intercept can be negative, the linear relationship cannot explain the real covariance. The G-RIP and SHIP models fit the negative correlation better. The future earnings-initial income correlation differs by households, the better fit by the G-RIP and SHIP models suggests that the aggregate shocks may influence this relationship.

Figure 2.8: Fitted $\operatorname{cov}\left(y_{t}-y_{3}, y_{1}\right)$

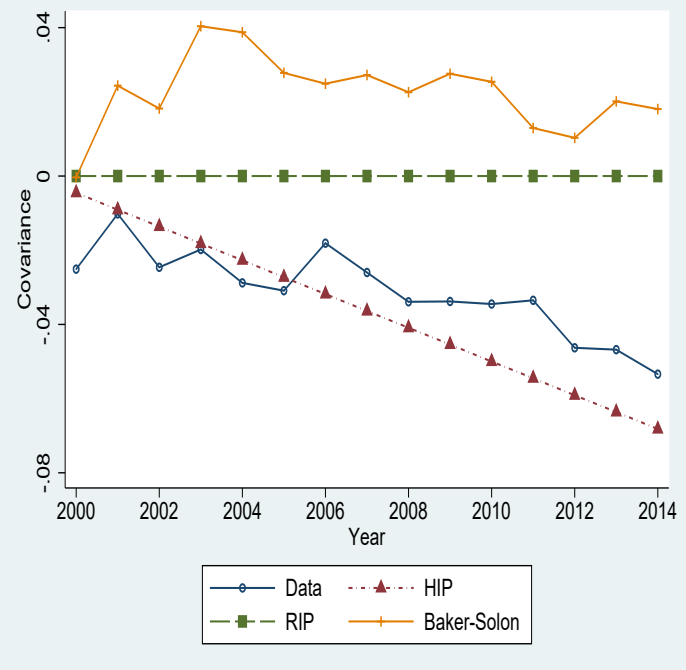

(a) Existing models

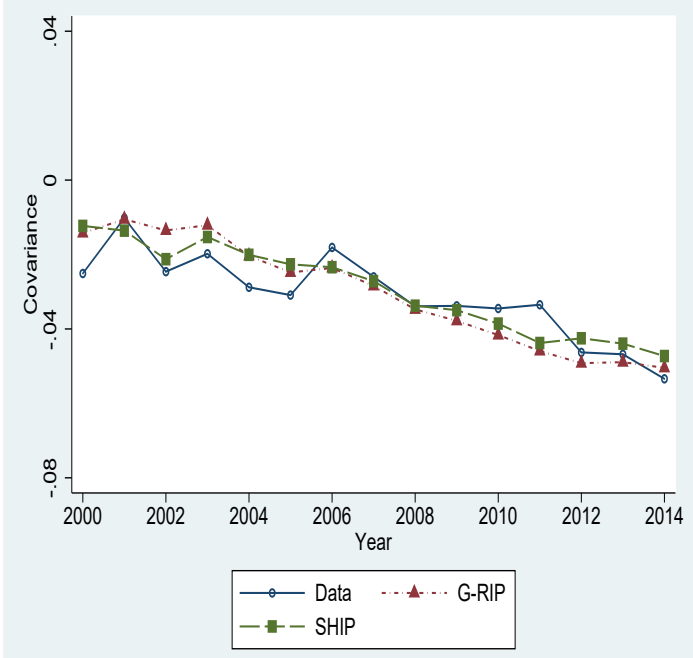

(b) New income models

\subsubsection{Mobility}

Mobility concerns how the relative standings of their own income change during the two consecutive years. Inequality and mobility may move in the same direction but it is possible that they move the in opposition direction. Under the assumption of 
the RIP model, inequality and mobility move in the same direction, increase during a recession and decrease during a recovery. Under the assumption of the HIP model, mobility depend on the variance of household-specific experience premium. If the variance of household-specific experience premium is big enough, inequality increase and mobility decrease over time and both do not depend on economic state. If the variance of household-specific experience premium is negligible, mobility depends on transitory shocks. Based on the estimates of the HIP model, the variance of household-specific experience premium is small (about .0006), which results in persistent mobility.

Figure 2.9: Fitted mobility

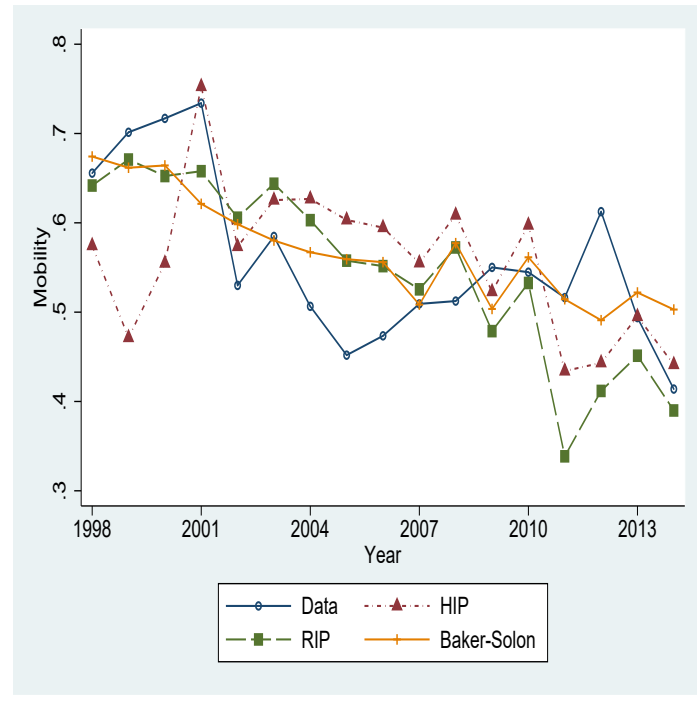

(a) Existing models

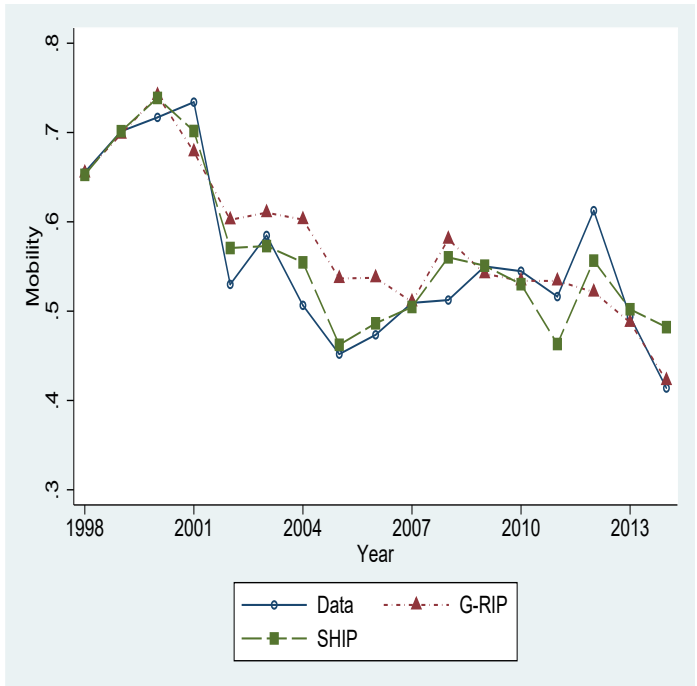

(b) New income models

We use $1-\hat{\rho}^{2}$ to measure mobility, where $\hat{\rho}$ is the correlation between $y_{t-1}$ and $y_{t}$. To better fit mobility, eventually, the income model should explain off-diagonal elements as well as diagonal elements of the covariance matrix, $\frac{1}{N} \mathbf{Y}^{\prime} \mathbf{Y}$ because the correlation $\operatorname{corr}\left(y_{t-1}, y_{t}\right)$ is determined by $\operatorname{var}\left(y_{t-1}\right), \operatorname{var}\left(y_{t}\right)$, and $\operatorname{cov}\left(y_{t-1}, y_{t}\right)$. Therefore, the G-RIP and SHIP models better fit than the existing models for mobility. 


\subsubsection{Model comparison}

Figures 2.6 to 2.9 show that the G-RIP and SHIP models better fit than the existing models of the RIP, HIP, and Baker/Solon models for $\operatorname{var}\left(y_{t}\right), \operatorname{var}\left(y_{t}-y_{1}\right)$, $\operatorname{cov}\left(y_{t}-y_{3}, y_{1}\right)$, and mobility. However, by including heterogeneous macro effects the G-RIP and SHIP models contain more parameters in than the RIP and HIP models, and are expected to fit better. A comparison of the generalized models with nested models should be based on criteria that account for both model fit and the number of parameters in the model.

Andrews and Lu (2001) suggest the moment selection criteria for GMM estimation. The selection criteria, MMSC-BIC, MMSC-AIC, and MMSC-HQIC developed by Andrews and $\mathrm{Lu}(2001)$ are based on $J$ statistics. $J$ statistics can be computed by the number of parameters and of moments reflects the trade-off between the "model fit" and the "number of parameters". We apply model selection criteria, MMSCBIC, MMSC-AIC, and MMSC-HQIC to the 5 competing income models and the model with minimum of each model criterion is deemed the best model. Table 2.6 shows that SHIP model is the best and G-RIP model is the second best model. This implies that income process model should consider both idiosyncratic shocks and household-specific factors of macroeconomy.

Table 2.6: Model comparison

\begin{tabular}{lcrrr}
\hline Model & Number of parameters & MMSC-BIC & MMSC-AIC & MMSC-HQIC \\
\hline RIP & 38 & 954.96 & 2056.23 & 1346.04 \\
HIP & 22 & 1101.13 & 2318.33 & 1533.38 \\
Baker/Solon & 40 & -110.15 & 976.63 & 275.78 \\
G-RIP & 54 & -599.66 & 385.69 & -249.74 \\
SHIP & 77 & -623.60 & 195.11 & -332.86 \\
\hline
\end{tabular}

Note: $\operatorname{MMSC}-\mathrm{BIC}(\mathrm{b}, \mathrm{c})=J_{n}(b, c)-(|c|-|b|) \ln n, \operatorname{MMSC}-\mathrm{AIC}(\mathrm{b}, \mathrm{c})=J_{n}(b, c)-2$ $(|c|-|b|)$, and MMSC-HQIC $(\mathrm{b}, \mathrm{c})=J_{n}(b, c)-Q(|c|-|b|) \ln (\ln n)$. Where, $J_{n}(b, c)$ is the $J$ statistics developed by Andrews and Lu (See pp. 10-11, 2001), $b$ is number of parameters, $c$ is number of moments, $n$ is the sample size, and $Q$ is a number greater than 2 . We select $Q=3$ to compute MMSC-HQIC(b,c). 


\subsubsection{Decomposing inequality in household earnings}

Understanding the sources of income inequality is useful for making of economic policy. There are two ways of decomposing cross-household inequality; one is by source of income variations that drive inequality (variance due to macro shocks, heterogeneity in lifecycle income profile, idiosyncratic permanent shocks and idiosyncratic transitory shocks), another is by within and between sub-sample groups (e.g., by highest education degree of household head.)

Fitting residuals (detrended) income to different models allows a decomposition of inequality by source of income variations in accord with estimated income models. In obtaining the residuals we control for head of household education, which removes effect of education from the mean of the whole sample as well as each subsample group.

We now decompose the log earnings (instead of the residuals) into within and between groups by education. The exercise quantifies how the trend of average in each group affect the overall income inequality. In particular, how does the "college premium" shape the trend of inequality for the cohort. Later in this section we decompose the change in income inequality by source of income variations as well as by education group.

We label households without (with) college degree as "low" and "high" education group. The variance of income can be written as the sum of high and low education groups:

$$
\operatorname{var}\left(\log Y_{t}\right)=\underbrace{s_{l} \operatorname{var}\left(\log Y_{t}^{l}\right)+s_{h} \operatorname{var}\left(\log Y_{t}^{h}\right)}_{\text {within }- \text { group inequality }}+\underbrace{s_{l}\left(\log Y_{t}^{l}-\log Y_{t}\right)^{2}+s_{h}\left(\log Y_{t}^{h}-\log Y_{t}\right)^{2}}_{\text {between }- \text { group inequality }}
$$

where $s_{l}\left(s_{h}\right)$ is the share of number of "low" ("high") education households, $\operatorname{var}\left(\log Y_{t}\right)$ is the variance of $\log Y$ for the sample in year t, $\operatorname{var}\left(\log Y_{t}^{l}\right)$ and $\operatorname{var}\left(\log Y_{t}^{h}\right)$ are variance of $\log Y$ of each group, and $\log Y_{t}^{l}$ and $\log Y_{t}^{h}$ are the mean of $\log \mathrm{Y}$ of each group, $\log Y_{t}$ is mean of $\log Y$ the sample in year t. 
Table 2.7 shows that the variance of log earnings for the sample tracks closely the within-group variance. The between-group variance is nearly constant over the lifecycle. This suggests that the "college premium" of log earnings is roughly constant over the lifecycle. This means that for the purpose of studying the trend of income inequality little is lost by removing the group mean by head education and focus on the inequality of residuals of each group.

Figure 2.10 plots the inequality of residuals of households in the "high" and "low" education groups. It shows that the inequality of the "high" education group differs from that of the "low" education group in level and trend. The inequality of the "high" education group is larger and trends upward. While the inequality among the "low" education households is flatter over time.

Table 2.7: The within- and between-group variance of log of earnings by education of household head

\begin{tabular}{c||ccc} 
Year & Variance & Within-group & Between-group \\
\hline \hline 1997 & 0.2964 & 0.2753 & 0.0210 \\
1998 & 0.3081 & 0.2820 & 0.0261 \\
1999 & 0.2665 & 0.2438 & 0.0227 \\
2000 & 0.2723 & 0.2490 & 0.0233 \\
2001 & 0.2600 & 0.2338 & 0.0262 \\
2002 & 0.2645 & 0.2387 & 0.0258 \\
2003 & 0.2806 & 0.2533 & 0.0273 \\
2004 & 0.2762 & 0.2553 & 0.0209 \\
2005 & 0.2759 & 0.2530 & 0.0229 \\
2006 & 0.2679 & 0.2472 & 0.0206 \\
2007 & 0.2573 & 0.2379 & 0.0194 \\
2008 & 0.3084 & 0.2882 & 0.0203 \\
2009 & 0.2618 & 0.2394 & 0.0224 \\
2010 & 0.3172 & 0.2939 & 0.0232 \\
2011 & 0.2939 & 0.2702 & 0.0237 \\
2012 & 0.2799 & 0.2532 & 0.0267 \\
2013 & 0.3262 & 0.3085 & 0.0177 \\
2014 & 0.3429 & 0.3222 & 0.0207 \\
2015 & 0.3858 & 0.3678 & 0.0180 \\
\hline
\end{tabular}

Note: The table is based on log earnings (instead of residuals of log earnings). 
Figure 2.10: Inequality of residuals of income by education

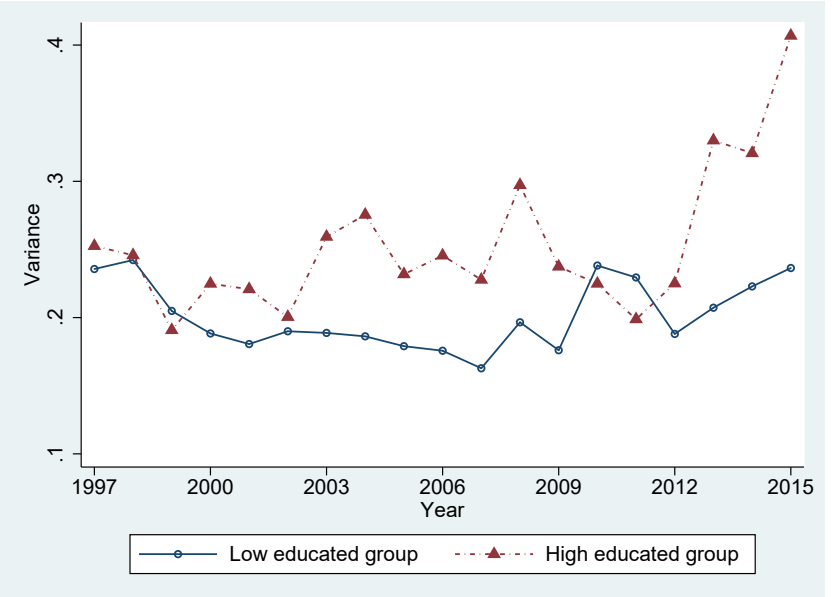

We now turn to finer decomposition of change in inequality. As noted in Section 2.3.1, unexplained earning inequality may be driven by macro effect, the effect of household's career trajectory (a deterministic career effect), permanent component, and transitory component. We decompose change in inequality into change in inequality driven by each component for the competing income models (See Table 2.8). The RIP and G-RIP models have permanent and transitory components. In the G-RIP model the heterogeneous macro effect is correlated with permanent shocks. The trend of inequality in the G-RIP model is driven by both permanent shocks and macro effects. The HIP model has deterministic career effect and transitory component. As the Baker/Solon and SHIP models nest the RIP model with the HIP model, both models have permanent component and deterministic career effect. However, permanent component and deterministic career effect are proportionally affected by macro effect in the Baker/Solon model. In the SHIP model, we group deterministic career effect with macro effect because household-specific intercept and experience premium in career trajectory are affected by aggregate factors. 


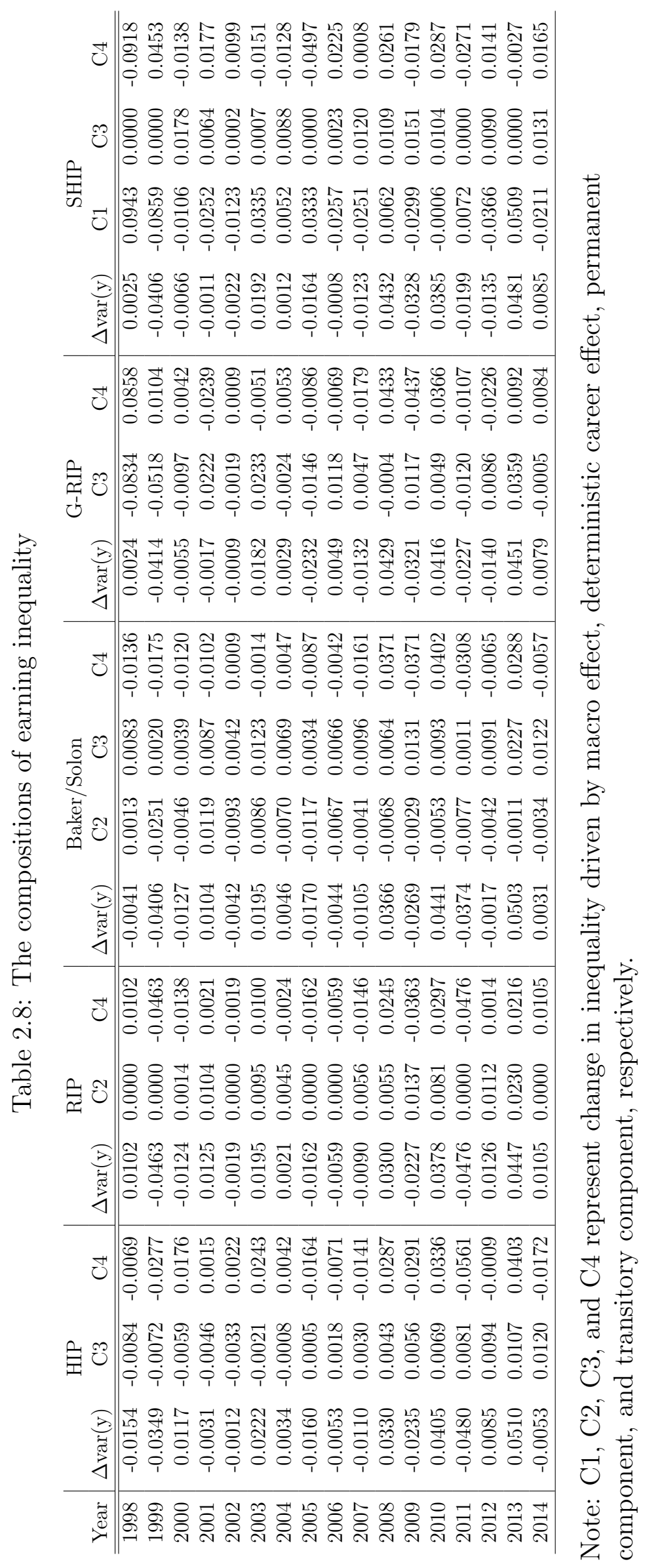


Under the conventional assumptions without heterogeneous macro effect, the variance driven by the deterministic career effect are increasing over time. So, the RIP model do not explain the high inequality during the East Asian Crisis of 1998, the beginning of the sample period. In the G-RIP model the high inequality during recessions such as the East Asian Crisis of 1998 and the Global Financial Crisis of 2008 is mainly driven by the transitory component. In the SHIP model the high inequality during the East Asian Crisis of 1998 is mainly driven by macro factors and an increase in inequality during the Global Financial Crisis of 2008 is driven by entire factors of macro effect, permanent component and transitory component. This implies that even with similar fit of data the explanation of income inequality differs by the income model.

Figure 2.10 shows earning inequality by education group. Interestingly, inequality of the group with low education increased but inequality of the high education group decreased during the East Asian Crisis of 1998. However, inequality of both groups increased and inequality of the high educated group increased more than the low educated group during the Global Financial Crisis of 2008. Also, inequality of both groups increased and inequality of the high education group increased more than the low education group at the end of the sample period.

Tables A.6 to A.10 in the Appendix A.3 present the composition of earning inequality by education level. The G-RIP and SHIP explain the trend in earnings inequality by education group neatly. Based on the G-RIP, an increase in inequality for the low educated group mainly comes from transitory shock during the East Asian Crisis of 1998 and an increase in inequality for the high educated group comes from both permanent and transitory shocks during the Global Financial Crisis of 2008. Based on the SHIP, macro effect leads to increases in inequality for the low educated group during the East Asian Crisis of 1998 and for the high educated group during the Global Financial Crisis of 2008. In 2013, the huge increase in inequality for the 
high education households is mainly driven by permanent component with the heterogeneous macro effect. The main reason why inequality of both groups increases at the end of the sample period is likely retirement by some head of households.

\subsection{Concluding Remarks}

This paper contributes to the literature of household income inequality by presenting new empirical observations and new models of income process that explain the empirical observations.

Using a long panel of Korean households of KLIPS we examine the trend of inequality and mobility of household earnings post the Asian Financial Crisis. We find income inequality is correlated with the macroeconomy and households with initial low income have higher future income. We also find persistently high income mobility.

We analyze the performance of commonly employed models of income process, the RIP and HIP, and a combination of the RIP and HIP model by Baker/Solon. We also introduce new generalizations of the RIP and HIP, the generalized RIP (G-RIP) and stochastic heterogeneous income profile (SHIP). Our G-RIP and SHIP models fit the KLIPS data better according to the model selection criteria of Andrews and $\mathrm{Lu}$ (2001). The G-RIP and SHIP models shed new light on the drivers of income equality. We find that a significant source of income inequality is heterogeneous responses by households to aggregate shocks. This means that a large recession not only reduces the average income but also widens inequality because some households do persistently worse over business cycles than the population in general. We also find that the sources of income inequality differ by the education level of the head of households. 


\section{Chapter 3}

\section{Household Inequality and Mobility over the Lifecyle: Evidence from Korean Household Panel Data on Income and Consumption}

\subsection{Introduction}

The trends in household inequality and consumption inequality have been examined in numerous recent studies (see e.g., Meghir and Pistaferri (2004); Blundell et al. (2008) (BPP); Blundell and Etheridge (2010); Jappelli and Pistaferri (2010); Moffitt and Gottschalk (2011)). Most of household data in the U.S. or other developed economies show rising income inequality. And a focus of the literature has been whether consumption inequality tracks the upward trends of income inequality (Krueger and Perri (2006)). With few exceptions, consumption data in this literature are cross-sectional or short panels, which renders it infeasible to test a well known implication of optimal consumption. Deaton and Paxson (1994) note that if household consumption is ap-

proximately a random walk then for a cohort of households the gain in cross-sectional 
variance, $\Delta \operatorname{var}\left(c_{i t}\right)$, is the variance of consumption growth $\operatorname{var}\left(\Delta c_{i t}\right)$, regardless of the nature of income and wealth shocks. Suppose one tracks a cohort of households over the lifecycle, the random walk of optimal consumption predicts rising consumption inequality over time.

Mathematically the proposition of rising consumption inequality follows from the fact that consumption smoothing implies optimal consumption only respond to unpredictable shocks. Hence growth in optimal consumption is uncorrelated with past consumption, and the variance of consumption is the cumulative sum of variance of innovations in optimal consumption.

Studies based on repeated cross-sectional or short panel data such as the Consumer Expenditure Survey (CEX) mostly conclude that consumption inequality increases over the lifecycle (e.g., Storesletten et al., 2004; Heathcote et al., 2005; Primiceri and Van Rens, 2009; Kaplan, 2012). PSID used by Deaton and Paxson (1994) offers a long panel of a fixed cohort. But its consumption is limited to food expenditure for annual data.

KLIPS, with its long panel of annual income and consumption of nondurable goods for a fixed cohort of 16 years, offers a good opportunity to study the trend in income and consumption inequality.

Figure 3.1 exhibits decoupling of income and consumption inequalities for a given cohort in KLIPS. The figure shows a drop in income inequality post the 1998 Asian financial crisis and a jump in income inequality in 2008 following the U.S. Great Recession. KLIPS covers a period of macro shocks and allows for analysis of interaction of lifecycle and business cycle.

The KLIPS data show a absence of upward trend in the consumption inequality over time for a long stretch of the lifecycle. The decrease consumption inequality after 2008 is inconsistent with the benchmark theory of random walk of consumption and stylized fact of consumption inequality over the lifecycle presented in the literature. 
Figure 3.1: Income and consumption inequality of a cohort of KLIPS households

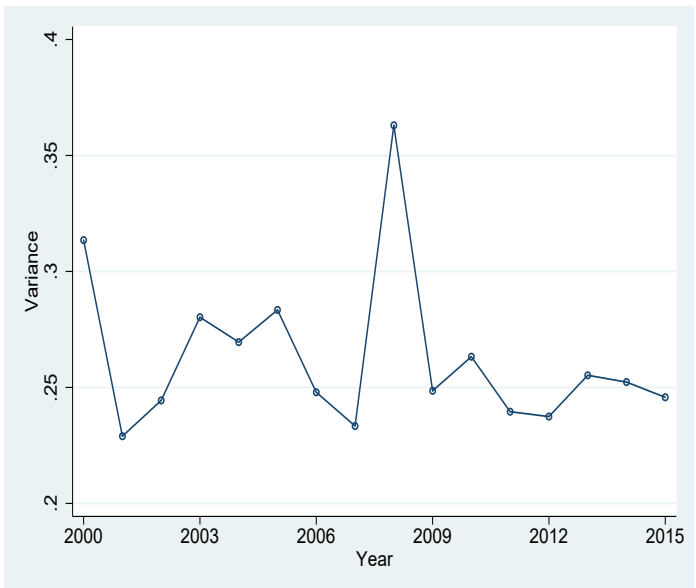

(a) Income

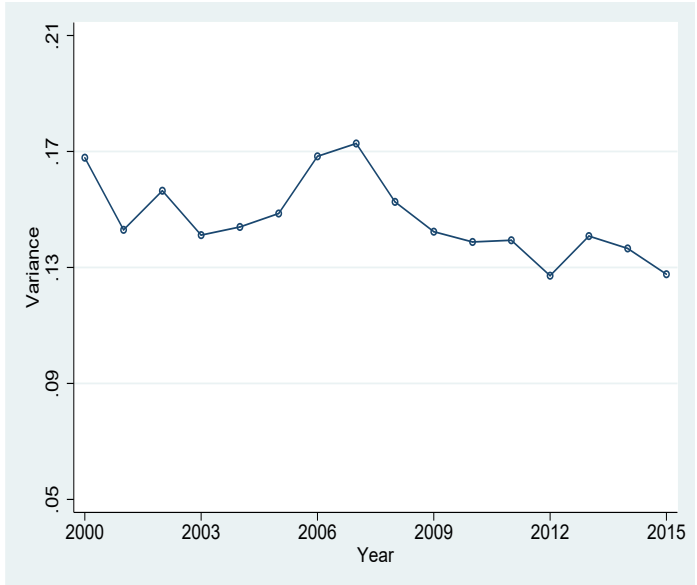

(b) Consumption

Further examination reveals that the decreasing consumption inequality is related to a negative correlation between consumption growth and past consumption.

Can the reported trend in consumption inequality in KLIPS be explained by income models? In the vast literature on household income and consumption two commonly used benchmark models for household income dynamics are RIP ("Restricted Income Profiles") and HIP (Heterogeneous Income Process) that may yield similar income profiles over the lifecycle but have distinctly different implications on household consumption decision. Conventionally income fluctuations are assumed to be driven by a permanent and a transitory component. For model identification the shocks to the permanent component and the innovations to the transitory component are assumed to be independent over time for each household and identically and independently distributed cross households in each period. We will show that these income models do not explain the observed decrease in consumption inequality.

A theory that can explain the decrease in consumption inequality is based on the assumption, the consumption risk is household-state-dependent, i.e., correlated with past consumption. Hence the risk premium (the conditional variance of consumption growth) has to be correlated with past consumption. If high consumption households 
have lower risk premium in consumption than poor households then consumption growth may be negatively correlated with past consumption. The idea here is that for each household optimal consumption in the past is uncorrelated with future shocks, but across households the conditional variance of future shocks can be correlated with the state of the households. Fundamentally, inequality stems from heterogeneity in the type of uncertainty known to households ex-ante and realized uncertainty expost. In a conventional setting, households are homogeneous and inequality is entirely driven by realized uncertainty. In contrast, we distinguish heterogeneity from realized uncertainty.

In this chapter we use consumption level and income level data from KLIPS to estimate income model through lifecycle income. We present the RIP and HIP models to illustrate the models' difference on household consumption decision.

In section 2 we offer more details of the KLIPS data and present the stylized facts of sample moments in Table 3.5. In Section 3 we introduce consumption model considering heterogeneous risk premium. In Section 4 we lay out the competing models. In Section 5 we discuss estimates and model fits.

\subsection{KLIPS Data and Stylized Facts}

\subsubsection{KLIPS data on income, consumption, and net wealth}

We use the sixteen waves from 2001 through 2016 to analyze inequality and mobility and only focus on married households with observations in all 16 years. We take several steps in sample selection. First, divorced, separated, and one-person households are dropped. Second, households with missing report on disposable income and on non-durable expenditures are dropped. Third, split offs of the original household are out of sample. Finally, households with a heads under 30 years old or over 65 years 
old are dropped. The final sample after filtering work consists of the balanced panel data with 677 households (10,832 observations). Hence the maximum age for the group is 65 and would still be included by the BPP sample selection criteria.

The three key variables for our research objectives are disposable income, nondurable expenditures, and net wealth. A household disposable income is a sum of labor earnings, transfer income, and other income during a year. Non-durable expenditure is a sum of expenditures on each non-durable consumption category in the month of the survey. KLIPS has total expenditure data since 1998 and expenditures on 11 consumption categories (i.e., food at home, food away from home, education, car maintenance, monthly rent and utilities related to house, health care, entertainment, family event, communication, furniture, and miscellaneous goods) since 2001. It includes data on apparel and shoes expenses since 2002 and gift contribution, public transportation, and pension since 2003. To be consistent in measuring non-durable expenditures during the sample periods, we defines non-durable expenditures as sum of expenditures on 8 non-durable items except health, education, and furniture (i.e., food at home, food away from home, car maintenance, monthly rent and utilities related to house, health care, entertainment, family event, communication, and miscellaneous goods). Household net wealth is measured by wealth minus debt at survey year $t$, and wealth is a sum of financial and real estate wealth. Based on the questionnaires in KLIPS, survey responses for income and consumption at year $t$ provide information at year $t-1$ because questions ask about earnings and expenditures of the previous year. However, survey responses for net wealth at year $t$ represent that at the year of survey. Every money value of income, non-durable expenditures, and net wealth is converted to real value deflated by consumer price index (CPI) thereafter $(2015=100)$ and monthly expenditures are converted to yearly expenditure multiplied by 12 .

Table 3.1 displays descriptive statistics of three key variables (i.e., average, 10 
percentile, median, and 90 percentile) over the sample periods for the balanced panel of 677 households. The disposable income exhibited an upward trend with the exception of the global financial crisis during 2008-2009, with the average disposable income decreased in 2008. Although the Korea economy recovered from the global financial crisis after the second half of 2009, the growth in average income was stagnant during 2009-2012. The average non-durable total expenditures was also stagnant during the sample periods and decreased during 2003-2005. In particular, the collapse of credit card bubble happened in 2003. ${ }^{1}$ Despite an increase in household's disposable income increased during 2003-2005, household's non-durable expenditures decreased corresponding to the periods. An average net wealth increased until 2009 and decreased in 2010, 2012, and 2014. Those reduction in the average net wealth seems to be caused by the decline in net wealth of the top $10 \%$ of households.

From 2000 to 2015 the average disposable income for the panel of households increased by $69 \%$, net wealth increased by $152 \%$, but nondurable consumption expenditure only increased by $10 \%$. In particular, the expenditure of the top 90 percentile households grew more slowly than that of the median households, and the expenditure of the median households grew more slowly than bottom 10 percentile households.

This is sharp contrast to the PSID data reported by Arellano et al. (2017) (ABB). ABB extract the balanced subsample of 792 households during 1999-2009 (See Table 3.2). Average earnings, consumption, net wealth increased by $18 \%, 32 \%$, and $80 \%$ during the period, respectively, which means that consumption increased faster than earnings, a pattern in sharp contrast to KLIPS data.

KLIPS implies that the mobility of income and consumption are high and persistent. Thus the negative correlation between future and current consumption coincides

\footnotetext{
${ }^{1}$ South Korea's government used the relaxation of regulation about credit card issuers after the Asian financial crisis in 1998 to boost household consumption expenditures. As a result, people without earnings obtained credit card easily, which resulted in increases in delinquent borrowers. The number of delinquent borrowers related to the credit cards increased by $550 \%$ from 444,000 persons in 2000 to $2,390,000$ persons in 2002 .
} 
Table 3.1: Descriptive statistics of disposable income, non-durable expenditures, and net wealth

\begin{tabular}{r||rrrr|rrrr|rrrrr}
\multicolumn{1}{l||}{} & \multicolumn{3}{c}{ Disposable Income } & \multicolumn{3}{c}{ Non-durable Expenditures } & \multicolumn{3}{c}{ Net Wealth } \\
Year & Mean & $10 \%$ & $50 \%$ & $90 \%$ & Mean & $10 \%$ & $50 \%$ & $90 \%$ & Mean & $10 \%$ & $50 \%$ & $90 \%$ \\
\hline 2000 & 3,802 & 1,532 & 3,245 & 6,309 & 1,887 & 973 & 1,676 & 3,010 & 11,018 & 1,502 & 7,713 & 22,532 \\
2001 & 4,316 & 1,905 & 3,753 & 7,145 & 1,925 & 1,057 & 1,732 & 2,997 & 11,802 & 722 & 7,939 & 24,538 \\
2002 & 4,445 & 1,995 & 3,811 & 7,445 & 2,010 & 1,096 & 1,770 & 3,152 & 13,234 & 983 & 8,779 & 28,093 \\
2003 & 4,813 & 1,954 & 4,071 & 8,142 & 2,008 & 1,091 & 1,726 & 3,224 & 15,071 & 1,038 & 10,318 & 32,838 \\
2004 & 4,983 & 1,991 & 4,244 & 8,153 & 1,952 & 1,069 & 1,713 & 3,034 & 16,632 & 655 & 10,741 & 39,297 \\
2005 & 5,419 & 2,261 & 4,564 & 9,331 & 1,956 & 1,040 & 1,683 & 3,151 & 17,534 & 510 & 11,473 & 42,068 \\
2006 & 5,529 & 2,381 & 4,563 & 9,414 & 2,108 & 1,032 & 1,825 & 3,352 & 20,044 & 873 & 11,222 & 47,380 \\
2007 & 5,942 & 2,614 & 4,961 & 10,032 & 2,191 & 1,065 & 1,853 & 3,444 & 22,001 & 888 & 12,403 & 54,964 \\
2008 & 5,782 & 2,323 & 4,798 & 9,947 & 2,308 & 1,199 & 1,938 & 3,722 & 24,916 & 1,743 & 15,009 & 59,364 \\
2009 & 5,955 & 2,453 & 4,816 & 9,497 & 2,196 & 1,180 & 1,899 & 3,378 & 24,663 & 2,261 & 14,697 & 57,093 \\
2010 & 5,935 & 2,570 & 5,136 & 9,885 & 2,168 & 1,173 & 1,898 & 3,268 & 24,262 & 2,306 & 15,376 & 57,111 \\
2011 & 5,871 & 2,587 & 5,237 & 9,755 & 2,210 & 1,191 & 1,900 & 3,535 & 24,666 & 2,112 & 16,365 & 53,845 \\
2012 & 5,997 & 2,480 & 5,435 & 10,166 & 2,159 & 1,178 & 1,885 & 3,422 & 25,643 & 2,066 & 17,564 & 53,725 \\
2013 & 6,218 & 2,545 & 5,263 & 10,709 & 2,167 & 1,163 & 1,909 & 3,329 & 25,433 & 2,040 & 17,338 & 53,545 \\
2014 & 6,220 & 2,538 & 5,505 & 10,574 & 2,156 & 1,148 & 1,934 & 3,323 & 25,592 & 3,021 & 17,120 & 56,497 \\
2015 & 6,438 & 2,617 & 5,600 & 11,040 & 2,083 & 1,116 & 1,872 & 3,204 & 27,581 & 3,000 & 19,500 & 60,500 \\
\hline
\end{tabular}

Note: Unit is ten thousand Korean Won in 2015, all households. Non-durable consumption is the sum of 8 expenditures: food at home, food away from home, car maintenance, monthly rent and utilities related to house (including equivalent rental payment of owner occupied housing), entertainment, family event, communication, and miscellaneous goods.

with income and consumption mobility: high (low) initial income and consumption households tend to face more negative (positive) shocks over the lifetime. Such reversal of fortune is unexpected hence not reflected in the initial consumption.

\subsubsection{Stylized facts on inequality and mobility for Korean income and consumption}

The income process for each household $i$ is (for $t=t_{i}, \cdots, T, i=1, . ., N$ )

$$
Y_{i t}=\mathbf{Z}_{\mathbf{i t}}^{\prime} \gamma_{y}+y_{i t}
$$

where real $(\log )$ income, $Y$, can be decomposed predictable and stochastic components. For the former, $\mathbf{Z}^{\prime}$ is a $1 \times m$ row vector of characteristics observable and 
Table 3.2: Descriptive statistics of $\mathrm{ABB}(2017)$

\begin{tabular}{lrrrrrr}
\hline \hline & 1999 & 2001 & \multicolumn{5}{c}{2003} & 2005 & 2007 & \multicolumn{1}{c}{2009} \\
\hline \multicolumn{7}{c}{ Earnings } \\
Mean & 87,120 & 93,777 & 96,289 & 98,475 & 103,442 & 102,893 \\
$10 \%$ & 34,863 & 37,532 & 36,278 & 35,005 & 35,533 & 31,992 \\
$25 \%$ & 50,709 & 53,000 & 52,975 & 54,696 & 53,813 & 52,451 \\
$50 \%$ & 73,423 & 77,000 & 76,576 & 78,944 & 80,292 & 79,181 \\
$75 \%$ & 102,211 & 106,000 & 105,292 & 109,391 & 113,604 & 112,607 \\
$90 \%$ & 145,789 & 152,000 & 150,280 & 154,971 & 171,688 & 163,879 \\
\multicolumn{5}{c}{ Consumption } \\
Mean & 30,761 & 34,784 & 37,553 & 43,199 & 44,511 & 40,598 \\
$10 \%$ & 15,804 & 17,477 & 18,026 & 20,365 & 21,634 & 20,008 \\
$25 \%$ & 20,263 & 21,786 & 22,834 & 26,322 & 28,341 & 26,167 \\
$50 \%$ & 26,864 & 29,366 & 31,924 & 37,381 & 38,704 & 34,570 \\
$75 \%$ & 36,887 & 41,030 & 45,071 & 51,529 & 53,239 & 47,300 \\
$90 \%$ & 48,977 & 53,870 & 62,864 & 73,338 & 73,715 & 67,012 \\
\multicolumn{5}{c}{ Net worth } \\
Mean & 224,127 & 283,539 & 311,664 & 387,830 & 447,323 & 406,290 \\
$10 \%$ & 19,016 & 26,100 & 28,494 & 38,287 & 41,854 & 33,592 \\
$25 \%$ & 48,095 & 59,600 & 69,397 & 83,137 & 101,005 & 85,179 \\
$50 \%$ & 114,096 & 137,500 & 159,230 & 191,663 & 217,599 & 188,354 \\
$75 \%$ & 248,000 & 301,750 & 345,549 & 413,955 & 489,224 & 384,625 \\
$90 \%$ & 535,827 & 586,000 & 654,437 & 830,462 & 939,583 & 867,786 \\
\hline
\end{tabular}

known by households at time $t$, the same as those used in the previous chapter. $\gamma_{y}$ is an $m$-dimensional unknown parameter vector. Boldface letters represent vectors or matrices. Defining $y_{i t}=Y_{i t}-\mathbf{Z}_{\mathbf{i t}}^{\prime} \gamma_{y}$ as the log of real income net of predictable individual components. Because of the presence of year dummy in (3.1), $y_{i t}$ has mean zero in each year $t$. Included in $\mathbf{Z}$ are year dummy and year-education dummy. So for each education group the residual $y_{i t}$ has zero mean across households.

We remove the predictable component of household consumption in the following model using the same set of control variables as in (3.1).

$$
\log C_{i t}=\mathbf{Z}_{\mathbf{i t}}^{\prime} \gamma_{c}+c_{i t}
$$

and focus on inequality in $c_{i t}$, the unexplained consumption in period $t$. 
We introduce the stylized facts of unexplained income and consumption and then discuss the problems with the RIP and HIP models, especially in terms of unexplained consumption (at the previous chapter, we already discussed the limitations of the RIP and HIP models on unexplained income).

Table 3.3 shows the residuals' statistics for the balanced panel of 677 households after removing the deterministic components.

Table 3.3: Residual statistics for income and consumption

\begin{tabular}{c||ccc|ccc}
\multicolumn{1}{l||}{} & \multicolumn{3}{c|}{ Income } & \multicolumn{3}{c}{ Consumption } \\
Year & Variance & Skewness & Kurtosis & Variance & Skewness & Kurtosis \\
\hline 2000 & 0.313 & -1.162 & 9.238 & 0.168 & -0.394 & 6.278 \\
2001 & 0.229 & -0.426 & 4.775 & 0.143 & 0.110 & 4.026 \\
2002 & 0.244 & -0.648 & 5.728 & 0.156 & 0.125 & 4.955 \\
2003 & 0.280 & -0.768 & 6.865 & 0.141 & 0.311 & 3.969 \\
2004 & 0.269 & -0.118 & 6.030 & 0.144 & 0.170 & 4.108 \\
2005 & 0.283 & -0.098 & 5.831 & 0.149 & 0.092 & 3.942 \\
2006 & 0.248 & -0.352 & 5.382 & 0.168 & 0.013 & 4.499 \\
2007 & 0.233 & 0.371 & 5.366 & 0.173 & -0.034 & 4.944 \\
2008 & 0.362 & -1.163 & 9.371 & 0.153 & 0.455 & 4.262 \\
2009 & 0.248 & 0.139 & 6.135 & 0.142 & 0.630 & 5.279 \\
2010 & 0.263 & -0.349 & 6.705 & 0.139 & 0.188 & 4.698 \\
2011 & 0.239 & -0.679 & 7.206 & 0.139 & 0.413 & 4.061 \\
2012 & 0.237 & -0.330 & 5.057 & 0.127 & 0.407 & 3.989 \\
2013 & 0.255 & -0.024 & 4.780 & 0.141 & 0.421 & 4.607 \\
2014 & 0.252 & -0.205 & 4.395 & 0.137 & 0.329 & 3.944 \\
2015 & 0.245 & -0.042 & 4.444 & 0.128 & 0.253 & 3.841 \\
\hline
\end{tabular}

The unexplained income and consumption have the following patterns:

(1) The inequality in unexplained income shows little trend (See Figure 3.1(a)).

(2) There is a slight downward trend in consumption inequality from 2008 onward (See Figure 3.1(b)).

(3) Cross household variance (inequality) and skewness are correlated with the macroeconomy. The Korean economy experienced two recessions (slow downs) during 2000-2015 as well as drop in average long term growth. For the two recessions GDP growth dropped from $7.4 \%$ in 2002 to $2.9 \%$ in 2003 (with a $0.3 \%$ increase in un- 
employment rate); and from 5.5\% in 2007 to $2.8 \%$ in 2008 and $0.7 \%$ in 2009 (with little change in unemployment rate.) The long term GDP growth also dropped from over 5\% during 2000-2010 to around 3\% after 2010. During the recessions income inequality increased, consumption inequality decreased. Income tends negatively skewed and consumption positively skewed.

(4) Inequality in income growth sharply increased during the Global financial crisis and inequality in consumption growth steadily decreased over time (See Figure 3.2).

Figure 3.2: Income and consumption growth inequality of a cohort of KLIPS households

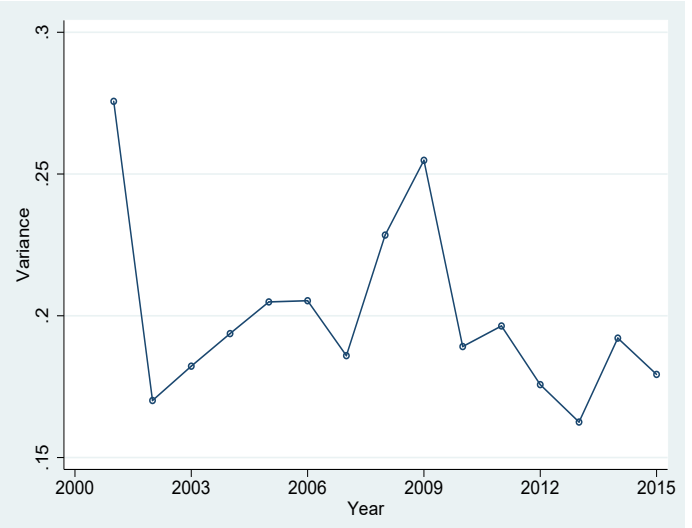

(a) Income

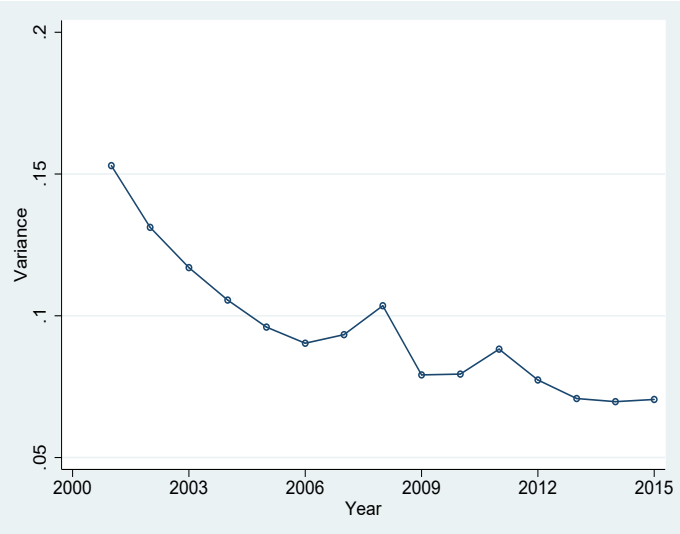

(b) Consumption

(5) Figure 3.3(a) shows that the inequality in cumulative growth rates expands over the lifecycle. Inequality in older cohort is higher than in younger cohort for both income and nondurable consumption expenditure for the 2000 cohort (Figure 3.4) and income and total consumption expenditure for a 1997 cohort (Figure 3.5). These observations suggest the presence of permanent income shocks.

(6) The cumulative income and consumption gains in the future is negatively correlated with initial value: $\operatorname{corr}\left(y_{t}-y_{3}, y_{1}\right)<0$ and $\operatorname{corr}\left(c_{t}-c_{3}, c_{1}\right)<0$. (See Table 3.4). 
Figure 3.3: Income and consumption inequality in cumulative growth rate

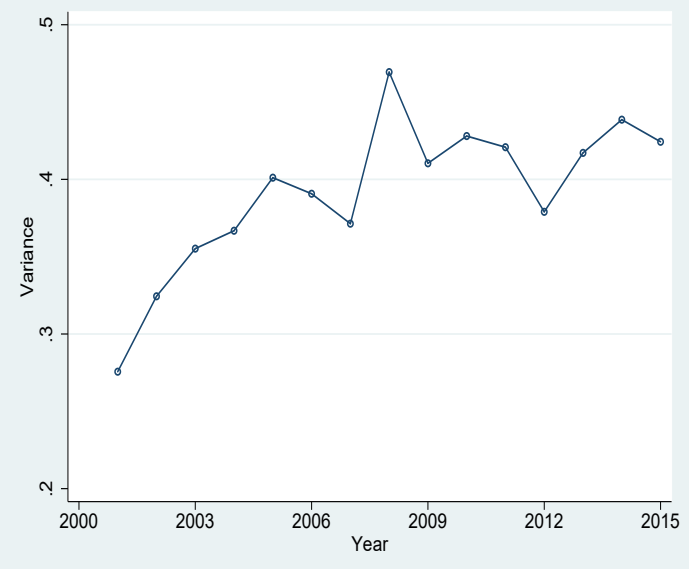

(a) Income

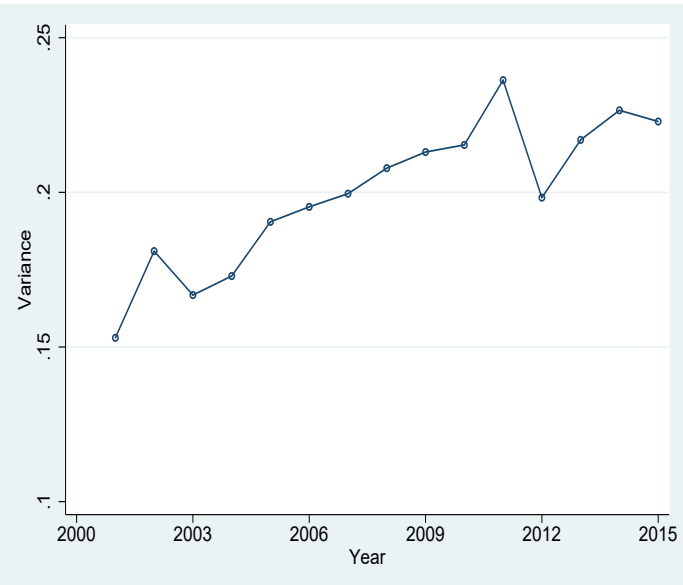

(b) Consumption

Figure 3.4: Income and consumption inequality by cohort for the balanced panel during 2000-2015

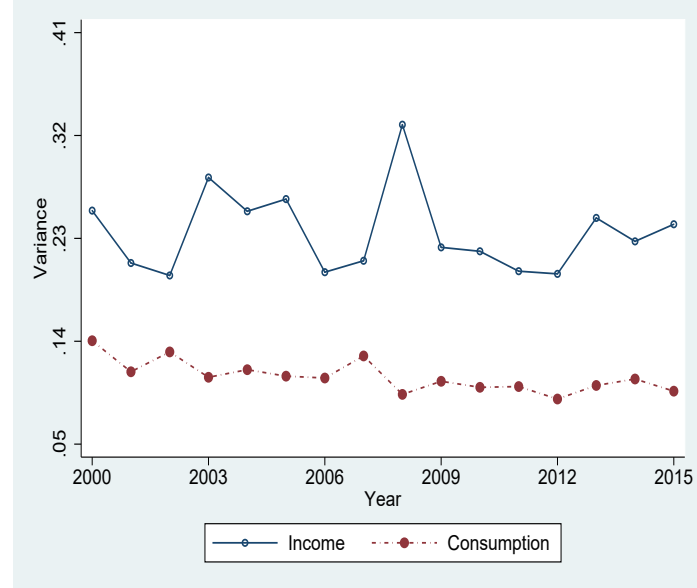

(a) age $30-40$ in 2000

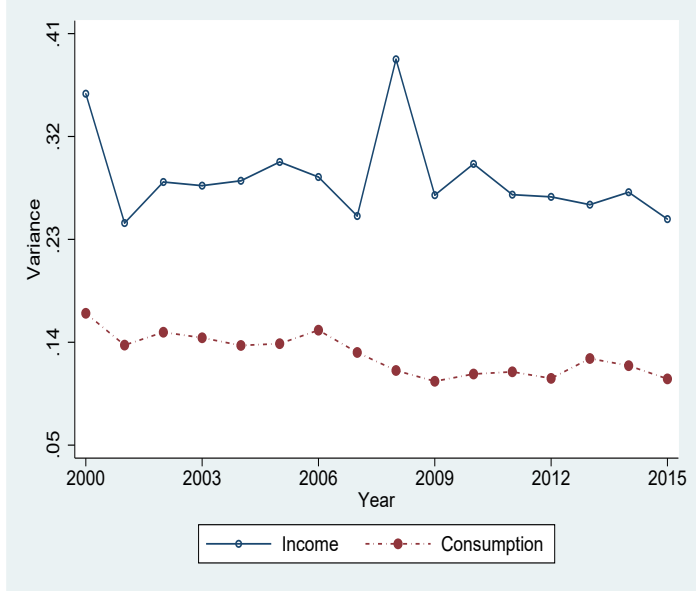

(b) age $41-50$ in 2000

Note: Consumption is expenditures on non-durable goods. 
Figure 3.5: Income and consumption inequality by cohort for the balanced panel during 1997-2015

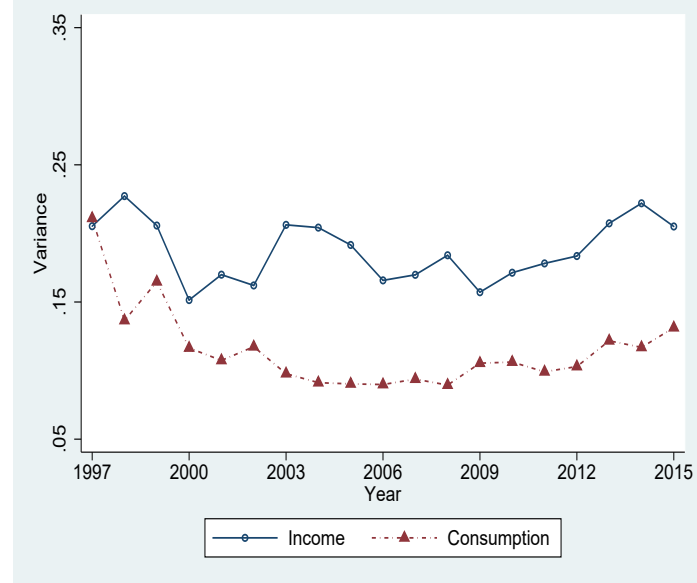

(a) age 25-37 in 1997

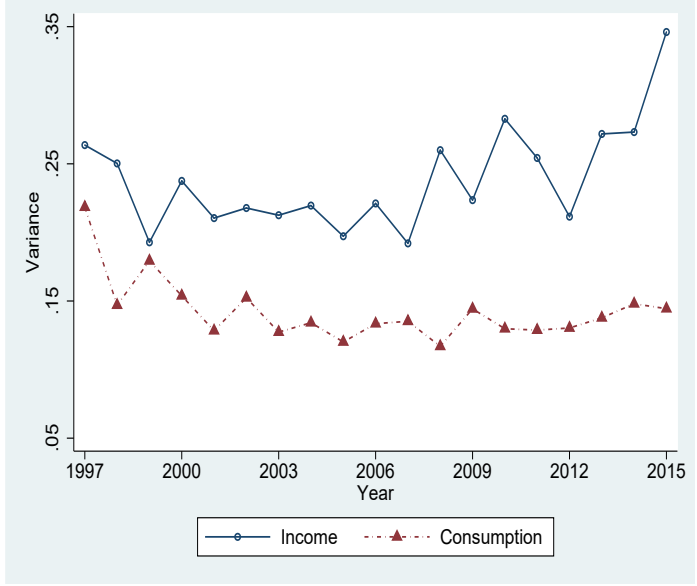

(b) age 38-47 in 1997

Note: Consumption is total expenditures.

Table 3.4: $\operatorname{cov}\left(y_{i t}-y_{i 3}, y_{i 1}\right)$ and $\operatorname{cov}\left(c_{i t}-c_{i 3}, c_{i 1}\right), \mathrm{t}=1$ is 2000

\begin{tabular}{c||c|c}
$\mathrm{t}$ & $\operatorname{cov}\left(y_{i t}-y_{i 3}, y_{i 1}\right)$ & $\operatorname{cov}\left(c_{i t}-c_{i 3}, c_{i 1}\right)$ \\
\hline \hline 2003 & 0.003 & -0.001 \\
2004 & -0.009 & -0.002 \\
2005 & -0.019 & -0.009 \\
2006 & -0.031 & -0.001 \\
2007 & -0.029 & -0.001 \\
2008 & -0.013 & -0.015 \\
2009 & -0.041 & -0.023 \\
2010 & -0.042 & -0.026 \\
2011 & -0.051 & -0.036 \\
2012 & -0.031 & -0.023 \\
2013 & -0.041 & -0.026 \\
2014 & -0.053 & -0.033 \\
2015 & -0.049 & -0.035 \\
\hline
\end{tabular}

(7) Income mobility is persistent after 2001 and consumption mobility exhibits a longer downward trend (See Figure 3.6). 
Figure 3.6: Income and consumption mobility

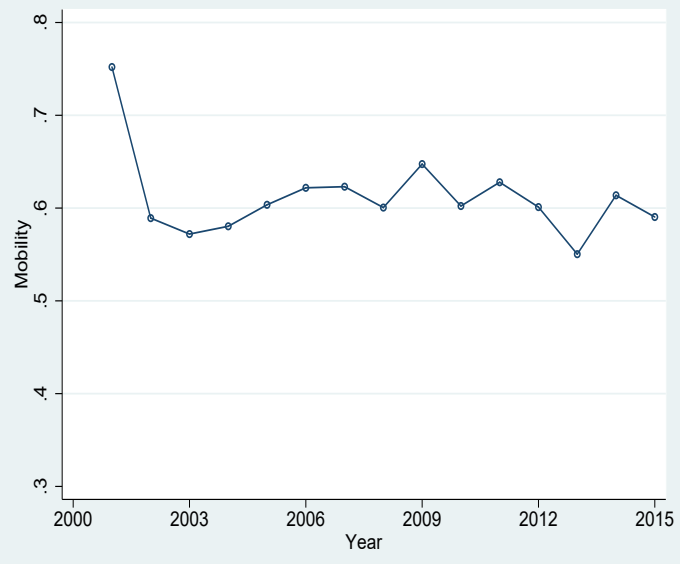

(a) Income

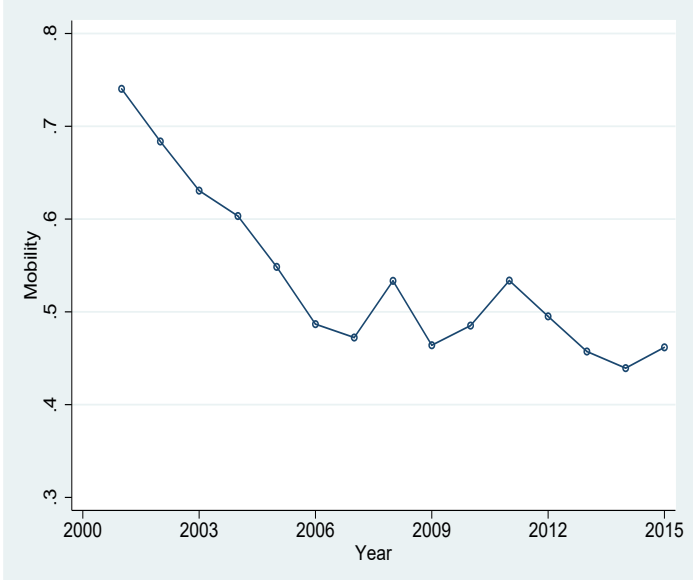

(b) Consumption

\subsubsection{Factoring in measurement errors in consumption ex- penditure}

The observed trend of consumption inequality is inconsistent with the random walk model, a benchmark theory of optimal consumption. We now discuss in more details the likely empirical and theoretical implications of the observation.

From the identity

$$
\operatorname{var}\left(c_{i t}\right)=\operatorname{var}\left(c_{i t}-c_{i 1}\right)-\operatorname{var}\left(c_{i 1}\right)+2 \operatorname{cov}\left(c_{i t}, c_{i 1}\right),
$$

the combination of the declining consumption inequality $\operatorname{var}\left(c_{i t}\right)$ and increasing $\operatorname{var}\left(c_{i t}\right.$ $\left.-c_{i 1}\right)$ over the lifecycle implies $\operatorname{cov}\left(c_{i t}, c_{i 1}\right)$ is decreasing, which means future consumption is negatively correlated with the initial consumption. If consumption follows a random walk with iid shocks $\operatorname{cov}\left(c_{i t}, c_{i 1}\right)$ should be positive and diminishing instead of being negative and expanding. Another presentation of the correlation that is based on the identity

$$
-\operatorname{var}\left(c_{i t}-c_{i 1}\right)+\operatorname{var}\left(c_{i t}\right)-\operatorname{var}\left(c_{i 1}\right)=2 \operatorname{cov}\left[\left(c_{i t}-c_{i 1}\right), c_{i 1}\right]
$$


$\operatorname{cov}\left[\left(c_{i t}-c_{i 1}\right), c_{i 1}\right]$ is negative and decreasing over time.

One contributing factor to this negative correlation is measurement error in consumption. If the true consumption is $c^{*}$ and the measured one is c with measurement error $m$ then $c_{t}=c_{t}^{*}+m_{t}, \operatorname{cov}\left(m_{t}, c_{t}^{*}\right)=0$. Hence $\operatorname{var}\left(c_{t}\right)=\operatorname{var}\left(c_{t}^{*}\right)+\operatorname{var}\left(m_{t}\right)$. If the true consumption is random walk then $c_{t}^{*}=c_{t-1}^{*}+e_{t}, \operatorname{cov}\left(e_{t}, c_{t-1}^{*}\right)=0$.

An estimate of the measurement error is

$$
\operatorname{cov}\left(\Delta c_{t}, \Delta c_{t-1}\right)=\operatorname{cov}\left(\Delta c_{t}^{*}+\Delta m_{t}, \Delta c_{t-1}^{*}+\Delta m_{t-1}\right)=-\operatorname{var}\left(m_{t-1}\right)
$$

or

$$
\operatorname{cov}\left(\Delta c_{t}, c_{t-1}\right)=\operatorname{cov}\left(\Delta c_{t}^{*}+\Delta m_{t}, c_{t-1}^{*}+m_{t-1}\right)=-\operatorname{var}\left(m_{t-1}\right)
$$

We find these covariances are negative and shrinking in magnitude. This may explain part of the shrinking variance in $\operatorname{var}\left(c_{t}\right)$.

And $c_{t}^{*}-c_{1}^{*}=\sum_{j=2}^{t} e_{j}$, so $\operatorname{cov}\left(c_{t}^{*}-c_{1}^{*}, c_{1}^{*}\right)=0 . \operatorname{cov}\left(c_{t}-c_{1}, c_{1}\right)=\operatorname{cov}\left(c_{t}^{*}+m_{t}-\right.$ $\left.c_{1}^{*}-m_{1}, c_{1}^{*}+m_{1}\right)=\operatorname{cov}\left(c_{t}^{*}-c_{1}^{*}, c_{1}^{*}\right)+\operatorname{cov}\left(m_{t}-m_{1}, m_{1}\right)=-\operatorname{var}\left(m_{1}\right)$.

To remove the effect of classical measurement error we plot $\operatorname{corr}\left(c_{t}-c_{2}, c_{1}\right)$ (see Figure 3.7). Note in theory $\operatorname{cov}\left(c_{t}-c_{2}, c_{1}\right)=\operatorname{cov}\left(c_{t}^{*}+m_{t}-c_{2}^{*}-m_{2}, c_{1}^{*}+m_{1}\right)=0$. But the data show a decreasing correlation over time.

Figure 3.7: $\operatorname{corr}\left(c_{t}-c_{2}, c_{1}\right)$

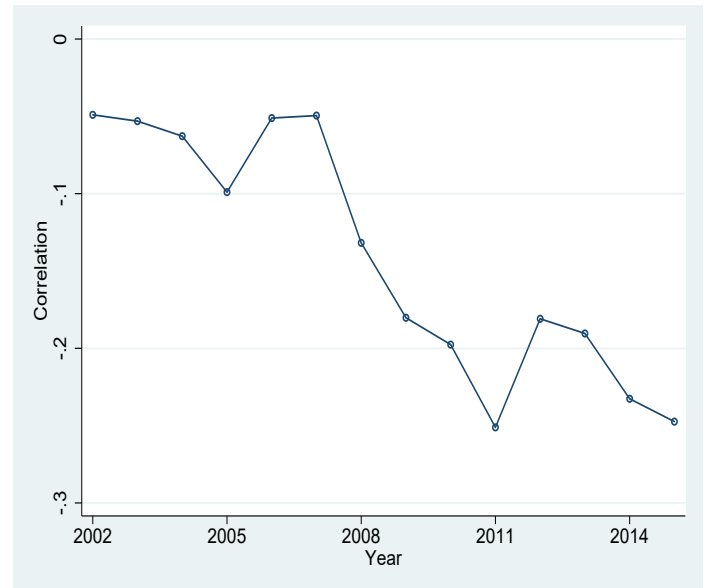


There are two possibilities: (i) measurement errors are not classical, e.g., $\operatorname{cov}\left(m_{t}, m_{1}\right)$ $<0$ and decreases over time. It is hard to see why this can be true. Or $\operatorname{corr}\left(c_{t}^{*}, m_{t}\right)$ is none zero. This is considered in the next chapter. (ii) $\operatorname{cov}\left(c_{t}^{*}-c_{1}^{*}, c_{1}^{*}\right)<0$, because of unexpected shocks are such that rich households get more negative shocks. This may be related to the $\operatorname{cov}\left(y_{t}-y_{3}, y_{1}\right)<0$. But under HIP $\operatorname{cov}\left(c_{t}^{*}-c_{1}^{*}, c_{1}^{*}\right)=0$ even with $\operatorname{cov}\left(y_{t}-y_{3}, y_{1}\right)<0$.

The reversion in consumption is inconsistent with the conventional theory. One possible explanation is that future permanent shocks are negatively correlated with the initial income.

In estimation because the measurement error in consumption may be very large we need to incorporate it. Although it is not sufficient in addressing the decreasing variance in consumption, it is necessary. We can replace $\operatorname{var}\left(c_{i t}\right)$ in the model without measurement errors by $\operatorname{var}\left(c_{i t}^{*}\right)=\operatorname{var}\left(c_{i t}\right)-\operatorname{var}\left(m_{i t}\right)$. Adjusting for classical measurement errors in the earlier formula, the equation (3.3),

$\operatorname{var}\left(c_{i t}^{*}\right)+\operatorname{var}\left(m_{i t}\right)=\operatorname{var}\left(c_{i t}^{*}-c_{i 1}^{*}\right)+\operatorname{var}\left(m_{i t}\right)+\operatorname{var}\left(m_{i 1}\right)-\operatorname{var}\left(c_{i 1}^{*}\right)-\operatorname{var}\left(m_{i 1}\right)+2 \operatorname{cov}\left(c_{i t}^{*}, c_{i 1}^{*}\right)$

we have the same formula as without the measurement errors:

$$
\operatorname{var}\left(c_{i t}^{*}\right)=\operatorname{var}\left(c_{i t}^{*}-c_{i 1}^{*}\right)-\operatorname{var}\left(c_{i 1}^{*}\right)+2 \operatorname{cov}\left(c_{i t}^{*}, c_{i 1}^{*}\right)
$$

is exactly the same as the one with measurement errors in (3.3). The declining trend in $\operatorname{var}\left(c_{i t}^{*}\right)$ and increasing trend in $\operatorname{var}\left(c_{i t}^{*}-c_{i 1}^{*}\right)$ imply decreasing $\operatorname{cov}\left(c_{i t}^{*}, c_{i 1}^{*}\right)$ (and decreasing and negative $\operatorname{cov}\left(c_{i t}^{*}-c_{i 1}^{*}, c_{i 1}^{*}\right)$ ), which is against conventional theory of consumption that predicts future consumption shocks be independent of current consumption.

The above formula links consumption inequality to moments of cumulative consumption growth. An alternative expression of the consumption inequality in terms 
of annual moments for $t>1$ :

$$
\operatorname{var}\left(c_{i t}^{*}\right)=\operatorname{var}\left(c_{i 1}^{*}\right)+\sum_{k=2}^{t}\left[\operatorname{var}\left(\Delta c_{i k}^{*}\right)+2 \operatorname{cov}\left(\Delta c_{i k}^{*}, c_{i k-1}^{*}\right)\right]
$$

To derive this, note in the presence of measurement errors iteration of the identity

$$
\operatorname{var}\left(c_{i t}\right)=\operatorname{var}\left(c_{i t-1}\right)+\operatorname{var}\left(\Delta c_{i t}\right)+2 \operatorname{cov}\left(c_{i t-1}, \Delta c_{i t}\right)
$$

yields

$$
\operatorname{var}\left(c_{i t}\right)=\operatorname{var}\left(c_{i 0}\right)+\sum_{k=1}^{t}\left[\operatorname{var}\left(\Delta c_{i k}\right)+2 \operatorname{cov}\left(\Delta c_{i k}, c_{i k-1}\right)\right] .
$$

Plugging in classical measurement errors $m_{t}$ to $(3.5)$ we have

$$
\begin{aligned}
& \operatorname{var}\left(c_{i t}^{*}\right)+\operatorname{var}\left(m_{i t}\right) \\
& =\operatorname{var}\left(c_{i t-1}^{*}\right)+\operatorname{var}\left(m_{i t-1}\right)+\operatorname{var}\left(\Delta c_{i t}^{*}\right)+\operatorname{var}\left(m_{i t}\right)+\operatorname{var}\left(m_{i t-1}\right) \\
& +2 \operatorname{cov}\left(c_{i t-1}^{*}, \Delta c_{i t}^{*}\right)-2 \operatorname{var}\left(m_{i t-1}\right) .
\end{aligned}
$$

The measurement error terms cancel and we have

$$
\begin{aligned}
& \operatorname{var}\left(c_{i t}^{*}\right)=\operatorname{var}\left(c_{i t-1}^{*}\right)+\operatorname{var}\left(\Delta c_{i t}^{*}\right)+2 \operatorname{cov}\left(c_{i t-1}^{*}, \Delta c_{i t}^{*}\right)=\operatorname{var}\left(c_{i t-2}^{*}\right)+ \\
& \operatorname{var}\left(\Delta c_{i t-1}^{*}\right)+2 \operatorname{cov}\left(c_{i t-2}^{*}, \Delta c_{i t-1}^{*}\right)+\operatorname{var}\left(\Delta c_{i t}^{*}\right)+2 \operatorname{cov}\left(c_{i t-1}^{*}, \Delta c_{i t}^{*}\right) \\
& \ldots \\
& =\operatorname{var}\left(c_{i 1}^{*}\right)+\sum_{k=2}^{t}\left[\operatorname{var}\left(\Delta c_{i k}^{*}\right)+2 \operatorname{cov}\left(\Delta c_{i k}^{*}, c_{i k-1}^{*}\right)\right] .
\end{aligned}
$$

For a third expression of the dynamics of consumption inequality, taking the difference in consumption inequality in (3.3) yields for all $t>1$

$$
\operatorname{var}\left(c_{i t}\right)-\operatorname{var}\left(c_{i t-1}\right)=\left[\operatorname{var}\left(c_{i t}-c_{1 i}\right)-\operatorname{var}\left(c_{i t-1}-c_{i 1}\right)\right]+2 \operatorname{cov}\left(\Delta c_{i t}, c_{i 1}\right) .
$$


(i.e., the first difference in consumption inequality $=$ first difference in inequality of cumulative consumption growth +2 times of the covariance of consumption growth with the initial consumption). Similar to the discussion above, (3.9) holds after removing classical measurement errors.

Identity (3.9) highlights the contradiction between the observed pattern of consumption inequality and the optimal consumption theory. Since the first difference in inequality of cumulative consumption growth is positive, declining consumption inequality (a negative first difference on the left hand side) implies a negative covariance between consumption growth and the initial consumption. But because an optimal consumption growth should only depend on new information after the initial period, it should be uncorrelated with the initial consumption.

\subsection{Empirical Observations and Models of Income and Consumption}

Observations summarize earlier pose challenges to conventional income and consumption models.

\subsubsection{Income Models of RIP and HIP}

Let $y_{i t}$ be unexplained earnings of household $i$ in period $t$,

$$
\mathbf{R I P}: y_{i t}=P_{i t}+v_{i t},
$$

where permanent component $P_{i t}=P_{i t-1}+\zeta_{i t}$ is random walk and independent of the transitory shocks $v_{i t}, v_{i t}=\xi_{i t}+\theta_{1} \xi_{i t-1}, \xi_{i t}$ is transitory income shock, The shocks $\zeta_{i t}$ and $\xi_{i t}$ are iid cross households and independent over time (see e.g.,Meghir and Pistaferri (2004); BPP (2008); Blundell and Etheridge (2010); Jappelli and Pistaferri 
(2010); Moffitt and Gottschalk (2011)).

HIP stipulates for household with experience $t_{i}$ in the initial period of the sample,

$$
\operatorname{HIP}: y_{i t}=\alpha_{i}+\left(t+t_{i}\right) \beta_{i}+v_{i t}
$$

where the slope $\beta_{i}$ is the experience premium. For the transitory component Guvenen (2009) assumes an $\operatorname{AR}(1): v_{i t}=\rho v_{i t-1}+\xi_{i t}$.

These models have quite different implications on household risk and lifetime mobility. Expanding income inequality due to heterogeneity should not affect consumption, but risk in permanent component affects consumption. Unlike inequality, mobility is negatively related to heterogeneity but positively related to transitory risk. So, the HIP model implies diminishing mobility, the RIP model also implies diminishing mobility if the variance of permanent risk is high.

We approximate unexplained consumption in period $t$ by

$$
c_{i t}=c_{i 1}+\sum_{j=2}^{t}\left[\phi_{j} \times(\text { permanent shock in } j)+\psi_{j} \times(\text { transitory shock in } j)+\omega_{i j}\right] \text {, }
$$

$\phi_{j}$ is near unity, $\psi_{j}$ is near 0 and $\omega_{i j}$ is iid. The cumulative consumption change from 1 to $\mathrm{t}, \Delta_{1, t} c_{i}=c_{i t}-c_{i 1}$ is the sum of response to cumulative shocks.

In the RIP model, the permanent shock in $j, \zeta_{i j}$, represents the main risk for the household and the driver of consumption growth. Expansion of consumption inequality indicates magnitude of the permanent shocks.

In the HIP model, income diverges over time as each household follows a linear trend with different slopes. But because the trends are deterministic, the heterogeneity in income trend does not add new information to alter consumption and consumption mobility. Hence, HIP separates household risk, inequality, and mobility. Tracking the lifecycle of a cohort of households with income generated by the HIP model yields transitory income risk, expanding income inequality and diminishing 
income mobility.

RIP and HIP are analogous to the random walk and trend-stationary models in time series. Research on time series models shows that tests on random walk vs trend stationary models have low power with moderate size samples. Similarly, one expect low power in testing RIP vs HIP using income data alone with a sample size smaller than 20. Because RIP and HIP has different implications on consumption, using consumption data jointly with income data likely improves the power of tests. Bring in consumption is important because if heterogeneity is the driver of income inequality consumption should not respond to current income shocks. Instead, given current income, future income should predict current consumption.

Using a long panel data set we explore the empirical relationships between inequality and mobility in Korean household income and consumption. A brief summary of implications of the RIP and HIP models;

(i) income and consumption inequality: $\operatorname{var}\left(y_{i t}\right)$ and $\operatorname{var}\left(c_{i t}\right)$

(ii) income and consumption growth inequality: $\operatorname{var}\left(\Delta y_{i t}\right)$ and $\operatorname{var}\left(\Delta c_{i t}\right)$

(iii) income and consumption inequality in cumulative gains from the initial level: $\operatorname{var}\left(y_{i t}-y_{i 1}\right)$ and $\operatorname{var}\left(c_{i t}-c_{i 1}\right)$

(iv) correlations of cumulative gains with the initial level: $\operatorname{corr}\left(y_{i t}-y_{i 3}, y_{i 1}\right)$ and $\operatorname{corr}\left(c_{i t}-c_{i 3}, c_{i 1}\right)$

(v) income and consumption mobility: $1-\hat{\rho}_{t}^{2}$ estimated from the regression $z_{i t}=$ $\rho_{t} z_{i t-1}+\mu_{i t}$ where $z_{i t}=\frac{q_{i t}}{\sqrt{\operatorname{var}\left(q_{i t}\right)}}(q=y$ and $c)$.

The summary shows that neither RIP nor HIP explains important patterns in income and consumption data. 
Table 3.5: A summary of likely patterns of cross-household moments over lifecycle for a given Cohort

\begin{tabular}{|l|c|c|c|}
\hline & RIP & HIP & KLIPS Data \\
\hline $\operatorname{var}\left(y_{i t}\right)$ & increasing in $\mathrm{t}$ & increasing in $t^{2}$ & no trend, increase in 2008 \\
\hline $\operatorname{var}\left(\Delta y_{i t}\right)$ & depends on $\sigma_{\zeta}, \sigma_{\xi}$ & depends on $\sigma_{\Delta \xi}$ & sharply increase in 2008 and 2009 \\
\hline $\operatorname{var}\left(y_{i t}-y_{i 1}\right)$ & roughly $\propto t$ & roughly $\propto t^{2}$ & roughly $\propto t$ \\
\hline $\operatorname{var}\left(c_{i t}\right)$ & increasing in $\mathrm{t}$ & increasing or flat in $\mathrm{t}$ & not increasing in $\mathrm{t}$ \\
\hline $\operatorname{var}\left(\Delta c_{i t}\right)$ & depends on $\sigma_{\zeta}, \sigma_{\xi}$ & depends on $\sigma_{\Delta \xi}$ & decreasing in $\mathrm{t}$ \\
\hline $\operatorname{var}\left(c_{i t}-c_{i 1}\right)$ & roughly $\propto t$ & increasing in $\mathrm{t} /$ no trend & roughly $\propto t$ \\
\hline $\operatorname{corr}\left(y_{i t}-y_{i 3}, y_{i 1}\right)$ & 0 & depends on $\operatorname{corr}\left(\alpha_{i}, \beta_{i}\right)$ & negative and decreasing in $\mathrm{t}$ \\
\hline $\operatorname{corr}\left(c_{i t}-c_{i 3}, c_{i 1}\right)$ & 0 & 0 & negative \\
\hline income mobility & decreasing in $\mathrm{t}$ & decreasing in $\mathrm{t}$ & persistent \\
\hline consumption mobility & decreasing in $\mathrm{t}$ & undetermined & decreasing \\
\hline
\end{tabular}

\subsection{Consumption Models}

\subsubsection{Empirical models of consumption growth}

We assume the level of consumption has classical measurement error $m_{i t}$ with variance $\sigma_{m}^{2}$. Hence observed consumption growth is

$$
\Delta c_{i t}=\Delta c_{i t}^{*}+\Delta m_{i t}
$$

The commonly employed form of $c_{i t}^{*}$ is random walk, with consumption growth $\Delta c_{i t}^{*}=$ response to permanent shock $)+($ response to transitory shock $)+$ errors.

In Table 3.4 we find negative correlations between $y_{t}-y_{3}$ and $y_{1}$, as well as $c_{t}-c_{3}$ and $c_{1}$. The correlation between $y_{t}-y_{3}$ and $y_{1}$ is inconsistent with the RIP model with iid income shocks. In estimating the income model (2.3) in the G-RIP model of Chapter 2 we introduced a macro factor $f_{t}$ is an unknown parameter that has heterogeneous impact on permanent component of household earnings, and the effect depends on the lag of the permanent component.

In Table 3.4 the correlation between $c_{t}-c_{3}$ and $c_{1}$ is inconsistent with random walk model of consumption. We now present a theory that implies that cross-households consumption growth is negatively correlated with the lag of consumption. 


\subsubsection{A theory of optimal consumption with heterogeneous conditional mean in consumption growth}

As noted earlier, empirical models of consumption growth as a linear function of iid income shocks cannot explain the trend in consumption inequality. Now we propose an alternative model based on a theory of optimal consumption with heterogeneous risk premium.

Consider the first order condition of optimal consumption level with CRRA utility and preference shifter $z_{t}$ :

$$
\beta R_{t-1} e^{z_{t-1}} \mathbb{E}_{t-1}\left(\frac{C_{i t}}{C_{i t-1}}\right)^{-\gamma}=1
$$

In Appendix B.1 we show that log linear approximation of the first order condition with heterogeneous conditional variance of consumption growth leads to a consumption growth model with heterogeneous conditional mean, which we refer as HCM consumption model.

$$
\Delta c_{i t}=u_{t-1} x_{i t-1}+\epsilon_{i t}
$$

where $x_{i t-1}$ is household-specific variable that captures heterogeneity in expected consumption growth conditional on information available in year $t-1$, and $u_{t-1}$ captures a time-varying macro effect known in $t-1$ on the conditional consumption growth. The consumption shock $\epsilon_{i t}$ is a sum of income shocks, wealth shocks, and shocks in risk premium with $\mathbb{E}_{t-1} \epsilon_{i t}=0$.

If $x_{i t-1}=c_{i t-1}$, then $\operatorname{cov}\left(\Delta c_{i t}, c_{i t-1}\right)=u_{t-1} \operatorname{var}\left(c_{i t-1}\right)$. The observed pattern suggests $u_{t-1}<0$. Under the assumption of homogeneous consumption shocks, the equation (3.13) is $\Delta c_{i t}=\epsilon_{i t}$ as in BPP (2008) and many other studies. One reason for $u_{t-1}$ being nonzero is that households differ in expected variance in consumption growth given information available in $t-1$. For instance if high income households ex-

pect to have smaller adjustment in consumption growth for some reason, say because 
of their income or wealth risk differs from that of low income households, then their optimal consumption has a lower conditional mean. In this case the corresponding $u_{t-1}$ is negative. Introduction in heterogeneity in conditional mean of consumption growth allows for cross-household correlation between consumption growth and past consumption.

\subsection{Estimation of Income and Consumption Model}

For a given structure of joint income and consumption model, one can devise different approaches to estimation. A common approach to estimating household income and consumption models is based on a selected set of moments of growth rate.

\subsubsection{Estimating a model income and consumption growth}

The seminal study by BPP (2008) estimates how consumption growth responds to income shocks in a RIP income growth model. Before presenting our method of estimation we first consider the BPP (2008) setting.

$\mathrm{BPP}(2008)$ identify the income process through autocovariances of income growth in the RIP model with MA(1) transitory income shocks

$$
\Delta y_{i t}=\zeta_{i t}+\Delta v_{i t}=\zeta_{i t}+\xi_{i t}+(\theta-1) \xi_{i t-1}+\xi_{i t-2}
$$

BPP (2008) assume consumption growth is

$$
\Delta c_{i t}=\phi_{t} \zeta_{i t}+\psi_{t} \xi_{i t}+\omega_{i t}
$$

where the insurance parameter $\phi_{t}$ is the response to permanent income shocks and $\psi_{t}$ the response to transitory income shocks, all innovations in consumption growth 
not attributable to income shocks are included in $\omega_{i t}$.

Under the assumption on iid income shocks the variance of income shocks $\operatorname{var}\left(\zeta_{t}\right)$ and $\operatorname{var}\left(\xi_{t}\right)$ can be identified from variance and covariances of income growth. The partial insurance parameter $\phi_{t}$ can be identified from the covariances of income and consumption growth:

$$
\frac{E\left[\Delta c_{i t}\left(\Delta y_{t-2}+\Delta y_{t-1}+\Delta y_{t}+\Delta y_{t+1}+\Delta y_{t+2}\right)\right]}{E\left[\Delta y_{i t}\left(\Delta y_{t-2}+\Delta y_{t-1}+\Delta y_{t}+\Delta y_{t+1}+\Delta y_{t+2}\right)\right]}=\phi_{t} .
$$

Similarly, the partial insurance to transitory shocks is

$$
\frac{E\left(\Delta c_{i t}\left(\Delta y_{i t+2}+\Delta y_{i t+1}\right)\right)}{E\left(\Delta y_{i t}\left(\Delta y_{i t+2}+\Delta y_{i t+1}\right)\right)}=\psi_{t}
$$

The details of derivation are provided in Appendix B.

BPP (2008) estimate the model based on a subset of moments of growth rates. While the approach intuitively connect some moments of income and consumption growth with model parameters and produces estimates that fit inequality of income and consumption growth rates, we find that this approach results in very poor fit for some elements of the covariance of income and/or consumption that are not considered for estimation. These elements ignored in the estimation may play crucial roles in some measures of interests, such as income and consumption mobility.

In contrast to this approach of focusing on a subset of covariance matrix, we estimate the whole covariance matrix of the income and consumption. As noted in the previous chapter, our approach is useful for analyzing dynamics of household variables besides inequality. 


\subsection{Estimating Income and Consumption Models Based on Covariance Matrices}

Denote the vector of unexplained income (consumption) for household $i$ as $\mathbf{y}_{\mathbf{i}}=$ $\left(y_{i 1}, . ., y_{i T}\right)^{\prime}$ and $\mathbf{c}_{\mathbf{i}}=\left(c_{i 1}, . ., c_{i T}\right)^{\prime}$. By design the cross-household averages of $\mathbf{y}_{\mathbf{i}}$ and $\mathbf{c}_{\mathbf{i}}$ are zero. The $T \times T$ sample covariance matrices of $\mathbf{y}_{\mathbf{i}}$ and $\mathbf{c}_{\mathbf{i}}$ are

$$
\operatorname{Var}(\mathbf{y})=\sum_{i=1}^{N} \frac{1}{N} \mathbf{y}_{\mathbf{i}} \mathbf{y}_{\mathbf{i}}^{\prime}
$$

and

$$
\begin{gathered}
\operatorname{Var}(\mathbf{c})=\sum_{i=1}^{N} \frac{1}{N} \mathbf{c}_{\mathbf{i}} \mathbf{c}_{\mathbf{i}}^{\prime} \\
\operatorname{Cov}(\mathbf{y}, \mathbf{c})=\sum_{i=1}^{N} \frac{1}{N} \mathbf{y}_{\mathbf{i}} \mathbf{c}_{\mathbf{i}}^{\prime}
\end{gathered}
$$

In matrix form we denote variables

$$
\mathbf{Y}=\left(\mathbf{y}_{\mathbf{1}} \cdots \mathbf{y}_{\mathbf{N}}\right)_{T \times N}, \mathbf{C}=\left(\mathbf{c}_{\mathbf{1}} \cdots \mathbf{c}_{\mathbf{N}}\right)_{T \times N} .
$$

Then $\operatorname{var}(\mathbf{y})=\frac{1}{N} \mathbf{Y} \mathbf{Y}^{\prime}, \operatorname{var}(\mathbf{c})=\frac{1}{N} \mathbf{C C}^{\prime}$, and $\operatorname{cov}(\mathbf{y}, \mathbf{c})=\frac{1}{N} \mathbf{Y} \mathbf{C}^{\prime}$.

Let $\mathbf{W}_{2 T \times N}=\left(\mathbf{Y}^{\prime}, \mathbf{C}^{\prime}\right)^{\prime}$. The income and consumption data can be summarized as the $2 T \times 2 T$ covariance matrix $\frac{1}{N} \mathbf{W W}^{\prime}$.

To estimate model parameters we match moments of income and consumption to the observed second moments $\operatorname{Var}(\mathbf{y}), \operatorname{Var}(\mathbf{c}), \operatorname{cov}(\mathbf{y}, \mathbf{c})$.

With observed consumption $c_{i t}=c_{i t}^{*}+m_{i t}$, where the true $c_{i t}^{*}$ is independent of the measurement error $m_{i t}$. The variance of $m_{i t}$ is $\sigma_{m}^{2} . \Delta c_{i t}=\Delta c_{i t}^{*}+\Delta m_{i t}$.

The initial unobserved consumption $c_{i 1}$ and the initial permanent income component $P_{i 1}$ are treated random effects. The variance of $\operatorname{var}\left(c_{i 1}\right)$ and $\operatorname{var}\left(P_{i 1}\right)$ and covariance of $\operatorname{cov}\left(c_{i 1}, P_{i 1}\right)$ are parameters to be estimated along with parameters of income process and consumption insurance parameters. 


\subsubsection{Three Models of Income and Consumption}

We consider three models that feature combinations of models of income and consumption. The details in identification and moment-based estimation are provided in the Appendix B2.

In HIP-Consumption Model, income is assumed to follow a heterogeneous income process (HIP)

$$
y_{i t}=\gamma_{i}+\beta_{i} t+v_{i t}, v_{i t}=\rho v_{i t-1}+\xi_{i t} .
$$

The unobserved true consumption growth is determined by the response to income shock $\xi_{i t}$ and iid innovation $\omega_{i t}$ not attributable to the income shock:

$$
\Delta c_{i t}^{*}=\psi_{t} \xi_{i t}+\omega_{i t}
$$

In RIP-Consumption model, income has a RIP income model with a random walk permanent component,

$$
y_{i t}=P_{i t}+v_{i t},
$$

with permanent component $P_{i t}=P_{i t-1}+\zeta_{i t}$, and MA(1) transitory component $v_{i t}$. The unobserved true consumption growth is given by

$$
\Delta c_{i t}^{*}=\phi_{t} \zeta_{i t}+\psi_{t} \xi_{i t}+\omega_{i t}
$$

\section{GRIP-HCM Consumption Model}

The third model model we consider is generalized-RIP with the consumption model with heterogeneous conditional mean in (3.13). The income model is GRIP:

$$
y_{i t}=P_{i t}+v_{i t},
$$


with permanent component $P_{i t}=P_{i t-1}\left(1+f_{t}\right)+\zeta_{i t}$, where $\zeta$ is permanent income shock with variance $\sigma_{t, \zeta}^{2}$, and the transitory component is $v_{i t}=\xi_{i, t}+\theta \xi_{i, t-1}$.

The growth of unobserved true consumption is determined by heterogeneous conditional mean (that are proportional to the lag consumption) as well as income shocks:

$$
\Delta c_{i t}^{*}=u_{t-1} c_{t-1}+\phi_{t} \zeta_{i t}+\psi_{t} \xi_{i, t}+\omega_{i t}
$$

The GRIP-HCM Consumption model seeks to remedy the the misfit of RIP income model and the consumption growth model with zero conditional mean.

\subsection{Estimates and Fit of Competing Income Mod- els}

Table 3.6 presents estimates of unknown parameters for the income process models, HIP and RIP with conventional consumption model and Table 3.7 presents estimation results for the income process model, GRIP with new consumption model with heterogeneous conditional mean in consumption growth. As the HIP-Consumption Model does not have unpredictable permanent component, the transitory loading factor $\left(\psi_{t}\right)$ should be higher to explain change in consumption. At the estimates of the RIP-Consumption Model, permanent shocks are small relative to transitory shocks

and permanent loading factor $\left(\phi_{t}\right)$ is higher than the transitory loading factor $\left(\psi_{t}\right)$ as well. The GRIP-HCM Consumption Model can capture the effects of macro state on income process as well as of past consumption on consumption growth. 
Table 3.6: Estimation results of RIP- and HIP-Consumption Models

\begin{tabular}{|c|c|c|c|c|c|c|c|c|}
\hline \multirow[b]{2}{*}{ Year } & \multicolumn{3}{|c|}{ HIP-Consumption Model } & \multicolumn{5}{|c|}{ RIP-Consumption Model } \\
\hline & $\sigma_{\xi}^{2}$ & $\psi$ & $\sigma_{\omega}^{2}$ & $\sigma_{\zeta}^{2}$ & $\sigma_{\xi}^{2}$ & $\phi$ & $\psi$ & $\sigma_{\omega}^{2}$ \\
\hline 2000 & $\begin{array}{c}0.0659 \\
(0.0142)\end{array}$ & & & & $\begin{array}{c}0.1946 \\
(0.0241)\end{array}$ & & & \\
\hline 2001 & $\begin{array}{c}0.0817 \\
(0.0166)\end{array}$ & $\begin{array}{c}-0.0664 \\
(0.0705)\end{array}$ & $\begin{array}{c}0.0045 \\
(0.0046)\end{array}$ & $\begin{array}{c}0.0120 \\
(0.0068)\end{array}$ & $\begin{array}{c}0.1112 \\
(0.0124)\end{array}$ & $\begin{array}{c}0.7368 \\
(0.3103)\end{array}$ & $\begin{array}{c}-0.0108 \\
(0.0446)\end{array}$ & $\begin{array}{c}0.0000 \\
(0.0070)\end{array}$ \\
\hline 2002 & $\begin{array}{c}0.1065 \\
(0.0188)\end{array}$ & $\begin{array}{l}-0.1131 \\
(0.0549)\end{array}$ & $\begin{array}{c}0.0000 \\
(0.0041)\end{array}$ & $\begin{array}{c}0.0044 \\
(0.0058)\end{array}$ & $\begin{array}{c}0.1448 \\
(0.0160)\end{array}$ & $\begin{array}{c}0.3724 \\
(0.7164)\end{array}$ & $\begin{array}{l}-0.0384 \\
(0.0430)\end{array}$ & $\begin{array}{c}0.0000 \\
(0.0051)\end{array}$ \\
\hline 2003 & $\begin{array}{c}0.1475 \\
(0.0218)\end{array}$ & $\begin{array}{c}-0.0318 \\
(0.0328)\end{array}$ & $\begin{array}{c}0.0045 \\
(0.0040)\end{array}$ & $\begin{array}{c}0.0078 \\
(0.0061)\end{array}$ & $\begin{array}{c}0.1678 \\
(0.0185)\end{array}$ & $\begin{array}{c}0.8757 \\
(0.5334)\end{array}$ & $\begin{array}{c}-0.0385 \\
(0.0374)\end{array}$ & $\begin{array}{c}0.0000 \\
(0.0076)\end{array}$ \\
\hline 2004 & $\begin{array}{c}0.1326 \\
(0.0205)\end{array}$ & $\begin{array}{l}-0.0223 \\
(0.0366)\end{array}$ & $\begin{array}{c}0.0032 \\
(0.0040)\end{array}$ & $\begin{array}{c}0.0016 \\
(0.0068)\end{array}$ & $\begin{array}{c}0.1523 \\
(0.0183)\end{array}$ & $\begin{array}{c}1.2944 \\
(3.4672)\end{array}$ & $\begin{array}{l}-0.0346 \\
(0.0391)\end{array}$ & $\begin{array}{c}0.0000 \\
(0.0097)\end{array}$ \\
\hline 2005 & $\begin{array}{c}0.1344 \\
(0.0209)\end{array}$ & $\begin{array}{c}-0.0259 \\
(0.0348)\end{array}$ & $\begin{array}{c}0.0039 \\
(0.0039)\end{array}$ & $\begin{array}{c}0.0010 \\
(0.0083)\end{array}$ & $\begin{array}{c}0.1575 \\
(0.0184)\end{array}$ & $\begin{array}{c}1.8674 \\
(13.0531)\end{array}$ & $\begin{array}{l}-0.0454 \\
(0.0334)\end{array}$ & $\begin{array}{c}0.0000 \\
(0.0248)\end{array}$ \\
\hline 2006 & $\begin{array}{c}0.1013 \\
(0.0139)\end{array}$ & $\begin{array}{c}0.1128 \\
(0.0466)\end{array}$ & $\begin{array}{c}0.0101 \\
(0.0041)\end{array}$ & $\begin{array}{c}0.0000 \\
(0.0084)\end{array}$ & $\begin{array}{c}0.1172 \\
(0.0158)\end{array}$ & $\begin{array}{c}0.4186 \\
(5.4418)\end{array}$ & $\begin{array}{c}0.0689 \\
(0.0418)\end{array}$ & $\begin{array}{c}0.0099 \\
(0.0039)\end{array}$ \\
\hline 2007 & $\begin{array}{c}0.1155 \\
(0.0181)\end{array}$ & $\begin{array}{c}-0.0178 \\
(0.0418)\end{array}$ & $\begin{array}{c}0.0000 \\
(0.0042)\end{array}$ & $\begin{array}{c}0.0021 \\
(0.0065)\end{array}$ & $\begin{array}{c}0.1216 \\
(0.0168)\end{array}$ & $\begin{array}{c}0.2922 \\
(1.9926)\end{array}$ & $\begin{array}{l}-0.0472 \\
(0.0459)\end{array}$ & $\begin{array}{c}0.0005 \\
(0.0046)\end{array}$ \\
\hline 2008 & $\begin{array}{c}0.2013 \\
(0.0347)\end{array}$ & $\begin{array}{l}-0.0018 \\
(0.0239)\end{array}$ & $\begin{array}{c}0.0000 \\
(0.0053)\end{array}$ & $\begin{array}{c}0.0166 \\
(0.0073)\end{array}$ & $\begin{array}{c}0.1967 \\
(0.0317)\end{array}$ & $\begin{array}{c}0.0342 \\
(0.3847)\end{array}$ & $\begin{array}{l}-0.0191 \\
(0.0344)\end{array}$ & $\begin{array}{c}0.0000 \\
(0.0056)\end{array}$ \\
\hline 2009 & $\begin{array}{c}0.0909 \\
(0.0182)\end{array}$ & $\begin{array}{c}0.0134 \\
(0.0561)\end{array}$ & $\begin{array}{c}0.0000 \\
(0.0043)\end{array}$ & $\begin{array}{c}0.0000 \\
(0.0078)\end{array}$ & $\begin{array}{c}0.0991 \\
(0.0144)\end{array}$ & $\begin{array}{c}0.8761 \\
(9.6371)\end{array}$ & $\begin{array}{l}-0.0379 \\
(0.0532)\end{array}$ & $\begin{array}{c}0.0000 \\
(0.0064)\end{array}$ \\
\hline 2010 & $\begin{array}{c}0.1123 \\
(0.0203)\end{array}$ & $\begin{array}{c}0.0811 \\
(0.0442)\end{array}$ & $\begin{array}{c}0.0000 \\
(0.0045)\end{array}$ & $\begin{array}{c}0.0000 \\
(0.0069)\end{array}$ & $\begin{array}{c}0.1095 \\
(0.0192)\end{array}$ & $\begin{array}{c}0.8562 \\
(12.8430)\end{array}$ & $\begin{array}{c}0.0415 \\
(0.0501)\end{array}$ & $\begin{array}{c}0.0000 \\
(0.0063)\end{array}$ \\
\hline 2011 & $\begin{array}{c}0.0764 \\
(0.0203)\end{array}$ & $\begin{array}{c}0.0216 \\
(0.0622)\end{array}$ & $\begin{array}{c}0.0000 \\
(0.0046)\end{array}$ & $\begin{array}{c}0.0000 \\
(0.0067)\end{array}$ & $\begin{array}{c}0.0905 \\
(0.0166)\end{array}$ & $\begin{array}{c}0.9437 \\
(10.3807)\end{array}$ & $\begin{array}{c}-0.0388 \\
(0.0622)\end{array}$ & $\begin{array}{c}0.0000 \\
(0.0074)\end{array}$ \\
\hline 2012 & $\begin{array}{c}0.0905 \\
(0.0154)\end{array}$ & $\begin{array}{c}0.0966 \\
(0.0525)\end{array}$ & $\begin{array}{c}0.0000 \\
(0.0039)\end{array}$ & $\begin{array}{c}0.0000 \\
(0.0069)\end{array}$ & $\begin{array}{c}0.1009 \\
(0.0161)\end{array}$ & $\begin{array}{c}0.8566 \\
(11.1358)\end{array}$ & $\begin{array}{c}0.0322 \\
(0.0509)\end{array}$ & $\begin{array}{c}0.0000 \\
(0.0062)\end{array}$ \\
\hline 2013 & $\begin{array}{c}0.0861 \\
(0.0155)\end{array}$ & $\begin{array}{c}0.1584 \\
(0.0603)\end{array}$ & $\begin{array}{c}0.0000 \\
(0.0045)\end{array}$ & $\begin{array}{c}0.0000 \\
(0.0061)\end{array}$ & $\begin{array}{c}0.1104 \\
(0.0156)\end{array}$ & $\begin{array}{c}0.9358 \\
(14.0370)\end{array}$ & $\begin{array}{c}0.0903 \\
(0.0472)\end{array}$ & $\begin{array}{c}0.0000 \\
(0.0057)\end{array}$ \\
\hline 2014 & $\begin{array}{c}0.0797 \\
(0.0145)\end{array}$ & $\begin{array}{c}0.1528 \\
(0.0631)\end{array}$ & $\begin{array}{c}0.0000 \\
(0.0042)\end{array}$ & $\begin{array}{l}0.0000 \\
(0.079)\end{array}$ & $\begin{array}{c}0.1071 \\
(0.0141)\end{array}$ & $\begin{array}{c}0.8862 \\
(9.7482)\end{array}$ & $\begin{array}{c}0.0830 \\
(0.0637)\end{array}$ & $\begin{array}{c}0.0000 \\
(0.0068)\end{array}$ \\
\hline$\theta$ & & & & & & $\begin{array}{c}0.3321 \\
(0.0262)\end{array}$ & & \\
\hline$\rho$ & & $\begin{array}{c}0.4388 \\
(0.0239)\end{array}$ & & & & & & \\
\hline$\sigma_{\gamma}$ & & $\begin{array}{c}0.3803 \\
(0.0192)\end{array}$ & & & & & & \\
\hline$\sigma_{\beta}$ & & $\begin{array}{c}0.0250 \\
(0.0018)\end{array}$ & & & & & & \\
\hline $\operatorname{corr}(\gamma, \beta)$ & & $\begin{array}{c}-0.5284 \\
(0.0527)\end{array}$ & & & & & & \\
\hline$\sigma_{P_{1}}^{2}$ & & & & & & $\begin{array}{c}0.0830 \\
(0.0043)\end{array}$ & & \\
\hline$\sigma_{\xi_{0}}^{2}$ & & & & & & $\begin{array}{c}0.1541 \\
(0.0323)\end{array}$ & & \\
\hline$\sigma_{c_{1}}$ & & $\begin{array}{c}0.2373 \\
(0.0125)\end{array}$ & & & & $\begin{array}{c}0.2326 \\
(0.0127)\end{array}$ & & \\
\hline $\operatorname{corr}\left(P_{1}, c_{1}\right)$ & & & & & & $\begin{array}{c}0.8858 \\
(0.0625)\end{array}$ & & \\
\hline $\operatorname{corr}\left(\xi_{1}, c_{1}\right)$ & & $\begin{array}{c}-0.3980 \\
(0.1678)\end{array}$ & & & & $\begin{array}{c}0.0083 \\
(0.0664)\end{array}$ & & \\
\hline $\operatorname{corr}\left(\gamma, c_{1}\right)$ & & $\begin{array}{c}0.9445 \\
(0.0766)\end{array}$ & & & & & & \\
\hline $\operatorname{corr}\left(\beta, c_{1}\right)$ & & $\begin{array}{c}-0.1506 \\
(0.1059)\end{array}$ & & & & & & \\
\hline $\operatorname{var}\left(m_{t}\right)$ & & $\begin{array}{c}0.0627 \\
(0.0025)\end{array}$ & & & & $\begin{array}{c}0.0638 \\
(0.0025)\end{array}$ & & \\
\hline
\end{tabular}

Note: Standard errors are in the parenthesis. 
Table 3.7: Estimation results of GRIP-HCM Consumption Model

\begin{tabular}{|c|c|c|c|c|c|c|c|}
\hline \multirow[b]{2}{*}{ Year } & \multicolumn{7}{|c|}{ GRIP-HCM Consumption Model } \\
\hline & $f_{t}$ & $\delta_{t}$ & $\sigma_{\zeta}^{2}$ & $\sigma_{\xi}^{2}$ & $\phi$ & $\psi$ & $\sigma_{\omega}^{2}$ \\
\hline 2000 & & $\begin{array}{c}-0.0375 \\
(0.0802)\end{array}$ & & $\begin{array}{c}0.1761 \\
(0.0357)\end{array}$ & & & \\
\hline 2001 & $\begin{array}{l}-0.0596 \\
(0.0877)\end{array}$ & $\begin{array}{l}-0.0811 \\
(0.0460)\end{array}$ & $\begin{array}{c}0.0232 \\
(0.0114)\end{array}$ & $\begin{array}{c}0.0769 \\
(0.0182)\end{array}$ & $\begin{array}{c}0.7821 \\
(0.3074)\end{array}$ & $\begin{array}{c}0.0075 \\
(0.1041)\end{array}$ & $\begin{array}{c}0.0000 \\
(0.0085)\end{array}$ \\
\hline 2002 & $\begin{array}{l}-0.0525 \\
(0.0482)\end{array}$ & $\begin{array}{l}-0.0227 \\
(0.0459)\end{array}$ & $\begin{array}{c}0.0185 \\
(0.0136)\end{array}$ & $\begin{array}{c}0.0946 \\
(0.0143)\end{array}$ & $\begin{array}{c}0.7295 \\
(0.5611)\end{array}$ & $\begin{array}{l}-0.0983 \\
(0.0959)\end{array}$ & $\begin{array}{c}0.0006 \\
(0.0122)\end{array}$ \\
\hline 2003 & $\begin{array}{l}-0.0777 \\
(0.0514)\end{array}$ & $\begin{array}{c}-0.0753 \\
(0.0444)\end{array}$ & $\begin{array}{c}0.0218 \\
(0.0086)\end{array}$ & $\begin{array}{c}0.1259 \\
(0.0170)\end{array}$ & $\begin{array}{c}0.7375 \\
(0.3260)\end{array}$ & $\begin{array}{l}-0.0488 \\
(0.0706)\end{array}$ & $\begin{array}{c}0.0000 \\
(0.0106)\end{array}$ \\
\hline 2004 & $\begin{array}{l}-0.0878 \\
(0.0461)\end{array}$ & $\begin{array}{l}-0.0528 \\
(0.0420)\end{array}$ & $\begin{array}{c}0.0161 \\
(0.0077)\end{array}$ & $\begin{array}{c}0.1228 \\
(0.0159)\end{array}$ & $\begin{array}{c}0.7547 \\
(0.4274)\end{array}$ & $\begin{array}{l}-0.0129 \\
(0.0689)\end{array}$ & $\begin{array}{c}0.0062 \\
(0.0097)\end{array}$ \\
\hline 2005 & $\begin{array}{l}-0.0179 \\
(0.0412)\end{array}$ & $\begin{array}{l}-0.0494 \\
(0.0413)\end{array}$ & $\begin{array}{c}0.0193 \\
(0.0090)\end{array}$ & $\begin{array}{c}0.1396 \\
(0.0210)\end{array}$ & $\begin{array}{c}0.7808 \\
(0.3437)\end{array}$ & $\begin{array}{l}-0.0873 \\
(0.0527)\end{array}$ & $\begin{array}{c}0.0019 \\
(0.0106)\end{array}$ \\
\hline 2006 & $\begin{array}{l}-0.0047 \\
(0.0369)\end{array}$ & $\begin{array}{l}-0.0089 \\
(0.0438)\end{array}$ & $\begin{array}{c}0.0000 \\
(0.0050)\end{array}$ & $\begin{array}{c}0.1064 \\
(0.0184)\end{array}$ & $\begin{array}{c}1.1568 \\
(9.7634)\end{array}$ & $\begin{array}{c}0.1223 \\
(0.0684)\end{array}$ & $\begin{array}{c}0.0196 \\
(0.0076)\end{array}$ \\
\hline 2007 & $\begin{array}{l}-0.0050 \\
(0.0403)\end{array}$ & $\begin{array}{l}-0.0711 \\
(0.0398)\end{array}$ & $\begin{array}{c}0.0101 \\
(0.0061)\end{array}$ & $\begin{array}{c}0.0873 \\
(0.0150)\end{array}$ & $\begin{array}{c}0.8419 \\
(0.4800)\end{array}$ & $\begin{array}{l}-0.0527 \\
(0.0817)\end{array}$ & $\begin{array}{c}0.0000 \\
(0.0097)\end{array}$ \\
\hline 2008 & $\begin{array}{c}-0.1522 \\
(0.0399)\end{array}$ & $\begin{array}{l}-0.1124 \\
(0.0465)\end{array}$ & $\begin{array}{c}0.0155 \\
(0.0091)\end{array}$ & $\begin{array}{c}0.1642 \\
(0.0317)\end{array}$ & $\begin{array}{c}0.9595 \\
(0.4734)\end{array}$ & $\begin{array}{l}-0.0101 \\
(0.0477)\end{array}$ & $\begin{array}{c}0.0000 \\
(0.0141)\end{array}$ \\
\hline 2009 & $\begin{array}{l}-0.0177 \\
(0.0371)\end{array}$ & $\begin{array}{l}-0.1019 \\
(0.0413)\end{array}$ & $\begin{array}{c}0.0283 \\
(0.0075)\end{array}$ & $\begin{array}{c}0.1038 \\
(0.0151)\end{array}$ & $\begin{array}{c}0.3988 \\
(0.1735)\end{array}$ & $\begin{array}{c}0.0915 \\
(0.0914)\end{array}$ & $\begin{array}{c}0.0075 \\
(0.0072)\end{array}$ \\
\hline 2010 & $\begin{array}{l}-0.0763 \\
(0.0429)\end{array}$ & $\begin{array}{l}-0.0977 \\
(0.0426)\end{array}$ & $\begin{array}{c}0.0181 \\
(0.0075)\end{array}$ & $\begin{array}{c}0.1028 \\
(0.0199)\end{array}$ & $\begin{array}{c}0.0697 \\
(0.3204)\end{array}$ & $\begin{array}{c}0.0967 \\
(0.0628)\end{array}$ & $\begin{array}{c}0.0128 \\
(0.0045)\end{array}$ \\
\hline 2011 & $\begin{array}{l}-0.0333 \\
(0.0429)\end{array}$ & $\begin{array}{l}-0.0053 \\
(0.0432)\end{array}$ & $\begin{array}{c}0.0039 \\
(0.0081)\end{array}$ & $\begin{array}{c}0.1016 \\
(0.0178)\end{array}$ & $\begin{array}{c}1.6592 \\
(3.1055)\end{array}$ & $\begin{array}{c}0.0100 \\
(0.0496)\end{array}$ & $\begin{array}{c}0.0000 \\
(0.0217)\end{array}$ \\
\hline 2012 & $\begin{array}{l}-0.0091 \\
(0.0414)\end{array}$ & $\begin{array}{c}0.0133 \\
(0.0411)\end{array}$ & $\begin{array}{c}0.0214 \\
(0.0069)\end{array}$ & $\begin{array}{c}0.0866 \\
(0.0148)\end{array}$ & $\begin{array}{c}0.3085 \\
(0.2256)\end{array}$ & $\begin{array}{c}0.0171 \\
(0.0557)\end{array}$ & $\begin{array}{c}0.0000 \\
(0.0060)\end{array}$ \\
\hline 2013 & $\begin{array}{l}-0.0220 \\
(0.0380)\end{array}$ & $\begin{array}{l}-0.0422 \\
(0.0348)\end{array}$ & $\begin{array}{c}0.0050 \\
(0.0072)\end{array}$ & $\begin{array}{c}0.1005 \\
(0.0161)\end{array}$ & $\begin{array}{c}1.0045 \\
(1.4860)\end{array}$ & $\begin{array}{c}0.0887 \\
(0.0520)\end{array}$ & $\begin{array}{c}0.0019 \\
(0.0117)\end{array}$ \\
\hline 2014 & $\begin{array}{l}-0.0668 \\
(0.0345)\end{array}$ & $\begin{array}{c}-0.0868 \\
(0.0382)\end{array}$ & $\begin{array}{c}0.0166 \\
(0.0104)\end{array}$ & $\begin{array}{c}0.0869 \\
(0.0150)\end{array}$ & $\begin{array}{c}0.4244 \\
(0.3720)\end{array}$ & $\begin{array}{c}0.1388 \\
(0.0719)\end{array}$ & $\begin{array}{c}0.0000 \\
(0.0057)\end{array}$ \\
\hline$\theta$ & & & & $\begin{array}{c}0.0958 \\
(0.0258)\end{array}$ & & & \\
\hline$\sigma_{P_{1}}^{2}$ & & & & $\begin{array}{c}0.1273 \\
(0.0153)\end{array}$ & & & \\
\hline$\sigma_{c_{1}}$ & & & & $\begin{array}{c}0.2962 \\
(0.0180)\end{array}$ & & & \\
\hline $\operatorname{corr}\left(P_{1}, c_{1}\right)$ & & & & $\begin{array}{c}0.8758 \\
(0.0306)\end{array}$ & & & \\
\hline $\operatorname{corr}\left(\xi_{1}, c_{1}\right)$ & & & & $\begin{array}{c}0.0797 \\
(0.0760)\end{array}$ & & & \\
\hline $\operatorname{var}\left(m_{t}\right)$ & & & & $\begin{array}{c}0.0432 \\
(0.0023)\end{array}$ & & & \\
\hline
\end{tabular}

Note: Standard errors are in the parenthesis. 


\section{Fit for income and consumption inequality}

Figure 3.8 plot the observed value and the fitted value of income and consumption inequality $\left(\operatorname{var}\left(y_{t}\right)\right.$ and $\left.\operatorname{var}\left(c_{t}\right)\right)$ for HIP-Consumption, RIP-Consumption, and GRIP-HCM Consumption Models . RIP-Consumption and GRIP-HCM Consumption Models explain the dynamics of lifecycle income very well but HIP-Consumption Model deviates from income inequality at the beginning of sample period. The conventional consumption model cannot explain the observed decrease in consumption inequality over time regardless of the income models employed. Figure 3.8(b) shows as conventional consumption model follows a random walk, the implied consumption inequality are biased downwards during the beginning of sample period and biased upwards at the end of sample period. The consumption model that allows for heterogeneous risk premium can explain the decline in consumption inequality. Although the estimated consumption inequality is biased downwards at the beginning of the sample period and biased little bit upwards at the end of sample period, the GRIPHCM Consumption Model shows the fitted consumption inequality has similar trend to the observed one after 2003. It better fits the dynamics of both income and consumption than the other two models (See Figures 3.8).

Figure 3.8: Model fit of income and consumption inequality for HIP-Consumption, RIP-Consumption, and GRIP-HCM Consumption Models

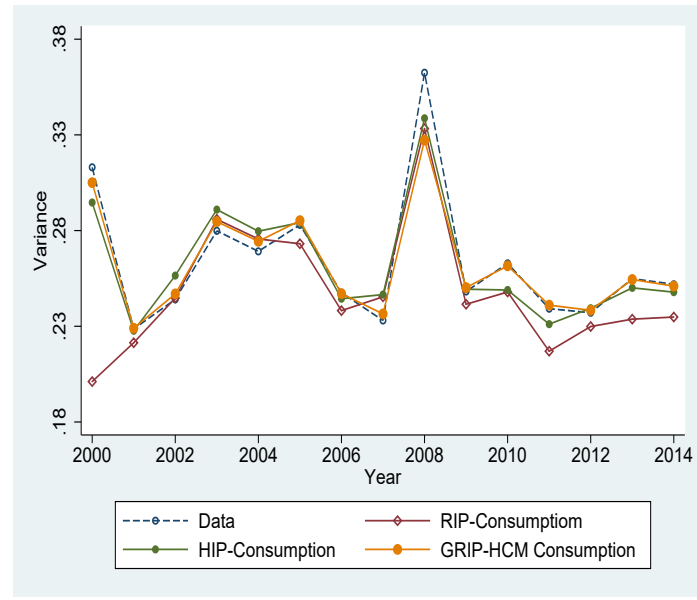

(a) Income

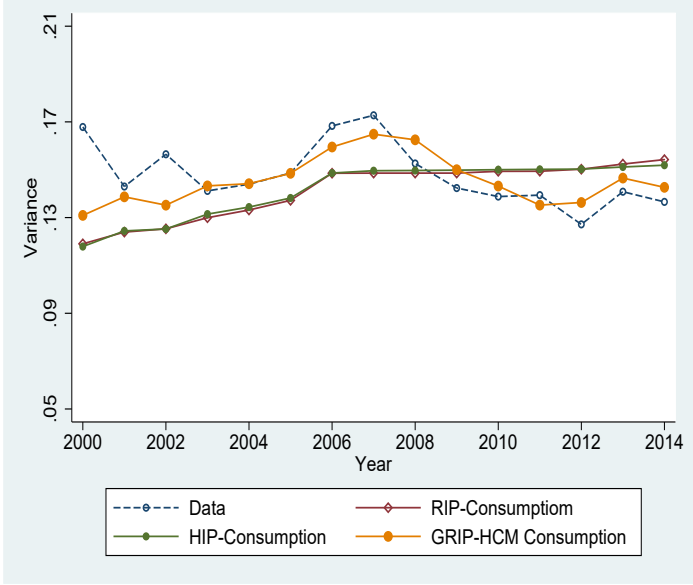

(b) Consumption 


\section{Fit for Income and Consumption Mobility}

In addition, consumption mobility are biased upwards during the entire sample period, which means the estimated correlation between $c_{i t}$ and $c_{i t-1}$ is biased downwards (See Figure 3.9(b)).

Figure 3.9: Model fit of income and consumption mobility for the HIP-Consumption, RIP-Consumption, and GRIP-HCM Consumption Models

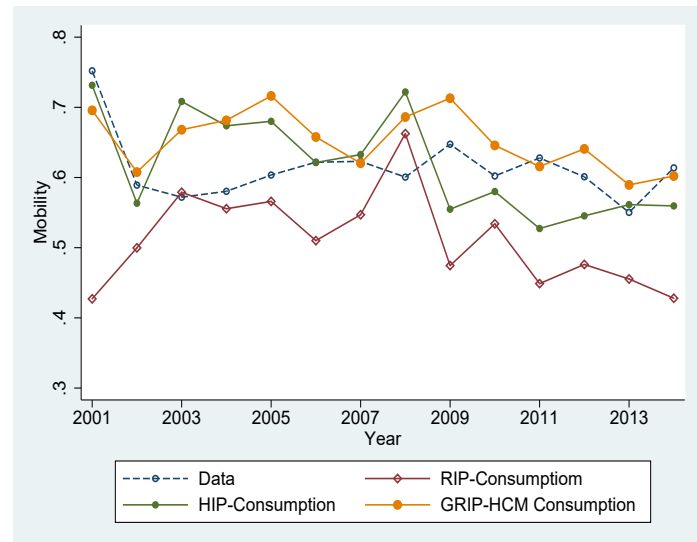

(a) Income

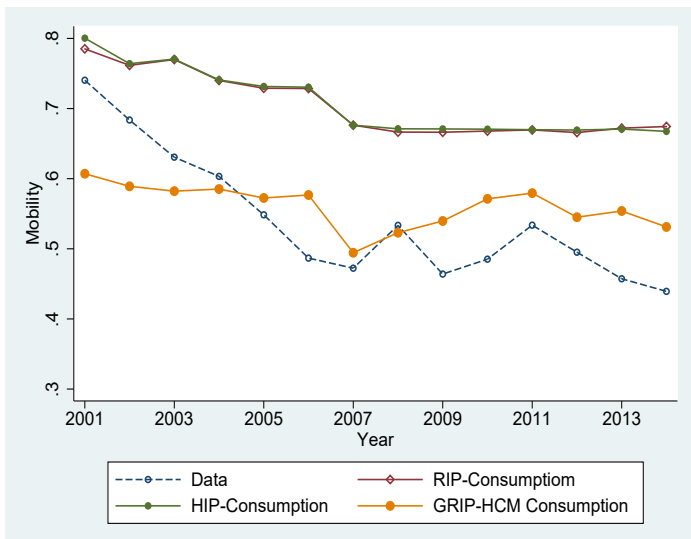

(b) Consumption

Fit for other moments

The GRIP-HCM Consumption Model also fits the trend of covariance between income and consumption and $\operatorname{cov}\left(c_{i t}-c_{i 2}, c_{i 1}\right)$ much closer to the consumption model with RIP- and HIP-based income models, see Figures 3.10 and 3.11.

Figure 3.10: Model fit of $\operatorname{cov}\left(y_{i t}, c_{i t}\right)$ for the HIP-Consumption, RIP-Consumption, and GRIP-HCM Consumption Models

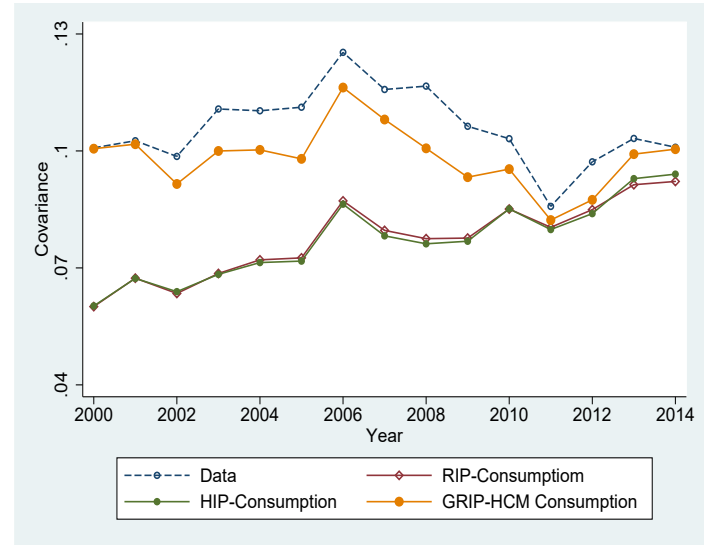


Figure 3.11: Model fit of $\operatorname{cov}\left(c_{i t}-c_{i 2}, c_{i 1}\right)$ for the HIP-Consumption, RIPConsumption, and GRIP-HCM Consumption Models

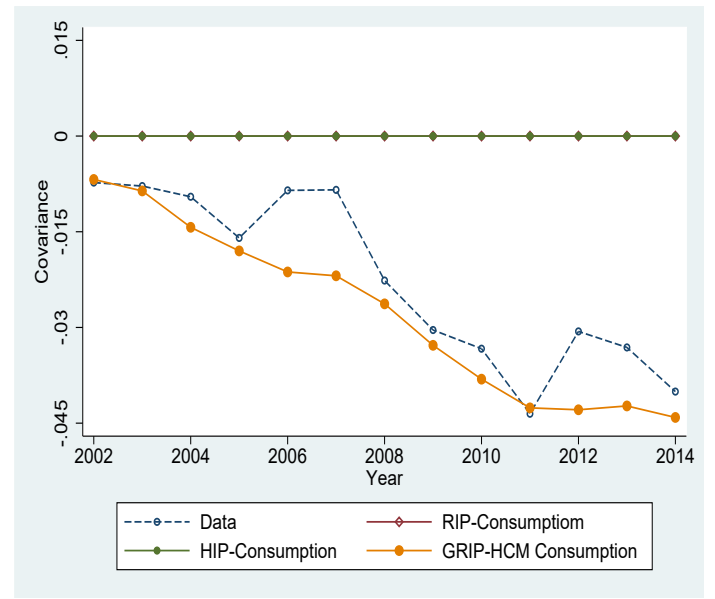

\section{Overall Model Fit}

Table 3.8 reports the overall fit of the three models based the Andrews and Lu (2001) selection criteria for GMM estimation. Based on the selection criteria, MMSC-BIC, MMSC-AIC, and MMSC-HQIC that the GRIP-HCM Consumption Model model is the best model among the three competing models.

Table 3.8: Model comparison

\begin{tabular}{lcccc}
\hline Model & $\begin{array}{c}\text { Number of } \\
\text { parameters }\end{array}$ & MMSC-BIC $^{a)}$ & MMSC-AIC $^{a)}$ & MMSC-HQIC $^{a)}$ \\
& 52 & 194.37 & 229.07 & 206.76 \\
HIP-Consumption & 78 & 280.47 & 313.28 & 292.19 \\
RIP-Consumption & 106 & 86.79 & 117.56 & 97.78 \\
GRIP-HCM Consumption & & & \\
\hline
\end{tabular}

Note: MMSC-BIC $(\mathrm{b}, \mathrm{c})=J_{n}(b, c)-(|c|-|b|) \ln n, \operatorname{MMSC}-\mathrm{AIC}(\mathrm{b}, \mathrm{c})=J_{n}(b, c)-2$ $(|c|-|b|)$, and MMSC-HQIC $(\mathrm{b}, \mathrm{c})=J_{n}(b, c)-Q(|c|-|b|) \ln (\ln n)$. Where, $J_{n}(b, c)$ is the $J$ statistics developed by Andrews and Lu (See pp. 10-11, 2001), $b$ is number of parameters, $c$ is number of moments, $n$ is the sample size, and $Q$ is a number greater than 2 . We select $Q=3$ to compute MMSC-HQIC (b,c). ${ }^{a)}$ means the statistics is multiplied by $10^{2}$. 


\subsection{Concluding Remarks}

This chapter makes the following contributions to the literature of income and consumption inequalities.

(1) We present two pieces of empirical evidence that contradict to the prediction of conventional consumption theory.

First, we present empirical evidence that for the given cohort cumulative consumption growth in the future is negatively correlated with initial consumption, a pattern mirrors that of income. This pattern contradicts to the prediction of income and consumption process driven by iid shocks (e.g., the RIP model for income, and random walk model for consumption.)

Second, the benchmark random walk model of consumption predicts that consumption inequality increases over time for a given cohort. This prediction is contradicted by the cohort of the KLIPS sample.

(2) We propose a consumption model that allows for a heterogeneous conditional mean in consumption growth, and combine this model with a GRIP income process to form a GRIP income-HCM consumption model. We compare the model fit of the GRIP-HCM consumption model with HIP income and RIP income models paired with consumption model with zero conditional mean in consumption growth. We find the GRIP-HCM consumption model fit the KILPS data much better than the HIP-consumption and RIP-consumption models. 


\section{Chapter 4}

\section{Estimating Consumption Inequality in the Presence of Non-classical Measurement Errors}

\subsection{Introduction}

In the chapter 3 , we raised a question on what consumption follows a random walk with iid shock and one possible solution to explain the negative correlation between initial consumption and future consumption (i.e., $\operatorname{corr}\left(c_{i t}, c_{i 1}\right)<0$, where $c$ is consumption), would be measurement error in consumption. Under the assumption of the classical measurement error, variance of measurement error (i.e., $\sigma_{m}^{2}$, where $m$ is measurement error in consumption) can be captured by $-\operatorname{cov}\left(\Delta c_{t}, \Delta c_{t-1}\right)$ and the estimate in the previous chapter was about 0.04 (around $25 \%$ of cross-sectional consumption variance).

One main issue of numerous literature on comparison of the trends in income and consumption inequalities is how measurement errors are adjusted in survey data. Of course, measurement errors may be present in both income and consumption but Attanasio and Pistaferri (2016) mentioned that measurement errors are likely larger 
in consumption than in income. The questionnaires in surveys typically ask "how much money a household spends on a monthly average for expenditures last year", but households tend to report their expenditures based on recent expenditures, which causes them to overstate or understate. Household monthly spending varies by each month of a year, particularly expenditures on durable goods such as a computer and furniture. The magnitude of measurement errors in survey data may be rising over time (Meyer et al. (2015)) and richer households tend to understate their ratio of consumption to income (Sabelhaus and Groen (2000)).

To specify consumption inequality adjusted for measurement errors, Aguiar and Bils (2015) developed the double differencing correction method. They consider three types of measurement errors in the reported expenditure of survey data (i.e., goodtime specific, income-time specific, and good-household-time specific measurement errors). ${ }^{1}$ The basic idea of the double differencing correction method is based on constancy of total expenditure elasticity over time. If total expenditure elasticity of a certain good does not change over time, then the percentage change in total expenditure over any period is proportional to the percentage change in expenditure on a certain good in the period.

The double differencing correction method consists of two steps: the first step estimates Engel curve for total expenditure elasticitiy of each consumption good and the second step estimates total expenditure by income group from the estimates of total expenditure elasticity for each consumption good. In the first step for estimating Engel curve for total expenditure elasticity, Aguiar and Bils assume the reported total expenditure is correlated with measurement errors still present in the error terms of the Engel curve. To deal with the endogeneity, they suggest using log current income

\footnotetext{
${ }^{1}$ Good-time specific measurement error is caused by expenditure on a certain good misreported for all households. Income-time specific measurement error is caused by expenditure on every good misreported for all households in a certain income group. Good-household-time specific measurement error is caused by expenditure on a certain good misreported for each household. The three types of measurement errors can be different across time.
} 
as an instrument for total expenditure.

In this study, we argue there may be more appropriate instrument than current income for total expenditure. My instrument for total expenditure is based on the permanent income hypothesis (PIH) which theorizes optimal consumption is determined by permanent income (current income plus discounted future income and current asset). We use a proxy for permanent income to estimate Engel curve using a Korean household panel data. We compare the estimates of consumption inequality in the double-differencing correction method based on different instruments (current income versus permanent income) in the first step.

We use the Korean Labor and Income Panel Study (KLIPS) of South Korea. KLIPS is similar to the Panel Study of Income Dynamics (PSID) in the U.S. and is published by Korea Labor Institute since 1998. KLIPS has advantages over the commonly used household data sets. The Consumer Expenditure Survey (CEX) employed by Aguiar and Bils has rich information on consumption but has known problems on income side. Since CEX does not have panel data on income, it is not feasible to use it to estimate permanent income. On the other hand, PSID has data on income but it became biennial survey since 1997 and has a poor measure of long panels consumption. KLIPS has annual data on most key household variables such as employment, income, expenditures, education, housing status, financial and real wealth, debt, and so on. Another interesting feature is that according to the OECD, the trend of Korean income inequality differs from inequality trend of the U.S. Korean disposable household income decreased from 0.314 in 2008 to 0.295 in 2015 (Morelli et al. (2015)). By using KLIPS, we can address whether consumption inequality tracks income inequality during a downward trend in income inequality.

We present three findings. First, the PIH instrument has a higher first stage $R^{2}$ than the Aguiar and Bils instrument in Engel curve, which leads to different level of consumption inequality even though the trend in consumption inequality based 
on the PIH instrument is similar to that based on the Aguiar and Bils instrument. Second, both income and consumption inequalities have decreased since the global financial crisis, and the income inequality declines more than consumption inequality. Specifically, during 2010-2015, income inequality decreased by 18.2 percent and consumption inequality for all goods and non-durable goods decreased by 11.3 and 9.2 percent, respectively. However, compared to previous sub-period (i.e., 2005-2007), during the global financial crisis, consumption inequality for all goods and non-durable goods dropped 22.4 and 14.1 percent, respectively, while income inequality does not change much. Third, the trend in income inequality changed from upward slope to downward slope at mid-2000s, whereas consumption inequality continues to increase before the global financial crisis and starts to decrease since the global financial crisis (2008-2009).

Section 4.2 summarizes key variables and descriptive statistics of my data set. Section 4.3 explains the double differencing correction method for eliminating three types of measurement errors and introduces an alternative instrument for total expenditure based on PIH. Section 4.4 presents the estimation results of total expenditure elasticity and relative consumption inequality based on Aguiar and Bils specification and using PIH as an instrument. Section 4.5 concludes.

\subsection{Data and inequality trends}

\subsubsection{Data}

The sample period covers 16 years ranging from the fourth wave in 2001 through the nineteenth wave in 2016. We focus on married households pertaining to the working years before retirement: first, divorced, separated, and one-person households are omitted. Second, households with missing report on disposable income and on total 
expenditures are trimmed. Third, households with a heads age under 30 years old or over 65 years old are dropped. Fourth, households considered to be potential outliers in disposable income and expenditures are eliminated in the sample. ${ }^{2}$ The final sample after filtering work consists of an unbalanced panel data with 5,137 households and 41,356 observations between 2001-2016. 547 households participate in every survey during 16 years of my research period and the balanced panel of 547 households is used to construct new proxy for permanent income in section 4.4.2.

The key variables for my research objectives are disposable income and expenditures on each consumption good. A household disposable income is a sum of labor earnings, financial income, real property income, transfer income, and other income during a year. For consumption category, we divide the consumption items reported in KLIPS into 12 consumption goods based on categories used to compute consumer price index (CPI) in South Korea (i.e., rental and utility payment related to house, education, food at home, vehicle maintenance, communication (phones and internet expenses), food away from home, family events (wedding party, funeral, etc.), entertainment, apparel and shoes, health expense, durable goods, and miscellaneous expenditure). ${ }^{3}$ According to classification in Attanasio and Weber (1995), 5 goods (i.e., rental and utility payment related to house, education, apparel and shoes, health expense, and durable goods) out of 12 goods are considered as durable goods and the other 7 goods are considered as non-durable goods. ${ }^{4}$

\footnotetext{
${ }^{2}$ We define potential outliers in disposable income as households with income growth above $500 \%$ or below $-80 \%$, which is suggested by Blundell, Pistaferri, and Preston (2008). For expenditures, we follow the rule suggested of Aguiar and Bils (2015) by dropping households that spend more than half of their disposable income on any category except housing and food expenditures.

${ }^{3}$ Computing CPI in South Korea, "alcohol and cigarette" category is also in the categories for CPI but KLIPS does not provide an information on "alcohol and cigarette" expenditure. Family event is not in CPI basket but is included in non-durable goods.

${ }^{4}$ Attanasio and Weber (1995) classified consumption categories into durable, semi-durable, and non-durable goods. They apparel and shoes are considered as semi-durable goods but we include semi-durable goods in durable goods. Also, they classified utility payment related to house such as electricity and heating fuel into non-durable goods but rental payment into durable goods. As utility payment and rental payment cannot distinguish in KLIPS, considering rental payment with higher portion of "rental and utility payment related to house" category, "rental and utility payment related to house" is classified into durable goods.
} 
We use a reported value answered by a household for expenditures on each consumption good except "rental and utility payment related to house". There are three types of housing status in South Korea unlike the U.S.: a home owner, a jeonsei renter, and a monthly renter. ${ }^{5}$ For a monthly renter, monthly rent paid to a a home owner every month is rental payment and the value is already reported in expenses related to house in KLIPS. We impute equivalent rental payment for house owners and jeonsei renters. For a home owner, a sum of mortgage interest and tax payment caused by holding a house is used for equivalent rental payment. Since 2005 owners of expensive houses have to pay comprehensive real estate holding tax (CREHT) in addition to property tax (PT). CREHT is also included in tax payment. For jeonsei renters, we impute equivalent rental payment by interest payment of a loan for a lump-sum deposit of jeonsei. Therefore, the sum of the imputed equivalent rental payment and utility payment reported in KLIPS is "rental and utility payment related to house" for both home owners and jeonsei renters. Table 4.1 shows tax base of PT and CREHT during the sample period.

\subsubsection{Inequality trends}

Table 4.2 provides descriptive statistics of key variables for all households and GDP growth rate for macro state during my sample period. Disposable income, total expenditure, and net wealth for all households are converted to real value deflated by aggregate CPI thereafter $(2015=100)$, we use GDP growth rate to represent macro state.

Figure 4.1 plots income and consumption inequalities based on four different inequality measures (i.e., cross-sectional variance of the $\log , 90^{t h} / 10^{t h}$ and $50^{t h} / 10^{t h}$ percentile ratio, and the ratio of the mean for the top $20 \%$ of income distribution

\footnotetext{
5 "Jeonsei" is another type of renters. Jeonsei renters give a lump-sum deposit more than $50 \%$ of the housing value to a home owner and get back the deposit at the end of the lease. Here, we distinguish jeonsei and monthly renters and a renter means a monthly renter.
} 
Table 4.1: Housing tax in South Korea

\begin{tabular}{|c|c|c|c|c|c|}
\hline & \multicolumn{2}{|l|}{$\mathrm{PT}$} & \multicolumn{3}{|l|}{ CREHT } \\
\hline Tax type & \multicolumn{2}{|l|}{ Local tax } & \multicolumn{3}{|l|}{ National tax } \\
\hline Taxpayer & \multicolumn{2}{|l|}{ Every house owner } & \multicolumn{3}{|c|}{ House owner with a house worth over certain amount } \\
\hline \multicolumn{6}{|l|}{ Tax base } \\
\hline \multicolumn{6}{|l|}{$\overline{1 . \mathrm{PT}}$} \\
\hline \multicolumn{2}{|c|}{ Year: $2000 \sim 2009$} & \multicolumn{2}{|c|}{ Year: $2010 \sim 2012$} & \multicolumn{2}{|c|}{ Year: 2013 2015 } \\
\hline Base & Rate & Base & Rate & Base & Rate \\
\hline $\mathrm{HV}^{a)} \leq 4$ & $0.15 \%$ & $\mathrm{HV} \leq 6$ & $0.10 \%$ & $\mathrm{HV} \leq 6$ & $0.10 \%$ \\
\hline $4<\mathrm{HV} \leq 10$ & $0.3 \%+60 \mathrm{k}(\mathrm{KRW})$ & $6<\overline{\mathrm{HV}} \leq 15$ & $0.15 \%+60 \mathrm{k}(\mathrm{KRW})$ & $6<\overline{\mathrm{H}} \mathrm{S} \leq 15$ & $0.15 \%+60 \mathrm{k}(\mathrm{KRW})$ \\
\hline $\mathrm{HV}>10$ & $0.5 \%+240 \mathrm{k}(\mathrm{KRW})$ & $15<\mathrm{HV} \leq 30$ & $0.25 \%+195 \mathrm{k}(\mathrm{KRW})$ & $15<\mathrm{HV} \leq 30$ & $0.25 \%+195 \mathrm{k}(\mathrm{KRW})$ \\
\hline & & $\mathrm{HV}>30$ & $0.4 \%+570 \mathrm{k}(\mathrm{KRW})$ & $\mathrm{HV}>30$ & $0.4 \%+300 \mathrm{k}(\mathrm{KRW})$ \\
\hline
\end{tabular}

\begin{tabular}{|c|c|c|c|}
\hline $\begin{array}{l}\text { 2. CREHT } \\
\text { Year: } 2005 \\
\end{array}$ & & Year: $2006 \sim 20$ & \\
\hline Base & Rate & Base & Rate \\
\hline $\mathrm{HV} \leq 55$ & $1 \%$ & $\mathrm{HV} \leq 30$ & $1 \%$ \\
\hline $55<\mathrm{HV} \leq 455$ & $2 \%$ & $30<\mathrm{HV} \leq 140$ & $1.5 \%$ \\
\hline $\mathrm{HV}>45 \overline{5}$ & $3 \%$ & $\begin{array}{l}140<\mathrm{HV} \leq 940 \\
\mathrm{HV}>940\end{array}$ & $\begin{array}{l}2 \% \\
3 \%\end{array}$ \\
\hline
\end{tabular}

Taxpayer $90<H V$

$60 \leq H V$

\begin{tabular}{ll}
\multicolumn{2}{l}{ Year: $2009 \sim 2015$} \\
Base & Rate \\
$\mathrm{HV} \leq 60$ & $0.5 \%$ \\
$60<\mathrm{HV} \leq 120$ & $0.75 \%$ \\
$120<\mathrm{HV} \leq 500$ & $1 \%$ \\
$500<\mathrm{HV} \leq 940$ & $1.5 \%$ \\
$\mathrm{HV}>940$ & $2 \%$
\end{tabular}

Note: ${ }^{a)}$ represents nominal appraised value of a house and the unit of HV is ten million Korean Won (KRW).

to the mean for the bottom $20 \%$ of income distribution) and is for all households corresponding to the descriptive statistics in Table 4.2. Regarding the trends in cross-sectional variance of the $\log$ and $90^{t h} / 10^{\text {th }}$ percentile ratio graphs, income and consumption inequalities are decreasing after the global financial crisis. At the other three graphs besides cross-sectional variance of the log, the decline in income inequality is greater than consumption inequality. Although the ratio used in the panel (d) is related to the relative inequality used for my study, the relative consumption inequality adjusted for measurement errors would generalize the trend in consumption inequality because the trends in income and consumption inequalities are similar regardless of inequality measures.

Figure 4.2 plots income and consumption inequalities for the balanced panel of 547 households. The graphs are likely to represent income and consumption inequalities over the life cycle because the balanced panel continue tracking income and 
consumption of each household during 2000-2015. Inequalities across households are influenced by household demographics. As household demographics are similar more in the 547 households of the balanced panel than in all households, both income and consumption inequalities for 547 households are somewhat lower than those for all households and both exhibit somewhat different trends. Overall, both income and consumption inequalities for the balanced panel are increasing when a household's head is getting old. Specifically, income inequality sharply increased during 20022003 and consumption inequality slightly increased during the same periods at all the panels in Figure 4.2. Interestingly, both income and consumption inequalities were even higher since 2012 than that during the global financial crisis.

\subsection{Estimating Consumption Inequality through "Double Differencing"}

\subsubsection{Double differencing correction method}

In this section, we introduce the double differencing correction method (Aguiar and Bils, 2015) to remove measurement errors. Let $h, g$, and $j$ represent a household, an income group, and a consumption good, respectively. In my dataset, $h=1, \ldots, H, g=$ $1, \ldots, G$, and $j=1, \ldots, J$ have 5,232 households, 5 income groups , and 12 consumption goods, respectively. ${ }^{6}$ And $t$ denotes time to represent year from 2000 to 2015 . When $x_{h j t}$ denotes the reported expenditure on good $j^{\text {th }}$ of household $h$ at time $t$, total expenditures of the household denotes $X_{h t}=\sum_{j=1}^{12} x_{h j t}$.

\footnotetext{
${ }^{6}$ We divide all households at each year into 5 income groups based on quintile of their disposable income. A household in the bottom quintile of disposable income is assigned to group 1 and a household in the group 5 represents the top quintile.
} 


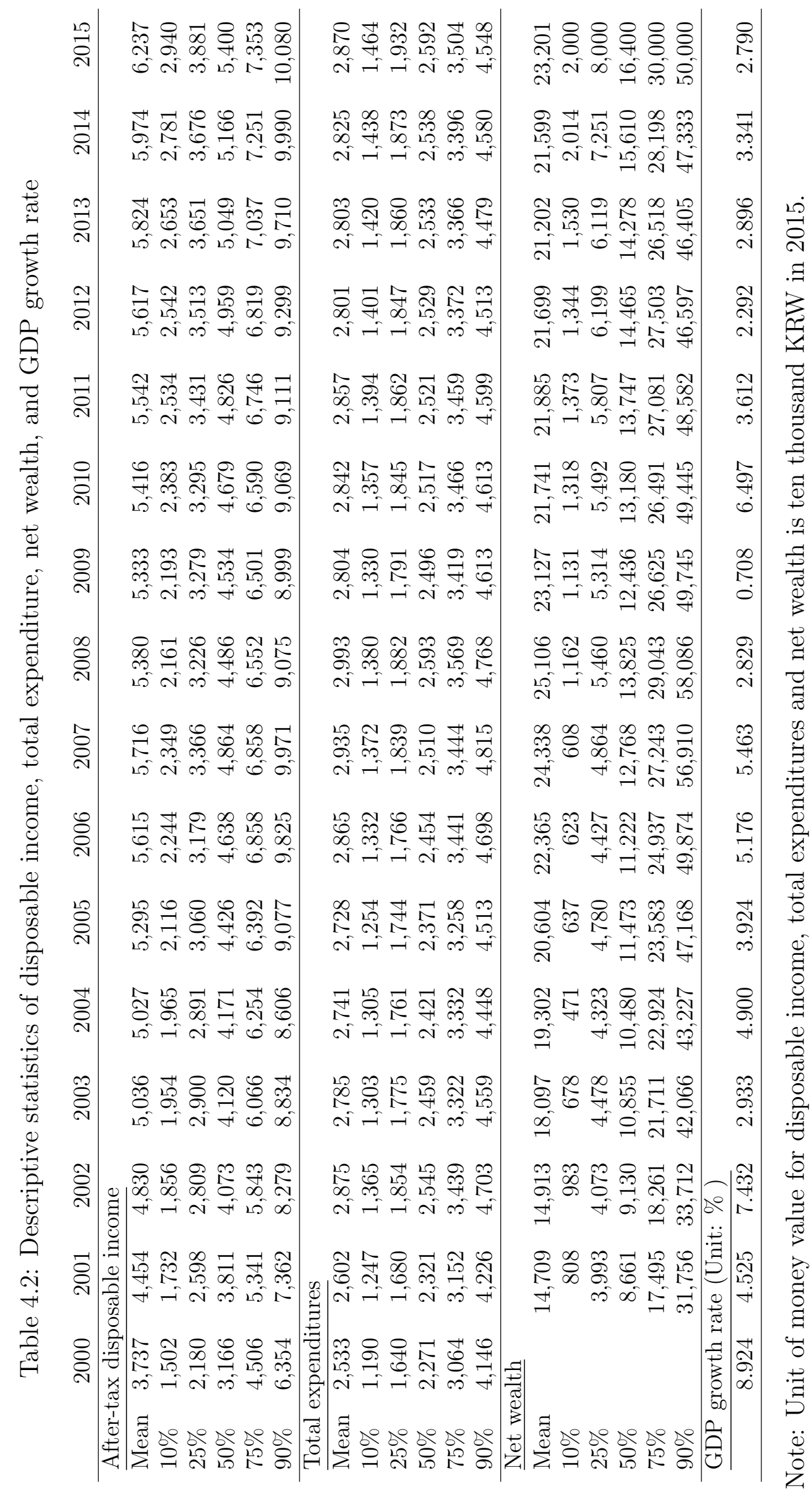


Figure 4.1: Income inequality and consumption inequality for "all households"

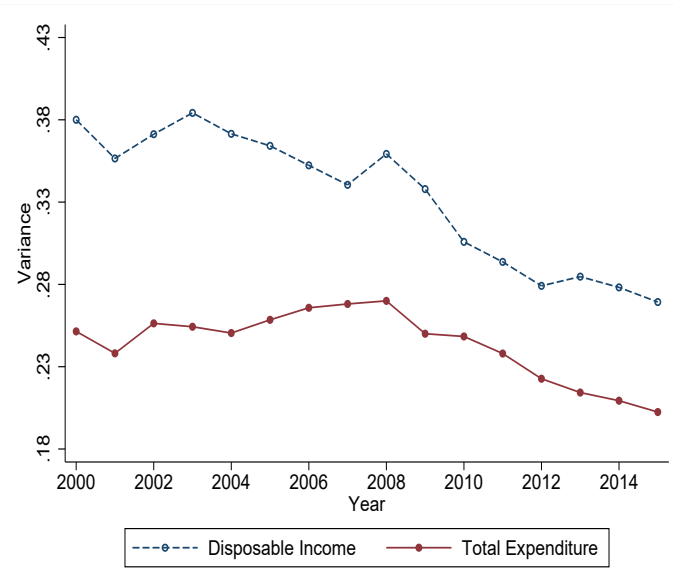

(a) Variance of the log

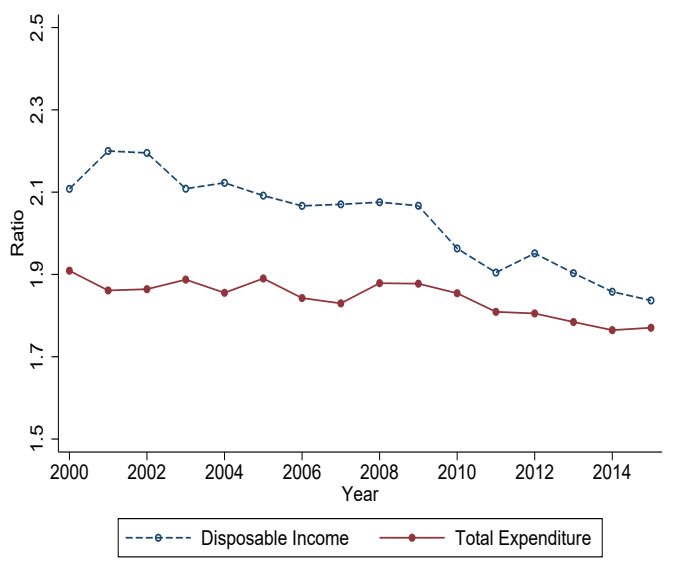

(c) $50^{t h} / 10^{t h}$ Percentile Ratio

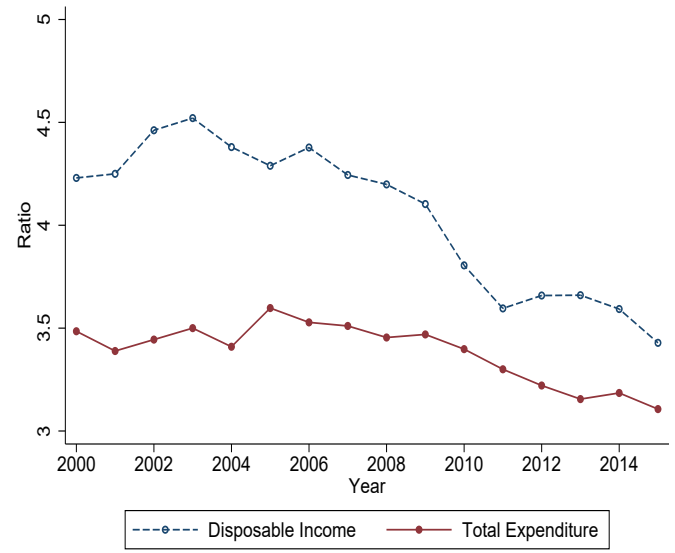

(b) $90^{t h} / 10^{t h}$ Percentile Ratio

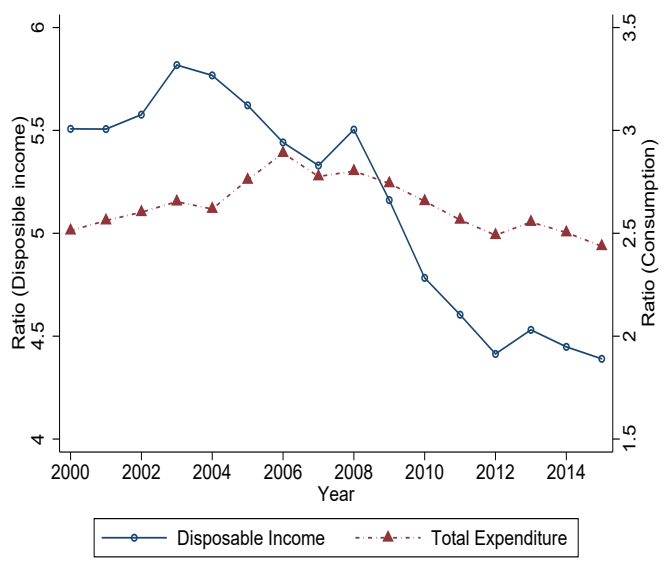

(d) Ratio of mean for the top $20 \%$ income bin to mean for the bottom $20 \%$ income bin 
Figure 4.2: Income inequality and consumption inequality for "547 households"

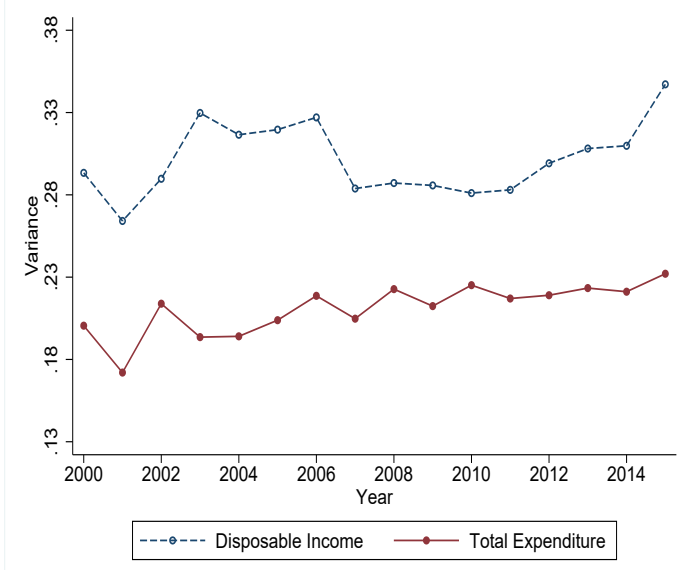

(a) Variance of the log

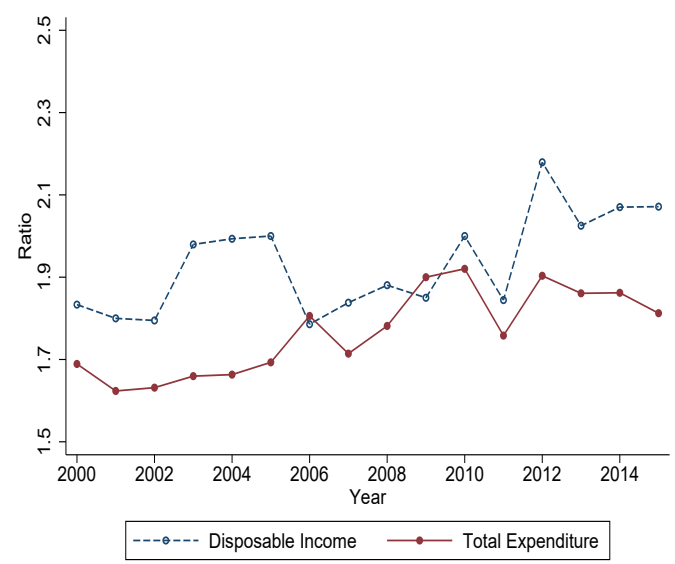

(c) $50^{\text {th }} / 10^{\text {th }}$ Percentile Ratio

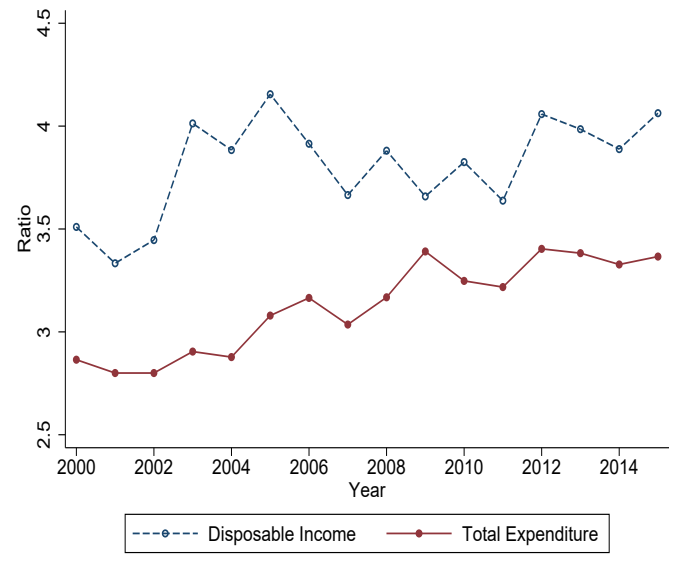

(b) $90^{t h} / 10^{t h}$ Percentile Ratio

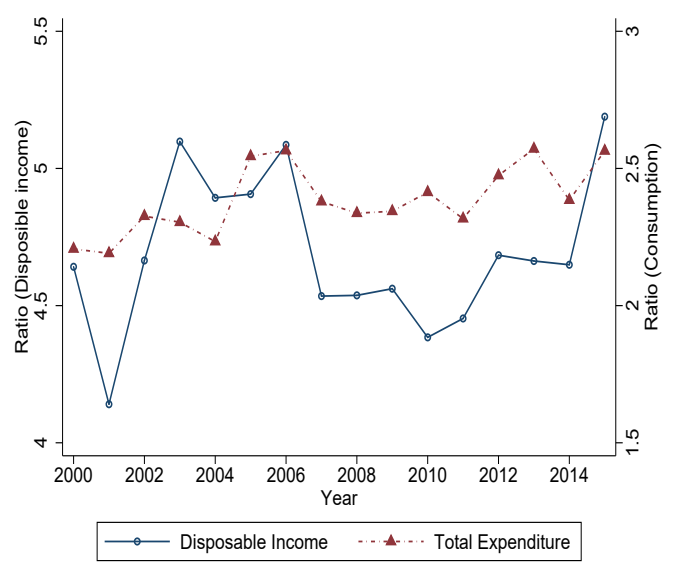

(d) Ratio of mean for the top $20 \%$ income bin to mean for the bottom $20 \%$ income bin 
The double differencing correction model assumes that the expenditures reported by a household includes three types of measurement errors at each time $t$ : good-time specific measurement error $\psi_{t}^{j}$, income-time specific measurement error $\phi_{t}^{g}$, and goodhousehold-time specific measurement error $\nu_{h j t}$. Therefore, the observed expenditures are divided into the true expenditures (i.e., $x_{h j t}^{*}$ ) and measurement error term (i.e., $\left.\zeta_{h j t}\right):$

$$
x_{h j t}=x_{h j t}^{*} e^{\zeta_{h j t}}
$$

We use "*" to denote the true variable through the paper. And measurement errors consist of the additive form of three types of errors,

$$
\zeta_{h j t}=\psi_{t}^{j}+\phi_{t}^{g}+\nu_{h j t}
$$

Here, good-household-time specific measurement error, $\nu_{h j t}$, is classical measurement error and independent of good $j$ and household $h$ at time $t$.

The first step of the double differencing correction method estimates total expenditure elasticity for each consumption good. Aguiar and Bils (2015) use the first-order expansion Engel curve with constant total expenditure elasticity over time because of its manageability to deal with measurement errors:

$$
\ln x_{h j t}^{*}-\ln \bar{x}_{j t}^{*}=\alpha_{j t}^{*}+\beta_{j} \ln X_{h t}^{*}+\Gamma_{\mathbf{j}} \mathbf{Z}_{\mathbf{h}}+\varphi_{h j t}
$$

where $\bar{x}_{j t}^{*}$ is the average expenditure on $j^{t h}$ good across all households at year $t ; \alpha_{j t}^{*}$ reflects the extent of the deviation from average total expenditure; $\mathbf{Z}_{\mathbf{h}}$ is a vector of demographic dummies (i.e., age range (30-41, 42-53, 54-65), number of workers $(<2$, $2+)$, and family members $(\leq 2,3-4,5+)) ; \boldsymbol{\Gamma}_{\mathbf{j}}$ is the coefficient vector for demographic variables across good $j$; the error term $\varphi_{h j t}$ represents idiosyncratic shocks. The $\beta_{j}$ is total expenditure elasticity for the $j^{t h}$ good. The RHS in equation (4.3) can be 
rewritten in terms of observed variables. From (4.1) and (4.2), we have

$$
\begin{aligned}
\ln x_{h j t} & =\ln x_{h j t}^{*}+\zeta_{h j t} \\
\ln \bar{x}_{h t} & =\ln \bar{x}_{j t}^{*}+\psi_{t}^{j}
\end{aligned}
$$

Taking the difference yields

$$
\ln x_{h j t}-\ln \bar{x}_{h t}=\ln x_{h j t}^{*}-\ln \bar{x}_{j t}^{*}+\phi_{t}^{g}+\nu_{h j t}
$$

It follows equation (4.3) can be written as equation (4.4) for estimation of total expenditure elasticity

$$
\begin{aligned}
\ln x_{h j t}-\ln \bar{x}_{j t} & =\alpha_{j t}^{*}+\beta_{j} \ln X_{h t}^{*}+\boldsymbol{\Gamma}_{\mathbf{j}} \mathbf{Z}_{\mathbf{h}}+\varphi_{h j t}+\phi_{t}^{g}+\nu_{h j t} \\
& =\alpha_{j t}^{*}+\beta_{j}\left(\ln X_{h t}^{*}-\ln X_{h t}\right)+\beta_{j} \ln X_{h t}+\boldsymbol{\Gamma}_{\mathbf{j}} \mathbf{Z}_{\mathbf{h}}+\varphi_{h j t}+\phi_{t}^{g}+\nu_{h j t} \\
& =\alpha_{j t}+\beta_{j} \ln X_{h t}+\boldsymbol{\Gamma}_{\mathbf{j}} \mathbf{Z}_{\mathbf{h}}+u_{h j t} .
\end{aligned}
$$

Here, $\alpha_{j t}=\alpha_{j t}^{*}+\beta_{j}\left(\ln X_{h t}^{*}-\ln X_{h t}\right)$ and $u_{h j t}=\phi_{t}^{g}+\nu_{h j t}+\varphi_{h j t}$. The good-time specific measurement error $\psi_{t}^{j}$ is eliminated from calculation of the gap of observed expenditure and average of observed expenditure.

However, there are two potential problems to estimate equation (4.4). First, some households' expenditures on a specific consumption good can be zero, which causes error to convert into logarithm of expenditure. To solve this problem, the percentage deviation from average expenditure on a specific consumption good (i.e., $\left.\tilde{x}_{h j t} \equiv \frac{x_{h j t}-\bar{x}_{j t}}{\bar{x}_{j t}}\right)$ is used for dependent variable instead of $\ln x_{h j t}-\ln \bar{x}_{j t}$. Second, the regressions are endogenous because residual terms and observed total expenditures both have the good-household specific measurement error. We run two-stage regression. Aguiar and Bils suggested log current income and dummies for 5 groups of household's income as instrument variables for the reported total expenditures. Afterwards, we construct proxy variable for permanent income and re-estimate it in 
section 4.4.2. The total expenditure elasticity for the $j^{\text {th }}$ good can be estimated from this equation:

$$
\tilde{x}_{h j t}=\alpha_{j t}+\beta_{j} \ln \hat{X}_{h t}+\Gamma_{\mathbf{j}} \mathbf{Z}_{\mathbf{h}}+u_{h j t} .
$$

The second step estimates relative consumption inequality. If we estimate each good $j$ 's elasticity of the total expenditure from Engel curve, equation (4.4) can be rewritten:

$$
\begin{aligned}
\ln \hat{x}_{h j t} & =\alpha_{j t}+\beta_{j} \ln X_{h t}^{*}+\phi_{t}^{g}+\varphi_{h j t}+\nu_{h j t} \\
& =\alpha_{j t}+\phi_{t}^{g}+\beta_{j} \ln X_{g t}^{*}+\beta_{j}\left(\ln X_{h t}^{*}-\ln X_{g t}^{*}\right)+\varphi_{h j t}+\nu_{h j t} \\
& =\alpha_{j t}+\phi_{t}^{g}+\beta_{j} \ln X_{g t}^{*}+\varepsilon_{h j t} .
\end{aligned}
$$

Here, $\ln \hat{x}_{h j t} \equiv \tilde{x}_{h j t}-\hat{\boldsymbol{\Gamma}}_{\mathbf{j}} \mathbf{Z}_{\mathbf{h}}$ and $\varepsilon_{h j t}=\beta_{j}\left(\ln X_{h t}^{*}-\ln X_{g t}^{*}\right)+\varphi_{h j t}+\nu_{h j t}$. To estimate $\ln X_{g t}^{*}, \ln X_{g t}^{*}$ is treated as a parameter in equation (4.6). We run the regression of $\ln \hat{x}_{h j t}$ on a vector of good-time dummies corresponding to $\alpha_{j t}$, a vector of incometime dummies, $D_{g, t}$ corresponding to $\phi_{t}^{g}$, and the interaction of income-time dummies and total expenditure elasticity of $j^{\text {th }}$ good estimated by Engel curve, $\hat{\beta}_{j}$.

In addition, we use the weighted least squares (WLS) specification to estimate total expenditure for each income group. If the equal weight of all consumption goods based on the ordinary least squares (OLS) is treated regardless of the share of total expenditure, it would be impacted by outliers of components that represent a small share of expenditure. Applying WLS specification with the weights to reflect the share of total expenditure,

$$
\ln \hat{x}_{h j t} \sqrt{w_{j t}}=\alpha_{j t} \sqrt{w_{j t}}+\phi_{t}^{g} \sqrt{w_{j t}}+\beta_{j} \sqrt{w_{j t}} \ln X_{g t}^{*}+\tilde{\varepsilon}_{h j t},
$$

the estimated coefficient of the last interaction term of equation (4.7) will be the estimation of each income group, $\ln X_{g t}^{*}$, where, $w_{j t}$ is the weight to reflect the share of total expenditure for $j$ 's good at year $t$. 
In this paper, the ratio of total expenditures in the top $20 \%$ income group to total expenditures in the bottom $20 \%$ group is used to measure the relative consumption inequality. The relative consumption inequality can be obtained by estimated log of the expenditure ratio, $\delta_{t}=\ln X_{5 t}^{*}-\ln X_{1 t}^{*}$. To estimate $\delta_{t}$, we need different time duration to identify relative consumption inequality excluding the effects of good-time dummies. So, whole sample periods divide into six sub-periods (i.e., 2000-2002, 20032004, 2005-2007, 2008-2009, 2010-2011, and 2012-2015) based on the GDP growth rate: Period 1 is the recovery period of the East Asian economic crisis. Period 2 is the recession period caused by the credit card bubble. ${ }^{7}$ Period 3 is the recovery period of the credit card bubble. Period 4 is the recession period caused by the global financial crisis. Period 5 is the recovery period of the global financial crisis. Period 6 shows little change in GDP growth rate. Even if good-time intercept term $\left(\alpha_{j t}\right)$ is different depending on every year, income-time specific measurement error $\left(\phi_{t}^{i}\right)$ and $\log$ of the relative expenditure ratio $\left(\delta_{t}\right)$ are assumed constant within each sub-period. The estimation of $\delta_{t+1}-\delta_{t}$ represents the log change in consumption inequality between sub-period $t$ and $t+1$.

\subsubsection{Proxy for permanent income based on PIH}

Aguiar and Bils (2015) suggest using log current income as an instrument for total expenditure to estimate total expenditure elasticity. We suggest two alternative instruments for total expenditure by using the balanced panel of 547 households and estimate total expenditure elasticity for each consumption good in Engel curve. We re-estimate consumption inequality based on the estimates of total expenditure elas-

\footnotetext{
${ }^{7}$ The collapse of credit card bubble happened in 2003 in South Korea because the government used the relaxation of regulation about credit card issuers after the Asian financial crisis in 1998 to boost household consumption expenditures. As a result, risky people without earnings can make credit card easily, which causes to increase delinquent borrowers. Specifically, the number of delinquent borrowers related to the credit cards increased by $550 \%$ from 444,000 persons in 2000 to $2,390,000$ persons in 2002.
} 
ticity for the balanced panel and compare the result with Aguiar and Bils estimates.

First alternative instrument is annuitized lifetime earnings based on heterogeneous income profile model. According to Haider and Solon (2006), the log real earning of worker $i, Y_{i t}$ in year $t$ follows

$$
Y_{i t}=\alpha_{i}+\beta_{i}\left(t+t_{i}\right)
$$

where $\alpha_{i}$ is initial log earnings and $\beta_{i}$ is the earnings growth rate, respectively. And $t_{i}$ is the initial work experience and assumes initial age-26. Under the constant real interest rate, $r$, the present discounted value of infinite lifetime earnings is

$$
V_{i}=\sum_{s=0}^{\infty} \frac{\exp \left(\alpha_{i}+\beta_{i}\left(s+t_{i}\right)\right)}{(1+r)^{-s}} \cong \exp \left(\alpha_{i}\right) \frac{1+r}{r-\beta_{i}}
$$

and the log of the present value of lifetime earnings is

$$
\log V_{i} \cong \alpha_{i}+r-\log r+\frac{\beta_{i}}{r}
$$

Second alternative instrument is the expected lifecycle income. Lifecyle income of individual $i$ at time $t$ is a sum of three components: current income, human wealth, and physical wealth. Here, the issue is to expect human wealth. Carroll (1994) suggests how to expect lifecycle human wealth. The disposable income $\left(Y_{i t}\right)$ of individual $i$ at age $a$ in year $t$ is

$$
Y_{i t}=\mathbf{Z}_{\mathbf{i t}} \mathbf{B}_{\mathbf{i t}}+V_{i t}
$$

where $\mathbf{Z}_{\mathbf{i t}}$ is the set of independent variables, $\mathbf{B}_{\mathbf{i t}}$ is the set of parameters, and $V_{i t}$ is the individual's idiosyncratic component of income. The individual's expected income 
in the $j$ future is

$$
E_{t} Y_{i t+j}=E_{t} \mathbf{Z}_{\mathbf{i t}+\mathbf{j}} \mathbf{B}_{\mathbf{i t}+\mathbf{j}}+E_{t} V_{i t+j}
$$

He makes three assumptions to expect future human income. First, the effect of the independent variables to labor income is time-invariant; $E_{t} \mathbf{B}_{\mathbf{i t}+\mathbf{j}}=\mathbf{B}_{\mathbf{i t}}$. Second, the occupation, education, and race except age and job experience in independent variable set do not change over time. Third, the idiosyncratic error follows an AR(1) process; $E_{t} V_{i t+j}=\rho^{j} V_{i t}$ where $\rho$ is the serial correlation parameter.

Specifically, socioeconomic information of a head is used for the expected future household-human income. $\mathbf{Z}_{\mathbf{i t}}$, the set of independent variables consists of dummy variables indicating the education, occupation, and the interaction terms of age and age squared; $\mathbf{Z}_{\mathbf{i t}}=\left[\mathbf{D}_{\mathbf{i t}}, \mathbf{D}_{\mathbf{i t}} a_{i t}, \mathbf{D}_{\mathbf{i t}} a_{i t}^{2}\right]$. The household-specific idiosyncratic error is extracted by $V_{i t}=Y_{i t}-\mathbf{Z}_{\mathbf{i t}} \hat{\mathbf{B}_{\mathbf{i t}}}$ where $\hat{\mathbf{B}_{\mathbf{i t}}}$ is estimated by OLS; $\hat{\mathbf{B}_{\mathbf{i t}}}=\left(\mathbf{Z}_{\mathbf{t}}^{\prime} \mathbf{Z}_{\mathbf{t}}\right)^{-\mathbf{1}} \mathbf{Z}_{\mathbf{t}}^{\prime} Y_{t}$. We use 0.95 for serial correlation parameter like Carroll (1994). Expected lifecycle income $\left(\tilde{Y}_{i t}\right)$ is computed by

$$
\tilde{Y}_{i t}=\hat{Y}_{i t}+H_{i t}+\hat{W}_{i t}
$$

where $Y_{i t}$ and $W_{i t}$ are current income and physical wealth of household $i$ at time $t$, respectively. $\hat{Y}_{i t}$ and $\hat{W}_{i t}$ are the predicted value by OLS regression of $Y_{i t}$ and $W_{i t}$ on $\mathbf{Z}_{\mathbf{i t}} \cdot H_{i t}$ is the ex post sum of future income corresponding to the expected human wealth;

$$
H_{i t}=\sum_{j=1}^{L_{i}} \frac{E_{t} Y_{i t+j}}{r^{j}}
$$

where $\mathrm{r}$ is the constant real interest rate and $L_{i}$ is the remainder year of a household $i$ 's retirement (i.e., $L_{i}=65-$ initial age, the age of retirement assumes 65 ). We use an average on three-year government bonds during the sample periods for the constant real interest rate (i.e., $\mathrm{r}=0.045$ ) and net wealth for physical wealth. 


\subsection{Estimation Result}

\subsubsection{Aguiar and Bils Estimates}

\subsubsection{Total expenditure elasticity}

Each good's total expenditure elasticity is estimated from Engel curve by using current income as an instrument for total expenditure. Table 4.3 reports average expenditure share of each consumption good out of total expenditures and the estimates of each good's total expenditure elasticity during the third sub-period (2005-2007) and during the fourth sub-period (2008-2009), respectively. To rationalize the key assumption that total expenditure elasticity of each consumption good is invariant over time, we compute correlation among each sup-period's elasticities in Table 4.4. There seems to be strongly positive correlation between elasticities estimated any two sub-periods, but the correlations between period 1 and period 4, between period 1 and period 6, and between period 2 and period 4 are lower than 0.8. So, we use average elasticities of six sub-periods and the average elasticities are highly correlated with elasticites for any sub-period. Figure 4.3 shows two scatter plots: the left panel depicts a scatter plot of total expediture elasticities estimated for 2005-2007 sample versus average elasticities while the right panel replaces total expediture elasticities estimated using 2008-2009 sample with 2005-2007 sample. The linear correlation of the left panel and the right panel is 0.993 and 0.939 , respectively, and the slope of the fitted line is 1.048 with an $R^{2}$ of 0.998 and .993 with an $R^{2}$ of 0.977 corresponding to the each panel. This supports applying average elasticities is not vulnerable to change in estimated elasticities over time.

Figure 4.4 plots the share of total expenditures by income group over the sample period and the graphs are in line with the estimated total expenditure elasticities in Table 4.3. According to Table 4.3, food at home has lowest total expenditure 
Table 4.3: $1^{\text {st }}$ step $\left(\beta_{j}\right)$ from period 3 (2005-2007) and period 4 (2008-2009) in KLIPS

\begin{tabular}{|c|c|c|c|c|}
\hline \multirow[b]{2}{*}{ Consumption Category } & \multicolumn{2}{|c|}{$\underline{2005-2007}$} & \multicolumn{2}{|c|}{ 2008-2009 } \\
\hline & Average Share & Elasticity & Average Share & Elasticity \\
\hline Food at home & $22.8 \%$ & $\begin{array}{c}0.463 \\
(0.014)\end{array}$ & $22.5 \%$ & $\begin{array}{c}0.464 \\
(0.016)\end{array}$ \\
\hline $\begin{array}{l}\text { Rental and utility payment } \\
\text { related to house }\end{array}$ & $20.7 \%$ & $\begin{array}{c}1.684 \\
(0.079)\end{array}$ & $19.8 \%$ & $\begin{array}{l}1.421 \\
(0.067)\end{array}$ \\
\hline Education & $16.8 \%$ & $\begin{array}{l}1.162 \\
(0.030)\end{array}$ & $16.2 \%$ & $\begin{array}{l}1.039 \\
(0.034)\end{array}$ \\
\hline Vehicle maintenance & $12.1 \%$ & $\begin{array}{l}1.083 \\
(0.024)\end{array}$ & $12.1 \%$ & $\begin{array}{l}1.120 \\
(0.027)\end{array}$ \\
\hline Phones and internet expenses & $8.6 \%$ & $\begin{array}{c}0.537 \\
(0.015)\end{array}$ & $7.6 \%$ & $\begin{array}{c}0.509 \\
(0.017)\end{array}$ \\
\hline Food away from home & $4.4 \%$ & $\begin{array}{l}1.606 \\
(0.036)\end{array}$ & $4.7 \%$ & $\begin{array}{l}1.422 \\
(0.036)\end{array}$ \\
\hline Entertainment & $2.2 \%$ & $\begin{array}{l}2.225 \\
(0.071)\end{array}$ & $4.5 \%$ & $\begin{array}{c}1.880 \\
(0.057)\end{array}$ \\
\hline $\begin{array}{l}\text { Family event } \\
\text { (wedding party, funeral, etc.) }\end{array}$ & $4.2 \%$ & $\begin{array}{l}1.268 \\
(0.033)\end{array}$ & $4.2 \%$ & $\begin{array}{l}1.207 \\
(0.036)\end{array}$ \\
\hline Apparel and shoes & $4.0 \%$ & $\begin{array}{l}1.393 \\
(0.032)\end{array}$ & $3.6 \%$ & $\begin{array}{l}1.285 \\
(0.039)\end{array}$ \\
\hline Health expenses & $3.0 \%$ & $\begin{array}{c}0.759 \\
(0.063)\end{array}$ & $3.1 \%$ & $\begin{array}{c}0.729 \\
(0.075)\end{array}$ \\
\hline Durable goods & $1.1 \%$ & $\begin{array}{l}1.975 \\
(0.137)\end{array}$ & $1.2 \%$ & $\begin{array}{l}1.588 \\
(0.129)\end{array}$ \\
\hline Miscellaneous goods & $0.1 \%$ & $\begin{array}{c}2.298 \\
(0.514)\end{array}$ & $0.4 \%$ & $\begin{array}{l}2.877 \\
(0.360)\end{array}$ \\
\hline
\end{tabular}

Note: Estimation results are for all households of the balanced panel and standard errors are in parentheses.

elasticity, $0.463-0.464$ among 12 consumption goods, which means that food at home is a typical necessary good. Other consumption goods with total expenditure elasticity less than 1 are phones and internet expenses and health expenses. The expenditure share of those 3 consumption goods decreases when disposable income increases. On the other hand, miscellaneous goods and entertainment have relative higher total expenditure elasticity and the expenditure share of those goods increase as disposable income increases. 
Table 4.4: Correlation of elasticities estimated in each sub-period

\begin{tabular}{l|ccccccc} 
& Period 1 & Period 2 & Period 3 & Period 4 & Period 5 & Period 6 & AVE. \\
\hline Period 1 & 1.000 & & & & & & \\
Period 2 & 0.983 & 1.000 & & & & & \\
Period 3 & 0.906 & 0.942 & 1.000 & & & & \\
Period 4 & 0.751 & 0.793 & 0.929 & 1.000 & & & \\
Period 5 & 0.818 & 0.865 & 0.968 & 0.973 & 1.000 & & \\
Period 6 & 0.795 & 0.843 & 0.957 & 0.976 & 0.994 & 1.000 & \\
AVE. & 0.922 & 0.950 & 0.993 & 0.939 & 0.974 & 0.964 & 1.000 \\
\hline
\end{tabular}

Note: Period $1=2000-2002$, Period 2=2003-2004, Period 3=2005-2007, Period $4=2008-2009$, Period 5=2010-2011, and Period 6=2012-2015. Each value of last row "AVE." presents correlation between elasticities in each period and average elasticities of six sub-periods.

\subsubsection{Estimation of consumption inequality}

Considering economic definition for total expenditure elasticity, each good $j$ 's total expenditure elasticity is the ratio of percentage change in expenditure on good $j$ to percentage change in total expenditure. Under the assumption of invariant elasticity over time, percentage change in relative expenditure during two consecutive subperiods is proportional to percentage change in total expenditure corresponding to the periods. We simply track the trend in the relative consumption inequality for entertainment over food at home by choosing only two consumption goods: food at home representative of necessary goods and entertainment representative of luxurious goods. We plot the percentage change in the relative expenditure about the top and the bottom quintile bins of income distribution in Figure 4.5. Percentage change in the relative expenditure for the top $20 \%$ income group is higher than the bottom $20 \%$ income group until sub-period 3 (2005-2007), which implies that consumption inequality measured by the ratio of the top $20 \%$ income group to the bottom $20 \%$ income group would increase until 2007. However, the percentage change in relative consumption in the bottom $20 \%$ income group is higher than the top $20 \%$ income group. Therefore, consumption inequality would decrease after 2008. 
Figure 4.3: Stability of expenditure elasticities over time

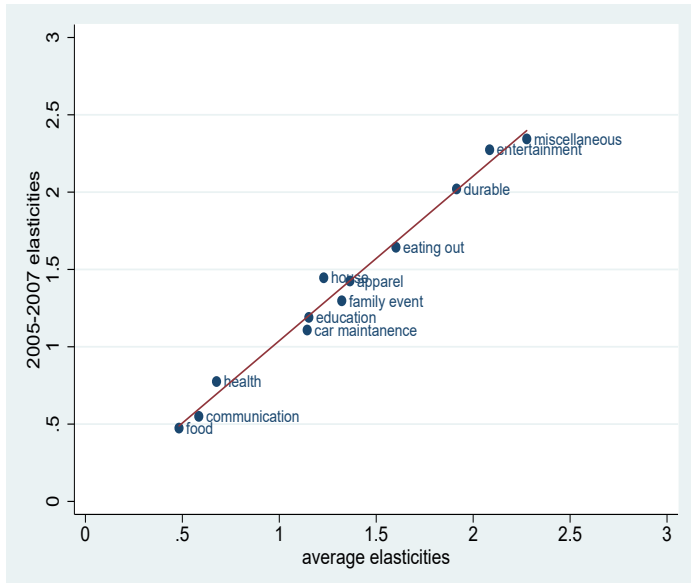

(a) 2005-2007 elasticities

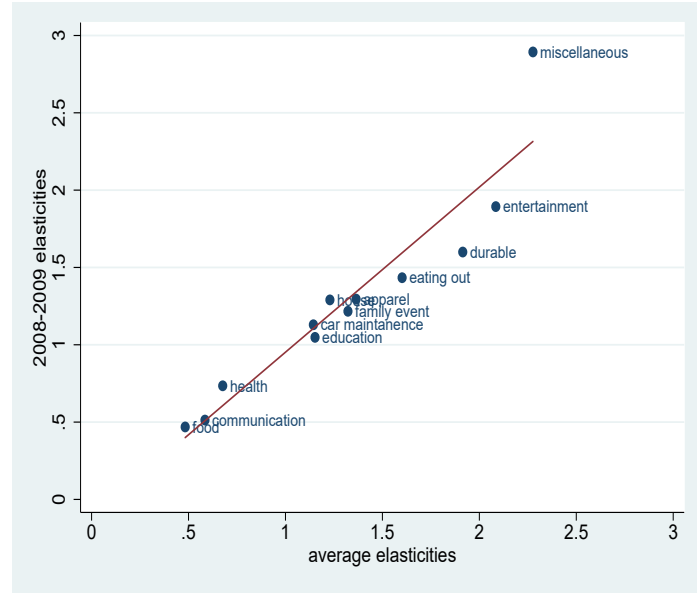

(b) 2008-2009 elasticities

Now, we estimate the relative consumption inequality for all households from equation (4.7). The second and third columns in Table 4.5 use all 12 consumption goods and 7 non-durable consumption goods to estimate the relative consumption inequality adjusted for measurement errors, respectively. Table 4.6 represents log change during two consecutive sub-periods constructed from Table 4.5. Comparing income inequality, income inequality increased until the second sub-period (20032004) and decreased thereafter but consumption inequality increased until the third sub-period (2005-2007) and decreased thereafter. Specifically, consumption inequality increased more than income inequality during the recession caused by the credit card bubble. As the descriptive statistics in Table 4.2, the credit card bubble had a negative effect on net wealth for the bottom income group, which exacerbates consumption inequality because households in the low-income group are more difficult to borrow money to substitute using credit card. During the recovery period from the credit card bubble, income inequality steadily decreased but consumption inequality decreased since the global financial crisis. During the global financial crisis, a decline in consumption inequality of $0.224 \log$ points is higher than a decline in income inequality of $0.024 \mathrm{log}$ points. My estimates confirm the finding of Aguiar and Bils 
Figure 4.4: The share of total expenditure by income group over sample period

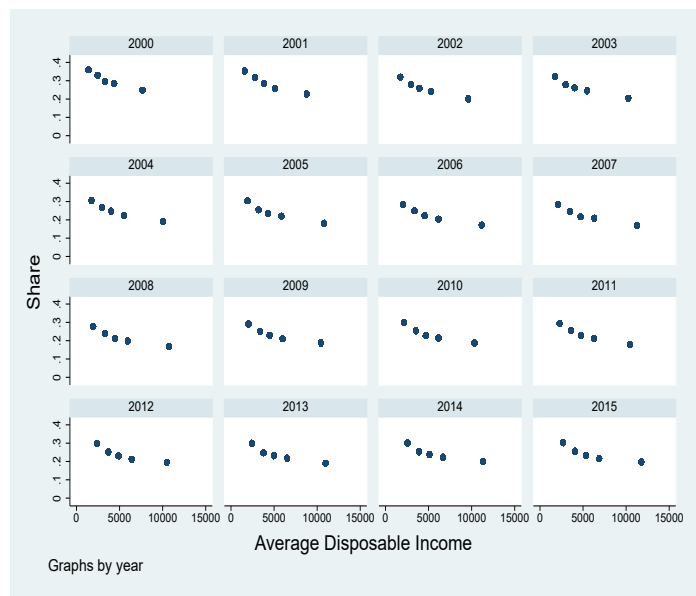

(a) Food at home

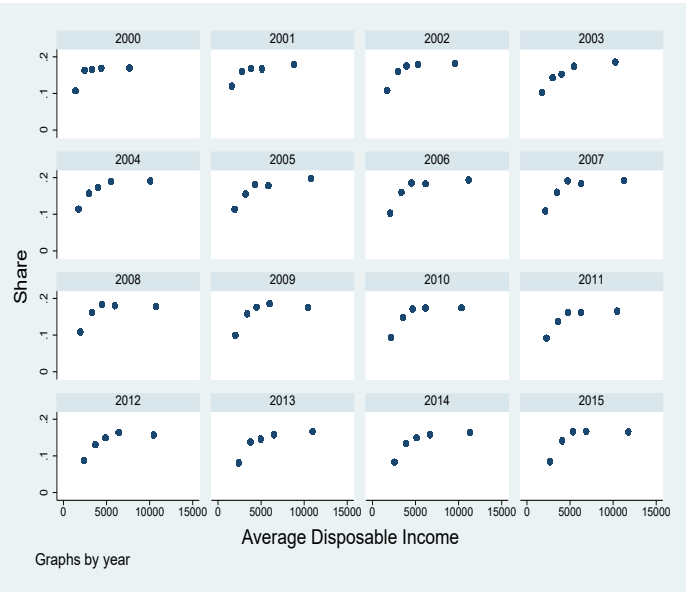

(c) Education

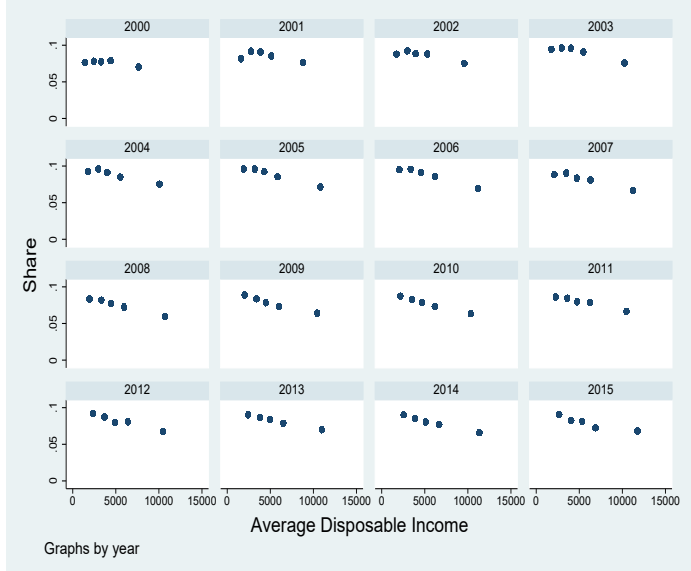

(e) Phones and internet expenses

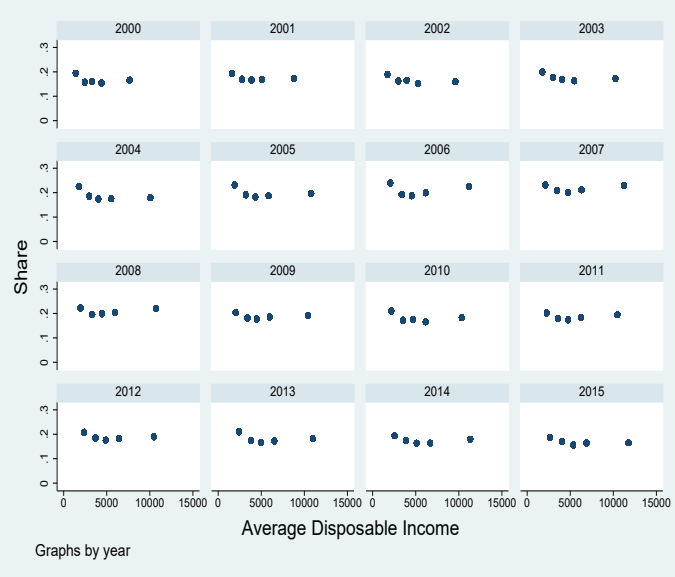

(b) Rental and utility payment related to house

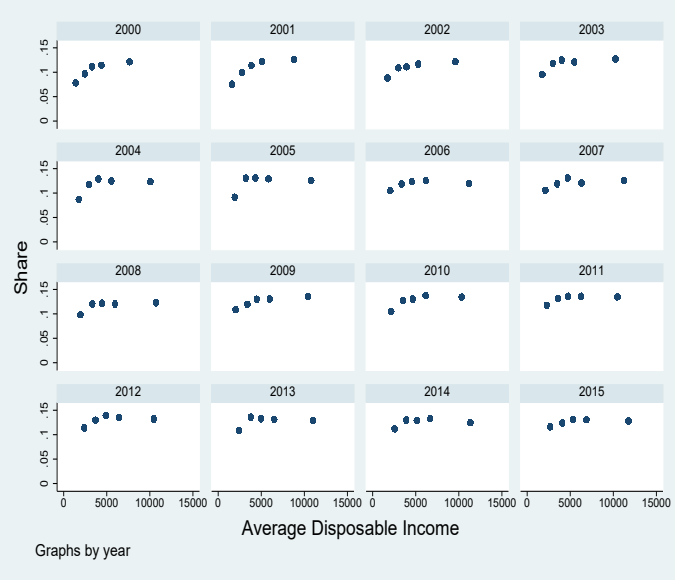

(d) Vehicle maintenance

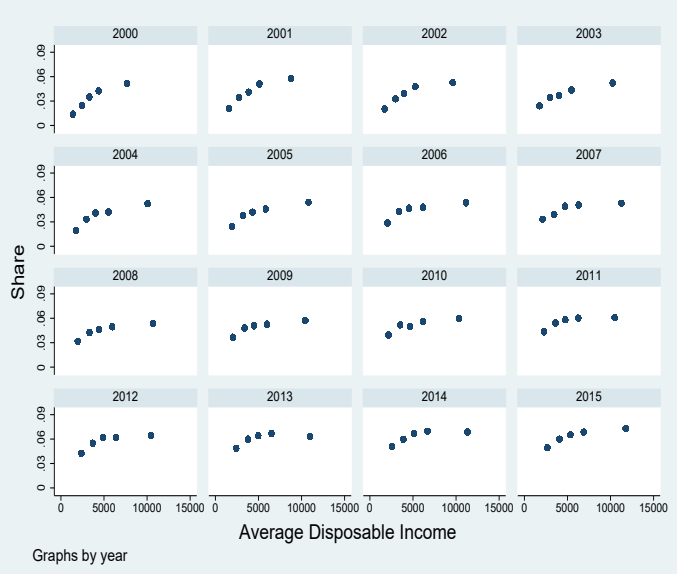

(f) Food away from home 


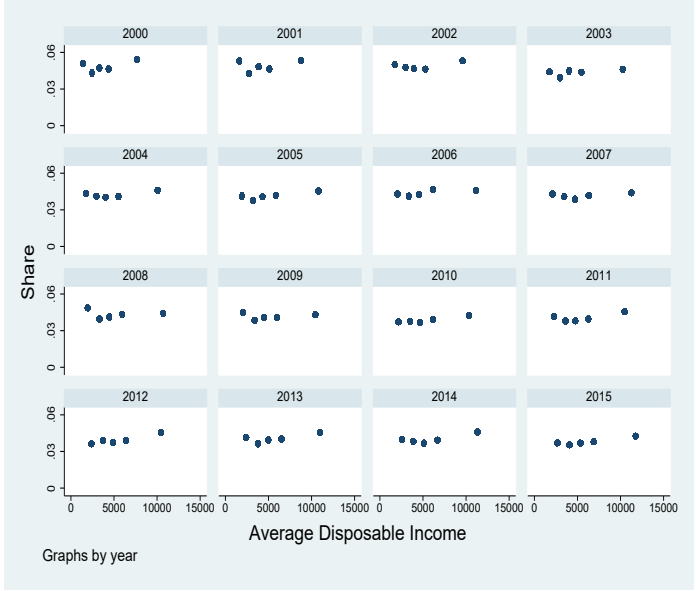

(g) Family event

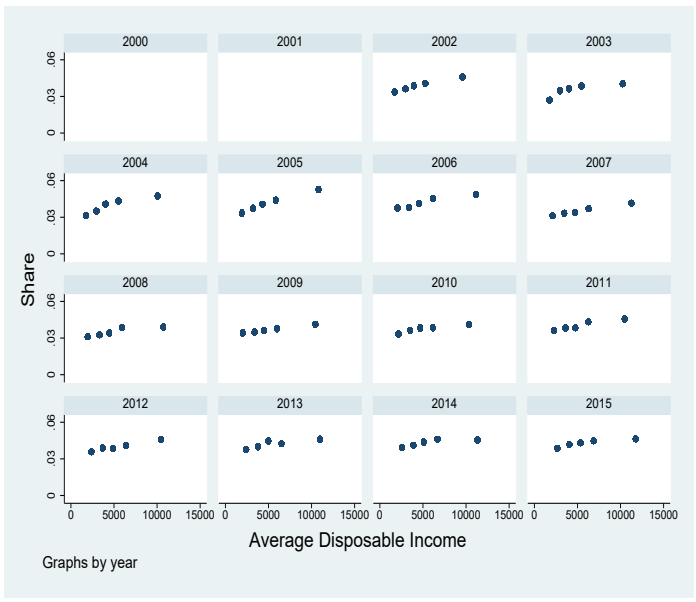

(i) Apparel and shoes

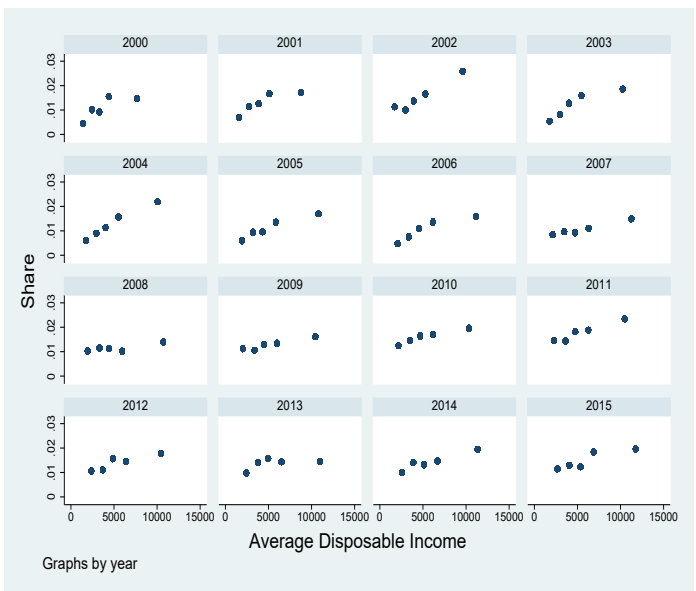

(k) Durable goods

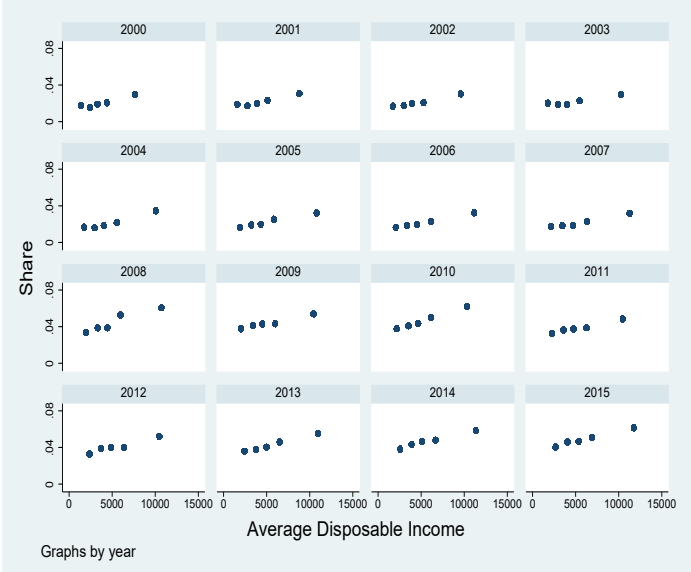

(h) Entertainment

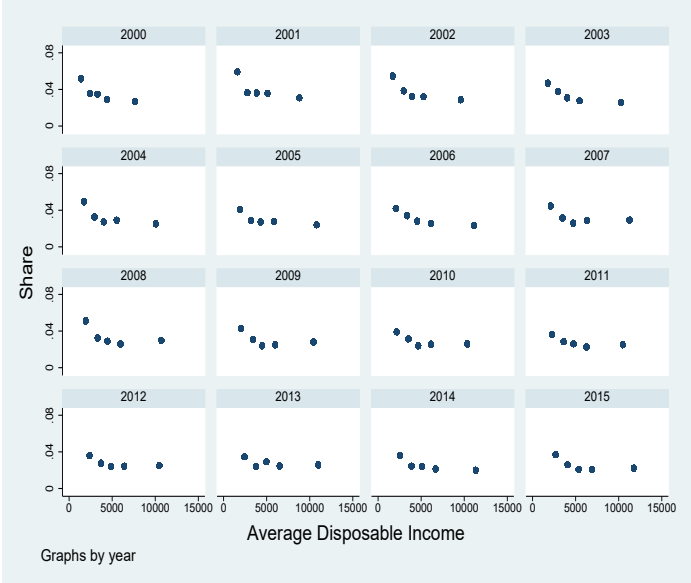

(j) Health expenses

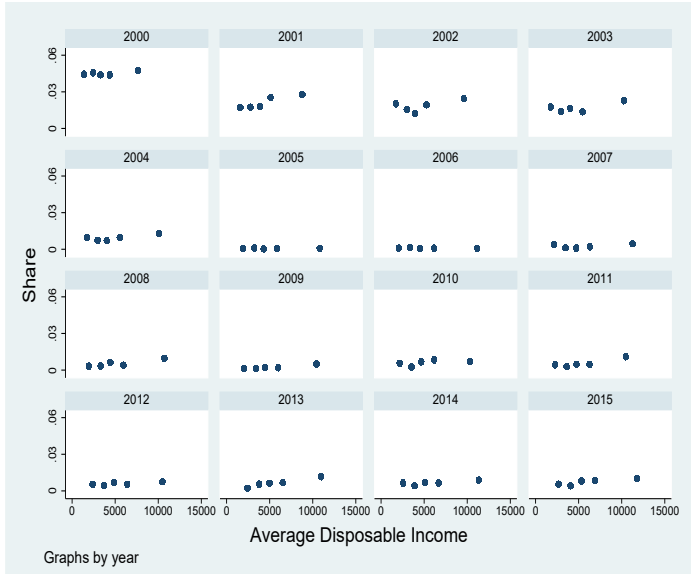

(l) Miscellaneous goods 
Figure 4.5: Percentage change in relative expenditure of entertainment over food at home about high-income and low-income households

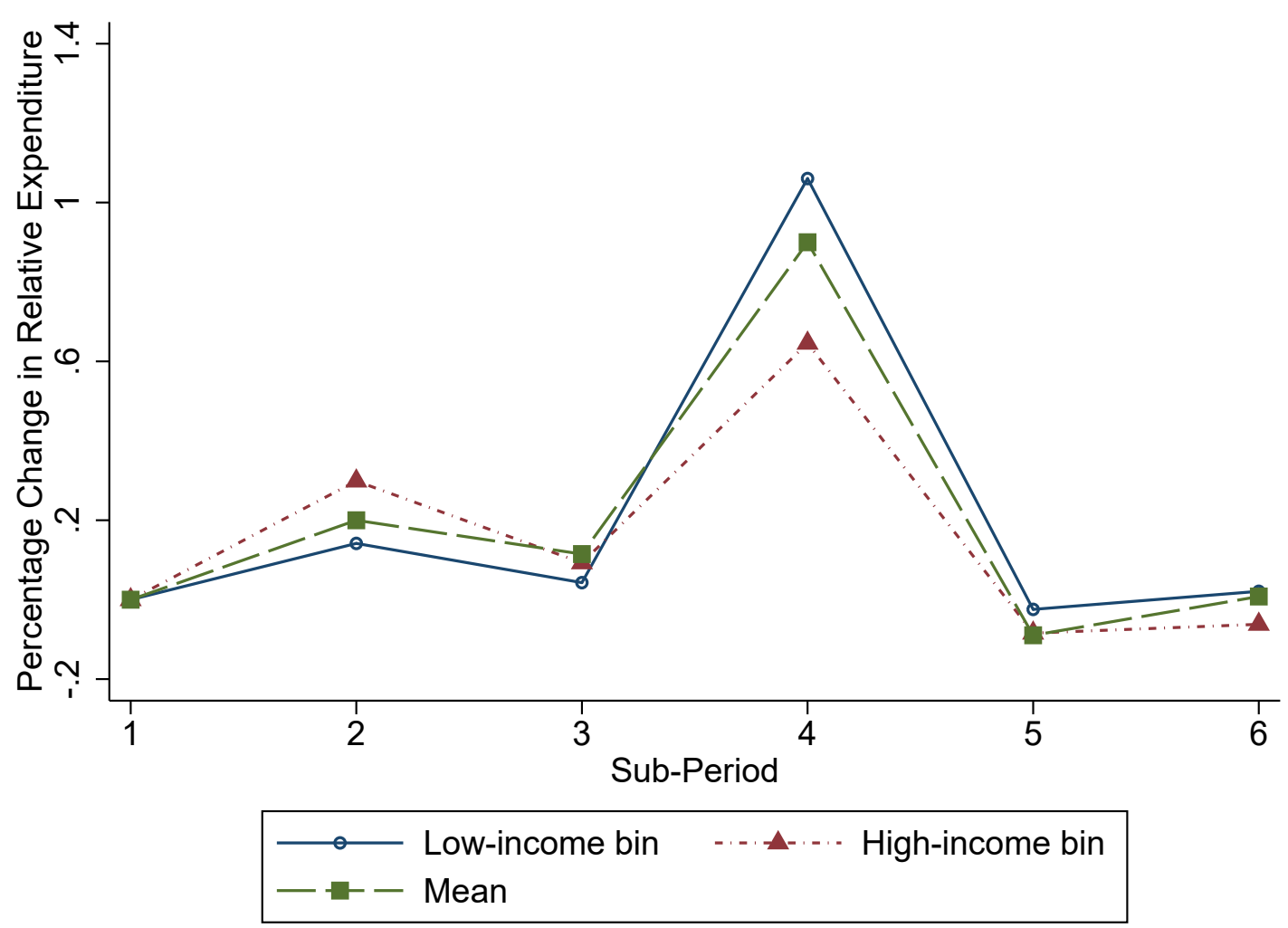

Note: Period $1=2000-2002$, Period 2=2003-2004, Period 3=2005-2007, Period $4=2008-2009$, Period 5=2010-2011, and Period 6=2012-2015.

(2015) that consumption inequality dropped and income inequality slightly increased during the global financial crisis. Since the recovery period of the global financial crisis, both income and consumption inequalities decreased and income inequality declined more than consumption inequality.

Figure 4.6 shows how measurement errors influence consumption inequality. Comparing consumption inequalities with and without adjusting for measurement errors, measurement errors affect the range of consumption inequality as well as the direction of consumption inequality. For example, consumption inequality based on the reported total expenditures decreased but consumption inequality with adjusting for 
Table 4.5: Inequalities for "all households" based on relative expenditure patterns

\begin{tabular}{lccc}
\hline Sub-period & All goods & Non-durables & Income \\
\hline Period 1 (2000-2002) & 2.3153 & 2.3151 & 5.5302 \\
Period 2 (2003-2004) & 2.6859 & 2.6958 & 5.7925 \\
Period 3 (2005-2007) & 3.1876 & 2.8144 & 5.4644 \\
Period 4 (2008-2009) & 2.5473 & 2.4442 & 5.3327 \\
Period 5 (2010-2011) & 2.4447 & 2.3969 & 4.6937 \\
Period 6 (2012-2015) & 2.2760 & 2.2302 & 4.4457 \\
\hline
\end{tabular}

Note: This table shows the estimation results of change in consumption inequality for the top $20 \%$ income group versus the bottom $20 \%$ income group. Second column named by "All goods" uses all 12 consumption goods and third column,

"Non-durables" only uses non-durable consumption goods for estimates applied by weighted least square (WLS) method to adjust average share of each consumption good's share. Finally, the last column represents the ratio of mean for the top $20 \%$ income group to mean for the bottom $20 \%$ income group for disposable income to compare estimated change in consumption inequality.

Table 4.6: Log change for "all households" during the two consecutive sub-periods

\begin{tabular}{lccc}
\hline Sub-period & All goods & Non-durables & Income \\
\hline$(2000-2002) /(2003-2004)$ & 0.1485 & 0.1522 & 0.0463 \\
$(2003-2004) /(2005-2007)$ & 0.1712 & 0.0431 & -0.0583 \\
$(2005-2007) /(2008-2009)$ & -0.2242 & -0.1410 & -0.0244 \\
$(2008-2009) /(2010-2011)$ & -0.0411 & -0.0195 & -0.1276 \\
$(2010-2011) /(2012-2015)$ & -0.0715 & -0.0721 & -0.0543 \\
\hline
\end{tabular}

Note: Log change during the two consecutive sub-periods is constructed from Table 4.5. For example, 0.1485 of log change from period 1 (2000-2002) to period 2 (2003-2004) in the second column is obtained from $\log (2.6859)-\log (2.3153)$.

measurement errors increased in second and third sub-periods of the panel (b). In addition, a difference between the reported and adjusted consumption inequalities depends on income-time specific measurement error during a certain sub-period. If the reported total expenditures of the top income bin relatively overstate (understate) than the bottom income bin, true consumption inequality adjusted for measurement errors would be less (more) than the reported consumption inequality. At the third sub-period of both the panel (a) and (b), the reported expenditures of the top income bin relatively understate than the bottom income bin, which leads consumption 
inequality after adjusting for measurement error to be more than consumption inequality without adjusting for measurement errors.

Figure 4.6: Consumption inequality for "all households" after adjusting for measurement errors

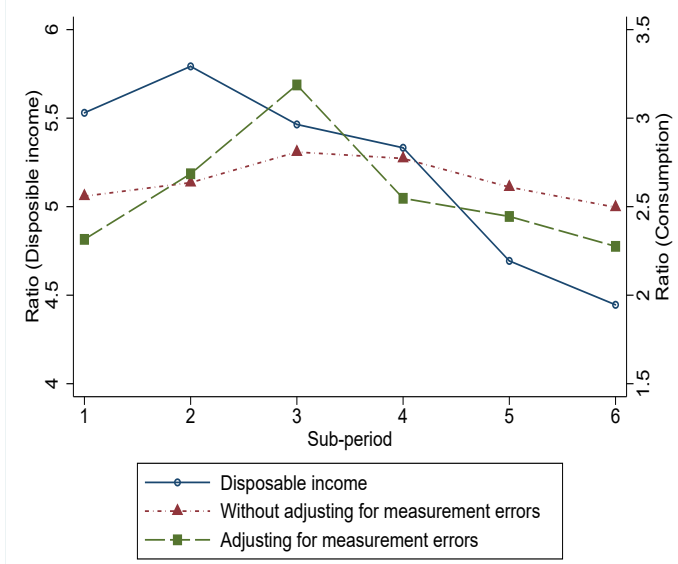

(a) All consumption goods

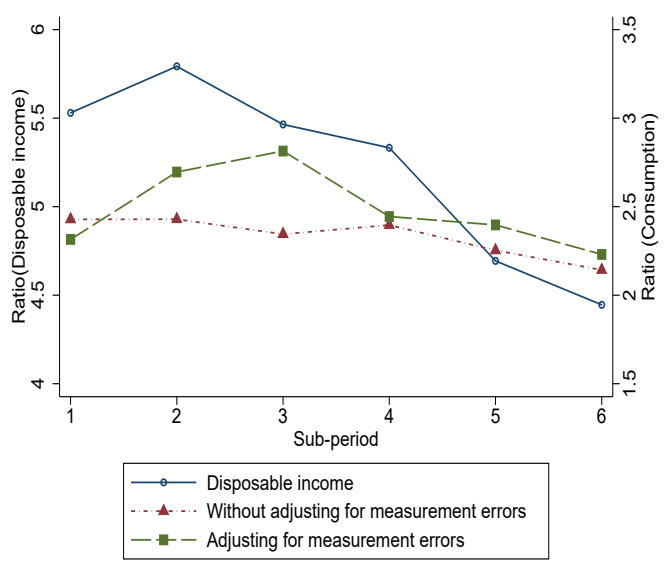

(b) Non-durable consumption goods

Note: Period 1=2000-2002, Period 2=2003-2004, Period 3=2005-2007, Period $4=2008-2009$, Period 5=2010-2011, and Period 6=2012-2015.

\subsubsection{Using $\mathrm{PIH}$ as instrument in the first step}

\subsubsection{Total expenditure elasticity}

We explain two alternative instruments based on permanent income in the section 4.3.2. Table 4.7 reports the estimates of total expenditure elasticity for the balanced panel of 547 households. The total expenditure elasticities in the second column labeled by "Aguiar and Bils" are estimated by using current income as an instrument for total expenditure. The estimates in the third column labeled by "PH1" are estimated by using annuitized lifetime earnings from equation (4.10) as an instrument for total expenditure. The estimates in the last column labeled by "PH2" are estimated 
by using the expected lifetime income from equation (4.13) as an instrument for total expenditure.

Table 4.7: Total expenditure elasticity for "547 households"

\begin{tabular}{lccc}
\hline Consumption Category & Aguiar and Bils & PI1 & PI2 \\
\hline Food at home & 0.515 & 0.488 & 0.441 \\
Rental and utility payment & 1.188 & 1.219 & 1.084 \\
Education & 1.022 & 1.077 & 1.007 \\
Vehicle maintenance & 1.240 & 1.230 & 1.107 \\
Phones and internet expenses & 0.587 & 0.567 & 0.488 \\
Food away from home & 1.792 & 1.759 & 1.541 \\
Entertainment & 2.199 & 2.166 & 1.936 \\
Family event & 1.500 & 1.510 & 1.286 \\
Apparel and shoes & 1.476 & 1.448 & 1.298 \\
Health expenses & 1.111 & 1.051 & 0.859 \\
Durable goods & 2.364 & 1.999 & 1.775 \\
Miscellaneous goods & 1.587 & 1.718 & 1.309 \\
\hline First stage $R^{2}$ & 0.440 & 0.425 & 0.469 \\
\hline
\end{tabular}

Note: The column labeled by "Aguiar and Bils" uses current income as IV for total expenditure. The columns labeled by "PH1" and "PH2" use annutized lifetime earnings and expected lifetime income as IV for total expenditure, respectively.

Like the estimates of total expenditure elasticity for the whole sample, "food at home" and "phones and internet expenses" are necessary goods with the lowest total expenditure elasticity and "entertainment" and "durable goods" are luxurious goods with the highest total expenditure elasticity. Comparing two alterative IVs with Aguiar and Bils's IV based on the first stage $R^{2}$, The model using the expected lifetime income for total expenditure is the best. This means that lifetime income considering future labor income and physical wealth more explains total expenditure than current income.

\subsubsection{Estimation of consumption inequality}

Table 4.8 represents the estimates of relative consumption inequality for the balanced panel of 547 households. Figure 4.7 plots the trends in consumption inequality for 
all consumption goods and for non-durable goods constructed from Table 4.8. Whatever instruments for total expenditure the trend in consumption inequality does not change over time. Moreover, about log changes in consumption inequality during two consecutive sub-periods, the model using Aguiar and Bils instrument is nearly identical to the model with two alternative instruments. The only different thing is the level of consumption inequality adjusted for measurement errors. Specifically, the level of consumption inequality adjusted for measurement error based on "PI2" is 2.0236 for all households in Period 1, which is higher by 0.22 than the consumption inequality based on "AB" and "PI1" in the same period. This implies that the procedure of Aguiar and Bils (2015) depends on total expenditure elasticity of consumption commodity and the relative consumption inequality would be affected by an instrument for total expenditure in the first stage regression.

Table 4.8: Trends in consumption inequality based on different instruments for "547 households"

\begin{tabular}{l|cc|cc|cc} 
& \multicolumn{2}{|c|}{ Aguiar and Bils } & \multicolumn{2}{c}{ PI1 } & \multicolumn{2}{c}{ PI2 } \\
Sub-period & All goods & Non-durables & All goods & Non-durables & All goods & Non-durables \\
\hline Period 1 & 1.7976 & 1.8594 & 1.7982 & 1.8137 & 2.0236 & 2.0621 \\
Period 2 & 2.1722 & 2.1706 & 2.1654 & 2.1500 & 2.4102 & 2.4395 \\
Period 3 & 2.0499 & 1.9869 & 2.0443 & 1.9667 & 2.2815 & 2.2276 \\
Period 4 & 1.8990 & 2.0087 & 1.9094 & 1.9930 & 2.0458 & 2.1876 \\
Period 5 & 1.9644 & 2.0180 & 1.9901 & 2.0008 & 2.1484 & 2.2015 \\
Period 6 & 2.0532 & 2.2152 & 2.0944 & 2.1964 & 2.0944 & 2.3222 \\
\hline
\end{tabular}

Note: Period $1=2000-2002$, Period $2=2003-2004$, Period $3=2005-2007$, Period $4=2008-2009$, Period $5=2010-2011$, and Period $6=2012-2015$. The relative consumption inequality for 547 households estimates equation (4.7). The columns named by "Aguiar and Bils", "PI1" and "PI2" represent estimates corresponding to IVs in Table 4.7. 
Figure 4.7: Consumption inequality for "547 households"

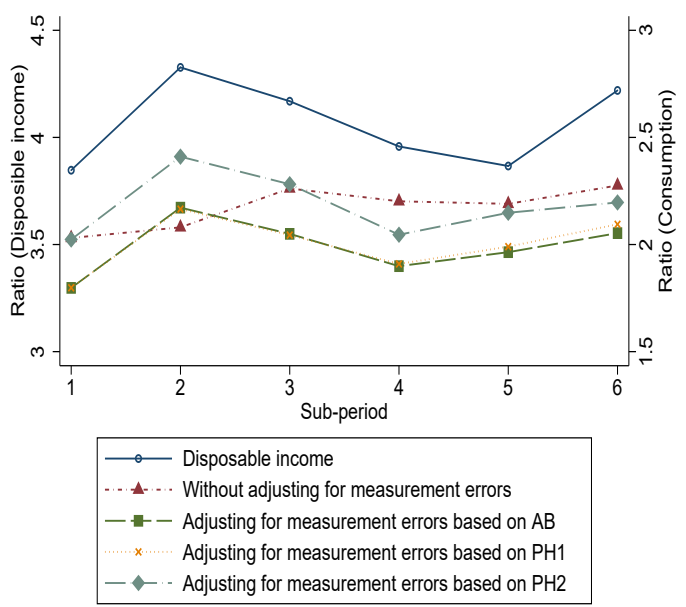

(a) All goods

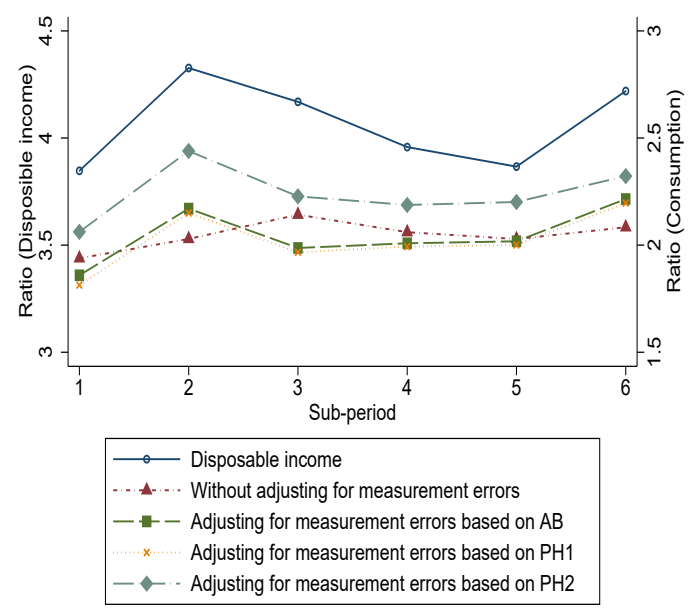

(b) Non-durable goods

The panel (a) and (b) represents inequality trends constructed from Table 4.8. "AB", "PI1", and "PI2" use current income, annuitized lifetime earnings, and expected lifetime income as an instrument for total expenditure, respectively. Period $1=2000-2002$, Period 2=2003-2004, Period 3=2005-2007, Period $4=2008-2009$, Period 5=2010-2011, and Period 6=2012-2015. 


\subsection{Conclusion}

The objective of this paper is to construct new proxy for permanent income to estimate Engel curve and to analyze how Aguiar and Bils specification for consumption inequality reacts to different total expenditure elasticity caused by using different instruments in a Korean household panel data. The double differencing correction method developed by Aguiar and Bils (2015) can eliminate three types of measurement errors (i.e., good-time specific measurement error, income-time specific measurement error, and good-household-time specific measurement error) from the reported total expenditure. Consumption inequality is measured by the ratio of average total expenditure of the top quintile income bin to average total expenditures of the bottom quintile income bin. The instrument based on PIH is better than current income suggested by Aguiar and Bils to estimate Engel curve, which leads to different level of consumption inequality compared with Aguiar and Bils specification even though the trend in consumption inequality is similar.

We also find from the estimates of consumption inequality for the whole sample that as income inequality has a downward trend, consumption inequality has decreased since the global financial crisis. Specifically, compared to previous sub-period, the log change of consumption inequality for all consumption goods (non-durable consumption goods) is $0.224(0.141) \log$ points more than the decline in income inequality of $0.024 \log$ points during the global financial crisis. After the global financial crisis, both income and consumption inequalities have steadily decreased and the width of decrease in income inequality is bigger than a decline in consumption inequality. The trend in income inequality changed from upward slope to downward slope at mid-2000s, whereas consumption inequality continues to increase before the global financial crisis and starts to decrease since the global financial crisis (i.e., 2008-2009).

This paper focuses on how a household allocates their expenditure on each consumption good given their total expenditure and how much difference there is in the 
share of expenditure on a luxury good and a necessary good between the top-income group households and the bottom-income group households over time. We show the trend of income and consumption inequalities declines and how measurement errors in the reported expenditures influence consumption inequality. After adjusting for measurement errors, decline in consumption inequality tracks that of income inequality more closely, which is similar to the Aguiar and Bils (2015) for the U.S. where consumption inequality tracks income inequality during an upward trend in income inequality. We also show the procedure of Aguiar and Bils (2015) would depend on instruments for total expenditure. This study does not answer why both inequalities decrease in South Korea since the late 2000s. Future research addressing the lifecycle model (Kaplan and Violante (2010)) and income uncertainty would be helpful to explain the decrease in income and consumption inequalities in South Korea. 


\section{Appendix A}

\section{Appendix to Chapter 2}

\section{A.1 Sample Selection}

\section{A.1.1 Test for bias in sample attrition}

Let an interesting model assume the linear parametric model:

$$
y_{t}=\beta_{0}+\beta_{1} x_{t}+\epsilon_{t}, y_{t} \text { observed if } A_{t}=0
$$

where $x_{t}$ is an independent variable (a vector is possible), $\epsilon_{t}$ is a random variable with zero mean, and $A_{t}$ is attrition indicator (a.g., $A_{t}=1$ if an observation, $y_{t}$ is missing at time $t$ because of attrition). As the density of primary interest is $f\left(y_{t} \mid x_{t}\right)$, if $f\left(y_{t} \mid x_{t}\right) \neq f\left(y_{t} \mid x_{t}, A_{t}=0\right)$ which is conditional on $x_{t}$ and $A_{t}=0$, attrition bias occurs. Let the attrition function be

$$
A_{t}^{*}=\delta_{0}+\delta_{1} x_{t}+\delta_{2} z_{t}+v_{t} .
$$


Table A.1: Response and nonresponse rates for original 5,000 households in KLIPS

\begin{tabular}{ccccc} 
Year & Remaning in sample & Attritors & Cumulative rate & In from attritors \\
\hline 1997 & 5,000 & & & \\
1998 & 4,378 & 622 & $12.44 \%$ & \\
1999 & 4,044 & 483 & $19.12 \%$ & 149 \\
2000 & 3,866 & 430 & $22.68 \%$ & 252 \\
2001 & 3,798 & 290 & $24.04 \%$ & 222 \\
2002 & 3,862 & 271 & $22.76 \%$ & 335 \\
2003 & 3,862 & 223 & $22.76 \%$ & 223 \\
2004 & 3,822 & 218 & $23.56 \%$ & 178 \\
2005 & 3,820 & 185 & $23.60 \%$ & 183 \\
2006 & 3,775 & 163 & $24.50 \%$ & 118 \\
2007 & 3,710 & 181 & $25.80 \%$ & 116 \\
2008 & 3,658 & 193 & $26.84 \%$ & 141 \\
2009 & 3,607 & 191 & $27.86 \%$ & 140 \\
2010 & 3,528 & 167 & $29.44 \%$ & 88 \\
2011 & 3,517 & 98 & $29.66 \%$ & 87 \\
2012 & 3,472 & 118 & $30.56 \%$ & 73 \\
2013 & 3,451 & 68 & $30.98 \%$ & 47 \\
2014 & 3,421 & 81 & $31.58 \%$ & 51 \\
2015 & 3,393 & 68 & $32.14 \%$ & 40 \\
\hline
\end{tabular}

$$
\begin{aligned}
A_{t} & =1 \text { if } A_{t}^{*} \geq 0 \\
& =0 \text { if } A_{t}^{*}<0,
\end{aligned}
$$

where $A_{t}^{*}$ is a latent index and $z_{t}$ is an auxiliary variable which is not included in explanatory variable, $x_{t}$. Attrition bias is attributed by i) selection on observables $\left(\operatorname{Pr}\left(A_{t}=0 \mid y_{t}, x_{t}, z_{t}\right)=\operatorname{Pr}\left(A_{t}=0 \mid x_{t}, z_{t}\right)\right)$ and ii $)$ selection on unobservables $\left(\operatorname{Pr}\left(A_{t}=\right.\right.$ $\left.\left.0 \mid y_{t}, x_{t}, z_{t}\right) \neq \operatorname{Pr}\left(A_{t}=0 \mid x_{t}, z_{t}\right)\right)$. According to Fitzgerald et al. (1998), the BGLW test developed by Becketti et al. (1988) can be used for attrition bias caused by selection on observables and another data set with much less attrition and comparable to KLIPS are used for test on attrition bias caused by selection on unobservables. Here, we test for attrition bias due to selection on observables. 
Table A.2: Drop-out sample

\begin{tabular}{l|c} 
Sample selection method & Number of households \\
\hline \hline One-person household & 560 \\
No-head or no-spouse household & 675 \\
Separate household & 351 \\
Head age (age $<25$ or age $>65)$ & 736 \\
Labor income (zero or missing report) & 650 \\
Not participation on whole survey & 1483 \\
\hline \hline Total & 4455 \\
\hline
\end{tabular}

An auxiliary variable, $z_{t}$ should be observed for both attritors as well as nonattritors and do not affect attrition, $A_{t}$ (Fitzgerald et al. (1998), Alderman et al. (2001)). Fitzgerald et al. (1998) suggest labor income of initial wave as $z_{t}$ for the test on attrition bias and we use labor income in 1997 for $z_{t}$. To find the effect of household's characteristics on attrition rate, we compare simple statistics about household's characteristics between "Always in" to represent non-attritors group and "Ever out except death" to represent attritors group in Table A.3. According to Table A.3, "Always in" and "Ever out except death" groups have statistical differences in characteristics such as age, education, number of children, and residential city under the $10 \%$ of significant level. High income households tend to be attritors but not statistically significant at the $10 \%$ level. 
Table A.3: 1997 characteristics by attrition: Age 25-64

Always in Ever out Ever out(died) Ever out(not died)

\begin{tabular}{|c|c|c|c|c|}
\hline Age & 45.6 & $42.1^{*}$ & $53.2^{*}$ & $41.1^{*}$ \\
\hline Male heads & $88.6 \%$ & $87.9 \%$ & $73.0 \%^{*}$ & $89.4 \%$ \\
\hline \multicolumn{5}{|l|}{ Education: } \\
\hline$<12$ & $41.6 \%$ & $27.3 \% *$ & $63.5 \% *$ & $23.8 \% *$ \\
\hline 12 & $39.0 \%$ & $37.9 \%$ & $29.7 \%$ & $38.7 \%$ \\
\hline $13-16$ & $16.8 \%$ & $30.6 \% *$ & $4.1 \% *$ & $33.2 \%^{*}$ \\
\hline$>16$ & $2.5 \%$ & $4.2 \% *$ & $2.7 \%$ & $4.3 \% *$ \\
\hline Own home & $60.3 \%$ & $46.2 \% *$ & $56.8 \%$ & $45.1 \% *$ \\
\hline \multicolumn{5}{|c|}{ Annual household's disposable income for those $\mathrm{w} /$ income $>0$ : } \\
\hline Mean & 3,088 & 3,107 & $1,518^{*}$ & 3,253 \\
\hline 10 percentile & 859 & 619 & 25 & 999 \\
\hline 50 percentile & 2,797 & 2,597 & 1,199 & 2,797 \\
\hline 90 percentile & 5,694 & 5,994 & 3,996 & 5,994 \\
\hline Var. of log income & 2.517 & $4.144^{*}$ & $10.270^{*}$ & $3.069^{*}$ \\
\hline \multicolumn{5}{|c|}{ Annual household's consumption for those w/ consumption $>0$ : } \\
\hline Mean & 2,079 & 2,083 & $1,400^{*}$ & 2,149 \\
\hline 10 percentile & 799 & 599 & 300 & 799 \\
\hline 50 percentile & 1,998 & 1,798 & 999 & 1,998 \\
\hline 90 percentile & 3,796 & 3,996 & 2,997 & 3,996 \\
\hline Var. of log consumption & 1.092 & $1.355^{*}$ & $2.157^{*}$ & 1.192 \\
\hline Num. of children & 1.1 & 1.1 & $0.3^{*}$ & $1.2^{*}$ \\
\hline Bigcity & $55.8 \%$ & $60.9 \% *$ & $48.6 \%$ & $62.1 \% *$ \\
\hline Sample size & 1,931 & 836 & 74 & 762 \\
\hline
\end{tabular}

Note:* represents significant difference from "Always in" at $10 \%$ level and the unit of household's disposable income and consumption is ten thousands Korean Won. 
Table A.4 represents whether labor income of initial wave affect an attrition. Based on the results estimated by the probit model, household labor income in 1997 does not statistically affect an attrition regardless of conditioning on other observable variables such as age, education, family size, residential city and so on. This implies that labor income in 1997 is suitable for an auxiliary variable.

Table A.4: Ever-Out attrition probits for household labor income

\begin{tabular}{lcccccc} 
& \multicolumn{2}{c}{ Model 1 } & \multicolumn{2}{c}{ Model 2 } & \multicolumn{2}{c}{ Model 3} \\
& Coeff. & $\partial p / \partial x$ & Coeff. & $\partial p / \partial x$ & Coeff. & $\partial p / \partial x$ \\
\hline Intercept & $-0.897^{*}$ & & $-0.897^{*}$ & & $-0.857^{*}$ & \\
Income $^{a)}$ & 0.014 & 0.004 & 0.018 & 0.005 & -0.019 & -0.005 \\
No income & -0.094 & -0.024 & -0.103 & -0.026 & -0.043 & -0.011 \\
Squared income $^{b)}$ & & & -0.022 & -0.006 & 0.070 & 0.017 \\
Age & & & & 0.016 & 0.004 \\
Squared age & & & & -0.342 & -0.085 \\
Male head $^{a)}$ & & & & -0.029 & -0.007 \\
Own house & & & & $-0.139^{*}$ & $-0.035^{*}$ \\
Education $<12$ & & & & $-0.114^{*}$ & $-0.028^{*}$ \\
Education $>13$ & & & & $0.270^{*}$ & $0.067^{*}$ \\
Bigcity & & & & 0.025 & 0.006 \\
Pseudo R & & & & & & 0.0323 \\
Log Like. & 0.0006 & -2024.27 & & & -1960.10 \\
\hline
\end{tabular}

Note: Ever-out attritors due to death are excluded and ${ }^{*}$ represents significance at $10 \%$ level. Also, ${ }^{a)}$ and ${ }^{b)}$ mean the coefficient and marginal effect are multiplied by $10^{3}$ and $10^{8}$, respectively. 
We implement BGWL test on whether effects of respondent's characteristics on auxiliary variable between total sample and nonattriting sample are different. If the test result is statistically insignificant, attrition bias caused by selection on observables is ignorable (Alderman et al. (2001)). Comparing the effects of respondent's characteristics on an auxiliary variable, variables related to age only are significantly different at the $10 \%$ level between two groups. However, the magnitude of differences are not large, which means that the attrition on observables is not ignorable but the effects of attrition on the coefficients, $\beta$ are not huge. In the case of the appearance of attrition bias, the residual, $\epsilon_{t}$ is larger than the residual under the unbiased estimators of $\beta$ and the inequality of the residuals extracted from the equation (2.1) would be slightly overstated because of attrition bias.

Table A.5: $1997 \log$ household labor income for BGLW test.

\begin{tabular}{l|ccc} 
& Total & Always in & Difference \\
\hline \hline Intercept & $5.422^{*}$ & $4.927^{*}$ & $0.495^{*}$ \\
Age & $0.090^{*}$ & $0.111^{*}$ & $-0.021^{*}$ \\
Squared age $^{a)}$ & $-0.099^{*}$ & $-0.122^{*}$ & $0.023^{*}$ \\
Male head & $0.388^{*}$ & $0.453^{*}$ & -0.065 \\
Own house & $0.112^{*}$ & $0.102^{*}$ & 0.010 \\
edu $<12$ & $-0.272^{*}$ & $-0.291^{*}$ & 0.019 \\
edu $>13$ & $0.334^{*}$ & $0.296^{*}$ & 0.038 \\
Bigcity & $0.115^{*}$ & $0.109^{*}$ & 0.006 \\
\hline \hline Sample size & 3,857 & 1,729 \\
Adj. R & 0.2135 & 0.2065 & \\
\hline
\end{tabular}

Note: Ever-out attritors due to death are excluded and ${ }^{*}$ represents significance at $10 \%$ level. Also, ${ }^{a)}$ means the coefficient is multiplied by 100 . 


\section{A.2 Moment Conditions of $\frac{1}{\mathrm{~N}} \mathbf{Y}^{\prime} \mathbf{Y}$}

\section{A.2.1 Estimation}

We estimate model using the Method of Simulated Moment (MSM). The estimator $\boldsymbol{\beta}$ minimizes the weighted distance between empirical moments $m^{e}$ and model based constructed moment conditions $m^{c}$ :

$$
\min _{\boldsymbol{\beta}}\left[m^{e}-m^{c}(\boldsymbol{\beta})\right]^{\prime} \Lambda\left[m^{e}-m^{c}(\boldsymbol{\beta})\right]
$$

where $\Lambda$ is a weighting matrix, and the elements in the main diagonal of inverse of $V$ are used as $\Lambda\left(\Lambda=\operatorname{diag}\left(V^{-1}\right)\right)$. $V$ denotes the variance-covariance matrix of $m^{e}$.

Standard errors of the MSM estimator is given by:

$$
\widehat{\operatorname{var}(\hat{\beta})}=\left(M^{\prime} \Lambda M\right)^{-1} M^{\prime} \Lambda V \Lambda M\left(M^{\prime} \Lambda M\right)^{-1},
$$

where $M$ measures the sensitivity of the moments to small changes of unknown parameter values $\left(M=\partial m^{c} /\left.\partial \beta\right|_{\beta=\hat{\beta}}\right)$. The derivative can be computed numerically.

\section{A.2.2 RIP Model}

$$
\text { RIP Model : } y_{i t}=P_{i t}+v_{i t} \text {. }
$$

The permanent component is

$$
P_{i t}=P_{i t-1}+\zeta_{i t}
$$

where $\zeta$ is permanent income shock with variance $\sigma_{i, t, \zeta}^{2}$, and the transitory component is $v_{i t}=\sum_{j=0}^{p} \theta_{j} \xi_{i, t-j}, \xi_{i, t}$ is transitory income shock, with variance $\sigma_{t, \xi}^{2}$.

We assume $\theta_{j}=1$ for $j=0, \theta_{j}=\theta$ for $j=1$, and $\theta_{j}=0$ for $j>1$, i.e., $v_{i t}=\xi_{i, t}+\theta \xi_{i, t-1}$ 
Identification assumption: $\xi_{i, t}$ independent of $\xi_{i, j}$ for $j \neq t$, and $\xi_{i, t}$ independent of $\zeta_{i, k}$ for all $k$.

Independence between the permanent and transitory shocks implies $\operatorname{var}\left(y_{i t}\right)=$ $\operatorname{var}\left(P_{i t}\right)+\operatorname{var}\left(v_{i t}\right)$,

$$
\begin{aligned}
\operatorname{cov}\left(v_{i t}, v_{t+j}\right)=\operatorname{var}\left(v_{i t}\right) & =\sigma_{\xi_{t}}^{2}+\theta^{2} \sigma_{\xi_{t-1}}^{2} \text { for } j=0 \\
& =\theta \sigma_{\xi_{t}}^{2} \text { for } j=1 \\
& =0 \text { for } j>1 .
\end{aligned}
$$

Independence between the permanent and transitory shocks implies $\operatorname{var}\left(y_{i t}\right)=$ $\operatorname{var}\left(P_{i t}\right)+\operatorname{var}\left(v_{i t}\right)$, From the assumptions of the idiosyncratic shocks,

$$
y_{i t}=P_{i 1}+\sum_{k=2}^{t} \zeta_{i k}+v_{i t}
$$

with $E\left(\zeta_{i t}\right)=E \zeta_{i t+j}=0 E\left(\zeta_{i t}\right)^{2}=\sigma_{\zeta, t}^{2} ; v_{i t}=\xi_{i, t}+\theta_{1} \xi_{i, t-1}$, with $E\left(\xi_{i t}\right)=0 E\left(\xi_{i t}\right)^{2}=$ $\sigma_{\xi, t}^{2} . E\left(\zeta_{i t} \xi_{t+j}\right)=0$.

Under these assumptions the elements of covariance $\operatorname{var}\left(y_{t}\right)$ are

$$
\operatorname{var}\left(y_{1}\right)=\operatorname{var}\left(P_{i 1}\right)+\sigma_{\xi, 1}^{2}+\theta^{2} \sigma_{\xi, 0}^{2}
$$

For $t=2, . . T$

$$
\operatorname{var}\left(y_{i t}\right)=\operatorname{var}\left(P_{i 1}+\sum_{k=1}^{t} \zeta_{i k}+v_{i t}\right)=\operatorname{var}\left(P_{1}\right)+\sum_{k=2}^{t} \sigma_{\zeta, k}^{2}+\sigma_{\xi, t}^{2}+\theta^{2} \sigma_{\xi, t-1}^{2}
$$

for $\mathrm{t}=1, . ., \mathrm{T}-1$,

$$
\begin{aligned}
\operatorname{cov}\left(y_{i t}, y_{i t+1}\right) & =\operatorname{cov}\left(P_{i 0}+\sum_{k=1}^{t} \zeta_{i k}+v_{i t}, P_{i 0}+\sum_{k=1}^{t+1} \zeta_{i k}+v_{i t+1}\right) \\
& =\operatorname{var}\left(P_{0}\right)+\sum_{k=1}^{t} \sigma_{\zeta, k}^{2}+\theta_{1} \sigma_{t, \xi}^{2}
\end{aligned}
$$


and for $2 \leq j \leq T-t$

$$
\begin{aligned}
\operatorname{cov}\left(y_{i t}, y_{i t+j}\right) & =\operatorname{cov}\left(P_{i 1}+\sum_{k=2}^{t} \zeta_{i k}+v_{i t}, P_{i 1}+\sum_{k=2}^{t+j} \zeta_{i k}+v_{i t+j}\right) \\
& =\operatorname{var}\left(P_{1}\right)+\sum_{k=2}^{t} \sigma_{\zeta, k}^{2} .
\end{aligned}
$$

In the initial period $\operatorname{var}\left(P_{i 1}\right)$ and $\sigma_{\zeta, 1}^{2}$ are observationally equivalent. We estimate $\operatorname{var}\left(P_{i 1}\right)$ instead of $\sigma_{\zeta, 1}^{2}$.

From

$$
\begin{gathered}
\operatorname{cov}\left(y_{i 1}, y_{i 2}\right)-\operatorname{cov}\left(y_{i 1}, y_{i 3}\right)=\theta \sigma_{\xi_{0}}^{2} \\
\operatorname{var}\left(y_{i 1}\right)-\operatorname{cov}\left(y_{i 1}, y_{i 3}\right)=\sigma_{\xi_{1}}^{2}+\theta^{2} \sigma_{\xi_{0}}^{2} \\
\operatorname{cov}\left(y_{i 2}, y_{i 3}\right)-\operatorname{cov}\left(y_{i 2}, y_{i 4}\right)=\theta \sigma_{\xi_{1}}^{2}
\end{gathered}
$$

From (A.8), (A.9), and (A.10) one can solve for $\theta, \sigma_{\xi_{1}}^{2}, \sigma_{\xi_{0}}^{2}$. Plugging (A.9) to $\operatorname{var}\left(y_{i 1}\right)$ solves $\operatorname{var}\left(P_{i 1}\right)$.

For $\mathrm{t}=2, . . \mathrm{T}-1, \sigma_{\xi_{t}}^{2}$ can be identified from $\operatorname{cov}\left(y_{i t}, y_{i t+1}\right)$, and then $\sigma_{\zeta_{t}}^{2}$ from $\operatorname{var}\left(y_{i t}\right)$.

At the end of the sample period, with $\operatorname{var}\left(P_{0}\right)=0$ and $\sigma_{\xi_{18}}^{2}$ identified, $\operatorname{var}\left(y_{i 19}\right)=$ $\sum_{k=1}^{19} \sigma_{\zeta_{k}}^{2}+\sigma_{\xi_{19}}^{2}+\theta^{2} \sigma_{\xi_{18}}^{2}$. We can only identify $\sigma_{\zeta_{19}}^{2}+\sigma_{\xi_{19}}^{2}$ but not $\sigma_{\zeta_{19}}^{2}$ and $\sigma_{\xi_{19}}^{2}$ separately because in the last period we cannot distinguish permanent from transitory shocks.

\section{Identified Parameters in RIP}

A total of $2 T$ parameters $(\mathrm{T}=19)$ can be identified: $V\left(P_{1}\right)\left(\right.$ or $\left.\sigma_{1, \zeta}^{2}\right), \sigma_{t, \xi}^{2}(\mathrm{t}=0, . ., \mathrm{T}-$ 1) and $\sigma_{t, \zeta}^{2}(\mathrm{t}=2, . ., \mathrm{T}-1), \theta$.

\section{A.2.3 Alternative Identification of RIP based on BPP}

Under RIP income growth becomes

$$
\Delta y_{i t}=\zeta_{i t}+\Delta v_{i t}
$$


The second moments are

$$
\operatorname{cov}\left(\Delta y_{t}, \Delta y_{t+s}\right)= \begin{cases}\operatorname{var}\left(\zeta_{t}\right)+\operatorname{var}\left(\Delta v_{t}\right), & \text { for } s=0 \\ \operatorname{cov}\left(\Delta v_{t}, \Delta v_{t+s}\right) & \text { for } s>0\end{cases}
$$

As before, we assume the transitory income shock $v_{i t}=\xi_{i, t}+\theta \xi_{i, t-1} \cdot \Delta v_{i t}=$ $\xi_{i, t}+(\theta-1) \xi_{i, t-1}-\theta \xi_{i t-2}$.

Then for $\mathrm{t}=2, . ., \mathrm{T}-1$

$$
\begin{aligned}
& \operatorname{var}\left(\Delta y_{t}\right)=\operatorname{var}\left(\zeta_{t}\right)+\operatorname{var}\left(\Delta v_{t}\right) \\
& =\operatorname{var}\left(\zeta_{t}\right)+\operatorname{var}\left(\xi_{t}\right)+(\theta-1)^{2} \operatorname{var}\left(\xi_{t-1}\right)+\theta^{2} \operatorname{var}\left(\xi_{t-2}\right)
\end{aligned}
$$

With $t=3, . ., T-2$

$$
\begin{aligned}
& \operatorname{cov}\left(\Delta y_{t}, \Delta y_{t-2}+\Delta y_{t-1}+\Delta y_{t}+\Delta y_{t+1}+\Delta y_{t+2}\right) \\
& =\operatorname{cov}\left(\zeta_{i t}+v_{i t}-v_{i t-1}, \zeta_{i t-2}+\zeta_{i t-1}+\zeta_{i t}+\zeta_{i t+1}+\zeta_{i t+2}+v_{i t+2}-v_{i t-3}\right) \\
& =\operatorname{var}\left(\zeta_{t}\right)
\end{aligned}
$$

$$
\begin{aligned}
& \operatorname{cov}\left(\Delta y_{t}, \Delta y_{t+1}\right) \\
& =\operatorname{cov}\left(\Delta v_{t}, \Delta v_{t+1}\right) \\
& =\operatorname{cov}\left(\xi_{i, t}+(\theta-1) \xi_{i, t-1}-\theta \xi_{i, t-2}, \xi_{i, t+1}+(\theta-1) \xi_{i, t}-\theta \xi_{i, t-1}\right) \\
& =(\theta-1) \operatorname{var}\left(\xi_{t}\right)+\theta(1-\theta) \operatorname{var}\left(\xi_{t-1}\right) .
\end{aligned}
$$

$$
\begin{aligned}
& \operatorname{cov}\left(\Delta y_{t}, \Delta y_{t+2}\right) \\
& =\operatorname{cov}\left(\Delta v_{t}, \Delta v_{t+2}\right) \\
& =\operatorname{cov}\left(\xi_{i, t}+(\theta-1) \xi_{i, t-1}-\theta \xi_{i, t-2}, \xi_{i, t+2}+(\theta-1) \xi_{i, t+1}-\theta \xi_{i, t}\right) \\
& =-\theta \operatorname{var}\left(\xi_{t}\right)
\end{aligned}
$$

$$
\begin{aligned}
& \operatorname{cov}\left(\Delta y_{i t}, \Delta y_{i t+2}+\Delta y_{i t+1}\right) \\
& =\mathbb{E}\left[\left(\zeta_{i t}+\left(\xi_{i t}+(\theta-1) \xi_{i t-1}-\theta \xi_{i t-2}\right)\right)\left(\zeta_{i t+2}+\zeta_{i t+1}+\left(\xi_{i t+2}+\theta \xi_{i t+1}-\xi_{i t}\right)\right)\right] \\
& =-\operatorname{var}\left(\xi_{t}\right)
\end{aligned}
$$


The above moments identify $2 T-7$ parameters: $\operatorname{var}\left(\zeta_{t}\right), \operatorname{var}\left(\xi_{t}\right)$ for $t=3, . ., T-2$ and $\theta$.

Identification based on the covariance of growth rates recovers fewer parameters than from the covariance of levels.

\section{A.2.4 HIP Model}

$$
\begin{gathered}
\operatorname{var}\left(y_{i t}\right)=\operatorname{var}\left(\delta_{i}+\left(t+t_{i}\right) \beta_{i}+v_{i t}\right) \\
=\sigma_{\delta}^{2}+\left(t+t_{i}\right)^{2} \sigma_{\beta}^{2}+2\left(t+t_{i}\right) \operatorname{cov}\left(\beta_{i}, \delta_{i}\right)+\operatorname{var}\left(v_{i t}\right) \\
\operatorname{var}\left(y_{i 1}\right)=\sigma_{\delta}^{2}+\left(1+t_{i}\right)^{2} \sigma_{\beta}^{2}+2\left(1+t_{i}\right) \operatorname{cov}\left(\beta_{i}, \delta_{i}\right)+\sigma_{\xi_{1}}^{2}+\theta^{2} \sigma_{\xi_{0}}^{2} \\
\operatorname{var}\left(y_{i 2}\right)=\sigma_{\delta}^{2}+\left(2+t_{i}\right)^{2} \sigma_{\beta}^{2}+2\left(2+t_{i}\right) \operatorname{cov}\left(\beta_{i}, \delta_{i}\right)+\sigma_{\xi_{2}}^{2}+\theta^{2} \sigma_{\xi_{1}}^{2} \\
\vdots \\
\operatorname{var}\left(y_{i 19}\right)=\sigma_{\delta}^{2}+\left(19+t_{i}\right)^{2} \sigma_{\beta}^{2}+2\left(19+t_{i}\right) \operatorname{cov}\left(\beta_{i}, \delta_{i}\right)+\sigma_{\xi_{18}}^{2}+\theta^{2} \sigma_{\xi_{18}}^{2} \\
\operatorname{cov}\left(y_{i t}, y_{i t+j}\right) \\
=\operatorname{cov}\left(\delta_{i}+\left(t+t_{i}\right) \beta_{i}+v_{i t}, \delta_{i}+\left(t+j+t_{i}\right) \beta_{i}+v_{i t+j}\right) \\
=\sigma_{\delta}^{2}+\left(t+t_{i}\right)\left(t+j+t_{i}\right) \sigma_{\beta}^{2}+\left(2 t+j+2 t_{i}\right) \operatorname{cov}\left(\beta_{i}, \delta_{i}\right)+\operatorname{cov}\left(v_{i t}, v_{i t+j}\right) .
\end{gathered}
$$




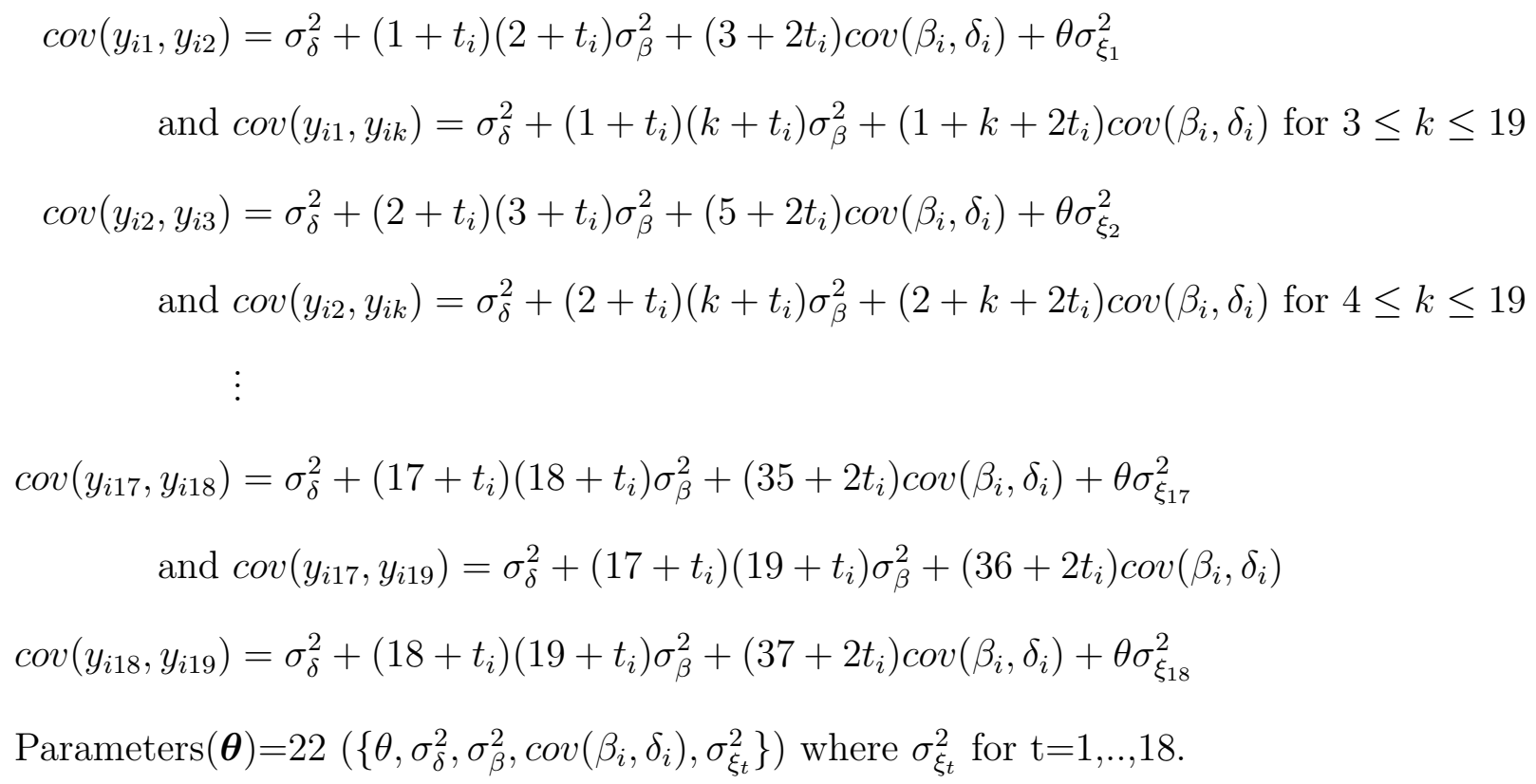

\section{A.2.5 Baker/Solon Model}

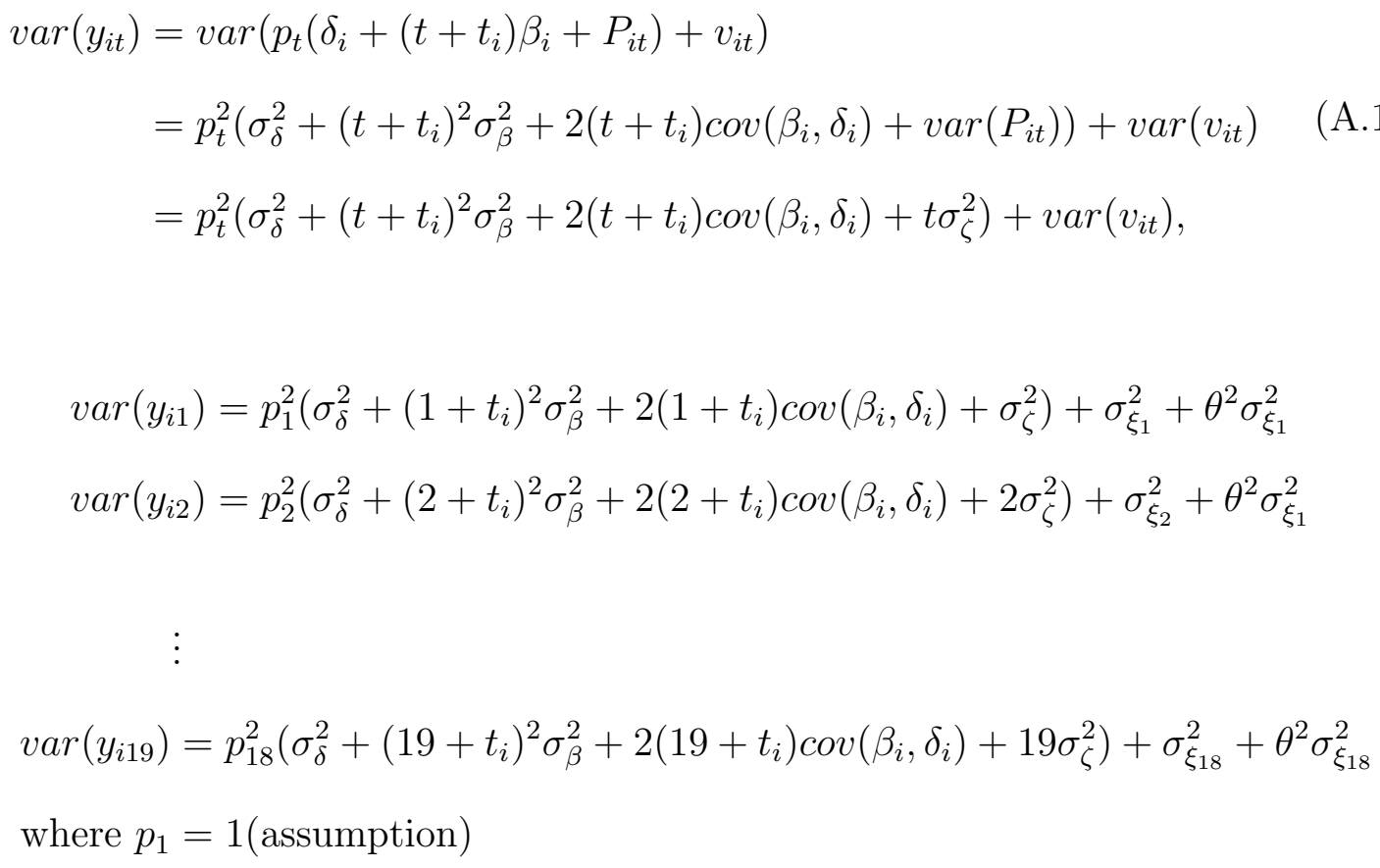




$$
\begin{aligned}
& \operatorname{cov}\left(y_{i t}, y_{i t+j}\right) \\
& =\operatorname{cov}\left(p_{t}\left(\delta_{i}+\left(t+t_{i}\right) \beta_{i}+P_{i t}\right)+v_{i t}, p_{t+j}\left(\delta_{i}+\left(t+j+t_{i}\right) \beta_{i}+P_{i t+j}\right)+v_{i t+j}\right) \\
& =p_{t} p_{t+j}\left[\sigma_{\delta}^{2}+\left(t+t_{i}\right)\left(t+j+t_{i}\right) \sigma_{\beta}^{2}+\left(2 t+j+2 t_{i}\right) \operatorname{cov}\left(\beta_{i}, \delta_{i}\right)\right. \\
& \left.+\operatorname{var}\left(P_{i t}\right)\right]+\operatorname{cov}\left(v_{i t}, v_{i t+j}\right) .
\end{aligned}
$$

$$
\begin{aligned}
& \operatorname{cov}\left(y_{i 1}, y_{i 2}\right)=p_{1} p_{2}\left[\sigma_{\delta}^{2}+\left(1+t_{i}\right)\left(2+t_{i}\right) \sigma_{\beta}^{2}+\left(3+2 t_{i}\right) \operatorname{cov}\left(\beta_{i}, \delta_{i}\right)+\sigma_{\zeta}^{2}\right]+\theta \sigma_{\xi_{1}}^{2} \\
& \text { and } \operatorname{cov}\left(y_{i 1}, y_{i k}\right)=p_{1} p_{k}\left[\sigma_{\delta}^{2}+\left(1+t_{i}\right)\left(k+t_{i}\right) \sigma_{\beta}^{2}+\left(1+k+2 t_{i}\right) \operatorname{cov}\left(\beta_{i}, \delta_{i}\right)\right. \\
& \left.+\sigma_{\zeta}^{2}\right] \text { for } 3 \leq k \leq 19 \\
& \operatorname{cov}\left(y_{i 2}, y_{i 3}\right)=p_{2} p_{3}\left[\sigma_{\delta}^{2}+\left(2+t_{i}\right)\left(3+t_{i}\right) \sigma_{\beta}^{2}+\left(5+2 t_{i}\right) \operatorname{cov}\left(\beta_{i}, \delta_{i}\right)+2 \sigma_{\zeta}^{2}\right]+\theta \sigma_{\xi_{2}}^{2} \\
& \text { and } \operatorname{cov}\left(y_{i 2}, y_{i k}\right)=p_{2} p_{k}\left[\sigma_{\delta}^{2}+\left(2+t_{i}\right)\left(k+t_{i}\right) \sigma_{\beta}^{2}+\left(2+k+2 t_{i}\right) \operatorname{cov}\left(\beta_{i}, \delta_{i}\right)\right. \\
& \left.+2 \sigma_{\zeta}^{2}\right] \text { for } 4 \leq k \leq 19 \\
& \vdots \\
& \operatorname{cov}\left(y_{i 17}, y_{i 18}\right)=p_{17} p_{18}\left[\sigma_{\delta}^{2}+\left(17+t_{i}\right)\left(18+t_{i}\right) \sigma_{\beta}^{2}+\left(35+2 t_{i}\right) \operatorname{cov}\left(\beta_{i}, \delta_{i}\right)+17 \sigma_{\zeta}^{2}\right]+\theta \sigma_{\xi_{17}}^{2} \\
& \text { and } \operatorname{cov}\left(y_{i 17}, y_{i 19}\right)=p_{17} p_{19}\left[\sigma_{\delta}^{2}+\left(17+t_{i}\right)\left(19+t_{i}\right) \sigma_{\beta}^{2}+\left(36+2 t_{i}\right) \operatorname{cov}\left(\beta_{i}, \delta_{i}\right)\right. \\
& \left.17 \sigma_{\zeta}^{2}\right]
\end{aligned}
$$

$\operatorname{cov}\left(y_{i 18}, y_{i 19}\right)=p_{18} p_{18}\left[\sigma_{\delta}^{2}+\left(18+t_{i}\right)\left(19+t_{i}\right) \sigma_{\beta}^{2}+\left(36+2 t_{i}\right) \operatorname{cov}\left(\beta_{i}, \delta_{i}\right)+18 \sigma_{\zeta}^{2}\right]+\theta \sigma_{\xi_{18}}^{2}$

$\operatorname{Parameters}(\boldsymbol{\theta})=40\left(\left\{\theta, \sigma_{\delta}^{2}, \sigma_{\beta}^{2}, \operatorname{cov}\left(\beta_{i}, \delta_{i}\right), \sigma_{\zeta}^{2}, p_{t}, \sigma_{\xi_{t}}^{2}\right\}\right)$ where $p_{t}$ for $\mathrm{t}=2, . ., 18$ and $\sigma_{\xi_{t}}^{2}$ for $\mathrm{t}=1, . ., 18$

\section{A.2.6 G-RIP Model}

$$
\begin{aligned}
\operatorname{var}\left(y_{i t}\right) & =\operatorname{var}\left(P_{i t}+v_{i t}\right)=\operatorname{var}\left(P_{i t}\right)+\operatorname{var}\left(v_{i t}\right) \\
& =\left(\prod_{j=2}^{t}\left(1+f_{j}\right)\right)^{2} \operatorname{var}\left(P_{i 1}\right)+\sum_{j=2}^{t-1}\left(\prod_{k=1+j}^{t}\left(1+f_{k}\right)\right)^{2} \sigma_{\zeta_{j}}^{2}+\sigma_{\zeta_{t}}^{2}+\operatorname{var}\left(v_{i t}\right),
\end{aligned}
$$




$$
\begin{aligned}
\operatorname{var}\left(y_{i 1}\right) & =\operatorname{var}\left(P_{i 1}\right)+\sigma_{\xi_{1}}^{2}+\theta^{2} \sigma_{\xi_{1}}^{2} \\
\operatorname{var}\left(y_{i 2}\right) & =\left(1+f_{2}\right)^{2} \operatorname{var}\left(P_{i 1}\right)+\sigma_{\zeta_{2}}^{2}+\sigma_{\xi_{2}}^{2}+\theta^{2} \sigma_{\xi_{1}}^{2} \\
\operatorname{var}\left(y_{i 3}\right) & =\left(\prod_{j=2}^{3}\left(1+f_{j}\right)\right)^{2} \operatorname{var}\left(P_{i 1}\right)+\left(1+f_{3}\right)^{2} \sigma_{\zeta_{2}}^{2}+\sigma_{\zeta_{3}}^{2}+\sigma_{\xi_{3}}^{2}+\theta^{2} \sigma_{\xi_{2}}^{2} \\
\vdots & \\
\operatorname{var}\left(y_{i 19}\right) & =\left(\prod_{j=2}^{19}\left(1+f_{j}\right)\right)^{2} \operatorname{var}\left(P_{i 1}\right)+\sum_{j=2}^{18}\left(\prod_{k=1+j}^{19}\left(1+f_{k}\right)\right)^{2} \sigma_{\zeta_{j}}^{2}+\sigma_{\zeta_{18}}^{2}+\sigma_{\xi_{18}}^{2}+\theta^{2} \sigma_{\xi_{18}}^{2}
\end{aligned}
$$

where $f_{19}=f_{18}$ because of identification problem

$$
\begin{aligned}
& \operatorname{cov}\left(y_{i t}, y_{i t+j}\right) \\
& =\operatorname{cov}\left(P_{i t}+v_{i t}, P_{i t+1}+v_{i t+j}\right)=\operatorname{cov}\left(P_{i}, P_{i t+j}\right)+\operatorname{cov}\left(v_{i t}, v_{i t+j}\right) \\
& =\operatorname{var}\left(P_{i t}\right) \prod_{k=1}^{j}\left(1+f_{t+k}\right)+\operatorname{cov}\left(v_{i t}, v_{i t+j}\right) \text {. } \\
& \operatorname{cov}\left(y_{i 1}, y_{i 2}\right)=\left(1+f_{2}\right) \operatorname{var}\left(P_{i 1}\right)+\theta \sigma_{\xi_{1}}^{2} \\
& \text { and } \operatorname{cov}\left(y_{i 1}, y_{i k}\right)=\prod_{j=2}^{k}\left(1+f_{j}\right) \operatorname{var}\left(P_{i 1}\right) \text { for } 3 \leq k \leq 19 \\
& \operatorname{cov}\left(y_{i 2}, y_{i 3}\right)=\left(1+f_{3}\right) \operatorname{var}\left(P_{i 2}\right)+\theta \sigma_{\xi_{2}}^{2} \\
& \text { and } \operatorname{cov}\left(y_{i 2}, y_{i k}\right)=\prod_{j=3}^{k}\left(1+f_{j}\right) \operatorname{var}\left(P_{i 2}\right) \text { for } 4 \leq k \leq 19 \\
& \operatorname{cov}\left(y_{i 17}, y_{i 18}\right)=\left(1+f_{18}\right) \operatorname{var}\left(P_{i 17}\right)+\theta \sigma_{\xi_{17}}^{2} \\
& \text { and } \operatorname{cov}\left(y_{i 17}, y_{i 19}\right)=\prod_{j=18}^{19}\left(1+f_{j}\right) \operatorname{var}\left(P_{i 17}\right) \\
& \operatorname{cov}\left(y_{i 18}, y_{i 19}\right)=\left(1+f_{19}\right) \operatorname{var}\left(P_{i 18}\right)+\theta \sigma_{\xi_{18}}^{2} \\
& \text { where } \operatorname{var}\left(P_{i t}\right)=\left(\prod_{j=2}^{t}\left(1+f_{j}\right)\right)^{2} \operatorname{var}\left(P_{i 1}\right) \text { and } f_{19}=f_{18}
\end{aligned}
$$


$\operatorname{Parameters}(\boldsymbol{\theta})=54\left(\left\{\theta, \operatorname{var}\left(P_{i 1}\right), f_{t}, \sigma_{\zeta_{t}}^{2}, \sigma_{\xi_{t}}^{2}\right\}\right)$ where $f_{t}$ for $\mathrm{t}=2, . ., 18, \sigma_{\zeta_{t}}^{2}$ for $\mathrm{t}=1, . ., 18$, and $\sigma_{\xi_{t}}^{2}$ for $\mathrm{t}=1, . ., 18$.

\section{A.2.7 SHIP Model}

In $(2.3)$, for $\mathrm{t}=1, . ., \mathrm{T}$

$$
y_{i t}=\delta_{i} h_{t}+\left(t+t_{i}\right) \beta_{i t}+P_{i t}+v_{i t}
$$

We assume

$$
v_{i t}=\xi_{i t}+\theta \xi_{i t-1} \text { for } t=1, . . T
$$

Both

$$
P_{i t}=P_{i t-1}+\zeta_{i t} \text { and } \beta_{i t}=\rho_{t} \beta_{i t-1}+w_{i t} \text { for } t=2, . . T \text {. }
$$

We assume shocks $\xi, \zeta$, and $w$ are mutually independent. The parameters to be estimated are $\sigma_{\zeta_{t}}^{2}=\operatorname{var}\left(\zeta_{i t}\right)($ for $\mathrm{t}=2, . ., \mathrm{T}-1), \sigma_{\xi_{t}}^{2}=\operatorname{var}\left(\xi_{i t}\right)($ for $\mathrm{t}=1, . ., \mathrm{T}-1) h_{t}, \rho_{t}$ $($ for $\mathrm{t}=2, . ., \mathrm{T}-1), \theta, \sigma_{w}^{2}=\operatorname{var}\left(w_{i t}\right), \sigma_{\delta}^{2}=\operatorname{var}\left(\delta_{i}\right), \operatorname{var}\left(P_{i 1}\right), \operatorname{var}\left(\beta_{i 1}\right), \operatorname{cov}\left(P_{i 1}, \beta_{i 1}\right)$, $\operatorname{cov}\left(\delta_{i}, \beta_{i 1}\right), \operatorname{cov}\left(\delta_{i}, P_{i 1}\right)$. The total number of parameters is $4 T+1(=77)$.

$$
\begin{aligned}
\operatorname{var}\left(y_{i t}\right) & =\operatorname{var}\left(\delta_{i} h_{t}+\left(t+t_{i}\right) \beta_{i t}+P_{i t}+v_{i t}\right) \\
& =h_{t}^{2} \operatorname{var}\left(\delta_{i}\right)+\left(t+t_{i}\right)^{2} \operatorname{var}\left(\beta_{i t}\right)+\operatorname{var}\left(P_{i t}\right)+\operatorname{var}\left(v_{i t}\right)+2 h_{t}\left(t+t_{i}\right) \operatorname{cov}\left(\delta_{i}, \beta_{i t}\right) \\
& +2 h_{t} \operatorname{cov}\left(\delta_{i}, P_{i t}\right)+2\left(t+t_{i}\right) \operatorname{cov}\left(\beta_{i t}, P_{i t}\right) \\
& =h_{t}^{2} \sigma_{\delta}^{2}+\left(t+t_{i}\right)^{2}\left(\left(\prod_{k=2}^{t} \rho_{k}\right)^{2} \sigma_{\beta_{i 1}}^{2}+\sum_{k=2}^{t-1}\left(\prod_{j=k+1}^{t} \rho_{j}\right)^{2} \sigma_{\omega_{k}}^{2}+\sigma_{\omega_{t}}^{2}\right)+\operatorname{var}\left(P_{i t}\right) \\
& +\operatorname{var}\left(v_{i t}\right)+2 h_{t}\left(t+t_{i}\right) \prod_{k=2}^{t} \rho_{k} \operatorname{cov}\left(\delta_{i}, \beta_{i 1}\right) \\
& +2 h_{t} \operatorname{cov}\left(\delta_{i}, P_{i 1}\right)+2\left(t+t_{i}\right)\left(\prod_{k=2}^{t} \rho_{k} \operatorname{cov}\left(\beta_{i 1}, P_{i 1}\right)\right)
\end{aligned}
$$




$$
\begin{aligned}
& \operatorname{var}\left(y_{i 1}\right)=h_{1}^{2} \sigma_{\delta}^{2}+\left(1+t_{i}\right)^{2} \sigma_{\beta_{i 1}}^{2}+\operatorname{var}\left(P_{i 1}\right)+\sigma_{\xi_{1}}^{2}+\theta^{2} \sigma_{\xi_{1}}^{2} \\
& +2 h_{1}\left(1+t_{i}\right) \operatorname{cov}\left(\delta_{i}, \beta_{i 1}\right)+2 h_{1} \operatorname{cov}\left(\delta_{i}, P_{i 1}\right)+2\left(1+t_{i}\right) \operatorname{cov}\left(\beta_{i 1}, P_{i 1}\right) \\
& \operatorname{var}\left(y_{i 2}\right)=h_{2}^{2} \sigma_{\delta}^{2}+\left(2+t_{i}\right)^{2}\left[\left(\rho_{2}\right)^{2} \sigma_{\beta_{i 1}}^{2}+\sigma_{\omega_{2}}^{2}\right]+\operatorname{var}\left(P_{i 1}\right)+\sigma_{\zeta_{2}}^{2}+\sigma_{\xi_{2}}^{2}+\theta^{2} \sigma_{\xi_{1}}^{2} \\
& +2 h_{2}\left(2+t_{i}\right) \rho_{2} \operatorname{cov}\left(\delta_{i}, \beta_{i 1}\right)+2 h_{2} \operatorname{cov}\left(\delta_{i}, P_{i 1}\right) \\
& +2\left(2+t_{i}\right) \rho_{2} \operatorname{cov}\left(\beta_{i 1}, P_{i 1}\right) \\
& \vdots \\
& \operatorname{var}\left(y_{i 19}\right)=h_{19}^{2} \sigma_{\delta}^{2}+\left(19+t_{i}\right)^{2}\left[\left(\prod_{k=2}^{19} \rho_{k}\right)^{2} \sigma_{\beta_{i 1}}^{2}+\sum_{k=2}^{18}\left(\prod_{j=k+1}^{19} \rho_{j}\right)^{2} \sigma_{\omega_{k}}^{2}+\sigma_{\omega_{18}}^{2}\right]+\operatorname{var}\left(P_{i 1}\right) \\
& +\sum_{j=2}^{18} \sigma_{\zeta_{j}}^{2}+\sigma_{\zeta_{18}}^{2}+\sigma_{\xi_{18}}^{2}+\theta^{2} \sigma_{\xi_{18}}^{2}+2 h_{19}\left(19+t_{i}\right) \prod_{k=2}^{19} \rho_{k} \operatorname{cov}\left(\delta_{i}, \beta_{i 1}\right) \\
& +2 h_{19} \operatorname{cov}\left(\delta_{i}, P_{i 1}\right)+2\left(19+t_{i}\right)\left(\prod_{k=2}^{19} \rho_{k} \operatorname{cov}\left(\beta_{i 1}, P_{i 1}\right)\right.
\end{aligned}
$$

where $h_{1}=\rho_{1}=0, h_{19}=h_{18}$, and $\rho_{19}=\rho_{18}$ because of identification problem

$$
\begin{aligned}
& \operatorname{cov}\left(y_{i t}, y_{i t+j}\right) \\
& =\operatorname{cov}\left(h_{t} \delta_{i}+\left(t+t_{i}\right) \beta_{i t}+P_{i t}+v_{i t}, h_{t+j} \delta_{i}+\left(t+j+t_{i}\right) \beta_{i t+j}+P_{i t+j}+v_{i t+j}\right) \\
& =h_{t} h_{t+j} \sigma_{\delta}^{2}+h_{t}\left(t+j+t_{i}\right) \operatorname{cov}\left(\delta_{i}, \beta_{i t+j}\right)+h_{t} \operatorname{cov}\left(\delta_{i}, P_{i t+j}\right)+h_{t+j}\left(t+t_{i}\right) \operatorname{cov}\left(\delta_{i}, \beta_{i t}\right) \\
& +\left(t+t_{i}\right)\left(t+j+t_{i}\right) \operatorname{cov}\left(\beta_{i t}, \beta_{i t+j}\right)+\left(t+t_{i}\right) \operatorname{cov}\left(\beta_{i t}, P_{i t+j}\right)+h_{t+j} \operatorname{cov}\left(\delta_{i}, P_{i t}\right) \\
& +\left(t+j+t_{i}\right) \operatorname{cov}\left(\beta_{i t+j}, P_{i t}\right)+\operatorname{cov}\left(P_{i t}, P_{i t+j}\right)+\operatorname{cov}\left(v_{i t}, v_{i t+j}\right)
\end{aligned}
$$




$$
\begin{aligned}
& =h_{t} h_{t+j} \sigma_{\delta}^{2}+h_{t}\left(t+j+t_{i}\right) \prod_{k=2}^{t+j} \rho_{k} \operatorname{cov}\left(\delta_{i}, \beta_{i 1}\right)+h_{t} \operatorname{cov}\left(\delta_{i}, P_{i 1}\right) \\
& +h_{t+j}\left(t+t_{i}\right) \prod_{k=2}^{t} \rho_{k} \operatorname{cov}\left(\delta_{i}, \beta_{i 1}\right)+\left(t+t_{i}\right)\left(t+j+t_{i}\right) \prod_{k=t+1}^{t+j} \rho_{k} \operatorname{var}\left(\beta_{i t}\right) \\
& +\left(t+t_{i}\right)\left(\prod_{k=2}^{t} \rho_{k} \operatorname{cov}\left(\beta_{i 1}, P_{i 1}\right)\right)+h_{t+j} \operatorname{cov}\left(\delta_{i}, P_{i 1}\right) \\
& +\left(t+j+t_{i}\right)\left(\prod_{k=2}^{t+j} \rho_{k} \operatorname{cov}\left(\beta_{i 1}, P_{i 1}\right)+\sum_{k=1}^{t}\left(\prod_{j=k+1}^{t+j} \rho_{j} \operatorname{cov}\left(\omega_{i k}, \zeta_{i k}\right)\right)+\operatorname{var}\left(P_{i t}\right)+\operatorname{cov}\left(v_{i t}, v_{i t+j}\right) .\right.
\end{aligned}
$$

$$
\begin{aligned}
& \operatorname{cov}\left(y_{i 1}, y_{i 2}\right)=h_{1} h_{2} \sigma_{\delta}^{2}+h_{1}\left(2+t_{i}\right) \rho_{2} \operatorname{cov}\left(\delta_{i}, \beta_{i 1}\right)+h_{1} \operatorname{cov}\left(\delta_{i}, P_{i 1}\right)+h_{2}\left(1+t_{i}\right) \operatorname{cov}\left(\delta_{i}, \beta_{i 1}\right) \\
&+\left(1+t_{i}\right)\left(2+t_{i}\right) \rho_{2} \operatorname{var}\left(\beta_{i 1}\right)+\left(1+t_{i}\right) \operatorname{cov}\left(\beta_{i 1}, P_{i 1}\right) \\
&+h_{2} \operatorname{cov}\left(\delta_{i}, P_{i 1}\right)+\left(2+t_{i}\right)\left(\rho_{2} \operatorname{cov}\left(\beta_{i 1}, P_{i 1}\right)\right)+\operatorname{var}\left(P_{i 1}\right)+\theta \sigma_{\xi_{1}}^{2} \\
& \text { and } \operatorname{cov}\left(y_{i 1}, y_{i k}\right)=h_{1} h_{k} \sigma_{\delta}^{2}+h_{1}\left(k+t_{i}\right) \prod_{l=2}^{k} \rho_{l} \operatorname{cov}\left(\delta_{i}, \beta_{i 1}\right)+h_{1} \operatorname{cov}\left(\delta_{i}, P_{i 1}\right) \\
&+h_{k}\left(1+t_{i}\right) \operatorname{cov}\left(\delta_{i}, \beta_{i 1}\right)+\left(1+t_{i}\right)\left(k+t_{i}\right) \prod_{l=2}^{k} \rho_{l} \operatorname{var}\left(\beta_{i 1}\right) \\
& \\
&+\left(1+t_{i}\right) \operatorname{cov}\left(\beta_{i 1}, P_{i 1}\right)+h_{k} \operatorname{cov}\left(\delta_{i}, P_{i 1}\right) \\
& \\
&+\left(k+t_{i}\right) \prod_{l=2}^{k} \rho_{l} \operatorname{cov}\left(\beta_{i 1}, P_{i 1}\right)+\operatorname{var}\left(P_{i 1}\right) \text { for } 3 \leq k \leq 19
\end{aligned}
$$




$$
\begin{aligned}
& \operatorname{cov}\left(y_{i 2}, y_{i 3}\right)=h_{2} h_{3} \sigma_{\delta}^{2}+h_{2}\left(3+t_{i}\right) \prod_{l=2}^{3} \rho_{l} \operatorname{cov}\left(\delta_{i}, \beta_{i 1}\right)+h_{2} \operatorname{cov}\left(\delta_{i}, P_{i 1}\right) \\
& +h_{3}\left(2+t_{i}\right) \rho_{2} \operatorname{cov}\left(\delta_{i}, \beta_{i 1}\right)+\left(2+t_{i}\right)\left(3+t_{i}\right) \rho_{3} \operatorname{var}\left(\beta_{i 2}\right) \\
& +\left(2+t_{i}\right)\left(\rho_{2} \operatorname{cov}\left(\beta_{i 1}, P_{i 1}\right)\right)+h_{3} \operatorname{cov}\left(\delta_{i}, P_{i 1}\right)+\left(3+t_{i}\right)\left(\prod_{l=2}^{3} \rho_{l} \operatorname{cov}\left(\beta_{i 1}, P_{i 1}\right)\right) \\
& +\operatorname{var}\left(P_{i 1}\right)+\sigma_{\zeta_{2}}^{2}+\theta \sigma_{\xi_{2}}^{2} \\
& \text { and } \operatorname{cov}\left(y_{i 2}, y_{i k}\right)=h_{2} h_{k} \sigma_{\delta}^{2}+h_{2}\left(k+t_{i}\right) \prod_{l=2}^{k} \rho_{l} \operatorname{cov}\left(\delta_{i}, \beta_{i 1}\right)+h_{2} \operatorname{cov}\left(\delta_{i}, P_{i 1}\right) \\
& +h_{k}\left(2+t_{i}\right) \rho_{2} \operatorname{cov}\left(\delta_{i}, \beta_{i 1}\right)+\left(2+t_{i}\right)\left(k+t_{i}\right) \prod_{l=3}^{k} \rho_{l} \operatorname{var}\left(\beta_{i 2}\right) \\
& +\left(2+t_{i}\right) \rho_{2} \operatorname{cov}\left(\beta_{i 1}, P_{i 1}\right)+h_{k} \operatorname{cov}\left(\delta_{i}, P_{i 1}\right)+\left(k+t_{i}\right)\left(\prod_{l=2}^{k} \rho_{l} \operatorname{cov}\left(\beta_{i 1}, P_{i 1}\right)\right) \\
& +\operatorname{var}\left(P_{i 1}\right)+\sigma_{\zeta_{2}}^{2} \text { for } 4 \leq k \leq 19 \\
& \vdots \\
& \begin{aligned}
\operatorname{cov}\left(y_{i 17}, y_{i 18}\right) & =h_{17} h_{18} \sigma_{\delta}^{2}+h_{17}\left(18+t_{i}\right) \prod_{l=2}^{18} \rho_{l} \operatorname{cov}\left(\delta_{i}, \beta_{i 1}\right)+h_{17} \operatorname{cov}\left(\delta_{i}, P_{i 1}\right) \\
& +h_{18}\left(17+t_{i}\right) \prod_{l=2}^{17} \rho_{l} \operatorname{cov}\left(\delta_{i}, \beta_{i 1}\right)+\left(17+t_{i}\right)\left(18+t_{i}\right) \rho_{18} \operatorname{var}\left(\beta_{i 17}\right) \\
& +\left(17+t_{i}\right)\left(\prod_{l=2}^{17} \rho_{l} \operatorname{cov}\left(\beta_{i 1}, P_{i 1}\right)\right)+h_{18} \operatorname{cov}\left(\delta_{i}, P_{i 1}\right)+\left(18+t_{i}\right)\left(\prod_{l=2}^{18} \rho_{l} \operatorname{cov}\left(\beta_{i 1}, P_{i 1}\right)\right. \\
& +\operatorname{var}\left(P_{i 1}\right)+\sum_{l=2}^{17} \sigma_{\zeta_{l}}^{2}+\theta \sigma_{\xi_{17}}^{2}
\end{aligned} \\
& \text { and } \operatorname{cov}\left(y_{i 17}, y_{i 19}\right)=h_{17} h_{19} \sigma_{\delta}^{2}+h_{17}\left(19+t_{i}\right) \prod_{l=2}^{19} \rho_{l} \operatorname{cov}\left(\delta_{i}, \beta_{i 1}\right)+h_{17} \operatorname{cov}\left(\delta_{i}, P_{i 1}\right) \\
& +h_{19}\left(17+t_{i}\right) \prod_{l=2}^{17} \rho_{l} \operatorname{cov}\left(\delta_{i}, \beta_{i 1}\right)+\left(17+t_{i}\right)\left(19+t_{i}\right) \prod_{l=18}^{19} \rho_{l} \operatorname{var}\left(\beta_{i 17}\right) \\
& +\left(17+t_{i}\right)\left(\prod_{l=2}^{17} \rho_{l} \operatorname{cov}\left(\beta_{i 1}, P_{i 1}\right)\right)+h_{19} \operatorname{cov}\left(\delta_{i}, P_{i 1}\right)+\left(19+t_{i}\right)\left(\prod_{l=2}^{19} \rho_{l} \operatorname{cov}\left(\beta_{i 1}, P_{i 1}\right)\right) \\
& +\operatorname{var}\left(P_{i 1}\right)+\sum_{l=2}^{17} \sigma_{\zeta_{l}}^{2}
\end{aligned}
$$




$$
\begin{aligned}
\operatorname{cov}\left(y_{i 18}, y_{i 19}\right) & =h_{18} h_{19} \sigma_{\delta}^{2}+h_{18}\left(19+t_{i}\right) \prod_{l=2}^{19} \rho_{l} \operatorname{cov}\left(\delta_{i}, \beta_{i 1}\right)+h_{18} \operatorname{cov}\left(\delta_{i}, P_{i 1}\right) \\
& +h_{19}\left(18+t_{i}\right) \prod_{l=2}^{18} \rho_{l} \operatorname{cov}\left(\delta_{i}, \beta_{i 1}\right)+\left(18+t_{i}\right)\left(19+t_{i}\right) \rho_{19} \operatorname{var}\left(\beta_{i 18}\right) \\
& +\left(18+t_{i}\right)\left(\prod_{l=2}^{18} \rho_{l} \operatorname{cov}\left(\beta_{i 1}, P_{i 1}\right)+h_{19} \operatorname{cov}\left(\delta_{i}, P_{i 1}\right)+\left(19+t_{i}\right)\left(\prod_{l=2}^{19} \rho_{l} \operatorname{cov}\left(\beta_{i 1}, P_{i 1}\right)\right.\right. \\
& +\operatorname{var}\left(P_{i 1}\right)+\sum_{l=2}^{18} \sigma_{\zeta_{l}}^{2}+\theta \sigma_{\xi_{18}}^{2}
\end{aligned}
$$

where $\operatorname{var}\left(\beta_{i t}\right)=\left(\prod_{l=2}^{t} \rho_{l}\right)^{2} \operatorname{var}\left(\beta_{i 1}\right)+\sum_{l=2}^{t-1}\left(\prod_{j=l+1}^{t} \rho_{j}\right)^{2} \sigma_{\omega_{l}}^{2}+\sigma_{\omega_{t}}^{2}$ 


\section{A.3 The Compositions of Earnings Inequality by Education}

Table A.6: The compositions of earning inequality for the RIP

\begin{tabular}{l||rrr|rrr} 
& \multicolumn{4}{c|}{$\mathrm{e}=1$} & & $\mathrm{e}=2$ \\
Year & $\Delta \operatorname{var}(\mathrm{y})$ & permanent & transitory & $\Delta \operatorname{var}(\mathrm{y})$ & permanent & transitory \\
\hline \hline 1998 & 0.0134 & 0.0034 & 0.0100 & 0.0032 & 0.0000 & 0.0032 \\
1999 & -0.0403 & -0.0011 & -0.0392 & -0.0597 & 0.0000 & -0.0597 \\
2000 & -0.0325 & 0.0028 & -0.0353 & 0.0288 & 0.0022 & 0.0266 \\
2001 & 0.0203 & 0.0057 & 0.0145 & 0.0036 & 0.0224 & -0.0188 \\
2002 & 0.0029 & 0.0012 & 0.0016 & -0.0169 & 0.0000 & -0.0169 \\
2003 & 0.0009 & 0.0091 & -0.0082 & 0.0614 & 0.0097 & 0.0518 \\
2004 & -0.0021 & 0.0013 & -0.0034 & 0.0135 & 0.0071 & 0.0064 \\
2005 & -0.0045 & 0.0013 & -0.0058 & -0.0403 & 0.0000 & -0.0403 \\
2006 & -0.0167 & 0.0003 & -0.0170 & 0.0107 & 0.0049 & 0.0058 \\
2007 & -0.0074 & 0.0092 & -0.0165 & -0.0093 & 0.0000 & -0.0093 \\
2008 & 0.0147 & 0.0014 & 0.0133 & 0.0587 & 0.0038 & 0.0548 \\
2009 & -0.0025 & 0.0235 & -0.0261 & -0.0588 & 0.0000 & -0.0588 \\
2010 & 0.0632 & 0.0141 & 0.0491 & -0.0227 & 0.0000 & -0.0227 \\
2011 & -0.0615 & -0.0027 & -0.0588 & -0.0255 & 0.0000 & -0.0255 \\
2012 & 0.0085 & 0.0138 & -0.0052 & 0.0316 & 0.0092 & 0.0224 \\
2013 & 0.0177 & 0.0172 & 0.0005 & 0.1150 & 0.0298 & 0.0852 \\
2014 & 0.0193 & 0.0001 & 0.0193 & -0.0167 & 0.0113 & -0.0281 \\
\hline
\end{tabular}

Note: $\mathrm{e}=1$ if head's education is high school or lower and $\mathrm{e}=2$ if head's education is college or higher. 
Table A.7: The compositions of earning inequality for the HIP

\begin{tabular}{l||rrr|rrr}
\multicolumn{1}{l||}{} & \multicolumn{5}{c|}{$\mathrm{e}=1$} & \multicolumn{3}{c}{$\mathrm{e}=2$} \\
Year & $\Delta \operatorname{var}(\mathrm{y})$ & deterministic & transitory & $\Delta \operatorname{var}(\mathrm{y})$ & deterministic & transitory \\
\hline \hline 1998 & -0.0163 & -0.0083 & -0.0080 & -0.0170 & -0.0087 & -0.0083 \\
1999 & -0.0286 & -0.0070 & -0.0216 & -0.0466 & -0.0074 & -0.0391 \\
2000 & -0.0055 & -0.0058 & 0.0003 & 0.0541 & -0.0061 & 0.0603 \\
2001 & -0.0006 & -0.0045 & 0.0039 & -0.0082 & -0.0048 & -0.0034 \\
2002 & 0.0045 & -0.0033 & 0.0078 & -0.0159 & -0.0035 & -0.0124 \\
2003 & 0.0034 & -0.0020 & 0.0054 & 0.0614 & -0.0022 & 0.0636 \\
2004 & -0.0017 & -0.0008 & -0.0009 & 0.0163 & -0.0009 & 0.0171 \\
2005 & -0.0036 & 0.0005 & -0.0041 & -0.0381 & 0.0004 & -0.0386 \\
2006 & -0.0174 & 0.0017 & -0.0191 & 0.0092 & 0.0017 & 0.0074 \\
2007 & -0.0069 & 0.0029 & -0.0099 & -0.0076 & 0.0030 & -0.0107 \\
2008 & 0.0148 & 0.0042 & 0.0106 & 0.0528 & 0.0044 & 0.0485 \\
2009 & -0.0008 & 0.0054 & -0.0062 & -0.0536 & 0.0057 & -0.0592 \\
2010 & 0.0694 & 0.0067 & 0.0627 & -0.0276 & 0.0070 & -0.0346 \\
2011 & -0.0544 & 0.0079 & -0.0623 & -0.0272 & 0.0083 & -0.0355 \\
2012 & -0.0048 & 0.0092 & -0.0139 & 0.0270 & 0.0096 & 0.0174 \\
2013 & 0.0201 & 0.0104 & 0.0096 & 0.1220 & 0.0109 & 0.1111 \\
2014 & 0.0107 & 0.0117 & -0.0010 & -0.0393 & 0.0122 & -0.0515 \\
\hline
\end{tabular}

Note: $\mathrm{e}=1$ if head's education is high school or lower and $\mathrm{e}=2$ if head's education is college or higher. 
Table A.8: The compositions of earning inequality for the Baker/Solon

\begin{tabular}{l||rrrr|rrrr}
\multicolumn{1}{l|}{} & \multicolumn{5}{c|}{} & \multicolumn{5}{c}{$\mathrm{e}=2$} \\
Year & $\Delta \operatorname{var}(\mathrm{y})$ & deterministic & permanent & transitory & $\Delta \operatorname{var}(\mathrm{y})$ & deterministic & permanent & transitory \\
\hline \hline 1998 & -0.0050 & -0.0012 & 0.0092 & -0.0130 & -0.0063 & 0.0082 & 0.0042 & -0.0187 \\
1999 & -0.0331 & -0.0233 & 0.0021 & -0.0119 & -0.0574 & -0.0221 & 0.0015 & -0.0368 \\
2000 & -0.0313 & -0.0059 & 0.0040 & -0.0294 & 0.0255 & -0.0022 & 0.0024 & 0.0253 \\
2001 & 0.0162 & -0.0011 & 0.0058 & 0.0116 & 0.0045 & 0.0464 & 0.0082 & -0.0501 \\
2002 & 0.0015 & -0.0011 & 0.0070 & -0.0045 & -0.0218 & -0.0298 & 0.0009 & 0.0071 \\
2003 & 0.0026 & 0.0037 & 0.0118 & -0.0129 & 0.0574 & 0.0233 & 0.0095 & 0.0246 \\
2004 & -0.0017 & -0.0131 & 0.0011 & 0.0104 & 0.0192 & 0.0147 & 0.0110 & -0.0066 \\
2005 & -0.0019 & -0.0052 & 0.0067 & -0.0034 & -0.0470 & -0.0327 & -0.0001 & -0.0142 \\
2006 & -0.0179 & -0.0104 & -0.0010 & -0.0065 & 0.0141 & 0.0163 & 0.0160 & -0.0182 \\
2007 & -0.0053 & -0.0002 & 0.0141 & -0.0193 & -0.0160 & -0.0239 & 0.0020 & 0.0059 \\
2008 & 0.0171 & -0.0092 & -0.0046 & 0.0310 & 0.0670 & 0.0113 & 0.0211 & 0.0347 \\
2009 & -0.0078 & 0.0020 & 0.0253 & -0.0351 & -0.0617 & -0.0306 & -0.0037 & -0.0274 \\
2010 & 0.0689 & -0.0027 & 0.0156 & 0.0560 & -0.0149 & -0.0169 & 0.0029 & -0.0009 \\
2011 & -0.0527 & -0.0055 & 0.0012 & -0.0484 & -0.0256 & -0.0151 & 0.0021 & -0.0126 \\
2012 & -0.0044 & -0.0030 & 0.0119 & -0.0133 & 0.0261 & -0.0098 & 0.0066 & 0.0293 \\
2013 & 0.0205 & -0.0032 & 0.0058 & 0.0179 & 0.1189 & 0.0079 & 0.0414 & 0.0696 \\
2014 & 0.0136 & -0.0021 & 0.0111 & 0.0047 & -0.0266 & -0.0086 & 0.0162 & -0.0342 \\
\hline
\end{tabular}

Note: $\mathrm{e}=1$ if head's education is high school or lower and $\mathrm{e}=2$ if head's education is college or higher. 
Table A.9: The compositions of earning inequality for the G-RIP

\begin{tabular}{|c|c|c|c|c|c|c|}
\hline \multirow[b]{2}{*}{ Year } & \multicolumn{3}{|c|}{$\mathrm{e}=1$} & \multicolumn{3}{|c|}{$e=2$} \\
\hline & $\Delta \operatorname{var}(\mathrm{y})$ & permanent & transitory & $\Delta \operatorname{var}(\mathrm{y})$ & permanent & transitory \\
\hline 1998 & 0.0064 & -0.0841 & $\overline{0.0906}$ & -0.0069 & -0.0799 & 0.0730 \\
\hline 1999 & -0.0360 & -0.0572 & 0.0212 & -0.0545 & -0.0357 & -0.0188 \\
\hline 2000 & -0.0222 & -0.0094 & -0.0128 & 0.0331 & -0.0133 & 0.0464 \\
\hline 2001 & -0.0005 & 0.0077 & -0.0082 & -0.0025 & 0.0533 & -0.0558 \\
\hline 2002 & 0.0071 & 0.0145 & -0.0074 & -0.0210 & -0.0355 & 0.0146 \\
\hline 2003 & 0.0003 & 0.0184 & -0.0181 & 0.0593 & 0.0380 & 0.0213 \\
\hline 2004 & -0.0022 & -0.0171 & 0.0149 & 0.0163 & 0.0294 & -0.0130 \\
\hline 2005 & -0.0136 & -0.0051 & -0.0085 & -0.0481 & -0.0360 & -0.0121 \\
\hline 2006 & 0.0003 & -0.0023 & 0.0026 & 0.0175 & 0.0422 & -0.0248 \\
\hline 2007 & -0.0111 & 0.0182 & -0.0293 & -0.0173 & -0.0245 & 0.0072 \\
\hline 2008 & 0.0304 & -0.0195 & 0.0498 & 0.0701 & 0.0406 & 0.0295 \\
\hline 2009 & -0.0188 & 0.0328 & -0.0516 & -0.0613 & -0.0381 & -0.0232 \\
\hline 2010 & 0.0644 & 0.0161 & 0.0482 & -0.0125 & -0.0170 & 0.0045 \\
\hline 2011 & -0.0250 & -0.0123 & -0.0127 & -0.0262 & -0.0123 & -0.0139 \\
\hline 2012 & -0.0271 & 0.0126 & -0.0396 & 0.0263 & 0.0028 & 0.0235 \\
\hline 2013 & 0.0187 & 0.0137 & 0.0051 & 0.1084 & 0.0793 & 0.0291 \\
\hline 2014 & 0.0161 & -0.0005 & 0.0166 & -0.0126 & 0.0033 & -0.0159 \\
\hline
\end{tabular}

Note: $\mathrm{e}=1$ if head's education is high school or lower and $\mathrm{e}=2$ if head's education is college or higher. 
Table A.10: The compositions of earning inequality for the SHIP

\begin{tabular}{l||rrrr|rrrr}
\multicolumn{1}{l||}{} & \multicolumn{5}{c|}{$\mathrm{e}=1$} & \multicolumn{3}{c}{$\mathrm{e}=2$} \\
Year & $\Delta \operatorname{var}(\mathrm{y})$ & macro & permanent & transitory & $\Delta \operatorname{var}(\mathrm{y})$ & macro & permanent & transitory \\
\hline \hline 1998 & 0.0063 & 0.1320 & 0.0000 & -0.1257 & -0.0017 & -0.0305 & 0.0151 & 0.0137 \\
1999 & -0.0364 & -0.1143 & 0.0065 & 0.0713 & -0.0565 & -0.0456 & 0.0077 & -0.0186 \\
2000 & -0.0222 & -0.0417 & 0.0136 & 0.0059 & 0.0326 & 0.0147 & 0.0000 & 0.0179 \\
2001 & -0.0003 & -0.0109 & 0.0051 & 0.0055 & 0.0018 & 0.0524 & 0.0130 & -0.0636 \\
2002 & 0.0073 & 0.0085 & 0.0004 & -0.0016 & -0.0223 & -0.0512 & 0.0070 & 0.0219 \\
2003 & 0.0215 & 0.0425 & 0.0000 & -0.0211 & 0.0620 & 0.0393 & 0.0039 & 0.0188 \\
2004 & 0.0138 & 0.0247 & 0.0021 & -0.0130 & 0.0196 & 0.0646 & 0.0000 & -0.0450 \\
2005 & 0.0128 & 0.0431 & 0.0056 & -0.0360 & -0.0479 & -0.0630 & 0.0001 & 0.0150 \\
2006 & -0.0363 & -0.0817 & 0.0000 & 0.0455 & 0.0235 & 0.0394 & 0.0075 & -0.0233 \\
2007 & -0.0117 & -0.0045 & 0.0141 & -0.0213 & -0.0231 & -0.0348 & 0.0025 & 0.0091 \\
2008 & 0.0298 & -0.0166 & 0.0063 & 0.0402 & 0.0770 & 0.0444 & 0.0097 & 0.0229 \\
2009 & -0.0266 & -0.0144 & 0.0225 & -0.0347 & -0.0678 & -0.0596 & 0.0032 & -0.0114 \\
2010 & 0.0744 & 0.0256 & 0.0130 & 0.0358 & -0.0133 & -0.0234 & 0.0010 & 0.0092 \\
2011 & -0.0236 & -0.0033 & 0.0000 & -0.0204 & -0.0230 & -0.0242 & 0.0028 & -0.0016 \\
2012 & -0.0416 & -0.0347 & 0.0116 & -0.0185 & 0.0241 & 0.0018 & 0.0000 & 0.0223 \\
2013 & 0.0280 & 0.0179 & 0.0034 & 0.0067 & 0.1308 & 0.0931 & 0.0107 & 0.0269 \\
2014 & 0.0246 & 0.0130 & 0.0001 & 0.0115 & -0.0197 & -0.0154 & 0.0016 & -0.0060 \\
\hline
\end{tabular}

Note: $\mathrm{e}=1$ if head's education is high school or lower and $\mathrm{e}=2$ if head's education is college or higher. 


\section{Appendix B}

\section{Appendix to Chapter 3}

\section{B.1 Euler Equation of Optimal Consumption}

Consider the log-linear approximation of FOC of optimal consumption level with CRRA utility and preference shifter $z_{t}$ :

$$
\beta R_{t-1} e^{z_{t-1}} \mathbb{E}_{t-1}\left(\frac{C_{i t}}{C_{i t-1}}\right)^{-\gamma}=1,
$$

Let $1+g_{t}=\frac{C_{t}}{C_{t-1}}$ and then $\left(\frac{C_{t}}{C_{t-1}}\right)^{-\gamma}=\left(1+g_{t}\right)^{-\gamma}$. By Taylor expansion at $g=0$,

$$
(1+g)^{-\gamma} \approx 1-\gamma g+\frac{\gamma(\gamma+1)}{2} g^{2}
$$

Under the assumption of $\beta R_{t-1} e^{z_{t-1}}=1$, (B.1) can express as $\mathbb{E}_{t-1}\left(1+g_{t}\right)^{-\gamma}=1$, which is

$$
\mathbb{E}_{t-1} g_{t}=\frac{\gamma+1}{2} \mathbb{E}_{t-1} g_{t}^{2}
$$


Applying $g_{t} \approx \log \left(1+g_{t}\right)=\log \left(\frac{C_{t}}{C_{t-1}}\right)=\Delta \log C_{t}$ to $(\mathrm{B} .2)$,

$$
\Delta \log C_{i t} \approx \lambda_{t-1}+\frac{\gamma+1}{2} \mathbb{E}_{t-1}\left(\Delta \log C_{i t}\right)^{2}+\epsilon_{i t}
$$

where $\lambda_{t}$ is same for all households.

The term $\frac{\gamma+1}{2} \mathbb{E}_{t-1}\left(\Delta \log C_{i t}\right)$ approximates the conditional variance of the unexpected consumption growth, i.e., the risk premium. The optimal condition only requires for each household the expectation conditional on its information in period $t$ is zero: $\mathbb{E}\left(\epsilon_{i t} \mid \Omega_{i t-1}\right)=0$. In particular, $\mathbb{E}\left(\epsilon_{i t} \mid \log C_{i t-1}\right)=0$.

Deaton and Paxson (1994) and Blundell et al. (2013) assume that for households with the same $z_{i t}$

$$
\operatorname{cov}\left(\log C_{i t-1}, \epsilon_{i t}\right)=0
$$

which implies

$$
\Delta \operatorname{var}\left(\log C_{i t}\right)=\operatorname{var}\left(\Delta \log C_{i t}\right)>0
$$

for a given cohort of households. Deaton-Paxson (page 455) argue that (B.5) holds if the impacts of macro shocks are uncorrelated with households.

Plug (3.2) in the FOC

$$
\Delta c_{i t}=-\Delta X_{i t}^{\prime} \gamma_{c}+\lambda_{t-1}+\frac{\gamma+1}{2} \mathbb{E}_{t-1}\left(\Delta c_{i t}+\Delta X_{i t}^{\prime} \gamma_{c}\right)^{2}+\epsilon_{i t}
$$

Because we follow the same cohort, it is reasonable to assume the change in demographics be similar across households hence all the terms involving $\Delta X_{i t}^{\prime} \gamma_{c}$ can be summed into a term of time and we have

$$
\Delta c_{i t}=a_{t-1}+\frac{\gamma+1}{2} \mathbb{E}_{t-1}\left(\Delta c_{i t}\right)^{2}+\epsilon_{i t}
$$


Denote

$$
\mathbb{E}_{t-1} \Delta c_{i t}=g_{i t-1}=a_{t-1}+\frac{\gamma+1}{2} \mathbb{E}_{t-1}\left(\Delta c_{i t}\right)^{2}
$$

and the conditional variance $E_{t-1} \epsilon_{i t}^{2}=\sigma_{i t-1}^{2}$. Then $E_{t-1}\left(\Delta c_{i t}\right)^{2}=E_{t-1}\left(g_{i t-1}+\epsilon_{i t}\right)^{2}=$ $g_{i t-1}^{2}+\sigma_{i t-1}^{2}$. Plugging the last formula to (B.9) and ignore $g_{i t}^{2}$, we have approximately (at $g_{i t}$ close to 0 )

$$
g_{i t-1}=a_{t-1}+b_{t-1} \sigma_{i t-1}^{2}
$$

where $b_{t-1}=\frac{\gamma+1}{2}$ and if $\gamma=1$ then $b_{t-1}$ is 1 . If

$$
\operatorname{cov}\left(\sigma_{i t-1}^{2}, c_{i t-1}\right)<0
$$

then

$$
\begin{aligned}
\operatorname{cov}\left(\Delta c_{i t}, c_{i t-1}\right) & =\operatorname{cov}\left(g_{i t-1}+\epsilon_{i t}, c_{i t-1}\right)=\operatorname{cov}\left(g_{i t-1}, c_{i t-1}\right) \\
& =\operatorname{cov}\left(b_{t-1} \sigma_{i t-1}^{2}, c_{i t-1}\right)<0
\end{aligned}
$$

Condition (B.11) says households with higher income in $t-1$ have lower risk premium. Suppose one can parameterize (B.11) by

$$
b_{t-1} \sigma_{i t-1}^{2}=b_{t-1} \sigma_{t-1}^{2}-f_{t-1} x_{i t-1}
$$

$\left(f_{t-1}>0\right)$ for some variable $x_{i t-1}$ that are positively correlated with $c_{i t-1}$.

$$
\Delta c_{i t} \approx \tau_{t-1}+u_{t-1} x_{i t-1}+\epsilon_{i t}
$$

where $u_{t-1}=-f_{t-1}<0$ and $\tau_{t-1}=a_{t-1}+b_{t-1} \sigma_{t-1}^{2}$. When we normalize $E c_{i t}$ at 0 , $\tau_{t-1}=0$. Hence we have a consumption model with heterogeneous conditional mean, 
which we refer as HCM consumption model.

$$
\Delta c_{i t}=u_{t-1} x_{i t-1}+\epsilon_{i t}
$$

where the consumption shock $\epsilon_{i t}$ is a sum of income shocks, wealth shocks, and shocks in risk premium with $\mathbb{E}_{t-1} \epsilon_{i t}=0$.

\section{B.2 Moment Conditions of $\frac{1}{\mathrm{~N}} \mathrm{CC}^{\prime}$ and $\frac{1}{\mathrm{~N}} \mathrm{YC}^{\prime}$}

\section{B.2.1 HIP-Consumption Model}

We estimate parameters $\operatorname{var}\left(c_{i 1}^{*}\right)$ and $\rho_{\gamma, c}=\operatorname{cov}\left(\gamma_{i}, c_{i 1}^{*}\right), \rho_{\beta, c}=\operatorname{cov}\left(\beta_{i}, c_{i 1}^{*}\right), \rho_{\xi, c}=$ $\operatorname{cov}\left(\xi_{i 1}, c_{i 1}^{*}\right)$. Assume $m_{i 1}$ is independent of all parameters. Hence

$$
\operatorname{cov}\left(y_{i j}, c_{i 1}\right)=\rho_{\gamma, c}+\left(j+t_{i}\right) \rho_{\beta, c}+\rho^{j-1} \rho_{\xi, c},
$$

for $t=1, . ., T$. From (B.16)

$$
\operatorname{cov}\left(y_{i 1}, c_{i 1}\right)+\operatorname{cov}\left(y_{i 3}, c_{i 1}\right)-2 \operatorname{cov}\left(y_{i 2}, c_{i 1}\right)=\left(1+\rho^{2}-2 \rho\right) \rho_{\xi, c},
$$

and

$$
\operatorname{cov}\left(y_{i 2}, c_{i 1}\right)+\operatorname{cov}\left(y_{i 4}, c_{i 1}\right)-2 \operatorname{cov}\left(y_{i 3}, c_{i 1}\right)=\rho\left(1+\rho^{2}-2 \rho\right) \rho_{\xi, c} .
$$

Take the ratio of (B.17) and (B.18) yields $\rho$. Plug $\rho$ into (B.17) yields $\rho_{\xi, c}$. Given $\rho$ and $\rho_{\xi, c}$, one can solve $\rho_{\beta, c}$ from (B.16)

$$
\operatorname{cov}\left(\Delta y_{i 2}, c_{i 1}\right)=\rho_{\beta, c}+(\rho-1) \rho_{\xi, c}
$$


Lastly, given $\rho, \rho_{\xi, c}$, and $\rho_{\beta, c}$, one can solve $\rho_{\gamma, c}$ from (B.16) with $j=1$.

$$
\operatorname{var}\left(c_{i 1}\right)=\operatorname{var}\left(c_{i 1}^{*}\right)+\sigma_{m}^{2} .
$$

If for $\mathrm{t}=2, . ., \mathrm{T}, \sigma_{\xi_{t}}^{2}$ is identified from moments of income then $\phi_{t}$ can be identified from $\operatorname{cov}\left(\Delta y_{i t}, \Delta c_{i t}\right)=\psi_{t} \sigma_{\xi_{t}}^{2}$. And with $\sigma_{m}^{2}, \psi_{t}, \sigma_{\xi_{t}}^{2}$ identified, the variance $\sigma_{\omega_{t}}^{2}$ can be identified from $\operatorname{var}\left(\Delta c_{i t}\right)=\psi_{t}^{2} \sigma_{\xi_{t}}^{2}+\sigma_{\omega_{t}}^{2}+2 \sigma_{m}^{2}$, for $t=2, . ., T$. Hence all parameters are identified in this model.

With this identified HIP model we can write the moments of consumption as

$$
\operatorname{var}\left(c_{i 1}\right)=\operatorname{var}\left(c_{i 1}^{*}\right)+\sigma_{m}^{2} .
$$

$\operatorname{cov}\left(y_{i t}, c_{i 1}\right)$ is give by (B.16).

And for $\mathrm{t}=2, . ., \mathrm{T}$

$$
\begin{gathered}
\operatorname{var}\left(c_{i t}^{*}\right)=\operatorname{var}\left(c_{i 1}^{*}\right)+\sum_{k=2}^{t} \psi_{k}^{2} \sigma_{\xi_{k}}^{2}+\sum_{k=2}^{t} \sigma_{\omega_{k}}^{2} \\
\operatorname{var}\left(c_{i t}\right)=\operatorname{var}\left(c_{i t}^{*}+m_{i t}\right)=\operatorname{var}\left(c_{i t}^{*}\right)+\operatorname{var}\left(m_{i t}\right)=\operatorname{var}\left(c_{i 1}^{*}\right)+\sum_{k=2}^{t} \psi_{k}^{2} \sigma_{\xi_{k}}^{2}+\sum_{k=2}^{t} \sigma_{\omega_{k}}^{2}+\sigma_{m}^{2}, \\
\operatorname{cov}\left(c_{i t}, c_{i t+s}\right)=\operatorname{cov}\left(c_{i t}^{*}+m_{i t}, c_{i t+s}^{*}+m_{i t+s}\right)=\operatorname{var}\left(c_{i t}^{*}\right)
\end{gathered}
$$

for $\mathrm{t}=2, \ldots, \mathrm{T}$

$$
\begin{aligned}
\operatorname{cov}\left(y_{i t}, c_{i t}\right) & =\operatorname{cov}\left(\gamma_{i}+\beta_{i} t+v_{i t}, c_{i t}^{*}+m_{i t}\right) \\
& =\operatorname{cov}\left(\gamma_{i}+\beta_{i} t+\rho^{t-1} v_{i 1}+\sum_{k=2}^{t} \rho^{t-k} \xi_{i k}, c_{i 1}^{*}+\sum_{k=2}^{t} \psi_{k} \xi_{i k}+\sum_{k=2}^{t} \omega_{i k}+m_{i t}\right) \\
& =\rho_{\gamma, c}+\left(t+t_{i}\right) \rho_{\beta, c}+\rho^{t-1} \rho_{\xi, c}+\sum_{k=2}^{t} \rho^{t-k} \psi_{k} \sigma_{\xi_{k}}^{2},
\end{aligned}
$$




$$
\begin{aligned}
& \operatorname{cov}\left(y_{i t}, c_{i t+s}\right)=\operatorname{cov}\left(\gamma_{i}+\beta_{i} t+v_{i t}, c_{i t+s}^{*}+m_{i t+s}\right)=\operatorname{cov}\left(y_{i t}, c_{i t}\right), \\
& \operatorname{cov}\left(y_{i t+s}, c_{i t}\right)=\operatorname{cov}\left(\gamma_{i}+\beta_{i}(t+s)+v_{i t+s}, c_{i t}^{*}+m_{i t}\right) \\
&=\operatorname{cov}\left(\gamma_{i}+\beta_{i}(t+s)+\rho^{s} v_{i t}+\sum_{k=1}^{s} \rho^{s-k} \xi_{i t+k}, c_{i 1}^{*}+\sum_{k=2}^{t} \psi_{k} \xi_{i k}+\sum_{k=2}^{t} \omega_{i k}+m_{i t}\right) \\
&=\rho_{\gamma, c}+\left(t+s+t_{i}\right) \rho_{\beta, c}+\rho^{t+s-1} \rho_{\xi, c}+\rho^{s} \sum_{k=2}^{t} \rho^{t-k} \psi_{k} \sigma_{\xi_{k}}^{2} .
\end{aligned}
$$

$\operatorname{Parameters}(\boldsymbol{\theta})=52\left(\left\{\rho, \sigma_{\gamma}^{2}, \sigma_{\beta}^{2}, \operatorname{cov}(\beta, \gamma), \operatorname{var}\left(c_{i 1}^{*}\right), \rho_{\gamma, c}, \rho_{\beta, c}, \rho_{\xi, c}, \sigma_{m}^{2}, \sigma_{\xi_{t}}^{2}, \psi_{t}, \sigma_{\omega_{t}}^{2}\right\}\right)$ where $\sigma_{\xi_{t}}^{2}$ for $\mathrm{t}=1, . ., 15, \psi_{t}$ for $\mathrm{t}=2, . ., 15$, and $\sigma_{\omega_{t}}^{2}$ for $\mathrm{t}=2, . ., 15$.

\section{B.2.2 RIP-Consumption Model}

Income Model

$$
\text { RIP Model : } y_{i t}=P_{i t}+v_{i t} \text {. }
$$

The permanent component is

$$
P_{i t}=P_{i t-1}+\zeta_{i t}
$$

where $\zeta$ is permanent income shock with variance $\sigma_{t, \zeta}^{2}$, and the transitory component is $v_{i t}=\xi_{i, t}+\theta_{1} \xi_{i, t-1}$. It follows that income growth

$$
\Delta y_{i t}=\zeta_{i t}+\Delta v_{i t}=\zeta_{i t}+\xi_{i, t}+(\theta-1) \xi_{i, t-1}-\theta \xi_{i t-2} .
$$

Real consumption growth

$$
\Delta c_{i t}^{*}=\phi_{t} \zeta_{i t}+\psi_{t} \xi_{i t}+\omega_{i t}
$$

$\zeta_{i t}$ and $\xi_{i t}$ are permanent and transitory income shocks, $\omega_{i t}$ are other shocks.

We assume consumption in period $t$ is observed with a measurement error $m_{i t}$, so $c_{i t}=c_{i t}^{*}+m_{i t}$ and $\operatorname{cov}\left(c_{i t}^{*}, m_{i t}\right)=0$. 
Chapter 1 shows the parameters $\operatorname{var}\left(P_{i 1}\right) \sigma_{\xi, t}^{2}(\mathrm{t}=0, . ., \mathrm{T}-1), \sigma_{\zeta, t}^{2}(\mathrm{t}=2, . ., \mathrm{T}-1)$, and $\theta$ in the income process can be identified from income data alone. Additional parameters that we need to estimate for consumption model include $\operatorname{var}\left(c_{i 1}^{*}\right), \phi_{t}, \psi_{t}, \sigma_{\omega, t}^{2}$, and $\sigma_{m}^{2}$. We assume measurement error in consumption is uncorrelated with other shocks.

As in the consumption model with HIP income process, one can identify $\sigma_{m}^{2}$ from $\sigma_{m}^{2}=\operatorname{var}\left(c_{i 1}\right)-\operatorname{cov}\left(c_{i 1}, c_{i 2}\right)=\operatorname{cov}\left(\Delta c_{i 2}, c_{i 1}\right)$ and $\operatorname{var}\left(c_{i 1}^{*}\right)=\operatorname{var}\left(c_{i 1}\right)-\sigma_{m}^{2}$.

In addition we assume $\operatorname{cov}\left(\xi_{i 0}, c_{i 1}^{*}\right)=0$ and estimate $\rho_{p, c}=\operatorname{cov}\left(P_{i 1}, c_{i 1}^{*}\right)$, and $\rho_{\xi, c}=\operatorname{cov}\left(\xi_{i 1}, c_{i 1}^{*}\right)$.

With $\operatorname{cov}\left(\xi_{i 0}, c_{i 1}^{*}\right)=0$, we have

$$
\operatorname{cov}\left(y_{i 1}, c_{i 1}\right)=\rho_{p, c}+\rho_{\xi, c},
$$

and because $\operatorname{cov}\left(\zeta_{i 2}, c_{i 1}^{*}\right)=0, \operatorname{cov}\left(\xi_{i 2}, c_{i 1}^{*}\right)=0$

$$
\operatorname{cov}\left(y_{i 2}, c_{i 1}\right)=\rho_{p, c}+\theta \rho_{\xi, c} .
$$

Taking the difference of (B.31) and (B.30) yields

$$
\operatorname{cov}\left(\Delta y_{i 2}, c_{i 1}\right)=(\theta-1) \rho_{\xi, c}
$$

Since $\theta$ can be identified from income model, (B.32) solves $\rho_{\xi, c}$. Plugging $\rho_{\xi, c}$ into (B.30) solves $\rho_{p, c}$.

Now with $\rho_{p, c}, \rho_{\xi, c}, \sigma_{\zeta 2}^{2}, \sigma_{\xi 2}^{2}, \theta$ identified we show $\phi_{2}$ and $\psi_{2}$ can be identified.

$$
\begin{aligned}
& \operatorname{cov}\left(y_{i 2}, c_{i 2}\right) \\
& =\operatorname{cov}\left(P_{i 2}+v_{i 2}, c_{i 1}^{*}+\phi_{2} \zeta_{i 2}+\psi_{2} \xi_{i 2}+\omega_{i 2}+m_{i 2}-m_{i 1}\right) \\
& =\operatorname{cov}\left(P_{i 1}+\zeta_{i 2}+\xi_{i 2}+\theta \xi_{i 1}, c_{i 1}^{*}+\phi_{2} \zeta_{i 2}+\psi_{2} \xi_{i 2}+\omega_{i 2}+m_{i 2}-m_{i 1}\right) \\
& =\rho_{p, c}+\phi_{2} \sigma_{\zeta_{2}}^{2}+\psi_{2} \sigma_{\xi 2}^{2}+\theta \rho_{\xi, c}, \\
& \quad \text { and }
\end{aligned}
$$




$$
\begin{aligned}
& \operatorname{cov}\left(y_{i 3}, c_{i 2}\right) \\
& =\operatorname{cov}\left(P_{i 3}+v_{i 3}, c_{i 1}^{*}+\phi_{2} \zeta_{i 2}+\psi_{2} \xi_{i 2}+\omega_{i 2}+m_{i 2}-m_{i 1}\right) \\
& =\operatorname{cov}\left(P_{i 1}+\zeta_{i 3}+\zeta_{i 2}+\xi_{i 3}+\theta \xi_{i 2}, c_{i 1}^{*}+\phi_{2} \zeta_{i 2}+\psi_{2} \xi_{i 2}+\omega_{i 2}+m_{i 2}-m_{i 1}\right) \\
& =\rho_{p, c}+\phi_{2} \sigma_{\zeta_{2}}^{2}+\theta \psi_{2} \sigma_{\xi 2}^{2}
\end{aligned}
$$

Taking the difference of the two equations,

$$
\operatorname{cov}\left(\Delta y_{i 3}, c_{i 2}\right)=\sigma_{\xi 2}^{2}(\theta-1) \psi_{2}-\theta \rho_{\xi, c}
$$

From (B.33) we can solve $\psi_{2}$. Plugging $\psi_{2}$ solved into $\operatorname{cov}\left(y_{i 3}, c_{i 2}\right)$ solves $\phi_{2}$.

Similarly we can identify $\phi_{t}$ and $\psi_{t}$ for $t=3, . ., T-1$. We identify $\sigma_{\omega_{t}}^{2}$ from $\operatorname{var}\left(\Delta c_{i t}\right)=\phi_{t}^{2} \sigma_{\xi_{t}}^{2}+\sigma_{\omega_{t}}^{2}+2 \sigma_{m}^{2}$, for $t=2, . ., T$.

The parameters to be estimated are $\operatorname{var}\left(c_{i 1}^{*}\right), \sigma_{m}^{2}, \rho_{p, c}=\operatorname{cov}\left(P_{i 1}, c_{i 1}^{*}\right)$, and $\rho_{\xi, c}=$ $\operatorname{cov}\left(\xi_{i 1}, c_{i 1}^{*}\right)$; as well as $\phi_{t}, \psi_{t}, \sigma_{\omega_{t}}^{2}$ for $\mathrm{t}=2, . ., \mathrm{T}-1$. The total number of parameters concerning the consumption model is $3 T-2$. We assume $\operatorname{cov}\left(\xi_{i 0}, c_{i 1}^{*}\right)=0$.

One can identify $\sigma_{m}^{2}$ from $\sigma_{m}^{2}=\operatorname{var}\left(c_{i 1}\right)-\operatorname{cov}\left(c_{i 1}, c_{i 2}\right)=\operatorname{cov}\left(\Delta c_{i 2}, c_{i 1}\right)$.

We identify $\operatorname{var}\left(c_{i 1}^{*}\right)=\operatorname{var}\left(c_{i 1}\right)-\sigma_{m}^{2}$. The moment conditions for $\operatorname{var}\left(c_{i t}\right)$ are for $t=1$,

$$
\operatorname{var}\left(c_{i 1}\right)=\operatorname{var}\left(c_{i 1}^{*}\right)+\sigma_{m}^{2},
$$

for $t>1$,

$$
\begin{aligned}
& \operatorname{var}\left(c_{i t}\right)=\operatorname{var}\left(c_{i t}^{*}+m_{i t}\right)=\operatorname{var}\left(c_{i t}^{*}\right)+\operatorname{var}\left(m_{i t}\right) \\
& =\operatorname{var}\left(c_{i 1}^{*}\right)+\sum_{k=2}^{t} \phi_{k}^{2} \sigma_{\zeta_{k}}^{2}+\sum_{k=2}^{t} \psi_{k}^{2} \sigma_{\xi_{k}}^{2}+\sum_{k=2}^{t} \sigma_{\omega_{k}}^{2}+\sigma_{m}^{2} . \\
& \begin{array}{r}
\operatorname{cov}\left(c_{i t}, c_{i t+s}\right)=\operatorname{cov}\left(c_{i t}^{*}+m_{i t}, c_{i t+s}^{*}+m_{i t+s}\right)=\operatorname{var}\left(c_{i t}^{*}\right) \\
=\operatorname{var}\left(c_{i 1}^{*}\right)+\sum_{k=2}^{t} \phi_{k}^{2} \sigma_{\zeta_{k}}^{2}+\sum_{k=2}^{t} \psi_{k}^{2} \sigma_{\xi_{k}}^{2}+\sum_{k=2}^{t} \sigma_{\omega_{k}}^{2},
\end{array}
\end{aligned}
$$


The covariances of income and consumption are

$$
\begin{aligned}
\operatorname{cov}\left(y_{i t}, c_{i 1}\right) & =\operatorname{cov}\left(P_{i t}+v_{i t}, c_{i 1}^{*}+m_{i 1}\right) \\
& =\operatorname{cov}\left(P_{i 1}+\sum_{k=2}^{t} \zeta_{i k}+\xi_{i t}+\theta \xi_{i t-1}, c_{i 1}^{*}+m_{i 1}\right) \\
& =\operatorname{cov}\left(P_{i 1}, c_{i 1}^{*}\right)+\operatorname{cov}\left(\xi_{i t}, c_{i 1}^{*}\right)+\operatorname{cov}\left(\theta \xi_{i t-1}, c_{i 1}^{*}\right) \\
& = \begin{cases}\operatorname{cov}\left(P_{i 1}, c_{i 1}^{*}\right)+\operatorname{cov}\left(\xi_{i t}, c_{i 1}^{*}\right), & \text { for } t=1 \\
\operatorname{cov}\left(P_{i 1}, c_{i 1}^{*}\right)+\theta \operatorname{cov}\left(\xi_{i 1}, c_{i 1}^{*}\right) & \text { for } t=2, \\
\operatorname{cov}\left(P_{i 1}, c_{i 1}^{*}\right) & \text { for } t>2\end{cases}
\end{aligned}
$$

For $\mathrm{t}=2, . ., \mathrm{T}-1$

$$
\begin{aligned}
\operatorname{cov}\left(y_{i t}, c_{i t}\right) & =\operatorname{cov}\left(P_{i t}+v_{i t}, c_{i t}^{*}+m_{i t}\right) \\
& =\operatorname{cov}\left(P_{i 1}+\sum_{k=2}^{t} \zeta_{i k}+\xi_{i t}+\theta \xi_{i t-1}, c_{i 1}^{*}+\sum_{k=2}^{t} \phi_{k} \zeta_{i k}+\sum_{k=2}^{t} \psi_{k} \xi_{i k}+\sum_{k=2}^{t} \omega_{i k}+m_{i t}\right) \\
& =\operatorname{cov}\left(P_{i 1}, c_{i 1}^{*}\right)+\sum_{k=2}^{t} \phi_{k} \sigma_{\zeta_{k}}^{2}+\psi_{t} \sigma_{\xi_{t}}^{2}+\theta \psi_{t-1} \sigma_{\xi_{t-1}}^{2} .
\end{aligned}
$$

For $s \geq 1$,

$$
\begin{aligned}
\operatorname{cov}\left(y_{i t}, c_{i t+s}\right) & =\operatorname{cov}\left(P_{i 1}+\sum_{k=2}^{t} \zeta_{i k}+\xi_{i t}+\theta \xi_{i t-1}, c_{i 1}^{*}+\sum_{k=2}^{t+s} \phi_{k} \zeta_{i k}+\sum_{k=2}^{t+s} \psi_{k} \xi_{i k}+\sum_{k=2}^{t+s} \omega_{i k}+m_{i t+s}\right) \\
& =\operatorname{cov}\left(y_{i t}, c_{i t}\right)
\end{aligned}
$$


For $t=2, . ., T-1$,

$$
\begin{aligned}
\operatorname{cov}\left(y_{i t+1}, c_{i t}\right) & =\operatorname{cov}\left(P_{i 1}+\sum_{k=2}^{t+1} \zeta_{i k}+\xi_{i t+1}+\theta \xi_{i t}, c_{i 1}^{*}+\sum_{k=2}^{t} \phi_{k} \zeta_{i k}+\sum_{k=2}^{t} \psi_{k} \xi_{i k}+\sum_{k=2}^{t} \omega_{i k}+m_{i t}\right) \\
& =\operatorname{cov}\left(P_{i 1}, c_{i 1}^{*}\right)+\sum_{k=2}^{t} \phi_{k} \sigma_{\zeta_{k}}^{2}+\theta \psi_{t} \sigma_{\xi_{t}}^{2},
\end{aligned}
$$

$$
\begin{aligned}
\operatorname{cov}\left(y_{i t+s}, c_{i t}\right) & =\operatorname{cov}\left(P_{i 1}+\sum_{k=2}^{t+s} \zeta_{i k}+\xi_{i t+s}+\theta \xi_{i t+s-1}, c_{i 1}^{*}+\sum_{k=2}^{t} \phi_{k} \zeta_{i k}+\sum_{k=2}^{t} \psi_{k} \xi_{i k}+\sum_{k=2}^{t} \omega_{i k}+m_{i t}\right) \\
& =\operatorname{cov}\left(P_{i 1}, c_{i 1}^{*}\right)+\sum_{k=2}^{t} \phi_{k} \sigma_{\zeta_{k}}^{2}, \text { for } \mathrm{s} \geq 2
\end{aligned}
$$

\section{The Moments Used For Estimation}

1. $\operatorname{Cov}\left(y_{i t}, y_{i s}\right)$ Moments

$$
\begin{aligned}
\operatorname{var}\left(y_{i t}\right)= \begin{cases}\operatorname{var}\left(P_{i 1}\right)+\sigma_{\xi_{1}}^{2}+\theta^{2} \sigma_{\xi_{0}}^{2}, & \text { for } t=1 \\
\operatorname{var}\left(P_{i 1}\right)+\sum_{k=2}^{t} \sigma_{\zeta_{k}}^{2}+\sigma_{\xi_{t}}^{2}+\theta^{2} \sigma_{\xi_{t-1}}^{2}, & \text { for } 2 \leq t \leq 15, \\
\operatorname{var}\left(P_{i 1}\right)+\sum_{k=2}^{15} \sigma_{\zeta_{k}}^{2}+\sigma_{\zeta_{15}}^{2}+\sigma_{\xi_{15}}^{2}+\theta^{2} \sigma_{\xi_{15}}^{2} & \text { for } t=16\end{cases} \\
\operatorname{cov}\left(y_{i 1}, y_{i 1+s}\right)= \begin{cases}\operatorname{var}\left(P_{i 1}\right)+\theta \sigma_{\xi_{1}}^{2}, & \text { for } s=1 \\
\operatorname{var}\left(P_{i 1}\right) & \text { for } 2 \leq s \leq 15 \\
\operatorname{var}\left(P_{i 1}\right)+\sum_{k=2}^{t} \sigma_{\zeta_{k}}^{2}+\theta \sigma_{\xi_{t}}^{2}, & \text { for } 2 \leq t \leq 15, s=1 \\
\operatorname{var}\left(P_{i 1}\right)+\sum_{k=2}^{t} \sigma_{\zeta_{k}}^{2} & \text { for } 2 \leq t \leq 15,2 \leq s \leq 16-t\end{cases} \\
\operatorname{cov}\left(y_{i t}, y_{i t+s}\right)=\left\{\begin{array}{l}
\operatorname{var}\left(y_{i 1}\right)-\operatorname{cov}\left(y_{i 1}, y_{i 3}\right)=\sigma_{\xi_{1}}^{2}+\theta^{2} \sigma_{\xi_{0}}^{2}, \\
\operatorname{cov}\left(y_{i 1}, y_{i 2}\right)-\operatorname{cov}\left(y_{i 1}, y_{i 3}\right)=\theta \sigma_{\xi_{1}}^{2},
\end{array}\right. \\
\operatorname{cov}\left(y_{i 2}, y_{i 3}\right)-\operatorname{cov}\left(y_{i 2}, y_{i 4}\right)=\theta \sigma_{\xi_{2}}^{2} .
\end{aligned}
$$


2. $\operatorname{Cov}\left(c_{i t}, c_{i s}\right)$ Moments

$\operatorname{var}\left(c_{i t}\right)= \begin{cases}\operatorname{var}\left(c_{i 1}^{*}\right)+\sigma_{m}^{2}, & \text { for } t=1 \\ \operatorname{var}\left(c_{i 1}^{*}\right)+\sum_{k=2}^{t} \phi_{k}^{2} \sigma_{\zeta_{k}}^{2}+\psi_{k}^{2} \sigma_{\xi_{k}}^{2}+\sigma_{\omega_{k}}^{2}+\sigma_{m}^{2}, & \text { for } 2 \leq t \leq 15 \\ \operatorname{var}\left(c_{i 1}^{*}\right)+\sum_{k=2}^{15} \phi_{k}^{2} \sigma_{\zeta_{k}}^{2}+\psi_{k}^{2} \sigma_{\xi_{k}}^{2}+\sigma_{\omega_{k}}^{2}+\phi_{15}^{2} \sigma_{\zeta_{15}}^{2}+\psi_{15}^{2} \sigma_{\xi_{15}}^{2}+\sigma_{\omega_{16}}^{2}+\sigma_{m}^{2} & \text { for } t=16\end{cases}$

$\operatorname{cov}\left(c_{i t}, c_{i t+s}\right)=\operatorname{var}\left(c_{i t}\right)-\sigma_{m}^{2}$ for $1 \leq t \leq 15,1 \leq s \leq 16-t$.

3. $\operatorname{Cov}\left(y_{i t}, c_{i s}\right)$ Moments

$$
\begin{aligned}
& \operatorname{cov}\left(y_{i t}, c_{i t}\right)=\left\{\begin{array}{ll}
\rho_{p, c}+\rho_{\xi, c}, & \text { for } t=1 \\
\rho_{p, c}+\phi_{2} \sigma_{\zeta_{2}}^{2}+\psi_{2} \sigma_{\xi_{2}}^{2}+\theta \rho_{\xi, c}, & \text { for } t=2 \\
\rho_{p, c}+\sum_{k=2}^{t} \phi_{k} \sigma_{\zeta_{k}}^{2}+\psi_{t} \sigma_{\xi_{t}}^{2}+\theta \psi_{t-1} \sigma_{\xi_{t-1}}^{2}, & \text { for } 3 \leq t \leq 15 \\
\rho_{p, c}+\sum_{k=2}^{15} \phi_{k} \sigma_{\zeta_{k}}^{2}+\phi_{15} \sigma_{\zeta_{15}}^{2}+\psi_{15} \sigma_{\xi_{15}}^{2}+\theta \psi_{15} & \text { for } t=16
\end{array},\right. \\
& \operatorname{cov}\left(y_{i t}, c_{i t+s}\right)=\operatorname{cov}\left(y_{i t}, c_{i t}\right) \text { for } 1 \leq t \leq 15,1 \leq s \leq 16-t \text {, } \\
& \operatorname{cov}\left(y_{i 1+s}, c_{i 1}\right)\left\{\begin{array}{ll}
\rho_{p, c}+\theta \rho_{\xi, c}, & \text { for } s=1 \\
\rho_{p, c} & \text { for } 2 \leq s \leq 15
\end{array},\right. \\
& \operatorname{cov}\left(y_{i t+s}, c_{i t}\right)\left\{\begin{array}{ll}
\rho_{p, c}+\sum_{k=2}^{t} \phi_{k} \sigma_{\zeta_{k}}^{2}+\theta \psi_{t} \sigma_{\zeta_{t}}^{2}, & \text { for } 2 \leq t \leq 15, s=1 \\
\rho_{p, c}+\sum_{k=2}^{t} \phi_{k} \sigma_{\zeta_{k}}^{2} & \text { for } 2 \leq t \leq 15,2 \leq s \leq 16-t
\end{array},\right. \\
& \operatorname{cov}\left(y_{i 2}, c_{i 1}\right)-\operatorname{cov}\left(y_{i 1}, c_{i 1}\right)=(\theta-1) \rho_{\xi, c}, \\
& \operatorname{cov}\left(y_{i 3}, c_{i 2}\right)-\operatorname{cov}\left(y_{i 2}, c_{i 2}\right)=(\theta-1) \psi_{2} \sigma_{\xi_{2}}^{2}-\theta \rho_{\xi, c} .
\end{aligned}
$$

$\operatorname{Parameters}(\boldsymbol{\theta})=78\left(\left\{\theta, \operatorname{var}\left(P_{i 1}\right), \operatorname{var}\left(c_{i 1}^{*}\right), \rho_{p, c}, \rho_{\xi, c}, \sigma_{m}^{2}, \sigma_{\zeta_{t}}^{2}, \sigma_{\xi_{t}}^{2}, \phi_{t}, \psi_{t}, \sigma_{\omega_{t}}^{2}\right\}\right)$ where $\sigma_{\zeta_{t}}^{2}$ for $\mathrm{t}=2, . ., 15, \sigma_{\xi_{t}}^{2}$ for $\mathrm{t}=0, . ., 15, \phi_{t}$ for $\mathrm{t}=2, . ., 15, \psi_{t}$ for $\mathrm{t}=2, . ., 15$, and $\sigma_{\omega_{t}}^{2}$ for $\mathrm{t}=2, . ., 15$. 


\section{B.2.3 The BPP Estimation of RIP-Consumption Model}

With MA(1) transitory income shocks

$$
\Delta y_{i t}=\zeta_{i t}+\Delta v_{i t}=\zeta_{i t}+\xi_{i t}+(\theta-1) \xi_{i t-1}+\xi_{i t-2}
$$

With $t=3, . ., T-2$

$$
\begin{aligned}
& \operatorname{cov}\left(\Delta y_{t}, \Delta y_{t-2}+\Delta y_{t-1}+\Delta y_{t}+\Delta y_{t+1}+\Delta y_{t+2}\right) \\
& =\operatorname{cov}\left(\zeta_{i t}+v_{i t}-v_{i t-1}, \zeta_{i t-2}+\zeta_{i t-1}+\zeta_{i t}+\zeta_{i t+1}+\zeta_{i t+2}+v_{i t+2}-v_{i t-3}\right) \\
& =\operatorname{var}\left(\zeta_{t}\right)
\end{aligned}
$$

$$
\begin{aligned}
& \operatorname{cov}\left(\Delta y_{i t}, \Delta y_{i t+2}+\Delta y_{i t+1}\right) \\
& =\left[\left(\zeta_{i t}+\left(\xi_{i t}+(\theta-1) \xi_{i t-1}-\theta \xi_{i t-2}\right)\left(\zeta_{i t+2}+\zeta_{i t+1}+\left(\xi_{i t+2}+\theta \xi_{i t+1}-\xi_{i t}\right)\right)\right]\right. \\
& =-\operatorname{var}\left(\xi_{t}\right)
\end{aligned}
$$

Identification of Consumption Process based on $\operatorname{cov}(\Delta c, \Delta y)$

Covariances of consumption growth and income growth can be used to identify the insurance parameters:

$$
\begin{aligned}
& \operatorname{cov}\left(\Delta c_{t}, \Delta y_{t+s}\right)=\phi_{t} \operatorname{var}\left(\zeta_{t}\right)+\psi_{t} \operatorname{var}\left(\xi_{t}\right), \text { for } s=0 \\
& \operatorname{cov}\left(\Delta c_{t}, \Delta y_{t+s}\right)=\psi_{t} \operatorname{cov}\left(\xi_{t}, \Delta v_{t+s}\right) \text { for } s>0 \\
& \operatorname{cov}\left(\Delta c_{t}, \Delta y_{t+s}\right)=0 \text { for } s<0 .
\end{aligned}
$$

If $v$ is an $\mathrm{MA}(1)$ process, then $\operatorname{cov}\left(\Delta v_{t}, \Delta v_{t+s}\right)$ is zero whenever $|s|>2$.

Identification of Consumption Process The autocovariances of consumption growth can identify the variance of the error term in the consumption equation:

$$
\operatorname{cov}\left(\Delta c_{t}, \Delta c_{t+s}\right)=\phi_{t}^{2} \operatorname{var}\left(\zeta_{t}\right)+\psi_{t}^{2} \operatorname{var}\left(\xi_{t}\right)+\operatorname{var}\left(\omega_{t}\right), \text { for } s=0
$$

The moments of consumption growth highlight the assumption on independence: 
for any $s \neq 0$

$$
\operatorname{cov}\left(\Delta c_{t}, \Delta c_{t+s}\right)=E\left[\left(\phi \zeta_{i t}+\psi \xi_{i t}+\omega_{i t}\right)\left(\phi \zeta_{i t+s}+\psi \xi_{i t+s}+\omega_{i t+s}\right)\right]=0
$$

because $\operatorname{cov}\left(\zeta_{i t}, \zeta_{i t+s}\right)=0, \operatorname{cov}\left(\xi_{i t}, \xi_{i t+s}\right)=0, \operatorname{cov}\left(\omega_{i t}, \omega_{i t+s}\right)=0$, regardless of the MA process for the transitory component $v_{i t}$.

The partial insurance parameter $\phi_{t}$ in BPP:

$$
\begin{aligned}
& \operatorname{cov}\left(\Delta c_{i t},\left(\Delta y_{t-2}+\Delta y_{t-1}+\Delta y_{t}+\Delta y_{t+1}+\Delta y_{t+2}\right)\right) \\
& =E\left[\left(\phi_{t} \zeta_{i t}+\psi_{t} \xi_{i t}+\omega_{i t}\right)\left(\zeta_{i t-2}+\zeta_{i t-1}+\zeta_{i t}+\zeta_{i t+1}+\zeta_{i t+2}+v_{i t+2}-v_{i t-3}\right)\right] \\
& =\phi_{t} \operatorname{var}\left(\zeta_{i t}\right),
\end{aligned}
$$

Recall $E\left[\Delta y_{i t}\left(\Delta y_{t-2}+\Delta y_{t-1}+\Delta y_{t}+\Delta y_{t+1}+\Delta y_{t+2}\right)\right]=\operatorname{var}\left(\zeta_{i t}\right)$, hence

$$
\frac{E\left[\Delta c_{i t}\left(\Delta y_{t-2}+\Delta y_{t-1}+\Delta y_{t}+\Delta y_{t+1}+\Delta y_{t+2}\right)\right]}{E\left[\Delta y_{i t}\left(\Delta y_{t-2}+\Delta y_{t-1}+\Delta y_{t}+\Delta y_{t+1}+\Delta y_{t+2}\right)\right]}=\phi_{t} .
$$

Similarly, the partial insurance to transitory shocks for BPP is $\frac{E\left(\Delta c_{i t}\left(\Delta y_{i t+2}+\Delta y_{i t+1}\right)\right)}{E\left(\Delta y_{i t}\left(\Delta y_{i t+2}+\Delta y_{i t+1}\right)\right)}=$ $\psi_{t}$.

To see why that's the case note

$$
\begin{aligned}
& \operatorname{cov}\left(\Delta c_{i t}, \Delta y_{i t+2}+\Delta y_{i t+1}\right) \\
& =E\left[\left(\phi_{t} \zeta_{i t}+\psi_{t} \xi_{i t}+\omega_{i t}\right)\left(\zeta_{i t+2}+\zeta_{i t+1}+\left(\xi_{i t+2}+\theta \xi_{i t+1}-\xi_{i t}\right)\right)\right]=-\psi_{t} v \operatorname{var}\left(\xi_{i t}\right),
\end{aligned}
$$

Recall $\operatorname{cov}\left(\Delta y_{i t}, \Delta y_{i t+2}+\Delta y_{i t+1}\right)=-\operatorname{var}\left(\xi_{i t}\right)$.

Hence the ratio $\frac{E\left(\Delta c_{i t}\left(\Delta y_{i t+2}+\Delta y_{i t+1}\right)\right)}{E\left(\Delta y_{i t}\left(\Delta y_{i t+2}+\Delta y_{i t+1}\right)\right)}=\psi_{t}$.

\section{B.2.4 GRIP-HCM Consumption Model}

We consider generalized-RIP with the consumption model in (3.13). Considering $x_{i t-1}=c_{i t-1}$ in $(3.13)$, 


\section{GRIP Model:}

$$
y_{i t}=P_{i t}+v_{i t} .
$$

The permanent component is

$$
P_{i t}=P_{i t-1}\left(1+f_{t}\right)+\zeta_{i t},
$$

where $\zeta$ is permanent income shock with variance $\sigma_{t, \zeta}^{2}$, and the transitory component is $v_{i t}=\xi_{i, t}+\theta_{1} \xi_{i, t-1}$.

The consumption model

$$
\begin{gathered}
\Delta c_{i t}^{*}=u_{t-1} x_{t-1}+\phi_{t} \zeta_{i t}+\psi_{t} \xi_{i, t}+\omega_{i t}, \\
c_{i t}=c_{i t}^{*}+m_{i t} .
\end{gathered}
$$

The parameters to be estimated in the income model: $V\left(P_{1}\right)\left(\right.$ or $\left.\sigma_{1, \zeta}^{2}\right), \sigma_{t, \xi}^{2}(\mathrm{t}=1, . ., \mathrm{T}-$ 1) and $\sigma_{t, \zeta}^{2}(\mathrm{t}=2, . ., \mathrm{T}-1), \theta$, and $f_{t}(\mathrm{t}=2, . ., \mathrm{T}-1)$. The parameters to be estimated in the consumption model are $\operatorname{var}\left(c_{i 1}^{*}\right), \sigma_{m}^{2}, \rho_{p, c}=\operatorname{cov}\left(P_{i 1}, c_{i 1}^{*}\right)$, and $\rho_{\xi, c}=\operatorname{cov}\left(\xi_{i 1}, c_{i 1}^{*}\right)$; as well as $\phi_{t}, \psi_{t}, \sigma_{\omega_{t}}^{2}$ for $\mathrm{t}=2, . ., \mathrm{T}-1 ; \delta_{t}$ for $\mathrm{t}=1, . ., \mathrm{T}-1$. We assume $\operatorname{cov}\left(\xi_{i 0}, c_{i 1}^{*}\right)=0$. The total number of parameters concerning the consumption model is $7 T-6$.

The equation (B.40) is $c_{i 1}^{*}$ at $t=1$ and for $t>1$

$$
c_{i t}^{*}=\prod_{j=1}^{t-1}\left(1+\delta_{j}\right) c_{i 1}^{*}+\sum_{j=2}^{t-1}\left(\prod_{k=j}^{t-1}\left(1+\delta_{j}\right)\left(\phi_{j} \zeta_{i j}+\psi_{j} \xi_{i j}+\omega_{i j}\right)\right)+\phi_{t} \zeta_{i t}+\psi_{t} \xi_{i t}+\omega_{i t} .
$$




$$
\begin{aligned}
& \operatorname{var}\left(c_{i t}\right)=\operatorname{var}\left(c_{i t}^{*}+m_{i t}\right)=\operatorname{var}\left(c_{i t}^{*}\right)+\sigma_{m}^{2} \\
& \operatorname{var}\left(c_{i t}^{*}\right)= \begin{cases}\operatorname{var}\left(c_{i 1}^{*}\right), & \text { for } t=1 \\
\left(1+\delta_{1}\right)^{2} \operatorname{var}\left(c_{i 1}^{*}\right)+\phi_{2}^{2} \sigma_{\zeta_{2}}^{2}+\psi_{2}^{2} \sigma_{\xi_{2}}^{2}+\sigma_{\omega_{2}}^{2}, & \text { for } t=2 \\
\prod_{j=1}^{t-1}\left(1+\delta_{j}\right)^{2} \operatorname{var}\left(c_{i 1}^{*}\right)+\sum_{j=2}^{t-1}\left(\prod_{k=j}^{t-1}\left(1+\delta_{j}\right)^{2} \phi_{j}^{2} \sigma_{\zeta_{j}}^{2}+\psi_{j}^{2} \sigma_{\xi_{j}}^{2}+\sigma_{\omega_{j}}^{2}\right) & \\
+\phi_{t}^{2} \sigma_{\zeta_{t}}^{2}+\psi_{t}^{2} \sigma_{\xi_{t}}^{2}+\sigma_{\omega_{t}}^{2}, & \text { for } t>3\end{cases} \\
& \operatorname{cov}\left(c_{i t}, c_{i t+s}\right)=\operatorname{cov}\left(c_{i t}^{*}+m_{i t}, c_{i t+s}^{*}+m_{i t+s}\right)=\prod_{j=t}^{t+s-1}\left(1+\delta_{j}\right) \operatorname{var}\left(c_{i t}^{*}\right) \\
& \operatorname{cov}\left(y_{i t}, c_{i t}\right)= \begin{cases}\rho_{p, c}+\rho_{\xi, c}, & \text { for } t=1 \\
\left(1+f_{2}\right)\left(1+\delta_{1}\right) \rho_{p, c}+\left(1+\delta_{1}\right) \theta \rho_{\xi, c}+\phi_{2} \sigma_{\zeta_{2}}^{2}+\psi_{2} \sigma_{\xi_{2}}^{2}, & \text { for } t=2 \\
\prod_{j=1}^{t-1}\left(\left(1+f_{j+1}\right)\left(1+\delta_{j}\right)\right) \rho_{p, c}+\sum_{k=2}^{t-1}\left(\prod_{j=k}^{t-1}\left(1+f_{j+1}\right)\left(1+\delta_{j}\right) \phi_{k} \sigma_{\zeta_{k}}^{2}\right) & \\
+\phi_{t} \sigma_{\zeta_{t}}^{2}+\left(1+f_{t}\right)\left(1+\delta_{t-1}\right) \theta \psi_{t-1} \sigma_{\xi_{t-1}}^{2}+\psi_{t} \sigma_{\xi_{t}}^{2}, & \text { for } t>2\end{cases} \\
& \operatorname{cov}\left(y_{i t}, c_{i t+s}\right)=\operatorname{cov}\left(y_{i t}, \prod_{j=t}^{t+s-1}\left(1+\delta_{j}\right) c_{i t}^{*}\right)=\prod_{j=t}^{t+s-1}\left(1+\delta_{j}\right) \operatorname{cov}\left(y_{i t}, c_{i t}\right) \\
& \operatorname{cov}\left(y_{i t+s}, c_{i t}\right)= \begin{cases}\left(1+f_{t+1}\right) \operatorname{cov}\left(P_{i t}, c_{i t}\right)+\theta \phi_{t} \sigma_{\xi_{t}}^{2}, & \text { for } s=1 \\
\prod_{j=t+1}^{t+s}\left(1+f_{j}\right) \operatorname{cov}\left(P_{i t}, c_{i t}\right), & \text { for } s>1\end{cases}
\end{aligned}
$$

where

$$
\operatorname{cov}\left(P_{i t}, c_{i t}\right)= \begin{cases}\rho_{p, c}, & \text { for } t=1 \\ \left(1+f_{2}\right)\left(1+\delta_{1}\right) \rho_{p, c}+\phi_{2} \sigma_{\zeta_{2}}^{2}, & \text { for } t=2 \\ \prod_{j=1}^{t-1}\left(\left(1+f_{j+1}\right)\left(1+\delta_{j}\right)\right) \rho_{p, c} & \\ +\sum_{k=2}^{t-1}\left(\prod_{j=k}^{t-1}\left(1+f_{j+1}\right)\left(1+\delta_{j}\right) \phi_{k} \sigma_{\zeta_{k}}^{2}\right)+\phi_{t} \sigma_{\zeta_{t}}^{2}, & \text { for } t>2\end{cases}
$$




\section{Bibliography}

Abe, Naohito and Tomoaki Yamada (2009) "Nonlinear income variance profiles and consumption inequality over the life cycle," Journal of the Japanese and International Economies, Vol. 23, pp. 344-366.

Aguiar, Mark and Mark Bils (2015) "Has consumption inequality mirrored income inequality?" American Economic Review, Vol. 105, pp. 2725-56.

Alderman, Harold, Jere R Behrman, Hans-Peter Kohler, John A Maluccio, and Susan Cotts Watkins (2001) "Attrition in longitudinal household survey data: some tests for three developing-country samples," Demographic research, Vol. 5, pp. 79124.

Andrews, Donald WK and Biao Lu (2001) "Consistent model and moment selection procedures for GMM estimation with application to dynamic panel data models," Journal of econometrics, Vol. 101, pp. 123-164.

Arellano, Manuel, Richard Blundell, and Stéphane Bonhomme (2017) "Earnings and consumption dynamics: a nonlinear panel data framework," Econometrica, Vol. 85, pp. 693-734.

Attanasio, Orazio, Erich Battistin, and Hidehiko Ichimura (2004) "What really happened to consumption inequality in the US?"Technical report, National Bureau of Economic Research.

Attanasio, Orazio, Erik Hurst, and Luigi Pistaferri (2012) "The evolution of income, consumption, and leisure inequality in the US, 1980-2010," Technical report, National Bureau of Economic Research.

Attanasio, Orazio P and Luigi Pistaferri (2016) "Consumption inequality," Journal of Economic Perspectives, Vol. 30, pp. 3-28.

Attanasio, Orazio P and Guglielmo Weber (1995) "Is consumption growth consistent with intertemporal optimization? Evidence from the consumer expenditure survey," Journal of political Economy, Vol. 103, pp. 1121-1157.

Baker, Michael (1997) "Growth-rate heterogeneity and the covariance structure of life-cycle earnings," Journal of labor Economics, Vol. 15, pp. 338-375. 
Baker, Michael and Gary Solon (2003) "Earnings dynamics and inequality among Canadian men, 1976-1992: Evidence from longitudinal income tax records," Journal of Labor Economics, Vol. 21, pp. 289-321.

Becker, Gary S (1975) "Front matter, human capital: a theoretical and empirical analysis, with special reference to education," in Human Capital: A Theoretical and Empirical Analysis, with Special Reference to Education, Second Edition: NBER, pp. $22-0$.

Becketti, Sean, William Gould, Lee Lillard, and Finis Welch (1988) "The panel study of income dynamics after fourteen years: An evaluation," Journal of Labor Economics, Vol. 6, pp. 472-492.

Blundell, Richard and Ben Etheridge (2010) "Consumption, income and earnings inequality in Britain," Review of Economic Dynamics, Vol. 13, pp. 76-102.

Blundell, Richard, Hamish Low, and Ian Preston (2013) "Decomposing changes in income risk using consumption data," Quantitative Economics, Vol. 4, pp. 1-37.

Blundell, Richard, Luigi Pistaferri, and Ian Preston (2008) "Consumption inequality and partial insurance," American Economic Review, Vol. 98, pp. 1887-1921.

Blundell, Richard and Ian Preston (1998) "Consumption inequality and income uncertainty," The Quarterly Journal of Economics, Vol. 113, pp. 603-640.

Carroll, Christopher D (1994) "How does future income affect current consumption?" The Quarterly Journal of Economics, Vol. 109, pp. 111-147.

Carroll, Christopher D and Lawrence H Summers (1991) "Consumption growth parallels income growth: some new evidence," in National saving and economic performance: University of Chicago Press, pp. 305-348.

Choi, Jemin, Sunghyun Kim, and Sangyeon Park (2018) "Income Inequality in Korea in the Post Global Financial Crisis Period," The Korean Journal of Economic Studies, Vol. 66, pp. 115-142.

Cutler, David M and Lawrence F Katz (1992) "Rising Inequality? Changes in the Distribution of Income and Consumption in the 1980s," Technical report, National Bureau of Economic Research.

Deaton, Angus and Christina Paxson (1994) "Intertemporal choice and inequality," Journal of political economy, Vol. 102, pp. 437-467.

Fitzgerald, John, Peter Gottschalk, and Robert Moffitt (1998) "An analysis of sample attrition in panel data: The Michigan Panel Study of Income Dynamics," Technical report, National Bureau of Economic Research.

Guvenen, Fatih (2009) "An empirical investigation of labor income processes," Review of Economic Dynamics, Vol. 12, pp. 58-79. 
Guvenen, Fatih, Fatih Karahan, Serdar Ozkan, and Jae Song (2015) "What do data on millions of US workers reveal about life-cycle earnings risk?" Technical report, National Bureau of Economic Research.

Haider, Steven J (2001) "Earnings instability and earnings inequality of males in the United States: 1967-1991," Journal of labor Economics, Vol. 19, pp. 799-836.

Haider, Steven and Gary Solon (2006) "Life-cycle variation in the association between current and lifetime earnings," American Economic Review, Vol. 96, pp. 1308-1320.

Heathcote, Jonathan, Fabrizio Perri, and Giovanni L Violante (2010) "Unequal we stand: An empirical analysis of economic inequality in the United States, 19672006," Review of Economic dynamics, Vol. 13, pp. 15-51.

Heathcote, Jonathan, Kjetil Storesletten, and Giovanni L Violante (2005) "Two views of inequality over the life cycle," Journal of the European Economic Association, Vol. 3, pp. 765-775.

Hong, Min-Ki (2015) "Top Wage Shares in the Long Run of Korea (1958-2013)," Korean Journal of Labor Studies, Vol. 21, pp. 191-220.

Jappelli, Tullio and Luigi Pistaferri (2010) "Does consumption inequality track income inequality in Italy?" Review of Economic Dynamics, Vol. 13, pp. 133-153.

Johnson, David S, Timothy M Smeeding, and Barbara Boyle Torrey (2005) "Economic inequality through the prisms of income and consumption," Monthly Lab. Rev., Vol. 128, p. 11.

Kaplan, Greg (2012) "Inequality and the life cycle," Quantitative Economics, Vol. 3, pp. $471-525$.

Kaplan, Greg and Giovanni L Violante (2010) "How much consumption insurance beyond self-insurance?" American Economic Journal: Macroeconomics, Vol. 2, pp. $53-87$.

Kim, Nak Nyeon and Jongil Kim (2015) "Top incomes in Korea, 1933-2010: Evidence from income tax statistics," Hitotsubashi Journal of Economics, pp. 1-19.

Krueger, Dirk and Fabrizio Perri (2006) "Does income inequality lead to consumption inequality? Evidence and theory," The Review of Economic Studies, Vol. 73, pp. 163-193.

Lise, Jeremy (2013) "On-the-job search and precautionary savings," Review of Economic Studies, Vol. 80, pp. 1086-1113.

Meghir, Costas and Luigi Pistaferri (2004) "Income variance dynamics and heterogeneity," Econometrica, Vol. 72, pp. 1-32.

Meyer, Bruce D, Wallace KC Mok, and James X Sullivan (2015) "Household surveys in crisis," Journal of Economic Perspectives, Vol. 29, pp. 199-226. 
Mincer, Jacob (1974) "Schooling, Experience, and Earnings. Human Behavior \& Social Institutions No. 2.."

Moffitt, Robert A and Peter Gottschalk (2011) "Trends in the covariance structure of earnings in the US: 1969-1987," The Journal of Economic Inequality, Vol. 9, pp. 439-459.

Morelli, Salvatore, Timothy Smeeding, and Jeffrey Thompson (2015) "Post-1970 trends in within-country inequality and poverty: rich and middle-income countries," in Handbook of income distribution, Vol. 2: Elsevier, pp. 593-696.

Primiceri, Giorgio E and Thijs Van Rens (2009) "Heterogeneous life-cycle profiles, income risk and consumption inequality," Journal of monetary Economics, Vol. 56, pp. 20-39.

Sabelhaus, John and Jeffrey A Groen (2000) "Can permanent-income theory explain cross-sectional consumption patterns?" Review of Economics and Statistics, Vol. 82, pp. 431-438.

Slesnick, Daniel T (1994) "Consumption, needs and inequality," International Economic Review, pp. 677-703.

Storesletten, Kjetil, Christopher I Telmer, and Amir Yaron (2004) "Consumption and risk sharing over the life cycle," Journal of monetary Economics, Vol. 51, pp. 609-633. 


\section{VITA}

Sanguk Kwon was born June 2, 1981 in South Korea. He received his bachelor's degree in double majors of statistics and economics from Kyungpook National University in South Korea in 2009. Then, he earned a master's degree in economics at Kyungpook National University in South Korea in 2012 and another master's degree in agricultural and resource economics at the University of Tennessee in 2015.

In Fall 2015, Sanguk Kwon entered economics department in University of Missouri to pursue the degree of Doctor of Philosophy. He was advised by Dr. Shawn Ni. and is interested in empirical macroeconomics, empirical microeconomics, and applied econometrics. He will graduate in 2021 May. 